\title{
Tropical forests and adaptation to climate change In search of synergies
}

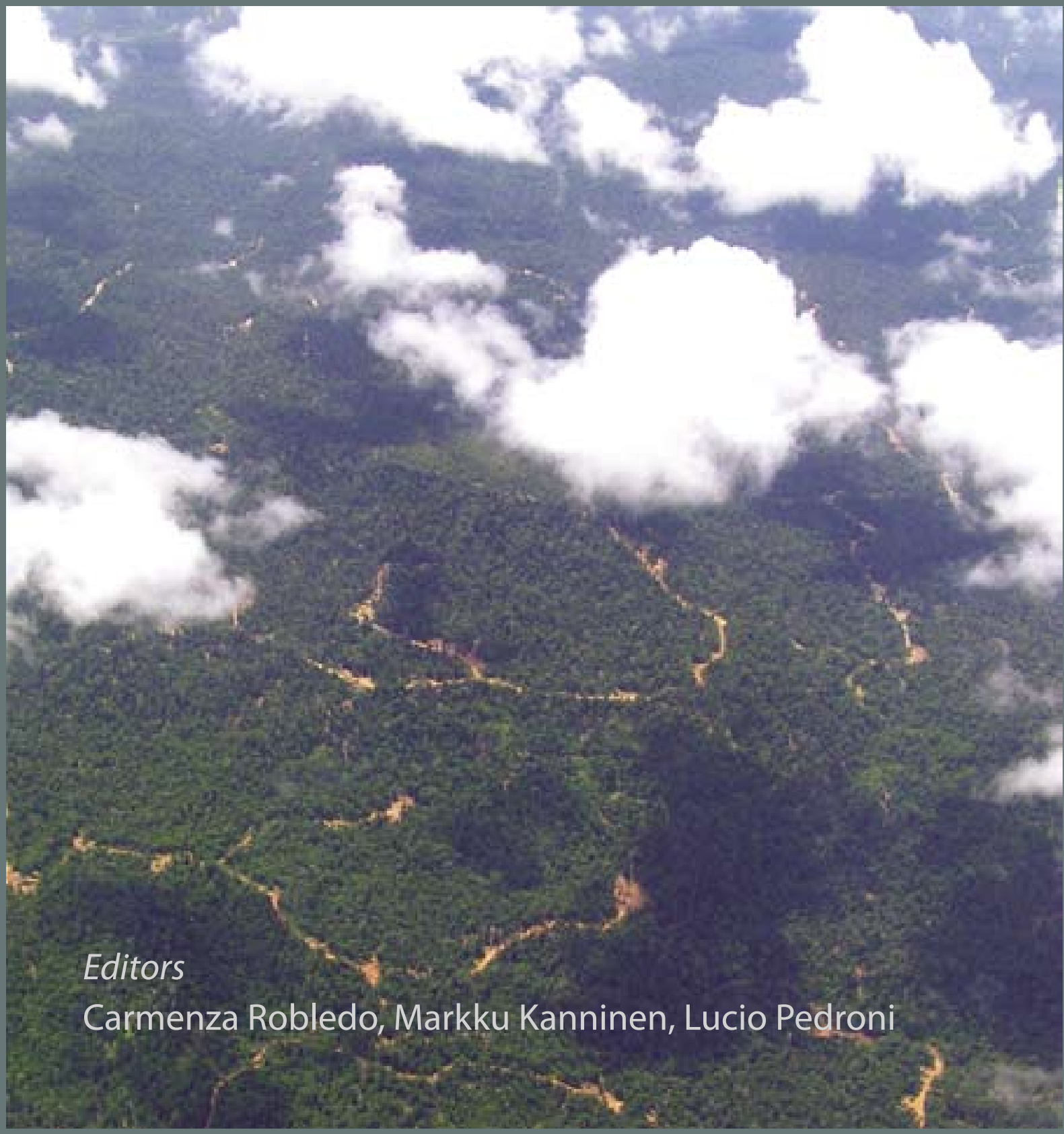




\section{Tropical forests and adaptation to climate change In search of synergies}

Editors

Carmenza Robledo

Markku Kanninen

Lucio Pedroni 


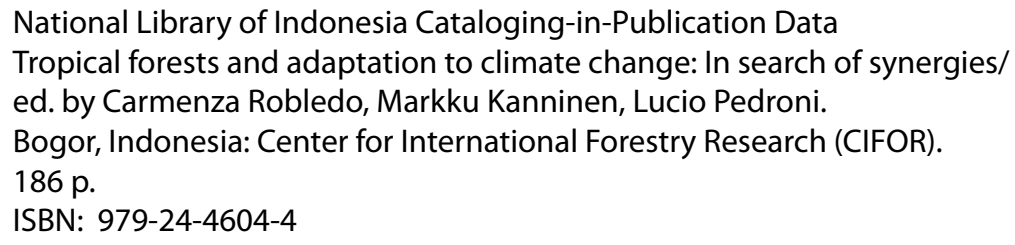

ISBN: 979-24-4604-4

1. climatic change 2 . adaptation 3 . natural resources 4 . resource management 5. policy 6 . livelihoods 7 . sustainability 8 . developing countries 9 . conferences I. Robledo, C. II. Kanninen, M. III. Pedroni, L.

\author{
(c) 2005 by CIFOR \\ All rights reserved. Published in 2005 \\ Printed by Indonesia Printer, Jakarta \\ Front cover photo by Christian Cossalter \\ Back cover photos by Markku Kanninen, Agung Prasetyo, \\ Christian Cossalter and Miriam Van Heist
}

Published by

Center for International Forestry Research

JI. CIFOR, Situ Gede, Sindang Barang

Bogor Barat 16680, Indonesia

Tel.: +62 (251) 622622; Fax: +62 (251) 622100

E-mail: cifor@cgiar.org

Web site: http://www.cifor.cgiar.org 


\section{Contents}

Foreword

\section{Introduction}

Presentation to the book

Markku Kanninen, Lucio Pedroni and Carmenza Robledo

Adaptation to climate change: Findings from the IPCC TAR José Romero

\section{Understanding and modeling local climate change}

Modelling local climate change in developing countries:

Problems and possible solutions

Peter G. Jones

How crop production will be affected by climate change in Africa and its repercussions on the continent Peter G. Jones and Philip K. Thornton

Generating climate change scenarios at high resolution for impact studies and adaptation: Focus on developing countries Peter G. Jones, Jorge Amador, Max Campos, Katharine Hayhoe, Mirna Marín, José Romero and Andreas Fischlin

\section{Sustainable livelihoods and poverty}

Climate change - Biodiversity and livelihood impacts Hannah Reid and Saleemul Huq

Using the sustainable livelihoods approach to reduce vulnerability to climate change Anne Hammill, Liza Leclerc, Outi Myatt-Hirvonen and Zenia Salinas 


\section{Inter-linkages between adaptation and mitigation}

Forests, adaptation and mitigation under the UNFCCC

Claudio Forner

Opportunities for linking adaptation and mitigation in agroforestry systems

Louis V. Verchot, Jens Mackensen, Serigne Kandji, Meine van Noordwijk, Tom Tomich, Chin Ong, Alain Albrecht, Cynthia Bantilan, K.V. Anupama and Cheryl Palm

Linkages between mitigation and adaptation in land-use change and forestry activities

Daniel Murdiyarso, Carmenza Robledo, Sandra Brown, Oscar Coto, John Drexhage, Claudio Forner, Markku Kanninen, Leslie Lipper, Nicole North and Marco Rondón

\section{Adaptation and biological diversity}

Biodiversity in a changing climate: a framework for assessing vulnerability and evaluating practical responses Jennifer Biringer, Manuel R. Guariguata, Bruno Locatelli, Jean-Laurent Pfund, Erika Spanger-Siegfried, Avelino G. Suarez, Sam Yeaman and Andy Jarvis

\section{Conclusions}

Carmenza Robledo, Markku Kanninen and Lucio Pedroni 


\section{Foreword}

Vulnerability to natural disasters has increased tremendously during the past 25 years and their effects disproportionately affect poor people. Natural disasters, such as storms, especially tropical cyclones, floods, droughts, forest fires, and landslides, affect the poor more severely because they are often forced to live in areas that are more susceptible to natural hazards. With few alternatives within their reach, the poor often make their living on steep hillsides, or lowlying riparian and coastal areas that are exposed to landslides, mudslides, floods and tidal waves. An increasing number of these fragile sites are facing rapid environmental degradation including erosion, reduced soil fertility, declining quality and availability of freshwater, increase in pests and diseases, and loss of biodiversity. Poor people generally do not have the savings or access to credit to mitigate these risks, and even fewer assets to rely on in such hard times.

Climatic variables are increasingly considered as a determinant factor in the development process. It is now well recognised that many developing countries, particularly in the tropics, are more exposed to extreme events and that they are likely to be more vulnerable than countries in other regions. This is especial relevant for poor households living in these countries because, in general, their livelihoods count with a much lower adaptation capacity.

Current changes in the climatic system tend to increase the vulnerability of livelihoods in two main ways: First, due to the fact that many of such livelihoods are exposed to more frequent and intense extreme events causing increasingly negative impacts. The second reason is related to the long-term impacts of changes in temperature and rain patterns. Some potential impacts are loss of land as a consequence of sea rise, loss of arable land due to extended drought periods, loss of food or other basic goods and in general an important reduction of the production basis of the poor. Understanding the interrelations between changes in the climatic system and development is therefore crucial for increasing adaptation capacity at the local level. This represents a challenge for scientists as for policy makers and those engaged in development cooperation.

In recognition of the need to establish a bridge between science, policy making and development cooperation, the Swiss Foundation for Development and International Cooperation (Intercooperation), the Centre for International Forestry Research (CIFOR), and the Tropical Agricultural Research and Higher 
Education Center (CATIE), with the financial support of the Swiss Agency for Development Cooperation (SDC), organized in March 2004 in Turrialba, Costa Rica an international workshop on "Adaptation to Climate Change, Sustainable Livelihoods and Biological Diversity".

The book we present here encompasses the discussions and conclusions made in the workshop and presents in addition some specific inputs from science and policy-making on the subject matter. As one of the initial efforts in linking climate change, sustainable livelihoods and biological diversity, the book opens up challenges to scientists and practitioners to commonly assess the needs of poor livelihoods to successfully cope with climate change and to bridge the gap for a meaningful implementation of lessons learned at the level of the field. It is hoped that the book can make a significant contribution towards a better understanding of the future challenges in development cooperation to help adapting poor households to the hazards of climate change.

Jürgen Blaser

Intercooperation
José Juaquín Campos

CATIE
David Kaimowitz CIFOR 


\section{Presentation to the book}

\section{Markku Kanninen ${ }^{1}$, Lucio Pedroni² and Carmenza Robledo ${ }^{3}$}

1. Center for International Forestry Research

JI. CIFOR, Situ Gede, Sindang Barang, Bogor Barat 16680, Indonesia,

Tel: +62 (251) 622622; Fax: +62 (251) 622100, E-mail: m.kanninen@cgiar.org

2. Tropical Agricultural Research and Higher Education Center, CATIE, 7170 Turrialba, Costa Rica.

Tel: +506-5582334, Fax: +506-5568470, E-mail: Ipedroni@catie.ac.cr

3. Intercooperation. Bern, Switzerland; and Technology and Society Laboratory, Swiss Federal Laboratories for material Testing and Research, EMPA. Dübendorf, Switzerland.

Tel: +41 182343 21, Fax: +41 182340 07, E-mail: carmenza.robledo@empa.ch

\section{Background}

Impacts of climate change on natural resources are many and its chain of causality yet difficult to understand. Projected changes in the climatic system will affect natural and social systems globally, increasing their vulnerability and affecting their ability to supply goods and services to meet constantly increasing demand. Along with changes in mean climatic conditions like global warming, the globe may face other severe changes that affect the whole climate system, such as changes in oceanic circulation and the melting of the Greenland ice sheet.

For forestry and other natural resources management, the major challenges are in developing best practices for adaptation measures to maintain ecosystem resilience and reduce vulnerability under various climate change scenarios, to find practical ways to integrate the production of multiple ecosystem services in landscapes as well as to integrate those social groups mostly affected.

Historically, shortages in food production and water stresses have often been buffered at the cost of forests. This has affected both natural and social systems increasing their overall vulnerability. Such consequences on the natural systems include e.g. the degradation of watersheds, lost of ecosystems and lost of soils. On the social side migration, lost of cultural habitat and increase of poverty levels for many segments of the population are the result. Under these circumstances climate change results in the increment of existing hazards for both natural and social systems (e.g. through the increment in floods or droughts). 
More pressure on forests and natural resources will also result from the response of human societies to climate change. Even if along the history, societies have adjusted their behavior to minimize the negative impacts of climatic changes, now, we are facing a new challenge: adapting to future climatic conditions, which are changing faster than in other periods.

As with many other natural phenomena, adaptation to changing climate has been reactive, in the sense that, until now, adaptation measures are carried out only when the natural phenomenon triggering this behavior has already occurred. However, in order to plan and carry out more cost-effective adaptation measures, anticipatory measures and actions aimed reducing vulnerability and increasing resilience are becoming in the sense that it is based on some assessment of conditions in the future. Therefore governments, civil society and resource managers should explore the alternatives for appropriate and cost-effective adaptation measures.

According to the Third Assessment Report of the Intergovernmental Panel on Climate Change (IPCC, 2001), "adaptation to climate change is defined as an adjustment in ecological, social or economic systems in response to observed or expected changes in climatic stimuli and their effects and impacts in order to alleviate adverse impacts of change or take advantage of new opportunities". Adaptation can involve both building adaptive capacity thereby increasing the ability of individuals, groups, or organizations to adapt to changes, and implementing adaptation decisions, i.e. transforming that capacity into action. Both dimensions of adaptation can be implemented in preparation for or in response to impacts generated by a changing climate. Hence, adaptation is a continuous stream of activities, actions, decisions and attitudes that informs decisions about all aspects of life, and that reflects existing social norms and processes (Adger et al., 2005).

In the past the international policy discussion on climate change has mainly focused on the preparation of modalities and rules that promote the mitigation strategy. Treated very often as a separate issue, the discussion on adaptation to climate change has made its progress at a slower pace. However, adaptation is the most critical climate change issue for many developing countries, and a solid scientific basis to address this topic through cost-effective, comprehensive and equitable policies and development efforts is urgently needed.

Developing countries are clearly disadvantaged for coping with the consequences of climate change. Their environment, economies and societies are highly vulnerable to the impacts of climate change, while their human and institutional capacities have limited response capacities. The most vulnerable are the poorer social groups, whose subsistence depends from the environment in which they live. Under the pressure of climate change, the environment is responding in many different ways, some of which are difficult to foreseen. Due to the changes in environmental patterns, existing problems are exacerbated and new ones can appear. As a consequence many vital factor for sustainable development such as water and food supply, health, infrastructure, and natural ecosystems are seriously endangered. 
As direct and indirect impacts of climate change are trans-boundary, they affect societies, peace and governance in entire regions of the world, unless appropriate adaptation strategies will be designed and implemented.

The role of science in forecasting climate change, modeling impacts, assessing vulnerability, and supporting the design of adaptation strategies is fundamental. However, scientific research can only be effective if it is interdisciplinary and articulated with policy and development efforts.

\section{The workshop on Adaptation to Climate Change, Sustainable Livelihoods ans Biological Diversity ${ }^{1}$ and its participants}

The aim of the workshop was to promote the implementation of adaptation strategies to climate change through a interdisciplinary approach that includes policy making, science and field expertise in natural resource management.

Its specific objectives were as follows:

- to exchange experiences and results regarding the adaptation strategy to climate change between science, community based experiences and policy developments;

- to generate a shared agenda of research, communication and coordination between research and development institutions on adaptation to climate change;

- to establish adequate mechanisms for informing policy makers and followup implementation of the agenda.

About 50 persons from 16 countries participated in the workshop. Approximately half of them came from developing countries. The workshop was an expert meeting, and participants expressed their views in their personal capacities, not as country representatives or representatives their specific institutions.

The workshop was divided into 3 sessions: two plenary sessions one at the beginning and the other at the end of workshop, and a session were the participants worked in four working groups. In the first plenary session, invited speakers introduced the four main themes of the workshop:

- Local climate change modeling;

- Climate change, sustainable livelihoods and poverty;

- Linking mitigation with adaptation; and

- Adaptation and biological diversity.

In the four parallel sessions were participants worked in working groups, the aim was to discuss and prepare an outline of a joint paper on the four themes

\footnotetext{
${ }^{1}$ This workshop, which took place in Turrialba, Costa Rica, in March 2004, was fully financed by the Swiss Agency for Development and Cooperation (SDC). It was organized by CATIE, CIFOR and Intercooperation.
} 
mentioned above. In the final plenary session, the working groups presented their results, and a general discussion on the findings was carried out.

The atmosphere of the CATIE workshop was highly constructive and cooperative, leading to innovative exchange of experiences and perspectives. The participants of theworkshop represented different disciplinary backgrounds, ways of thinking, geographical focus, and experience. This led into an unusually vivid discussions and debate.

\section{This book}

This book is divided into three main parts. The first part focuses on the four main themes of the workshop and raises important issues and questions on adaptation to climate change. The second part consists of joint papers written by the working groups, where they analyze further the issues raised, and present case studies to illustrate these issues. The final part consists of conclusions of the workshop and the papers presented.

\section{References}

Adger, W.N., Arnell, N. W. and Tompkins, E. (2005) 'Successful adaptation to climate change across the scales'. Global Environmental Change 15:77-86.

Intergovernmental Panel on Climate Change (IPCC) (2001) 'Intergovernmental Panel on Climate Change (IPCC), Climate Change 2001: Impacts, Adaptation and Vulnerability' Summary for Policy Makers, World Meteorological Organisation, Geneva. 


\section{Adaptation to climate change: Findings from the IPCC TAR}

\section{José Romero}

International Affairs Division, Section Conventions, Swiss Agency for the Environment, Forests and Landscape, $\mathrm{CH}-3003$ Berne, Switzerland.

Tel: +41 3132268 62, Fax: + 413132303 49, E-mail: jose.romero@buwal.admin.ch

\section{Anthropogenic climate change}

Anthropogenic emissions of greenhouse gases and aerosols influence the climate of the Earth. Working Group I (WG I) of the Intergovernmental Panel on Climate Change (IPCC) assesses observed and potential future changes in climate. The report contributed by WG I to the IPCC's Third Assessment Report (TAR), concludes, inter alia, that the globally averaged surface temperatures have increased by $0.6 \pm 0.2^{\circ} \mathrm{C}$ over the 20th century (Houghton et al., 2001). For the range of scenarios considered in the TAR, projections which involve no climate policy intervention (Nakicenovic and Swart, 2000) indicate that the globally averaged surface air temperature is expected to rise between 1.4 and $5.8^{\circ} \mathrm{C}$ by 2100 relative to 1990 and the globally averaged sea level to rise between 0.09 and $0.88 \mathrm{~m}$ by 2100 . The projections suggest that the warming would vary by region, and be accompanied by increases and decreases in precipitation. In addition, there would be changes in the variability of climate, and changes in the frequency and intensity of some extreme climate phenomena. These changes will have impacts on natural and human systems.

The Earth's climate system is complex, non-linear and adaptive. Its response to an external forcing such as anthropogenic greenhouse gas emissions is slow. This slowness, known as 'inertia', implies that even if greenhouse gas emissions are reduced dramatically in the near future and atmospheric concentrations are stabilised, surface air temperature will continue to rise by a few tenths of a degree per century for a century or more, impacting natural and human systems. Therefore, adaptation to the new situation is inevitable and is already necessary in some cases. Early adaptation measures are appropriate because 
the inertia of the climate system, but also because ecological and socioeconomic systems have inertia and decisions on adaptation measures need time. Furthermore adaptation is increasingly recognised as a component for attaining sustainable development and is essential for the achievement of many global environmental objectives.

The TAR indicates that many uncertainties are associated with the projections and the impacts of climate change. Nevertheless, the confidence level associated to each one of the findings of the TAR is higher than that associated to related findings in previous IPCC assessments.

\section{Definitions}

In its glossary, the TAR provides definitions of the concepts adaptation, mitigation, vulnerability and sensitivity. This section lists these definitions (McCarthy et al., 2001):

\section{Adaptation}

Adjustment in natural or human systems in response to actual or expected climatic stimuli or their effects, which moderates harm or exploits beneficial opportunities. Various types of adaptation can be distinguished, including anticipatory and reactive adaptation, private and public adaptation, and autonomous and planned adaptation:

- Anticipatory Adaptation-Adaptation that takes place before impacts of climate change are observed. Also referred to as proactive adaptation.

- Autonomous Adaptation-Adaptation that does not constitute a conscious response to climatic stimuli but is triggered by ecological changes in natural systems and by market or welfare changes in human systems. Also referred to as spontaneous adaptation.

- Planned Adaptation-Adaptation that is the result of a deliberate policy decision, based on an awareness that conditions have changed or are about to change and that action is required to return to, maintain, or achieve a desired state.

- Private Adaptation-Adaptation that is initiated and implemented by individuals, households or private companies. Private adaptation is usually in the actor's rational self-interest.

- Public Adaptation-Adaptation that is initiated and implemented by governments at all levels. Public adaptation is usually directed at collective needs.

- Reactive Adaptation-Adaptation that takes place after impacts of climate change have been observed.

\section{Adaptation Assessment}

The practice of identifying options to adapt to climate change and evaluating them in terms of criteria such as availability, benefits, costs, effectiveness, efficiency, and feasibility. 


\section{Adaptation Benefits}

The avoided damage costs or the accrued benefits following the adoption and implementation of adaptation measures.

\section{Adaptation Costs}

Costs of planning, preparing for, facilitating, and implementing adaptation measures, including transition costs.

\section{Adaptive Capacity}

The ability of a system to adjust to climate change (including climate variability and extremes) to moderate potential damages, to take advantage of opportunities, or to cope with the consequences.

\section{Maladaptation}

Any changes in natural or human systems that inadvertently increase vulnerability to climatic stimuli; an adaptation that does not succeed in reducing vulnerability but increases it instead.

\section{Mitigation}

An anthropogenic intervention to reduce the sources or enhance the sinks of greenhouse gases.

\section{Vulnerability}

The degree to which a system is susceptible to, or unable to cope with, adverse effects of climatechange, including climatevariabilityand extremes.Vulnerability is a function of the character, magnitude, and rate of climate variation to which a system is exposed, its sensitivity, and its adaptive capacity.

\section{Sensitivity}

The degree to which a system is affected, either adversely or beneficially, by climate-related stimuli. Climate-related stimuli encompass all the elements of climate change, including mean climate characteristics, climate variability, and the frequency and magnitude of extremes. The effect may be direct (e.g., a change in crop yield in response to a change in the mean, range or variability of temperature) or indirect (e.g. damages caused by an increase in the frequency of coastal flooding due to sea-level rise).

\section{Findings from the TAR on impacts of climate change}

The TAR presents a number of 'emergent findings' on impacts of climate change on natural and human systems. The observed and predicted impacts from these emergent findings would need adaptation measures in order to minimise their adverse consequences. The most relevant emergent findings are the following: 
Recent regional climate changes, particularly temperature increases, have already affected many physical and biological systems.

Observations indicate that regional changes in climate, particularly increases in temperature, have already affected physical and biological systems in many parts of the world. Examples include: shrinkage of glaciers, thawing of permafrost, later freezing and earlier break-up of ice on rivers and lakes, lengthening of mid- to high-latitude growing seasons, pole-ward and altitudinal shifts of plant and animal ranges, declines of some plant and animal populations, and earlier flowering of trees, emergence of insects, and egg-laying in birds. Changes in many aquatic, terrestrial and marine environments have been associated with changes in regional temperatures.

There are preliminary indications that some human systems (infrastructure, economic activities such as agriculture, etc.) have been affected by recent increases in floods and droughts.

Some social (e.g. human settlements) and economic (e.g. agriculture) systems have been affected by the recent increasing frequency of floods and droughts in some areas.

Natural systems are vulnerable to climate change and some will be irreversibly damaged.

A number of natural systems are especially vulnerable to climate change because of limited adaptive capacity and some of these systems may undergo significant and irreversible damage. Natural systems at risk include: glaciers, coral reefs and atolls, mangroves, boreal and tropical forests, polar and alpine ecosystems, prairie wetlands, and remnant native grasslands. While some species may increase in abundance or range, climate change will increase existing risks of extinction of some more vulnerable species and loss of biodiversity. The geographical extent of the damage or loss and the number of systems affected will increase with the magnitude and rate of climate change.

\section{Many human systems are sensitive to climate change, and some are vulnerable.}

Among the human systems that are sensitive to climate change are: water resources; agriculture (especially food security) and forestry; coastal zones and marine systems (fisheries); human settlements, energy, and industry; insurance and other financial services; and human health. The vulnerability of these systems varies with geographic location, time, and social, economic, and environmental conditions.

Projected adverse impacts include: a general reduction in crop yields in most tropical and sub-tropical regions for most projected increases in temperature; a general reduction, with some variation, in potential crop yields in most regions in mid-latitudes for increases in annual-average temperature of more than a few degrees; decreased water availability for populations in many water-scarce regions, particularly in the sub-tropics; an increase in the 
number of people exposed to vector- (e.g. malaria) and water-borne diseases (e.g. cholera), and an increase in heat stress mortality; a widespread increase in the risk of flooding for many human settlements (tens of millions of inhabitants in settlements studied) from both increased heavy precipitation events and sea-level rise; and increased energy demand for space cooling due to higher summer temperatures.

There are also projected beneficial impacts of climate change among which: increased potential crop yields in some regions at mid-latitudes for increases in temperature of less than a few degrees; a potential increase in global timber supply from appropriately managed forests; increased water availability for populations in some water-scarce regions - for example, in parts of SouthEast Asia; reduced winter mortality in mid- and high-latitudes; reduced energy demand for space heating due to higher winter temperatures.

Projected changes in climate extremes could have major consequences.

Some extreme events (e.g. droughts, floods, heat waves, avalanches, and windstorms) are projected to increase in frequency and/or severity during the 21 st Century due to changes in the mean and/or variability of climate. The severity of their impacts will also increase in concert with global warming. Conversely, the frequency and magnitude of extreme low temperature events, such as cold spells, is projected to decrease in the future, with both positive and negative impacts. The impacts of future changes in climate extremes are expected to fall disproportionately on the poor.

The potential for large-scale and possibly irreversible impacts poses risks that have yet to be reliably quantified.

Projected climate changes during the 21st century may lead to large-scale irreversible changes in Earth systems. Examples include: significant slowing of the ocean circulation that transports warm water to the North Atlantic; large reductions in the Greenland and West Antarctic Ice Sheets; accelerated global warming due to carbon cycle feedbacks in the terrestrial biosphere; and release of terrestrial carbon from permafrost regions and methane from hydrates in coastal sediments. The possibility of these changes is currently not well-known, but their likelihood is expected to increase with the rate, magnitude, and duration of climate change.

Impacts of these changes would be widespread and sustained. For example, significant slowing of the oceanic thermohaline circulation would impact deepwater oxygen levels and carbon uptake by oceans and marine ecosystems, and would reduce warming over parts of Europe. Disintegration of the West Antarctic Ice Sheet or melting of the Greenland Ice Sheet could raise global sea level up to $3 \mathrm{~m}$ each over the next 1,000 years, submerge many islands, and inundate extensive coastal areas. Releases of terrestrial carbon from permafrost regions and methane from hydrates in coastal sediments, induced by warming, would further increase greenhouse gas concentrations in the atmosphere and amplify climate change. 
Adaptation is a necessary strategy at all scales to complement climate change mitigation efforts.

Adaptation may reduce adverse impacts of climate change and may enhance beneficial impacts, but will incur costs and will not prevent all damages. Although human and natural systems will, to some degree, adapt autonomously to climate change, planned adaptation can supplement autonomous adaptation. In order to reduce adverse impacts of climate change, adaptation is necessary to complement mitigation.

Experience with adaptation to climate variability and extremes can be used to develop appropriate strategies for adapting to anticipated climate change. Maladaptation, such as promoting development in hazard-prone high-risk locations, has to be avoided but can also occur due to decisions based on shortterm considerations, neglect of known climatic variability, imperfect foresight, insufficient information, and over-reliance on insurance mechanisms.

\section{Vulnerability varies across regions.}

The vulnerability of human populations and natural systems to climate change differs substantially across regions and across populations within regions.

Those with the least resources have the least capacity to adapt and are the most vulnerable.

The capacity to adapt to climate change depends on factors such as wealth, technology, education, information, skills, infrastructure, access to resources, and management capabilities. Developing countries, particularly the least developed countries (LDCs), are generally poorest in this regard. As a result, they have lesser capacity to adapt and are more vulnerable to climate change damages. This condition is most extreme among the poorest people.

The effects of climate change on loss of life and on investment and the economy will be greatest in developing countries. So far, the relative percentage damages to GDP from climate extremes have been substantially greater in developing countries than in developed countries.

More people are projected to be harmed than benefited by climate change, even for global mean temperature increases of less than a few degrees.

In spite of uncertainties, it seems that increases in global mean temperature would produce net economic losses in many developing countries for all magnitudes of warming, and losses would be greater in magnitude the higher the level of warming. In developed countries, an increase in global mean temperature of up to a few degrees would produce a mixture of economic gains and losses, with economic losses for larger temperature increases.

Adaptation, sustainable development, and enhancement of equity can be mutually reinforcing.

Many communities and regions that are vulnerable to climate change are also under pressure from forces such as population growth, resource depletion, and 
poverty. Policies that lessen pressures on resources, improve management of environmental risks, and increase the welfare of the poorest members of society can simultaneously advance sustainable development and equity, enhance adaptive capacity, and reduce vulnerability to climate and other stresses. Inclusion of climatic risks in the design and implementation of national and international development initiatives can promote equity and development that is more sustainable and that reduces vulnerability to climate change.

\section{Approaches to adaptation to climate change}

After identifying potential impacts of climate change, the TAR deals with approaches to adaptation, in particular in its Synthesis Report (Watson et al., 2001). It concludes that reduction of greenhouse gas emissions, even stabilisation of their concentrations in the atmosphere at a low level, will not prevent climate change and its impacts. Furthermore, given the inertia in the climate system, some adaptation to climate change is inevitable and already necessary. But it will entail costs and will not prevent all damages resulting from climate change.

In the context of adaptation, inertia plays an important role in ecological systems and in socio-economic sectors. The TAR indicates that there is typically a delay of years to decades between perceiving a need to respond to a major challenge, planning, researching and developing a solution, and implementing it. The same delay happens also in social structures. As a result of these inertias, some of the consequences of actions taken, or not taken, will only be felt many years in the future. Therefore anticipatory adaptive action can be very efficient and cost-effective if the anticipated trend materialises. This is particularly true for sectors with long-lived infrastructure, such as dams and bridges, and large social inertia, such as misallocated property rights.

Concerning the costs of adaptation, the TAR concludes that adaptation costs and challenges can be lessened by mitigation of climate. In fact, greenhouse gas emission reductions would reduce the magnitude and rate of changes to be adapted to, possibly including changes in the frequencies and intensities of extreme events. The smaller changes to which systems would be exposed and slower pace at which stresses would increase would allow more time for adaptation and lessen the degree to which current practices for coping with climate variability and extremes might need to be modified. More substantial mitigation measures will therefore reduce adaptation costs to attain a specified adaptation objective.

Finally, the TAR finds that adaptation can complement mitigation as part of a cost-effective approach to reducing climate change risks. An optimal combination of adaptationandmitigation can advancesustainabledevelopment objectives. In order to assure that such an appropriate design is achieved, adaptation and mitigation decisions have to be done in coordination. 


\section{Adaptation under the UNFCCC and its Kyoto Protocol}

The articles of the UN Framework Convention on Climate Change (UNFCCC) and its Kyoto Protocol contain reference to adaptation (UN, 1992; UNFCCC, 1997). The past sessions of the Conference of the Parties (COP) to the UNFCCC have adopted specific decisions in relation to adaptation to support the implementation of the principles outlined in the articles. A list of these elements follows.

Article 4.1 of the UNFCCC requires all Parties to undertake actions relating to adaptation, facilitate adequate adaptation and cooperate in preparing for adaptation. Articles 4.4, 4.8 and 4.9 request developed country Parties to assist developing country Parties that are particularly vulnerable to the adverse effects of climate change in meeting the costs of adaptation.

To implement these provisions, the COP has adopted the following decisions :

- COP 1 (Berlin, 1995): decision 11/CP1. Adaptation will require short, medium and long-term strategies to be implemented sequentially in three stages. Stage I consists of planning (i.e. studies on climate change impacts); Stage II includes identification of measures to prepare for adaptation, including further capacity building; and Stage III includes measures to facilitate adequate adaptation. COP I requested the Global Environment Facility (GEF), as the financial mechanism of the UNFCCC, to fund Stage I activities through national communications. Under the guidance of the COP, the GEF assists developing country Parties technically and financially to implement their commitments under the Convention.

- COP 4 (Buenos Aires, 1998): decision 2/CP.4. The GEF was given the mandate to fund and implement Stage II activities in particularly vulnerable countries and regions identified in Stage I.

- COP 7 (Marrakech, 2001): the 'Marrakech Accords' address the vulnerability and adaptation in several decisions (5/CP.7, 6/CP.7, 7/CP.7 and 10/CP.7) and established three new funds, including two Convention funds with significant adaptation components, and an explicit Adaptation Fund under the Kyoto Protocol. All funds will be managed by the GEF.

- Decision 7/CP.7: creation of the LDC Fund to support the preparation of the National Adaptation Programmes of Action (NAPAs), and establishment of the Special Climate Change Fund to support adaptation, technology transfer and other activities to assist developing countries in diversifying their economies.

- Decision 10/CP.7: establishment of the Adaptation Fund under the Kyoto Protocol.

- Decision 5/CP.7: states that actions related to adaptation should follow an assessment and evaluation process based on the information provided by Parties (in the so-called 'national communications') or other relevant information so as to prevent maladaptation and to ensure adaptation actions. This decision identifies a number of vulnerability and adaptation related activities to be supported by 
the GEF or other donors such as: enabling activities for vulnerability and adaptation assessment; technical training for vulnerability and adaptation assessment; capacity building to integrate adaptation into sustainable development programmes; capacity building for preventive measures, planning, preparedness of disasters relating to climate change, including contingency for droughts and floods; and promotion of adaptation technologies.

- Decision 6/CP.7: the GEF is requested to establish pilot or demonstration projects to show how adaptation planning and assessment can be practically translated into projects that will provide real benefits and may be integrated into national policy and sustainable development planning on the basis of information provided in the national communications or in-depth studies, including NAPAs and of the staged approach. This includes: building the capacity, including where appropriate, institutional capacity for preventive measures, planning preparedness for disaster related to climate change, including in particular, contingency planning for droughts and floods in areas prone to extreme weather events; and strengthening existing and, where needed, establishing early warning systems for extreme weather events in an integrated and interdisciplinary manner to assist developing country Parties in particular those most vulnerable to climate change.

- COP 8 (New Delhi, 2002): decision 17/CP.8. Parties agreed on improved guidelines for the second national communications of developing countries, which provide expanded scope for support of vulnerability assessments and consideration of measures to prepare for adaptation.

- COP 9 (Milan, 2003): decisions with implications to the GEF adaptation portfolio:

- Decision 4/CP.9: the COP request the GEF to operationalise the new strategic priority in the climate change focal area ('Piloting an operational approach to adaptation' (GEF Council, 2004)) as soon as possible, and to include in its report to COP 10 information on specific steps undertaken to implement this decision.

- Decision 10/CP.9: establishment of an agenda item on adaptation to focus on exchanging information and sharing experiences and views among Parties on practical opportunities and solutions to facilitate the implementation of the Convention.

Adaptation is also mentioned in Article 10 of the Kyoto Protocol, where Parties are requested to formulate and to implement measures to facilitate adequate adaptation. 


\section{Conclusions}

The IPCC has established solid basis for action on adaptation to climate change, including information on impacts of climate change at the global and regional level, and conceptual frameworks for the development of measures, including coordination with mitigation. Among the main findings of the IPCC is that adaptation to climate change is inevitable and already necessary in some cases, given the inertia in the climate system, but will not prevent all damages resulting from climate change.

At the international level, the UNFCCC and its Kyoto Protocol contain provisions on adaptation allowing international cooperation. Decisions of the COP request the GEF to provide assistance to developing countries.

\section{References}

GEF Council (2004) 'GEF Assistance to Address Adaptation'Document GEF/C.23/ Inf.8/Rev.1, 1 May 2004.

Houghton, J.T., Y. Ding, D.J. Griggs, M. Noguer, P.J. van der Linden, X. Dai, K. Maskell, C.A. Johnson (2001) (eds.) Climate Change 2001: The Scientific Basis, IPCC WG I contribution to the TAR, Cambridge University Press: Cambridge.

UNFCCC (1997) 'COP-3 Report, part II: Action taken', Document No. FCCC/ CP/1997/7/Add.1, Decision No. 1/CP.3 'Adoption of the Kyoto Protocol to the UNFCCC', http://www.unfccc.int

McCarthy, J.J., O.F. Canziani, N.A. Leary, D.J. Dokken, K. S. White (2001) (eds.) Climate Change2001: Impacts, Adaptation, and Vulnerability, IPCC WG II contribution to the TAR, Cambridge University Press: Cambridge.

Nakicenovic, N., R. Swart (eds.) (2000) Emissions Scenarios 2000, Special Report of the IPCC, Cambridge University Press: Cambridge.

UN (1992) United Nations Framework Convention on Climate Change, in 'Report of the Intergovernmental Negotiating Committee for a Framework Convention on Climate Change on the work of the second part of its fifth session, held at New York from 30 April to 9 May 1992. Addendum, Document No. A/AC.237/18 (Part II) /Add.1, Annex I, UN: New York. Internet: http://www.unfccc.int

Watson, R.T., Core Writing Team (2001) Climate Change 2001: Synthesis Report, IPCC: Geneva. 


\title{
Modelling local climate change in developing countries: Problems and possible solutions
}

\author{
Peter G. Jones \\ Centro Internacional de Agricultura Tropical (CIAT), AA 67-13, Cali, Colombia. \\ Tel: 57-2-4450068 (Col), 44-1341-423561(UK), Fax: 57-2-4450073, E-mail: p.jones@cgiar.org
}

\section{Introduction}

For users of climate change data, one of the biggest problems is that General Circulation Models (GCMs) have a large footprint; for example, the Hadley II Grid Cells cover the whole of Panama. Although later models have smaller pixel sizes, none as yet can model the local environment. One way around this problem is to nest the models; this is known as dynamic downsizing.

We have used a GCM of the whole world at the outset, then within certain cells of that model we nest another copy of the model; this could model up to the same number of grid cells as the original world model. We could even go down to a third-level model, to simulate local climate on a daily basis, 50 to 100 years in the future, although there are limitations to the precision of such a study. Furthermore, such an exercise is very costly, even at first level. The Hadley Centre employed two, multi-million dollar supercomputers for their original model. Once nested, using the same number of pixels and computation, the same level of computer input is needed to model them. Thus, even to simulate the weather of a small region requires a considerable input.

The International Center for Tropical Agriculture (CIAT, the Spanish acronym) has been developing a set of climate mapping tools: FloraMap ${ }^{\circledR}$ predicts the distribution of plants and other organisms in the wild; MarkSim ${ }^{\circledast}$ generates simulated weather data for crop modelling and risk assessment; GxEngine ${ }^{\mathrm{TM}}$ maps varietal yield potential from the results of large trial networks; and Homologue $^{T M}$ identifies environmental homologues throughout the tropical world. We have been testing how the first two of these tools can be used to estimate the local effects of climate change using the alternative approach of statistical downscaling. 


\section{Methods}

\subsection{FloraMap}

FloraMap is a software package for predicting the distribution of plants and other organisms in the wild. It uses the climate data from a set of known collection points where a given species has been found, to build a model of the probability of finding the organism in a given climate. It can be used to produce a map of the probability of finding a specific species based only on climate. The algorithm was originally published in Jones et al. (1997) and was used in its original Fortran for a number of studies (e.g. Sawkins et al., 1999). It has subsequently been released as a complete version for Windows ${ }^{\circledR}$ (Jones and Gladkov, 1999). FloraMap has been used successfully on many species, including wild bean, Phaseolus vulgaris L. (Jones and Beebe, 2001), Passiflora sp. (Segura et al., 1999) and Arachis sp., the wild relatives of the peanut (Arachis hypogaea [L].) (Jarvis et al., 2002).

FloraMap uses climatic data from a 10-arc-minute grid (corresponding to 18 by $18 \mathrm{~km}$ at the equator) for Latin America and Africa, and 2.5 arc-minutes for Asia, interpolated from observations from about 20,000 meteorological stations throughout the tropics. The interpolation algorithm is based on the inverse square of the distance between five stations closest to the interpolated pixel. The climatic variables included are the monthly averages for temperature, rainfall and diurnal temperature range.

Mean temperature is standardised with elevation using the NOAA TGP-006 digital elevation model (NOAA, 1984) and a lapse rate model (Jones, 1991). The CIAT climate applications can work with other interpolated surfaces and are being adapted to use the 30 arc-second surfaces produced at the University of California at Berkeley by Robert Hijmans.

For each accession, the 36 climate variables (12 monthly means for temperature, rainfall, and diurnal temperature range) are extracted for the pixel in which the accession is located, and a principal components analysis (PCA) is applied to identify a smaller number of variables that account for the bulk of the variance in climates among the accession locations. The PCA is performed on the variance-covariance matrix to maintain the weightings between the variates. A multivariate-Normal distribution is fitted to the principal component scores, and the multidimensional probability of belonging to the distribution can then be calculated for all pixels. The result is a surface where the value of each pixel denotes the probability that the climate of that pixel belongs to the multivariate-Normal distribution fitted in the model.

\subsection{MarkSim}

Over the last few years, we have developed and extensively tested a third-order Markov rainfall model (Jones and Thornton, 1993; 1997; 1999). MarkSim (Jones and Thornton, 2000; Jones et al., 2002) is an application derived from this work, available on CD-ROM, which will generate synthetic daily weather files for use 
with models such as the Decision Support System for Agrotechnology Transfer (DSSAT) ${ }^{1}$ series of crop models (ICASA, 2004). The MarkSim model can be run for each distinct point on the map by estimating the third-order Markov model parameters from interpolated climate surfaces. The relevant characteristics can be extracted from each model run and can be readily mapped in the study area. Being able to model outlying rainfall years satisfactorily is particularly important in studies aimed at quantifying production system risk.

A Markov model works by randomly sampling a series of events where the probability of observing an event depends on the occurrence of previous events. A third-order Markov model takes into account events occurring over the previous three days. We have found that, whereas a lower order model is often sufficient for temperate climates, the third order is necessary for many tropical climates. This simple model should be able to simulate the variance of monthly and annual rainfall for sites in the tropics and subtropics, but even the third order model falls short of reality. The MarkSim rainfall generator makes good this deficit by means of annual random re-sampling of certain of the model's own parameters, however, this comes at a price. The resulting model has 117 parameters; fortunately, there is considerable redundancy.

Jones and Thornton (1997) showed that patterns could be discerned in the parameter values that were typical for certain types of climate. In MarkSim, world climates are clustered into about 700 types and regression models are used to predict the Markov model parameters within the restricted climate sets (Jones and Thornton, 1999; 2000). The MarkSim system identifies the climate set relevant to any required point on the globe using interpolated climate surfaces and evaluates the model parameters for that point. The model can thus be used to interpolate rainfall data for places where actual data do not exist.

\subsection{Standardising dates}

The climatic events that occur through the year, such as summer/winter and start/finish of the rainy season, are of prime importance when comparing one climate with another. Unfortunately, they occur at different dates in many climate types. The most obvious case is where climates are compared between points in the Northern and Southern Hemispheres but more subtle differences can be seen in climate event timing throughout the tropics. What we need is a method of eliminating these differences to allow us to make comparisons free of these annual timing effects.

Let us look at two hypothetical climate stations. They are in a typical Mediterranean climate - warm wet winters, hot dry summers. 'Northville' could be somewhere in California, and 'Southville' might be in Chile. The August rainfall in Southville is received in January in Northville. If we plot these rainfalls in polar co-ordinates, we can readily see that to compare them we need to rotate them to a standard time (Figure 1).

\footnotetext{
${ }^{1}$ http://www.icasa.net/dssat/
} 


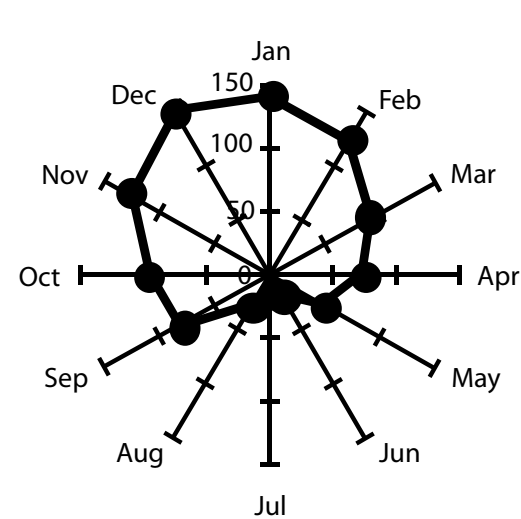

Northville

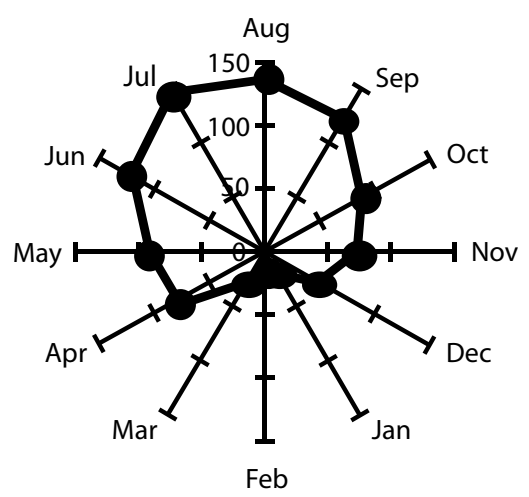

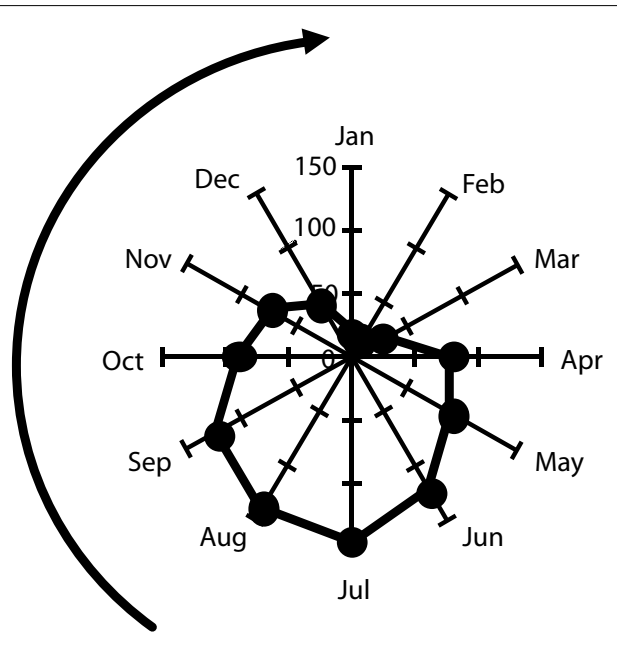

Southville

Southville rainfall rotated to coincide with timing of Northville

\section{Monthly rainfalls for Northville and Southville}

\begin{tabular}{lrrrrrrrrrrrr}
\hline & Jan & Feb & Mar & Apr & May & Jun & Jul & Aug & Sep & Oct & Nov & Dec \\
\cline { 2 - 13 } Northville & 137 & 120 & 87 & 72 & 46 & 18 & 14 & 27 & 78 & 92 & 123 & 145 \\
Southville & 18 & 14 & 27 & 78 & 92 & 123 & 145 & 137 & 120 & 87 & 72 & 46 \\
\hline
\end{tabular}
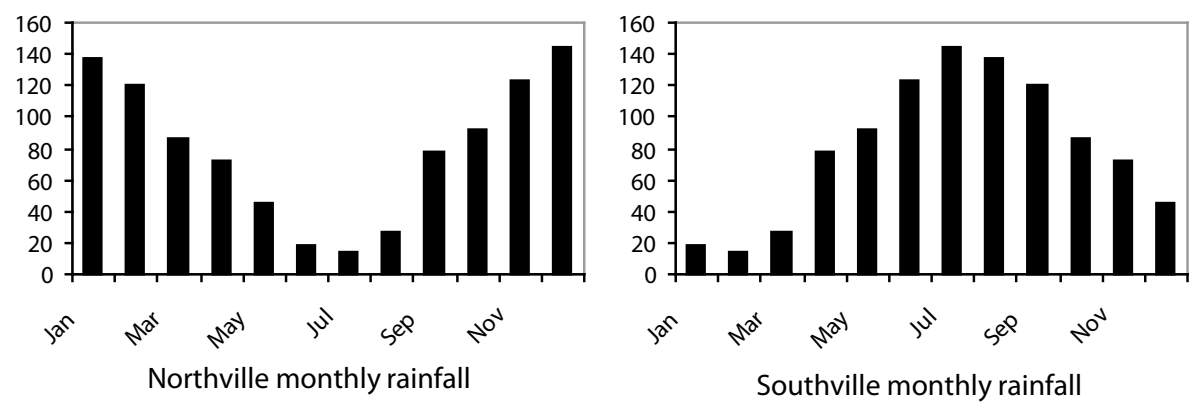

Figure 1. Illustration of data rotation (Source: Jones \& Gladkov, 1999) 
How do we rotate this data automatically? The answer is the 12-point Fourier transform. This is fortunately the simplest of all the possible Fourier transform algorithms. It is highly computationally efficient and fast. In fact, it is the basis of nearly all Fast Fourier transform algorithms that break the problem down sequentially into the simple 12-point case. It takes the 12 monthly values and converts them to a series of sine and cosine functions. The one used in FloraMap has a modification to make it conserve the monthly total values (Jones, 1987). The equation produced is:

$$
r=a_{0}+\sum_{i=1}^{6} a_{i} \cos (i x)+b_{i} \sin (i x)
$$

This can be rewritten as a series of frequency vectors, each with an amplitude, $\alpha_{l}$, and a phase angle, $\theta_{i \text { : }}$

$$
\alpha_{i}=\sqrt{a_{i}^{2}+b_{i}^{2}} \quad \theta_{i}=\sin \frac{b_{i}}{\alpha_{i}}=\cos \frac{a_{i}}{\alpha_{i}}
$$

If we subtract the phase angle of the resultant of the first frequency vectors for rainfall and temperature from all the other vectors in the set, then we have produced a rigid rotation of the vectors. This standardises the dates for all pixels and we can transform the data back to monthly (but not calendar) values.

\section{Results}

At CIAT, we have used the Hadley Centre old HadCM2 model, which is moderately conservative, predicting an increase of about $3^{\circ} \mathrm{C}$ in the next 50 years. There are, however, more recent models that can be used that run with a range of greenhouse gas emission scenarios. HadCM2 uses a cell size of $3.75^{\circ}$ longitude by $2.5^{\circ}$ latitude. The downscaling technique we used was the simple delta change method. There may be some inaccuracies in this (Gyalistras et al., 1994; Hay et al., 2000) but it is a relatively simple method and can be used quickly for large areas. The difference of the rainfall temperature and diurnal temperature range from the HadCM2 model for the present and 2055 (mean of 2040 to 2069) were calculated (Figure 2). These were interpolated to the precision of the climate surface by the inverse square distance method and added to the climate grid.

We carried out a study on wild bean in Central America for the present and in about 50 years' time (Jones and Beebe, 2001), for which we made a 30 arc-second climate surface for Central America and added in the HadCM2 differences. We used a dataset of some 40 accessions of wild bean. The presentday distribution (Figure 2) shows an almost contiguous strip through the highlands of Southern Mexico, Guatemala, Honduras and El Salvador with localised concentrations into Honduras and Nicaragua. Under the 2040-2069 climate scenario, the analysis indicates that its range may be restricted by up 

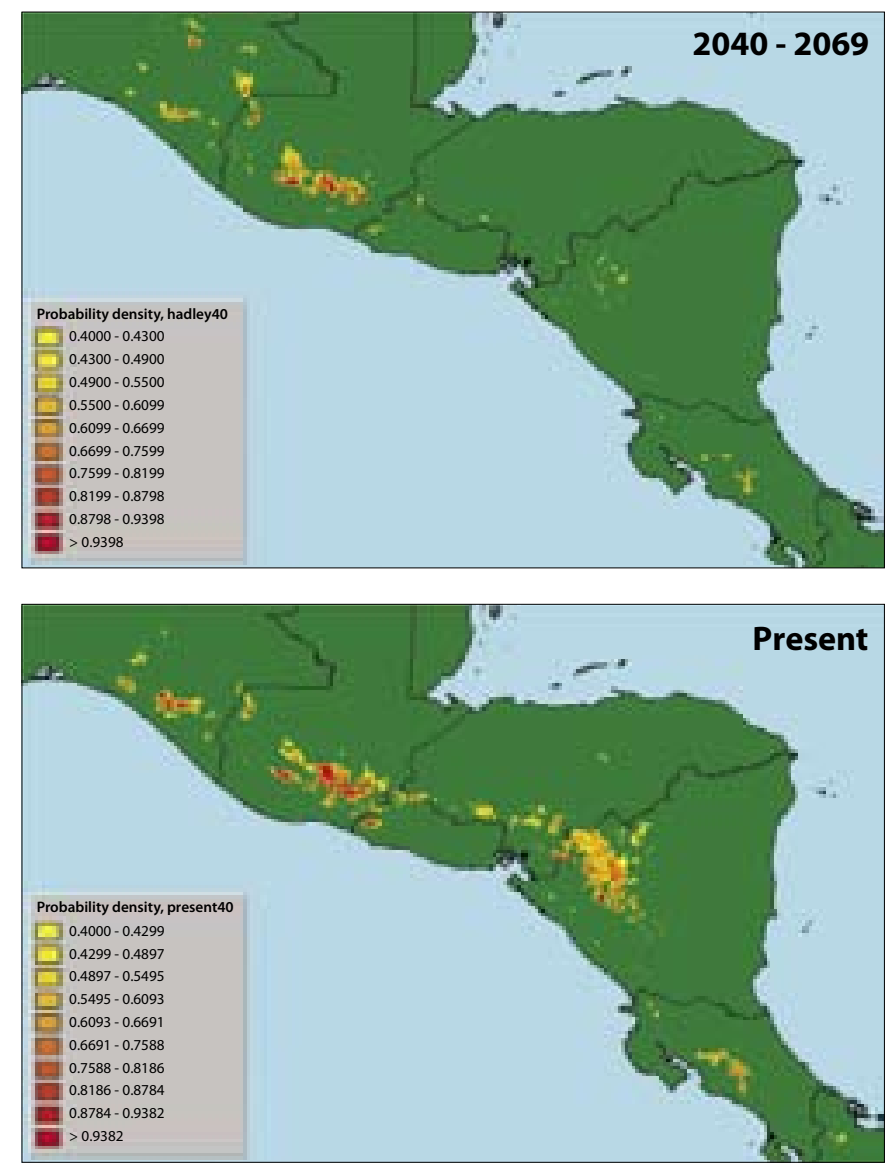

Figure 2. Potential distribution of wild bean in Central America. FloraMap ${ }^{\oplus}$ prediction based on HadCM2 for years 2040 to 2069 (Source: Jones \& Beebe, 2001)

to $70 \%$ with many of the isolated areas of occurrence disappearing completely. Reductions in El Salvador, Nicaragua and Honduras are about $90 \%$ to $100 \%$. In Panama, beans disappear completely. This will be an important loss. Wild beans have been used to recover genes lost when the crop was domesticated. One of these was the gene for resistance to bean weevil (Bruchid) attack. It is estimated that this insect damages over US\$2 billion worth of beans. The protein from the wild beans collected in Arcelia in Mexico gives complete resistance and is being incorporated in commercial varieties. Nobody knows what other important genes are out there in the wild populations; if they disappear, we have no idea what we are losing.

One of the problems we face in plant breeding and agronomy is how to deal with climate change. If a future climate is nothing like what we can experience now, then we have real problems. Plant breeding is a long-term process. At CIAT, studies started 25 years ago are now yielding commercial drought-tolerant varieties of beans with a potential of yielding almost 1 ton in conditions where current bean crops would practically fail to give any harvest at all. No matter how much biotechnology and controlled environment work is done, the final 
evaluation of a variety must be done in the conditions it will meet in the field. But where do we find a field similar to the climate of 25 years in the future?

With the FloraMap algorithm, we can look at how the overall long-term climate will change. Figure 3 shows an example for the Amazon. I made an artificial accession set of points in the area of Manaus, Brazil and fitted the FloraMap climate similarity model to them. The top left map in the figure shows the extent of this climate. It is confined to the area around Manaus without any homologues in other areas. The map at the top right shows where this climate will be found in 50 years' time. Fitting the model against the HadCM2 downscaled grid for the 2040-2069 period gives the extent of the future climate of Manaus (bottom left in Figure 3). When this model is mapped over the present day climate grid, we can identify an area in the present day that is the homologue of the climate of Manaus 50 years into the future. This turns out to be in and around the municipality of Puerto Lopez, south of the Meta River in the southern llanos of Colombia. This would make a fine laboratory for testing varieties and agronomic practices for the future of Manaus, present-day security problems permitting.

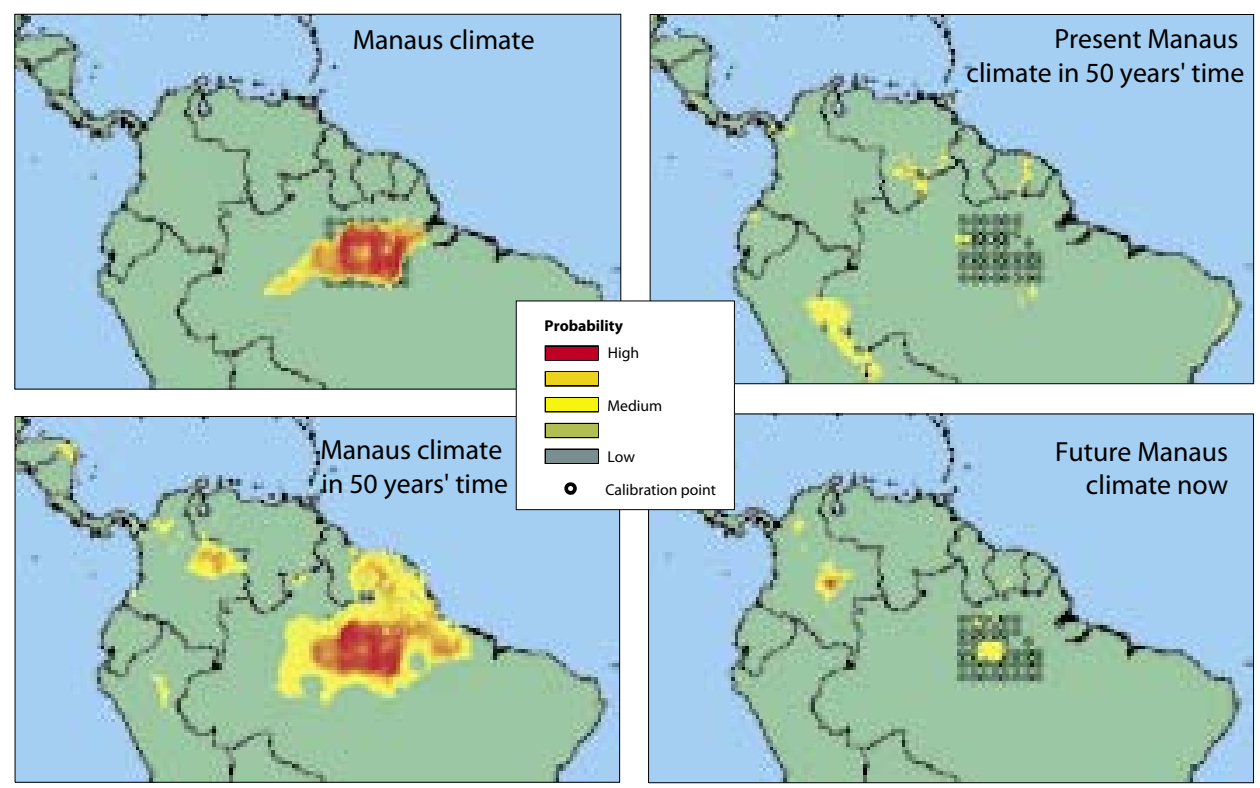

Figure 3. Present and future climates similar to the area around Manaus, Brazil (Source: P. G. Jones Unpublished data, CIAT internal presentation)

These models show us how the climate will behave on average at local scale. When we try to determine what will happen with cropping patterns, yields, etc., we need an estimate of daily data. GCMs give these but at massive global footprint scale. We need a detailed level. Some form of statistical downscaling is therefore needed. Here, MarkSim comes in useful. The clustered climates are a form of weather typing with the model parameters fitted by regression within each cluster. Using an interpolated grid we can simulate daily weather for any period, present and future described by a GCM. 
Various outputs can be used but the most frequent is for input to DSSAT models that now include many crops. DSSAT is a microcomputer software programme combining crop, soil and weather databases, and programmes to manage them, with crop model and application programmes, to simulate multi-year outcomes of crop management strategies. As a software package integrating the effects of soil, crop phenotype, weather and management options, DSSAT allows users to ask "what if?" questions and simulate results by conducting, in minutes on a desktop computer, experiments that would consume a significant part of an agronomist's career.

We have made simulations of the maize (Zea mays L.) crop. In the study reported in Jones and Thornton (2003), we made about 64,000,000 simulations of a maize growing season to map the effects of climate change on this important tropical crop. The details of this study are reported elsewhere (Jones, this volume). Suffice it to say that we found that there was a very wide range of responses. In some areas, yields actually improved. In Figure 4, these areas show in southern Brazil, the Central African Highlands and Ethiopia, among a few others. In these areas it will be vitally important for adaptation to make the correct selection of varieties to maximise the benefit of the change. In most areas, there is a moderate yield loss. We would hope that judicious agronomic changes and plant breeding

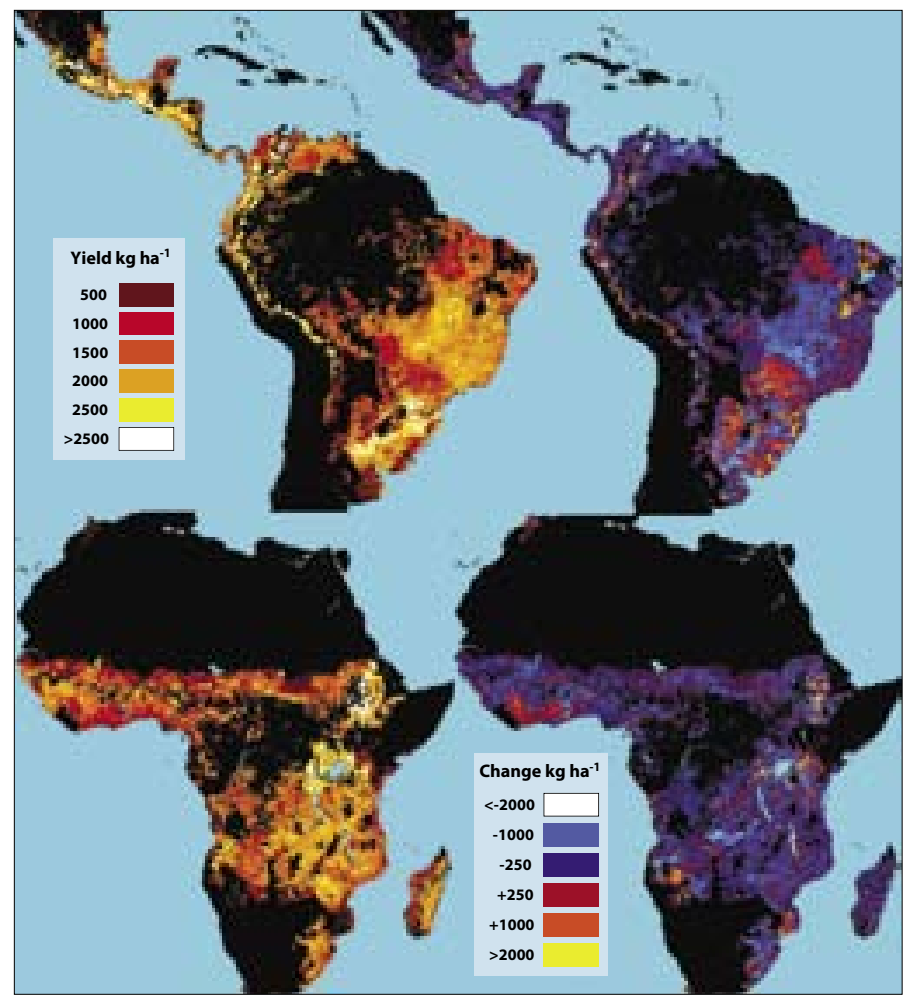

Figure 4. Maize yields in Latin America and Africa at present (left-hand side) with the yield change to the year 2050 (right-hand side) (Source: Jones \& Thornton, 2003) 
could avoid this. It is vital that the plant breeding starts now, as this is a very time-consuming process and stress tolerance will be needed in a large range of varieties. In some areas, there is almost complete crop loss. The light blue areas in North-East Brazil show a 2-ton loss on a 2-ton yield. Plant breeding is unlikely to solve this problem and it is probable that major changes to the agricultural system will be needed - including the re-location of some populations.

An important finding is that these effects are in many cases highly localised. Farmers gaining by the change in North-East Brazil are situated only a few kilometres from those who lose completely. This means that adaptation studies and recommendations cannot be made at a regional or national level but must be essentially local.

\section{Discussion}

There are drawbacks to using climate grid models. Simulation with MarkSim depends on a representation climate existing now. If event frequencies change, we cannot model them because we are dependent on change to existing patterns, for example, changes in El Niño events and wind patterns where we can have changes in orogenic rainfall patterns. What can we do? The weather typing in MarkSim is entirely based on present climates. Other types of statistical downscaling could be applied but this would change the structure of the MarkSim system and would be costly. One solution would be to extend the MarkSim weather typing to include the output of various scenarios of the GCM of choice. This is actually feasible but requires large quantities of data at a high temporal resolution.

Can we afford to use nested GCMs? At present, they are highly expensive and outside the realms of possibility for developing countries. Computing power is increasing all the time but a PC is still very far from becoming a supercomputer. Parallel processing can solve this problem. The Message Passing Interface (MPI) allows many computers to work on one task.

CIAT has over 500 PCs, most of them only $5 \%$ utilised. We have started tests using MPICH${ }^{2}$ with Fortran application on 36 machines on the geographic information systems (GIS) network. It proved surprisingly easy to use. Using a test case of calculations on heterogeneity, we found that parallel processing can increase the speed as much as 15 times using 11 or 12 machines, reducing runs from days to hours. The application uses only the spare capacity of the machines and the users do not notice it running. In fact, in the 2 months of trials in CIAT, I only received three complaints about the speed of a user's computer, and in all three cases, the relevant machine was not included in the parallel set. Instead, MPI was being used as a scapegoat for some other fault in their setup.

In Japan, scientists are putting 5120 processors into the Earth Simulator ${ }^{3}$ that will run large-scale GCMs; this is a specially designed machine and very

\footnotetext{
${ }^{2}$ http://www-unix.mcs.anl.gov/mpi/mpich/

${ }^{3}$ http://www.es.jamstec.go.jp/esc/eng/index.html
} 
costly. An ordinary PC network cannot hope to have the speed and efficiency of such a machine but much can be achieved for a moderate cost and often using the spare capacity of existing machines (Word ${ }^{\circledR}$ does not normally take more than a few percent of the CPU capacity - as I am typing this it is varying between $2-11 \%)$. The only drawback is that we would need access to GCM software that could take advantage of MPICH or similar software. This is certainly not out of the question because the cellular nature of a GCM is ideal for parallelisation.

\section{Conclusions}

With relatively limited computing resources it is possible to downscale to local scales in developing countries. This can be done using statistical or dynamic downscaling. While the capability to do this may not yet be in place in many institutions in developing countries, it is not beyond possibility with a modicum of effort.

The need for this is evident for both biodiversity and agricultural planning and one can envisage a whole realm of other situations needing this input. The ability to effect mitigation on the part of developing countries is often vastly overstated. Climate change is upon us and even with the best will in the world it will not abate for the foreseeable future. It is necessary to adapt to it, and that will require careful forward planning in the case of agriculture and forestry. The effects will be local and cannot be predicted except at a local level. Therefore, we should make sure that the capability to analyse it at the local level is in place in the relevant institutions in the countries affected.

In certain cases, the change expected over the next 50 years may change the climate of a location into one similar to an area that presently experiences that climate. In this case, experimentation and planning can proceed with the certainty that we have a present homologue from which to learn. In other cases, the climate, particularly in the lowland tropics, will change to one that has no present homologue. This will present problems for planners and will probably require careful modelling of the system to produce timely solutions.

\section{References}

Gyalistras, D., H. von Storch, A. Fischlin, M. Beniston (1994) 'Linking GCMsimulated climatic changes to ecosystem models: case studies of statistical downscaling in the Alps' Climatic Research 4(3): 167-189.

Hay, L.E., R.L. Wilby, G.H. Leavesley (2000) 'A comparison of delta change and downscaled GCM scenarios for three mountainous basins in the United States' Journal of American Water Resources 36:387-397.

ICASA (International Consortium for Agricultural Systems Applications) (2004) ICASA DSSAT version 4.0. Available at http://www.icasa.net/dssat/

Jarvis, A., M.E. Ferguson, D.E. Williams, L. Guarino, P.G. Jones, H.T. Stalker, J.F.M. Valls, R.N. Pittman, C.E. Simpson, P. Bramel (2002) 'Biogeography of wild Arachis: assessing conservation status and setting future priorities' Crop Science 43: 1100-1108. 
Jones, P. G. (1987) 'Current availability and deficiencies in data relevant to agroecological studies in the geographical area covered by the IARCs' in A.M. Bunting (ed.) Agricultural Environments, CAB International: Wallingford.

Jones, P. G. (1991). 'The CIAT Climate Database version 3.7: Machine readable dataset of long-term climatic normals for the tropics' Centro Internacional de Agricultura Tropical (CIAT): Cali.

Jones, P. G., S. Beebe (2001) 'Predicting the impact of climate change on the distribution of plant genetic resources in wild common bean (Phaseolus vulgaris L.) in Central America' Paper presented at the III International Conference on Geospatial Information in Agriculture and Forestry, Denver, CO, USA, November 2001.

Jones P. G., A. Gladkov (1999) 'FloraMap: A computer tool for predicting the distribution of plants and other organisms in the wild'. Version 1, 1999. CIAT CD-ROM Series. CIAT: Cali.

Jones, P. G., P.K. Thornton (1993) 'A rainfall generator for agricultural applications in the tropics' Agricultural and Forest Meteorology 63: 1-19.

Jones, P. G., P.K. Thornton (1997) 'Spatial and temporal variability of rainfall related to a third order Markov model' Agricultural and Forest Meteorology 86: 127-138.

Jones P. G., P.K. Thornton (1999) 'Fitting a third-order Markov rainfall model to interpolated climate surfaces' Agricultural and Forest Meteorology 97: 213231.

Jones, P. G., P.K. Thornton (2000) 'MarkSim: Software to generate daily weather data for Latin America and Africa' Agronomy Journal 92: 445-453.

Jones, P. G., P.K. Thornton (2003) 'The potential impacts of climate change on maize production in Africa and Latin America in 2055' Global Environmental Change 13: 51-59.

Jones, P. G., S.E. Beebe, J. Tohme, N.W. Galway (1997) 'The use of geographical information systems in biodiversity exploration and conservation' Biodiversity Conservation 6: 947-958.

Jones, P. G., P.K. Thornton, W. Díaz, P.W. Wilkens (2002) MarkSim version 1. CIAT CD-ROM Series, CIAT: Cali.

NOAA (National Oceanographic and Atmospheric Agency) (1984) TGP-OO6 D Computer compatible tape. NOAA: Boulder.

Sawkins, M. C., N. Maxted, P.G. Jones, R. Smith, L. Guarino (1999)'Predicting species distributions using environmental data: Case studies using Stylosanthes Sw' in S.L. Greene, L. Guarino, L. (eds.) 'Linking genetic resources and geography: Emerging strategies for conserving and using crop biodiversity'. Crop Science Society of America (CSSA) Special Publication 27: 87-99.

Segura, S. D., L. Guarino, G. Coppens d'Eeckenbrugge, M. Grum, P. Ollitrault (1999) 'Mapping the distribution and regions climatically suitable for four species in Passiflora subgenus Tacsonia (Passifloraceae) and P. manicata' Poster presented at the II Simposio de Recursos Genéticos para América Latina e el Caribe, Brasilia, Brazil, 21-26 November 1999. 


\title{
How crop production will be affected by climate change in Africa and its repercussions on the continent
}

\author{
Peter G. Jones ${ }^{1}$ and Philip K. Thornton ${ }^{2}$ \\ 1. Centro Internacional de Agricultura Tropical (CIAT) \\ AA 67-13, Cali, Colombia. Tel: 57-2-4450068 (Col), 44-1341-423561(UK), \\ Fax: 57-2-4450073, E-mail: p.jones@cgiar.org \\ 2. International Livestock Research Institute (ILRI) \\ P.O. Box 30709, Nairobi 00100, Kenya. Tel: +254 26307 43, Fax: +254 2631499 , \\ E-mail: p.thornton@cgiar.org
}

\section{Introduction}

Various assessments of the effect of climate change on agriculture have been published. The Agro Ecological Zones approach of Fischer et al. (2002) provides a comprehensive worldwide summary based on an aggregate method on halfdegree grid squares. As noted by the authors, this is an approximation because the spatial variability in agricultural production requires a much more precise approach. However, the grid size is restricted by the cell size of the Global Circulation Model (GCM) and to gain better precision the results must be downscaled to a smaller pixel size. Modern dynamic growth and yield models now are available for a wide range of crops and can give a detailed seasonby-season estimate of yield and yield variability down to field level. To do this, we need estimates of daily weather variables. Thus, the downscaling needs to produce not only high-precision data on a spatial scale but also daily data.

We use a combination of statistical downscaling techniques that include both weather typing and stochastic weather generation based on the software tool, MarkSim ${ }^{\oplus}$. These results are from two studies published as Jones and Thornton $(2002 ; 2003)$ that use the dynamic crop model, CERES-Maize. In the first, we ran the model for 30 seasons on a sample of points in a study area in south-east Africa and, in the second, we modelled maize yields over 20 seasons for every pixel with a maize-growing potential for the whole of Africa - a total of over 30,000,000 model runs. 


\section{Methods}

For the first study, we chose a window in southern Africa extending from $22^{\circ}$ $\mathrm{E}$ to $42^{\circ} \mathrm{E}$ and from $23^{\circ} \mathrm{S}$ to $5^{\circ} \mathrm{S}$, covering an area of about 38,000 square kilometres. This window covers the southern part of Tanzania, Malawi, much of Mozambique and all of Zimbabwe, and extends west from the Indian Ocean to include Zambia, the south-eastern part of the Democratic Republic of Congo (DRC) and small portions of Angola. We chose this area because of its overall single, well-defined growing season and the considerable spatial variability in total annual rainfall.

Having tested the capacity to run the combination of MarkSim weather generation and seasonal crop modelling, we extended the study to all relevant pixels in Africa. We ran a water balance model for each pixel and eliminated all those with no possibility of a maize growing season. We then overlaid an estimate of agricultural land cover (Wood et al., 2000) and eliminated pixels with no cultivated area.

\subsection{MarkSim}

Being able to model outlying rainfall years satisfactorily is particularly important in studies aimed at quantifying production system risk. Over the last 20 years we have developed and extensively tested a third-order Markov rainfall model. We reported the first stages of analysis and validation in Jones and Thornton (1993). A Markov model works by randomly sampling a series of events where the probability of observing an event depends on the occurrence of previous events. A third-order Markov model takes into account events occurring over the previous 3 days. We found that, whereas a lower order model is often sufficient for temperate climates, the third order is necessary for many tropical climates. This simple model should be able to simulate the variance of monthly and annual rainfall for sites in the tropics and subtropics but even the third order model falls short of reality. The MarkSim rainfall generator makes good this deficit by means of annual random re-sampling of the parameters for the transition probabilities of the model.

We showed that patterns could be discerned in the parameter values that were typical for certain types of climate (Jones and Thornton, 1997). We then used a leader cluster algorithm on the standardised climate variables to divide the world climates into 702 clusters. Within each cluster, we fitted regression models to the 117 model parameters (fortunately, there is considerable redundancy and we could fit reasonable regressions using the 36 variables available). Interpolated climate surfaces at 10 arc-minutes were fitted to the National Oceanographic and Atmospheric Administration (NOAA) data set TGP006 (NOAA, 1984) using inverse square distance weights for spatial interpolation, and a standard lapse rate model to correct temperature for elevation effects. These surfaces were based on historical data from over 20,000 stations throughout the tropics having more than 10 years of record taken from the period 1920 to 1990 . They are not therefore standard climate normals but compensate for the lack of time standardisation by including more stations. 
Jones and Thornton $(1999 ; 2000)$ describe the programme in detail. Hartkamp et al. (1999) have shown that inverse distance weighting methods perform equally as well as thin plate smoothing and co-Kriging.

Thus the model can be used to interpolate rainfall data for places where they do not exist. The MarkSim system identifies the climate set relevant to any required point on the globe using interpolated climate surfaces and evaluates the model parameters for that point.

We took the difference of the mean results for HadCM2 for the periods 1960-1990 and 2040-2070, and interpolated them to the 10 arc-minute grid using inverse least squares. This was added in to the 1975 climate grid. This stage is therefore a simple delta change downscaling (Hay et al., 2000). The MarkSim climate patterns of the 702 clusters can be considered a form of weather typing, see Wilby (1995). The final downscaling to daily weather data is performed by the MarkSim stochastic algorithm, using parameters derived by regression within the weather class determined for each point. Although we use a stage of simple delta change, this alters the future climate point and can substantially alter the stochastic parameters, even to moving the point from one weather type to another - thus ensuring a good simulation of future daily weather patterns. We simulated 30 seasons for the first study of 1024 points and 20 seasons for the much larger, second study.

\subsection{Soils data}

We used the Food and Agriculture Organization (FAO) 1:5,000,000 digital soil map of the world (FAO 1974; 1995) and cut out the appropriate window. For all the soil types in the window, we made a qualitative assessment (based on the soil unit ratings in FAO [1978]) as to their agricultural suitability for maize production: class 1 , unsuitable; class 2 , moderately suitable; and class 3 , highly suitable. We then assembled representative profiles from the International Soils Reference and Information Centre's (ISRIC's) World Inventory of Soil Emission Potentials (WISE) database (Batjes and Bridges, 1994; Batjes, 1995) for each of the soils in the FAO soil map units that fell into classes 2 and 3. We used a combination of the pedotransfer functions in the decision support system for agricultural technology transfer (DSSAT), implemented in a Visual Basic programme by Ravic Nijbroek at the International Livestock Research Institute (ILRI), and a database at the International Center for Tropical Agriculture (CIAT, the Spanish acronym), assembled by Jamie Fairbairn (unpublished), to estimate water-holding capacities.

Figure 1 shows an example of a typical pixel of the soils from the FAO map - a river valley fluvisol and ferrasols on the boundaries. Figure 2 shows how we allocate the soil extents using the soil classes and percentage figures from both the coverage within the pixel and the percentage cover of each soil with the soil mapping unit. 


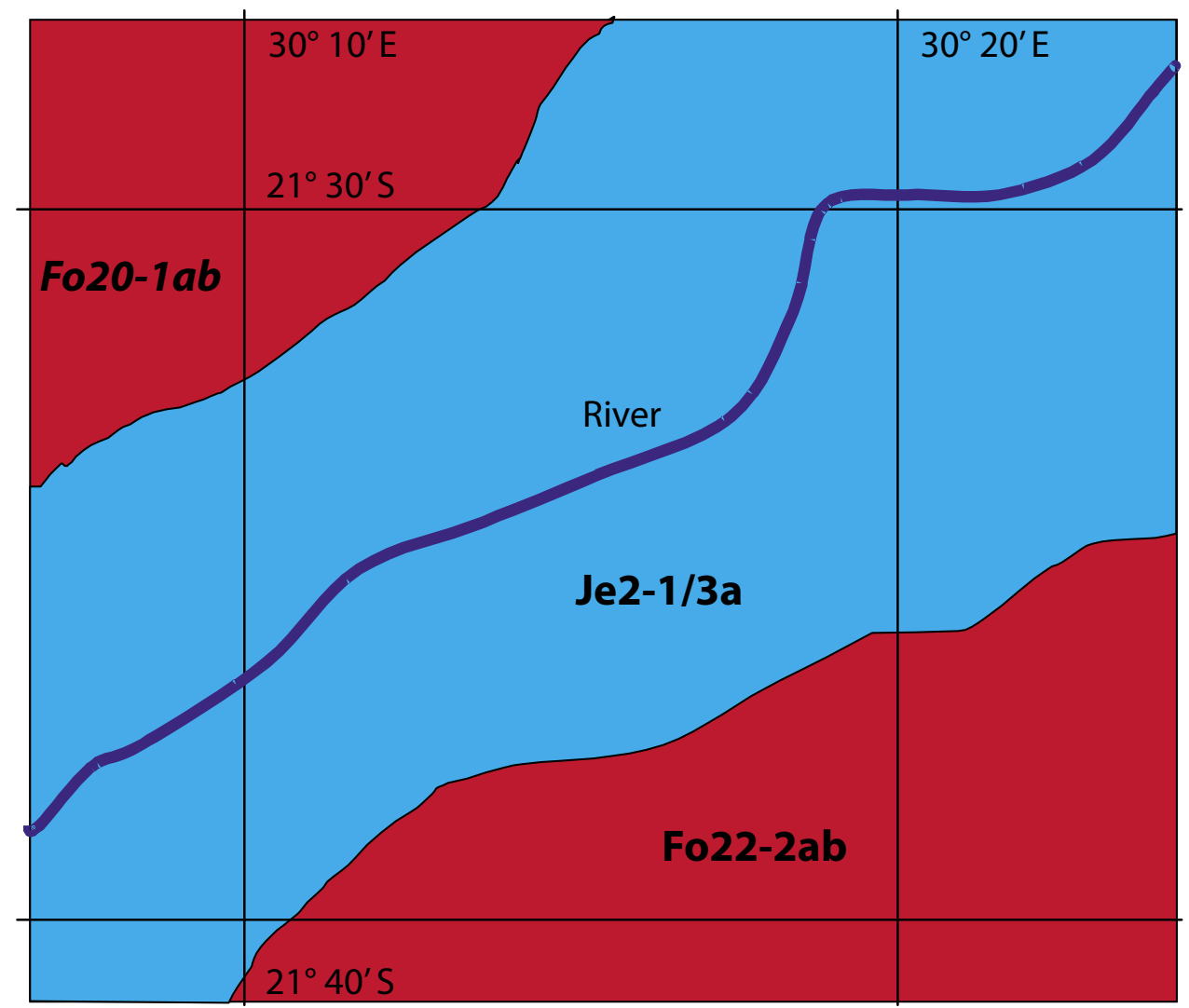

Figure 1. Schematic diagram of the soils in a pixel

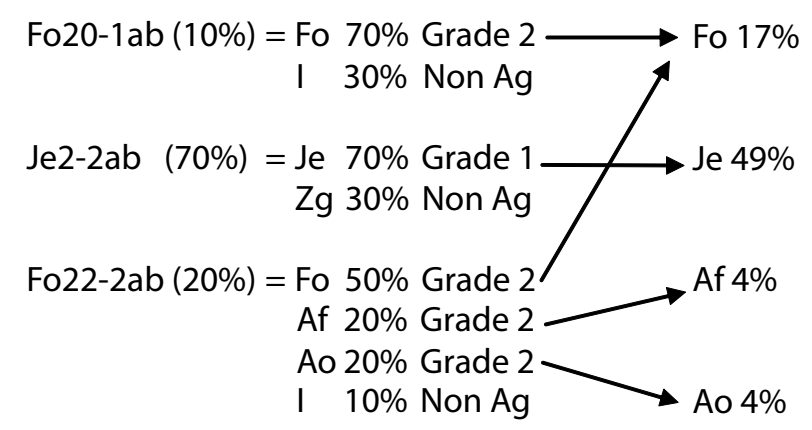

Figure 2. Calculation of soil proportions

\subsection{CERES-Maize}

CERES-Maize is a model that simulates the growth, development and yield of the maize crop. It was designed to use a minimum set of soil, weather, genetic and management information. The model is run with a daily time step and requires daily weather data (maximum and minimum temperature, solar radiation and rainfall). It calculates crop phasic and morphological development using temperature, day length and genetic characteristics. Leaf area index, plant 
population and row width provide information for determining the amount of light interception, which is assumed to be proportional to biomass production. A water and nitrogen balance sub-model provides feedback that influences the development of growth processes (Ritchie et al., 1998). CERES-Maize has been widely used in North America and in the tropics and subtropics (Tsuji et al., 1998). The model also has been validated and applied successfully at many sites in our study window - see, for example, Muchena and Iglesias (1995) for Zimbabwe, Thornton et al. (1995) for Malawi, and Schulze (2000) and Durand and du Toit (2000) for southern Africa. To run CERES-Maize, we need data on daily weather, the soil profile, genetic coefficients for the variety simulated and information on the crop management.

In the first study, we used Katumani Composite B (KCB), a Kenyan, open-pollinated maize variety developed more than 25 years ago as a fairly short-season variety (about 120 days) for the dry mid-altitude conditions of Kenya (Hassan, 1998). We felt that it was a good variety for small-scale farmer maize growth in the study area. For the second study, we needed a more flexible approach. We chose a set of four generic varieties with a range of maturity dates that could be matched to the potential growing season. This would be the normal strategy of smallholder maize farmers whose varieties would be selected for long-term success in the area where grown.

Input and analysis programmes were custom-written in Fortran, and maps were generated using IDRISI (Eastman, 1993). Figure 3 shows the process.

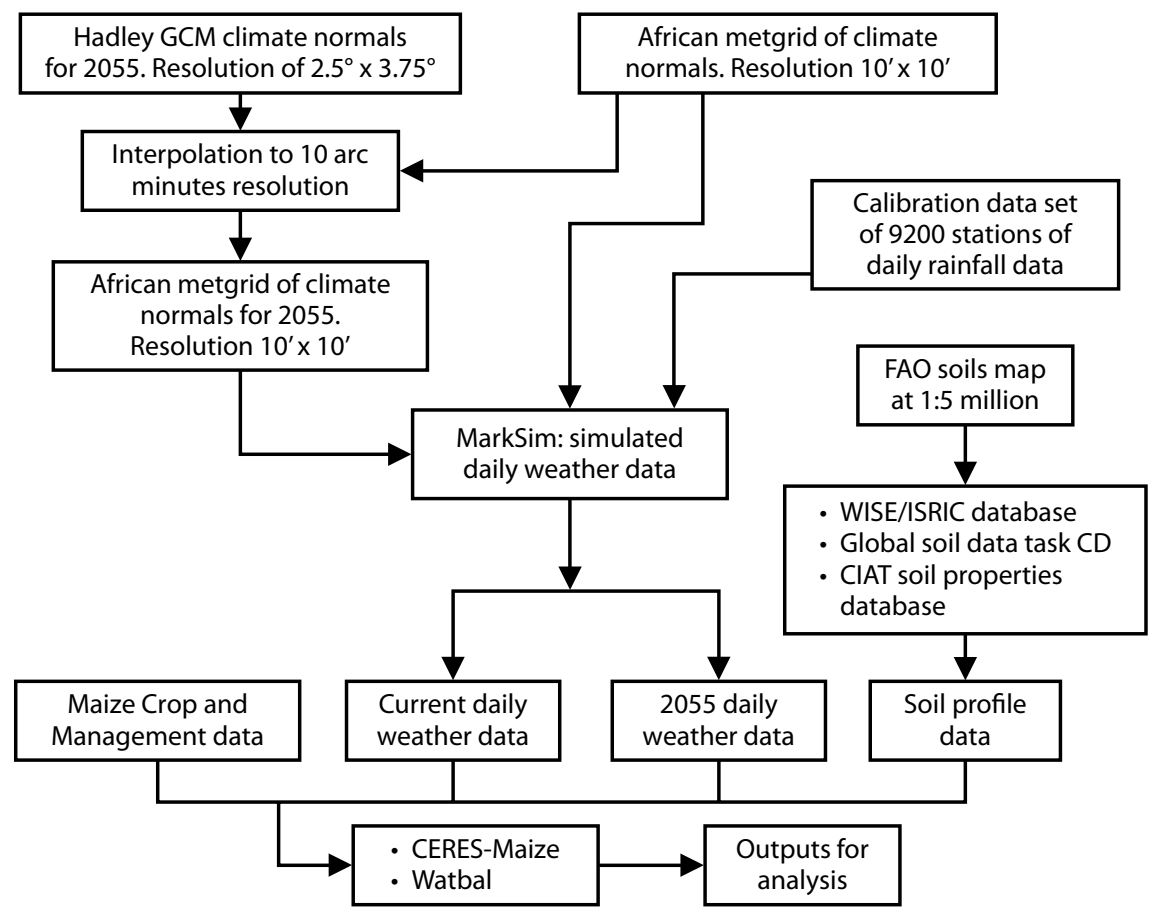

Figure 3. The modelling process 


\section{Results}

From the first study, we produced a map of the changes expected in 50 years' time for the study area. Figure 4 shows the present and future yields. The results in some areas are dire. The drier areas of Botswana, southern Zimbabwe, Mozambique and DRC could be hard hit, as could certain areas in southern Tanzania. Northern Zambia appears to have a yield shortfall, whereas the higher ground in the central and southern areas of the country might actually see more stable yields. In Zimbabwe, we see a marked movement of higher yield areas from the southeast into northern Matabeleland. We also note that areas of higher yield move across country boundaries as the climate changes. The case of southern Malawi is particularly sad if these prognostications come about. The susceptibility of all these nations to seasonal drought is well noted, particularly in recent years. If maize yields are to become more erratic in the future then this could be a major case for concern.

$\mathrm{P}=0$
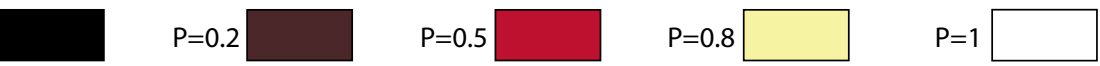

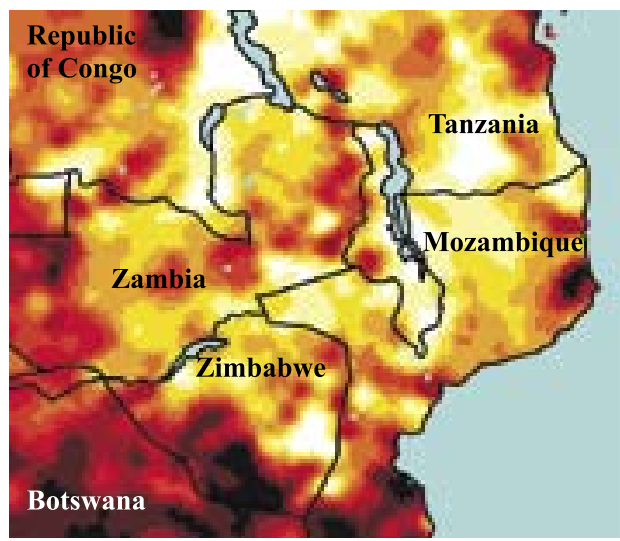

Present day

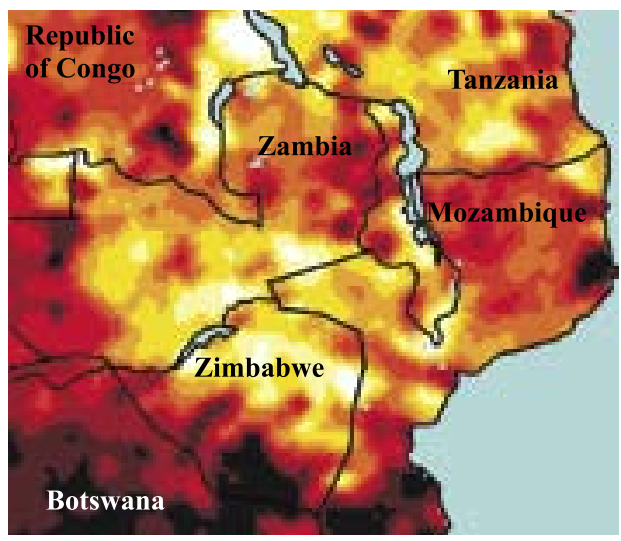

Year 2055

Figure 4. Study 1: Yields of maize variety Katumani composite B simulated by CERES Maize for south-east Africa

The second study showed dramatically how small-scale farmer maize crops could be affected over the whole continent. Figures 5 to 7 show a variety of scenarios. Figure 5 shows the yield and potential change to 2055 in the Horn of Africa. In Ethiopia, some areas are potentially hefty winners. Increases in yield of up to 2 tons or more with moderately low inputs might be expected. However, these areas are relatively restricted, they are at higher elevations and are adjacent to other areas where severe losses are predicted. These areas are not presently main maize producing areas but there may be a potential for the future. 

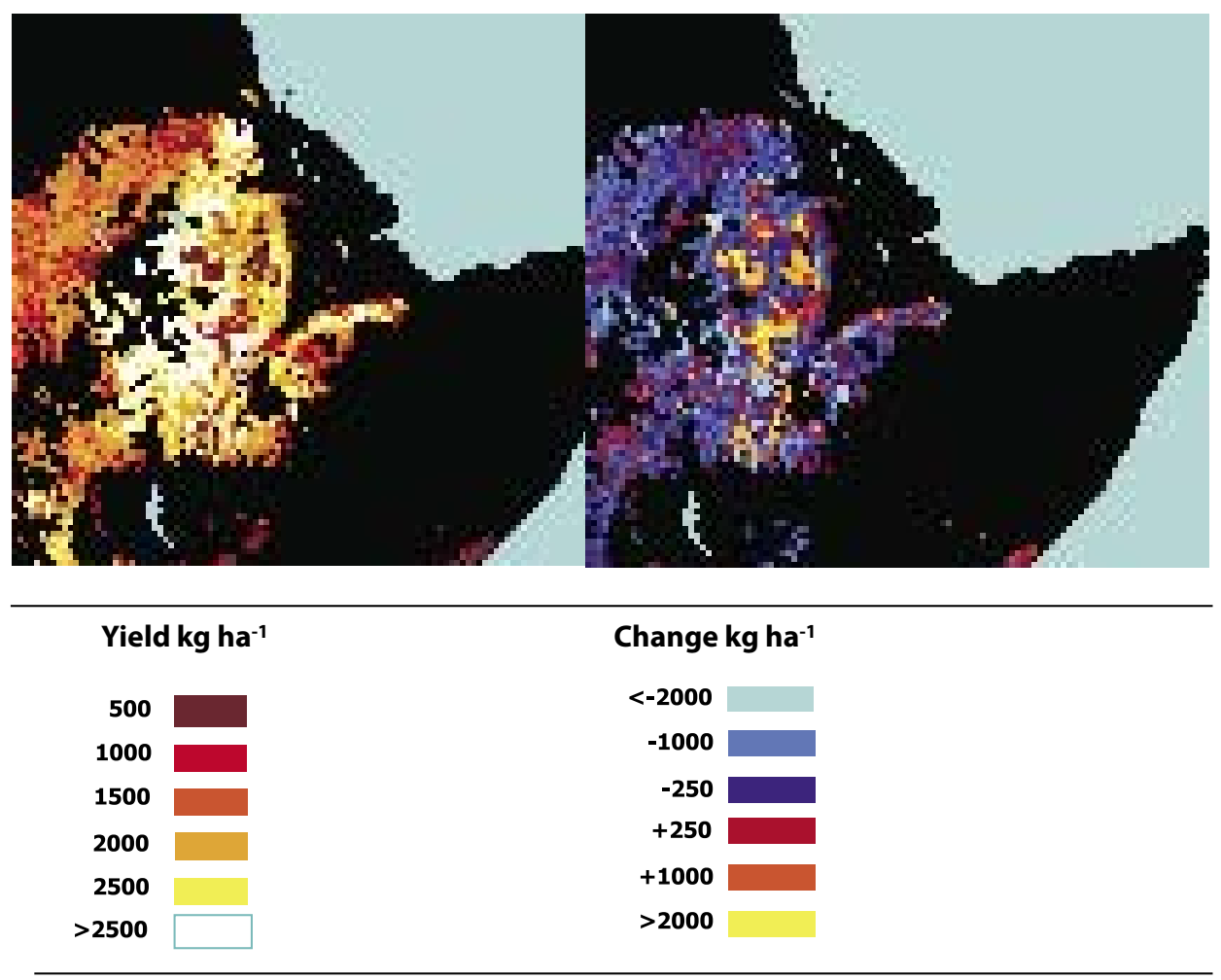

Figure 5. Potential small-scale farmer maize yield at present in the Horn of Africa and the predicted change to the year 2055

Figure 6 shows areas that are major maize-producing regions, in fact, maize in these areas is a major staple for human diet and also the stover is used for animal feed. It is vital to the local economy. The changes indicated will have major impacts. The increases in the highlands will be most welcome; the decreases in the lowlands could be disastrous. In many areas, as can be seen from the maps in Figures 5 to 7 , the situation is equivocal. Yields may remain the same, increase marginally or in the main suffer a small decrease. The local variation is marked. The pixel size is about $18 \mathrm{~km}$ on a side at the equator, so farmers will encounter very varied effects depending on exactly where they are in the topography. Figure 7 shows us two markedly different areas. Large areas of southern Angola will almost certainly lose all capability of growing maize with varieties such as those simulated. The interesting case, which is in all probability an artefact of the simulation, is the large area in northern Namibia that becomes a potential maize-growing area. The GCM results do show areas where rainfall is moderately increased and this could possibly be a result. 


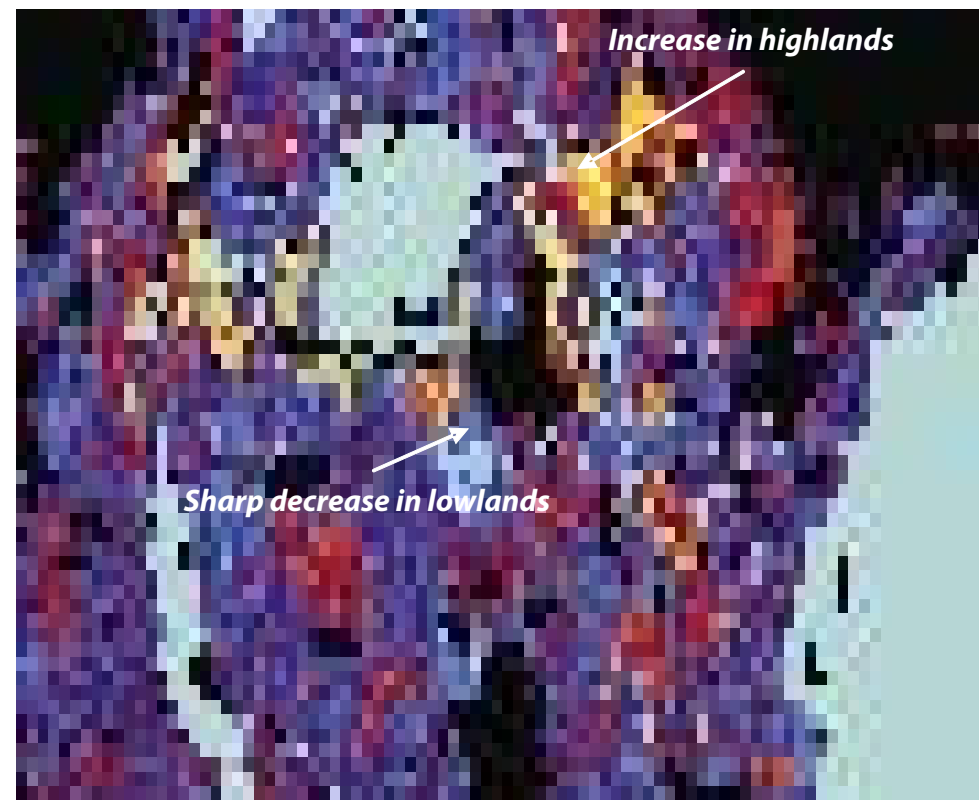

Change kg ha-1

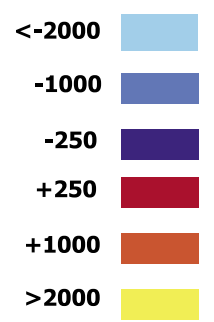

Figure 6. Change in simulated smallholder maize yields from present to the year 2055 in East Africa, Great Lakes Region

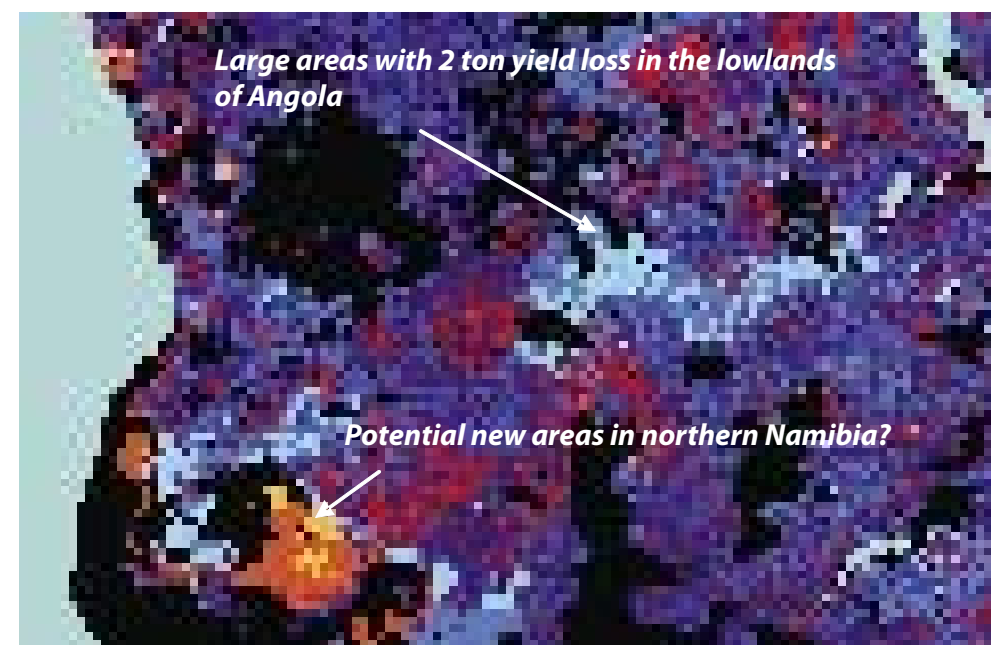

\section{Change kg ha-1}

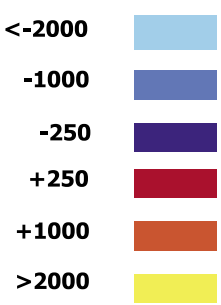

Figure 7. Potential change in maize yields to the year 2055 in south-western Africa 


\section{Conclusions}

There are therefore three main scenarios. What are they and what can we do about them?

(1) The crop loses yield but within reasonable limits: We can breed tolerant crops, change the cropping mix or modify agronomic practices and farming systems. This is within the competence of the international and national agricultural research community. Timely warning to plant breeders as to where this will occur and which varietal types will be affected will be critical in planning.

(2) Crop benefits from climate change: We should make sure that the crops and varieties used make the maximum use of the benefits. There are not many places where this will happen, so the plant breeders need advance warning.

(3) The crop loses yield drastically: We should warn farmers and policy makers about potential drastic changes in the farming systems, even to population migration.

We are proposing the project "Farming Futures" to investigate the effects of climate change on farming systems of the tropics. We use MarkSim and dynamic crop models with present and future climate grids to help solve problems and take advantages of new opportunities. The aim is to inform the agricultural scientific community and policy makers of short- and long-term effects. We will work with the agricultural scientific community and farmers to evaluate potential solutions. DSSAT models are available for a wide variety of crops.

The time-scale is most important. If we can point the world's plant breeders towards new goals, hopefully to be achieved in 25 years' time, then we will have done well. How do we get the information to the farmers? Since response to climate change is variable from place to place, we cannot make overarching recommendations. The best approach is a participatory one. Luckily, in some areas there will be analogues of future climates at other locations. Farmers might learn from their neighbours. Unfortunately, for some there will be no present analogue.

Climate change is not easy to see. It is random and varies from year to year but we can see changes in extreme events. Figure 8 shows a hypothetical example of a random variable greatly increasing over time. We can see the reduction in the number events that score low, and gradual increase in frequency that score high. These could be storms, droughts, frosts or many other manifestations of climate that affect agriculture. The fact that change, although gradual, will be experienced by extreme events gives us an advantage. Farmers may be able to learn from their own experiences. By seeing how they have dealt with problems in the past, we can warn them of increasing or decreasing risks in their future. Participatory research can help introduce new varieties or crops to cope with the changing environment. 


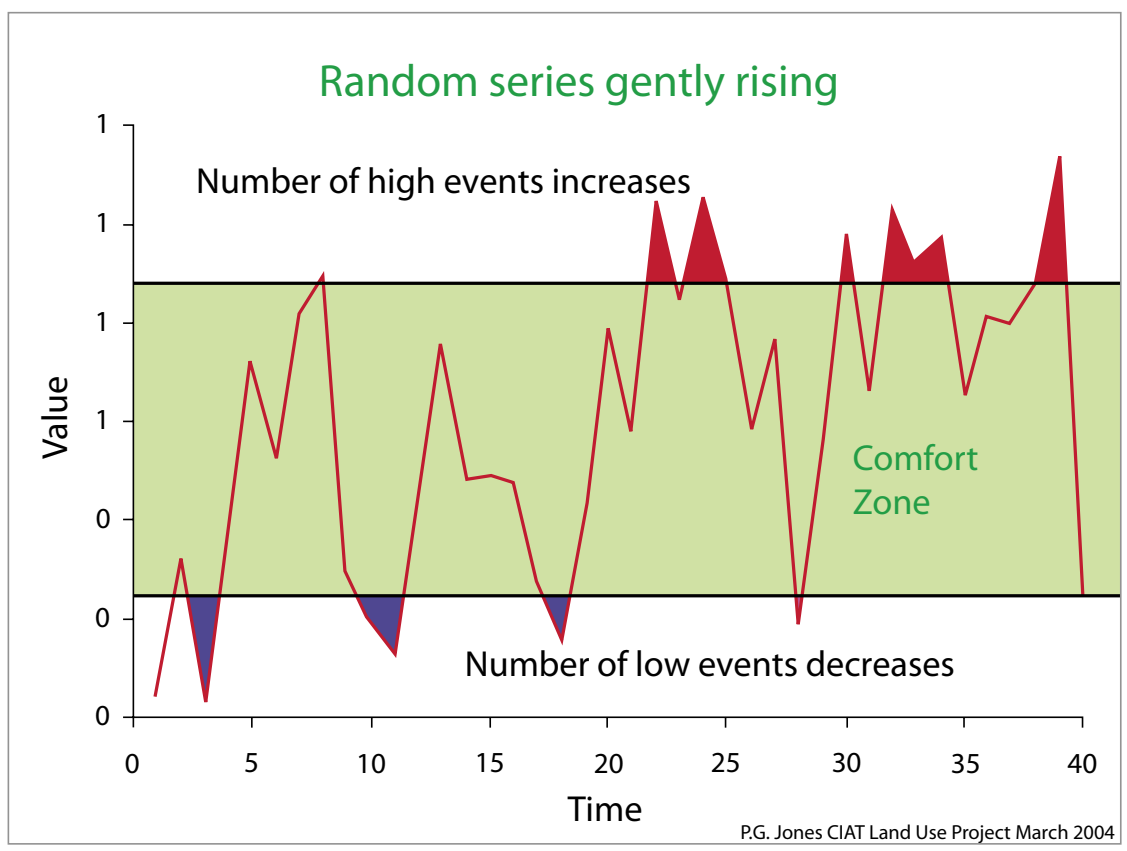

Figure 8. Illustration of a random series rising through a zone regarded as the comfort zone for a species

\section{References}

Batjes, N. H. (ed.) (1995) 'A homogenised soil data file for global environmental research: a subset of FAO, ISRIC, and NRCS profiles (Version 1.0)' Working Paper 95/10, International Soil Reference and Information Centre (ISRIC): Wageningen.

Batjes, N. H., E.M. Bridges (1994) 'Potential emissions of radiatively active trace gases from soil to atmosphere with special reference to methane: development of a global database (WISE)' Journal of Geophysical Resources 99(D8): 16,479-16,489.

Durand, W., A.S. du Toit (2000) 'Using crop growth models and GIS to address issues influencing sustainability in the short, medium and long term' in W. Durand, A.S. du Toit (eds.) 'Proceedings of the Highveld Ecoregion Workshop on Methodology and Strategy Development Using Systems Analysis for Sustainability in the South African Highveld Eco-region', ARC-Grain Crops Institute: Potchefstroom.

Eastman, J. R. (1993) IDRISI Version 4.1 Clark University: Worcester.

FAO (Food and Agriculture Organisation) (1974) FAO-UNESCO Soil Map of the World 1:5 000 000. Volume 1, UNESCO and FAO: Paris and Rome.

FAO (1978) 'Report on the AgroEcological Zones Project'Volume 1: Methodology and Results for Africa. World Soil Resources Report 48, FAO: Rome.

FAO (1995) Digital soil map of the world and derived soil properties, Version 3.5, Land and Water Digital Media Series 1, FAO: Rome. 
Fischer, G., H.T. van Velthuizen, M.M. Shah, F.O. Nachtergaele (2002) ‘Global agroecological assessment for agriculture in the 21st century: methodology and results' International Institute for Applied Systems Analysis, Laxenburg. Internet: http://www.iiasa.ac.at/cgi-bin/pubsrch?RR02002

Hartkamp, A. D., K. de Beurs, A. Stein, J.W.White (1999)'Interpolation techniques for climate variables' NRG-GIS Series 99-01, International Maize and Wheat Improvement Center (CIMMYT): Mexico D.F.

Hassan, R. M. (ed.) (1998) Maize technology development and transfer. A GIS application for research planning in Kenya, CAB International: Wallingford.

Hay, L., R.L. Wilby, G.H. Leavesley (2000) 'A comparison of delta change and downscaled GCM scenarios for three mountainous basins in the United States' Journal of the American Water Resources Association 362: 387-397.

Jones, P. G., P.K. Thornton (1993) 'A rainfall generator for agricultural applications in the tropics' Agricultural Forest Meteorology 63: 1-19.

Jones, P. G., P.K. Thornton (1997) 'Spatial and temporal variability of rainfall related to a third-order Markov model' Agricultural Forest Meteorology 86: 127-138.

Jones, P. G., P.K. Thornton (1999) 'Fitting a third-order Markov rainfall model to interpolated climate surfaces' Agricultural Forest Meteorology 97: 213-231.

Jones, P. G., P.K. Thornton (2000) 'MarkSim: Software to generate daily weather data for Latin America and Africa' Agronomy Journal 92: 445-453.

Jones, P. G., P.K. Thornton (2002) 'Spatial modelling of risk in natural resource management'Conservation Ecology 5(2):27. Internet: http://www.consecol. org/vol5/iss2/art27

Jones, P. G., P.K. Thornton (2003) 'The potential impacts of climate change on maize production in Africa and Latin America in 2055' Global Environmental Change 13: 51-59.

Muchena, P., A. Iglesias (1995) 'Vulnerability of maize yields to climate change in different farming sectors in Zimbabwe' in C. Rosenzweig, L.H. Allen Jr, L.A. Harper, S.E. Hollinger, J.W. Jones (eds.) 'Climate change and agriculture: analysis of potential international impacts' American Society of Agronomy, Special Publication No. 59: Madison.

NOAA (National Oceanographic and Atmospheric Administration) (1984) TGPOO6 D. Computer compatible tape. NOAA: Boulder.

Ritchie, J.T., U. Singh, D.C. Godwin, W.T. Bowen (1998) 'Cereal growth, development and yield' in G.Y. Tsuji, G. Hoogenboom, P.K. Thornton (eds.) Understanding options for agricultural production. Kluwer Academic Publishers: Dordrecht.

Schulze, R.(2000) 'Transcending scales of space and time in impact studies of climate and climate change on agrohydrological responses' Agriculture, Ecosystems and Environment 82: 185-212.

Thornton, P.K., A.R. Saka, U. Singh, J.D.T. Kumwenda, J.E. Brink, J.B. Dent (1995) 'Application of a maize crop simulation model in the central region of Malawi' Experimental Agriculture 31: 213-226. 
Tsuji, G.Y., G. Hoogenboom, P.K. Thornton (eds.) (1998) Understanding options for agricultural production, Kluwer Academic Publishers: Dordrecht.

Wilby, R. L. (1995) 'Simulation of precipitation by weather pattern and frontal analysis' Journal of Hydrology 173: 91-109.

Wood, S., K. Sebastian, S.J. Scherr (2000) Pilot analysis of global ecosystems: agroecosystems, International Food Policy Research Institute and World Resources Institute: Washington D.C. 


\title{
Generating climate change scenarios at high resolution for impact studies and adaptation: Focus on developing countries
}

\author{
Peter G. Jones' ${ }^{1}$, Jorge Amador ${ }^{2}$, Max Campos ${ }^{3}$, \\ Katharine Hayhoe ${ }^{4}$, Mirna Marín ${ }^{5}$, José Romero ${ }^{6}$ \\ and Andreas Fischlin ${ }^{7}$
}

1. Centro Internacional de Agricultura Tropical (CIAT)

AA 67-13, Cali, Colombia. Tel: 57-2-4450068 (Col), 44-1341-423561(UK), Fax: 57-2-4450073, E-mail: p.jones@cgiar.org

2. Center for Geophysical Research (CIGEFI), University of Costa Rica, San Jose, Costa Rica.

Tel: (506) 207 5320, Fax: (506) 234 2703, E-mail: jamador@cariari.ucr.ac.cr

3. Comité Regional de Recursos Hidráulicos del Istmo Centroamericano (CRRH)

Apartado 21-2300, Curridabat, San Jose, Costa Rica. Tel: (506) 296 4641, E-mail: crrhcr@racsa.co.cr 4. (1) Department of Geosciences, Texas Tech University, Box 41053, Rm 217, Physics \& Geosciences Building, Lubbock, TX 79409-1053. Tel: 806-742-0015, Fax: 806-742-0100.

(2) ATMOS Research \& Consulting, P.O. Box 16578, Lubbock, TX 79490. Tel: 773-437-1081, Fax: 419-715-6765, E-mail: hayhoe@atmosresearch.com

5. Secretariat of Natural Resources and the Environment Edificio de Ciencias Biologicas \#240, Ciudad Universitaria, Blvd Suyapa, Tegucigalpa MDC, Honduras.Tel/Fax: (504) 257 3470. E-mail: mirmarin@yahoo.com

6. International Affairs Division, Section Conventions,

Swiss Agency for the Environment, Forests and Landscape, $\mathrm{CH}-3003$ Berne, Switzerland. Tel: +41 3132268 62, Fax: + 413132303 49, E-mail: jose.romero@buwal.admin.ch

7. Swiss Federal Institute of Technology (ETHZ)

Grabenstrasse 3, CH-8952, Schlieren/Zurich, Switzerland. Tel: +41 (1) 633 6090,

Fax: +41 (1) 6331123, E-mail: andreas.fischlin@env.ethz.ch

\section{Introduction}

As defined by the Intergovernmental Panel on Climate Change (IPCC),"adaptation refers to adjustments in ecological, social, or economic systems in response to actual or expected climatic stimuli and their effects or impacts" (Watson et al., 2001). Such adjustments require the availability of bioclimatic scenarios that adequately represent the local conditions in a changing climate system.

In human systems, private decision makers and public agencies or governments undertake adaptation (Ahmad et al., 2001) and it requires sound 
scientific information. Climate change scenarios are built from a baseline data set characterising the current climate plus projections for possible future climatic means and event frequencies. The latter typically are based on a welldefined set of socio-economic and demographic assumptions resulting in scenarios of greenhouse gas emission (Nakicenovic et al., 2000). The IPCC's Third Assessment Report (TAR) Working Group II Report on Impacts, Adaptation, and Vulnerability (Ahmad et al., 2001: 17) finds that "because the available studies have not employed a common set of climate scenarios and methods, and because of uncertainties regarding the sensitivities and adaptability of natural and social systems, the assessment of regional vulnerabilities is necessarily qualitative". This is particularly true for developing countries. The problem is exacerbated by the expectation that those with least resources have least capacity to adapt and are most vulnerable to future climate change (Watson et al., 2001).Therefore, capacity building and improvements in outreach activities are needed to support informed decision making in adaptation to cope with the impacts of climate change. This is particularly relevant in countries often already suffering from insufficient means and economic resources, such as the least developed countries.

How then should impact studies, vulnerability assessments and adaptation strategies be developed? To develop sound adaptation strategies, quantitative assessments of climate change impacts on entire regions, including ecosystems and socio-economic systems, are needed. They form the basis for assessing the vulnerability. Vulnerability here is understood as defined in the IPCC TAR Working Group II Report, "the degree to which a system is susceptible to, or unable to cope with, adverse effects of climate change, including climate variability and extremes. Vulnerability is a function of the character, magnitude, and rate of climate variation to which a system is exposed, its sensitivity, and its adaptive capacity" (McCarthy et al., 2001).

Quantitative information is required not only on the climate and its possible, anticipated changes but also on the responses of the affected systems. The required data include those on climate and climate change, soils, agro-ecology, and socio-economic aspects. The difficulty of obtaining and managing these four types of data increases in that order. A vast investment has been made in collecting, managing, standardising and modelling climate data, and because of this they are definitely the easiest type of data to manage. Yet considerable efforts have been made in all the other areas as well, albeit to a highly variable extent. As a result, some data are available for all needed types and can be used to quantitatively assess climate change impacts and the sensitivities of the systems to adverse effects of climate change. These quantitative results are required for identifying the vulnerability of a system. Collapse will occur whenever a sensitive system is affected to such a degree that its capacity to adapt to the new climate is exceeded. Thus, all the data and the quantitative analysis performed on them form an indispensable basis from which to formulate possible adaptation strategies on how to cope with the identified vulnerabilities. 
It is important to make assessments for adaptation using compatible data sets. Studies need not use the same climate models provided they use ones with at least two different sensitivities and scenarios of the Special Report on Emissions Scenarios (SRES), either mid-range A2/B2 or the full range of A1fi/ B1 or A1fi/A1T. This is imminently feasible but it is important that the study also use population, land use or economic development assumptions that are compatible with the climate scenario. This may be more difficult at a local scale but it is possible. Arnell et al. (2004) have developed a fine-scale set of socioeconomic scenarios that can be used at the country and even smaller scale regional level to complement the SRES emission/climate scenarios.

We show in this paper that, with existing techniques and approaches, bioclimatic scenarios at high resolution can be generated in developing countries despite the many remaining gaps and challenges, which are also discussed here.

\section{Requirements}

We believe that many, if not most, of the data requirements can be met in developing countries with a minimum of extra effort.

\section{1 input data sets and processing capacities}

Simulation results from Atmosphere-Ocean General Circulation Models (AOGCMs) should be made available to researchers involved in downscaling to local models ("downscalers") and should be based on standard emission scenarios such as in the IPCC SRES (Nakicenovic et al., 2000). Downscaling typically needs AOGCM results in long runs and at high temporal resolution, for example, 6 hours or daily. For other applications, such as stochastic weather generation, it may be sufficient to have the monthly means only. Whenever possible, one should favour results from AOGCM models that are well tested and state-of-the-art.

It is possible to run regional climate models with boundary conditions constrained by Global Climate or General Circulation Model (GCM) output on high performance PCs or with parallel processing using an array of PCs forming some cluster, or connected via local area networks. These are within the capacities of many institutions in developing countries.

Local or regional databases containing records from weather stations within and adjacent to the region of interest should be made available to researchers needing these data. There has been a lamentable tendency in recent years for national meteorological institutions to start charging exorbitant prices for data, even though in many cases other organisations collected the data.

Digital terrain models with spatial characteristics supporting those of regional climate models and bioclimatic scenarios are available and should be used to account for orographic effects (see NASA, 2004). This innovation is particularly welcome because many areas in the developing world are poorly surveyed and the cost of digitising from local maps is very high. 


\subsection{Data considerations}

Characteristics of the data sets and bioclimatic scenarios generated may vary strongly depending on the actual system under study. The resolution and extent of the needed data are typically given by the input requirements of the involved impact models where the following points must be considered.

Necessary temporal resolution ranges from hourly, daily, monthly, and seasonal, up to a year; in the case of landscape models sometimes even to a decade. Spatial resolution may range from $100 \mathrm{~m}$, for example, in an orographically highly variable terrain such as mountains, up to $10 \mathrm{~km}$ in the plains.

Temporal extent ranges from 1 year for annual crops up to 3,000 years. Forest succession requires 600-800 years to reach a new equilibrium between climate and vegetation (e.g., Fischlin et al., 1995), while soil dynamics are so slow that several millennia are required to reach a new steady-state after climate has changed (e.g., Perruchoud et al., 1999). Spatial domains may range from $10 \mathrm{~km}$ up to sub-continental and continental dimensions.

\subsection{Other considerations}

Appropriate scientific personnel with the necessary know-how and skills are a prerequisitetoconduct thetask ofgenerating reliablestate-of-the-artbioclimatic scenarios. Furthermore, particularly in developing countries, institutional capacities, which provide the specific computing and communication facilities, are also necessary. Finally, in many developing countries, it is unfortunately not a matter of course to readily access the current scientific literature, in general a necessity for any fruitful scientific environment.

\section{Current techniques and approaches}

In some cases, analogues can be used. These rely on hypothetical changes to a regional climate, such as an overall temperature increase added on to an existing climate surface. They are simple and quick to evaluate and can give an assessment of the effects of the hypothetical change. Yet, since an analogue or arbitrary change imposed on a climate surface does not necessarily have any scientific basis, bioclimatic scenario generation should be used with caution. Whenever possible, GCM results should be used to reflect the expected changes and spatial distribution.

AOGCM output has a relatively coarse spatial resolution compared to the scales at which many impacts must be assessed and therefore must be downscaled before being applied to the development of regional- and localscale bioclimatic scenarios. Three principal methods are available for obtaining accurate downscaled results. First is the use of GCM output to determine a change factor or "delta", which then is superimposed on existing climatology. The second method is dynamic downscaling or regional climate modelling. The third method, statistical downscaling, includes more complex regression techniques than the delta approach, as well as weather typing and generation. Downscaled data can be refined further and localised by using accurate surface information that captures fine-scale variations in topography and orographical 
features, and through detailed historical records of observed climate means and variance.

\subsection{Delta change}

The simplest use of AOGCM results is to use the predicted future differences as a Change Factor (CF), or delta, to modify an interpolated climate surface. This is relatively easy to do but has inherent errors, particularly in mountainous regions (Gyalistras et al., 1994; Fischlin, this volume). As with all statistical approaches, the downscaling is only as good as the underlying surface derived and interpolated from observed climate.

\subsection{Dynamical downscaling (Regional Climate Modelling)}

In dynamical downscaling, global model outputs are used as boundary conditions to drive regional climate models that explicitly simulate the physical dynamics of the regional climate system. Regional Climate Models (RCMs) typically cover areas that range from a region within a country up to a small continent. Downscaled forcing sets the boundary conditions for each step of the regional model from the GCM. This approach allows the simulated local climate to respond to the GCM output in a manner that is meteorologically and hydrologically consistent, producing climate projections at scales as fine as $5-50 \mathrm{~km}$. Comparing RCM, $G C M$, reanalysis and observational temperature shows that RCMs potentially can improve GCM simulations even beyond what is possible with reanalysis.

Downscaling GCM output via RCMs has clear advantages in terms of consistency and scientific understanding of the climate system. However, dynamical downscaling is currently limited by two factors. First, RCMs require that the GCM output used to force the boundary conditions has a temporal resolution of 6 hours and vertical resolution for key variables including temperature, geopotential, wind speed and direction. Very few GCMs provide output at this level of detail and the large file sizes require significant storage (on the order of $\sim 80 \mathrm{~GB}$ per decade of 6 hour GCM input to the RCM). Second, RCMs also require a significant investment of time and computing resources. For this reason, dynamical downscaling requires high-speed processors and can be applied only to limited periods, rather than the full 100-year timeline out to 2100 that most impact studies require and that most AOGCMs cover.

Downscaling grids can be nested at various levels to gain the maximum precision at the points of most interest. In practice, it is doubtful that accuracy greater than $2 \mathrm{~km}$ can be achieved reliably even with highly accurate DTM data. The models can be nested within the grid at a higher level, providing boundary conditions to the embedded higher precision grid. This seems to imply that a generalisation to a 'quadtree' grid representation' should be possible to maximise the boundary condition information flow and the precision in the area of interest. However, no example of an actual application of this approach has come to the authors' attention.

\footnotetext{
${ }^{1}$ A quadtree representation is a geographic information systems (GIS) device to allow pixel size to vary across a grid. It relies on sequential subdivisions of pixels into four smaller ones until the required area is defined.
} 
The data volume for specifying boundary conditions could be reduced if only the boundary cells are requested. These could be specified as row, column and altitude and by variable to bound the nested model volume. In the case of a quadtree-nested model, this would not necessarily be a rectangular box. Agencies running GCMs would need to develop an automated method of extracting such results, but this kind of system would be a significant advantage to dynamic downscalers with limited resources.

\subsection{Statistical downscaling}

Statistical downscaling methods lack the explicit solving of the climate system dynamics inherent in regional climate models. However, these methods have the advantage of low-cost and rapid simulation of climate features at sub-grid scale using empirical relationships developed between modelled and observed climate variables (e.g., von Storch et al., 1993; Gyalistras et al., 1994; Hewitson and Crane, 1996; Wilby and Wigley, 1997; Wilby et al., 1998a; b). Downscaling is accomplished through developing relationships between historical observed variables at local scale, typically long-term records from weather stations, and modelled climate patterns over the region. Three approaches are commonly used.

The first is a more sophisticated approach than delta change and involves developing linear and non-linear transfer functions that range from traditional interpolation and canonical correlation techniques (e.g., Gyalistras et al., 1994; Gyalistras and Fischlin, 1999) to innovative artificial neural networks (e.g., Widmann et al., 2003). These regression approaches are extremely flexible. They can incorporate the influence of multiple GCM output variables on surface variables, ranging from standard temperature and rainfall projections to impact-relevant indices. Examples of such indices include human health thresholds, soil moisture, streamflow and other hydrological indicators, and extreme event frequencies (e.g., Hayhoe et al., 2004).

The second approach uses GCM data to drive stochastic weather generators (Wilks and Wilby, 1999). Weather generators are of great importance for realistic scenarios. Weather generators can be used in various forms and also can be nested and combined with both global and regional modelling to generate monthly, daily and hourly weather data. This is critical in the case of statistical downscaling, because GCM data are best downscaled to monthly climatic parameters (Gyalistras and Fischlin, 1999; Fischlin, this volume). Yet an application such as an impact study on agricultural crops may require daily temporal resolution (Riedo et al., 1999). Most temperate studies can use a first or 1.5 order model comfortably (Richardson and Wright, 1984; Hutchinson, 1987) but, for the tropics, Jones and Thornton (1993) showed that a third order model ${ }^{2}$ was necessary in many environments.

\footnotetext{
${ }^{2}$ The order of a Markov model is the number of steps considered in calculating the transition probabilities for the process. In a typical daily rainfall model, a first order model considers only what happened yesterday. A third order model considers the last 3 days. A 1.5 order model considers the day before yesterday only if it rained yesterday.
} 
The last approach, called 'weather typing', classifies recurrent large-scale atmospheric circulation patterns and their relationship to local climate (Wilby, 1995).

An advantage of a statistical approach is the potential to generate a number of realisations in order to assess uncertainty in regional-scale predictions at the same spatial scale as the historical observations used to develop the relationships.

Lacking any treatment of the physical dynamics in the system, the validity of statistical relationships developed under current climate conditions for projecting the future under very different conditions often is questioned. However, comparison of $50 \times 50 \mathrm{~km}$ Parallel Climate Model- (PCM) driven RCM simulations with statistical downscaling combined with bias removal (see Wood et al., 2004) shows that careful statistical downscaling, particularly when combined with bias removal using a gridded and detailed historical database (Gyalistras and Fischlin, 1999; Gyalistras, 2002; 2003), can produce highly similar results to an RCM with much less computational effort. The same objection applies to weather typing because the downscaling depends on relationships existing now. If climate change produces weather types that do not exist today, models may be extrapolated into ranges for which they are not appropriate. However, weather typing including the GCM results ensures that this eventuality is covered.

\subsection{Combining and integrating downscaling methodologies}

Often, delta change and regression approaches of statistical downscaling can be combined; see Gyalistras and Fischlin (1999), Fischlin (this volume) and the Statistical Downscaling Model (SDSM) software developed by R. Wilby, which is freely available ${ }^{3}$. Combining stochastic weather generation with regressiontype analysis addresses the issue of variance deflation common to regressiononly schemes. Careful comparison of retrofitted results from this technique with actual measurements showed that combining stochastic weather generation with downscaling techniques can yield results that fit observed daily temperature and precipitation not only in their means but also in their inter-daily, inter-monthly, inter-seasonal and inter-annual variability (e.g., Gyalistras, 1997).

Combining stochastic weather generation with weather typing, as in Jones and Thornton (2003), provides a rapid way to downscale over large areas. Regression models of the stochastic weather generator are fitted within preclassified weather types and used to determine the parameters point-by-point depending on present or future indicated climate normals. Weather types can be classified from AOGCM predictions to avoid fitting only to present-day weather patterns.

Current AOGCMs as well as RCMs still fall short of matching the high spatial resolution requirements of most impact models. Thus, some of the most

\footnotetext{
${ }^{3}$ https://co-public.lboro.ac.uk/cocwd/SDSM/
} 
promising techniques are a combination of dynamic and statistical downscaling techniques. Such an integrated methodology attempts to use each of the available techniques where they provide the most robust results (Gyalistras and Fischlin, 1999; Fischlin, this volume). For instance, the results from dynamical downscaling are used at a spatial resolution where this method provides the most robust estimates. For finer-scale estimates required as input to many types of impact models and assessments, on the order of $4 \mathrm{~km}^{2}$ or smaller, statistical downscaling can overcome the remaining insufficient spatial resolution by "introducing" into the scheme the essential information from the local weather records. Moreover, using stochastic weather generators whose parameters are driven by the statistical downscaling techniques overcomes the lack in temporal resolution (e.g., Gyalistras and Fischlin, 1999). Finally, using temporal extrapolation techniques derived from the relationships obtained via the statistical downscaling obtains transient climate change scenarios for nearly any temporal extent, even beyond that of the current AOGCM simulation time, that is, up to many centuries into the future (Gyalistras and Fischlin, 1999; Fischlin, this volume).

\subsection{Refining downscaling methodologies}

All the downscaling methods described above rely on interpolated climate surfaces that, in turn, rely on accurate Digital Terrain Model (DTM) information. Until recently, a reliable DTM data set for the globe has not been available. TGP-006 (NOAA, 1984) has been available for some time at a resolution of 10 arc-minutes but had serious failings and is not recommended for mountainous regions. GTOPO30 (USGS, 1996) was much better at a resolution of 30 arcseconds but still carried some of the failings of TGP-006 in certain areas. Nevertheless, it is used widely. Where no DTM is readily available, topographic maps of the region to be studied often have to be digitised. This is costly and time consuming. With the release of the Shuttle Radar Topographic Mission data (SRTM) (NASA, 2004), a global 90-m DTM has become available. Jarvis et al. (2004) have reprocessed these data and checked them against accurate digitised data from Colombian topographic maps at a scale of 1:10,000. The authors have found that the remotely sensed data are highly reliable.

Regardless of the DTM, climate information is needed at points without any weather records. Then, to cover all the points of interest, various climate interpolation techniques can be used. Jones et al. (1997) and Jones and Thornton (2000) used inverse square distance weighting, which is fast and conservative where large data gaps occur but is probably best used at coarse resolutions, as in these global studies. Kriging is a technique widely used in geographical information systems (GIS) but seems not to have found favour with climate interpolators. Sánchez et al. (1999) developed an interesting technique using local multiple regression within a river catchment. This ensures that the climate/ topography relationships are locally correct but for large areas a smoothing must be applied from one catchment to another. The most commonly used, however, is thin plate smoothing. Hutchinson (1989) first applied this technique to climate data. 


\section{Strengths and weaknesses in climate data, models and techniques}

\subsection{Data records}

In the study of climate, we rely on both observed and modelled data in order to chronicle the climate we have observed over the region in the last century and, calibrated on observed climate, we attempt to project characteristics of future climate resulting from a range of greenhouse gas emissions from human activities.

Long-term weather station records offer the best view of what climate has been like and how it has changed already. Studies using observed station data in the US Midwest have shown how the length of the frost-free season has increased by as much as 2 weeks since the beginning of the century, mainly due to earlier dates for the last spring freeze (Kling et al., 2003). These studies have identified an increase in heavy rainfall events, such that these are now twice as frequent as during the early part of the century (Kunkel et al., 1999). Lake records show a significant decrease in ice extent, particularly on inland lakes, as well as a tendency towards earlier seasonal cycles in the North American Great Lakes (Lenters, 2001; Kling et al., 2003).

Many other proxy data sources also exist, such as ice cores, tree rings, pollen records from lake sediments or bogs, the distribution and abundance of insects and other species from the taxon Arthropoda etc., which all may be used to characterise past climates. All these techniques offer the advantage of reaching far into the past, yet they still need all the data from the instrumental period in order to become useful for precise, quantitative projections.

Although each source of data has certain strengths, each also includes shortcomings that limit application to regional projections of climate change.

\subsection{Weather station data}

Observations are the primary data source used to characterise current and historic climate. For North America and Europe, temperature and precipitation records from individual stations are the most detailed and highly resolved data available, often extending back over 100 years. These stations offer the most essential opportunity to characterise climate at the local and regional level with maximum precision. Records of lake levels, ice cover, and sea level also extend back over the past century.

As useful as instrumental data are, however, station records are susceptible to significant uncertainty introduced by urban heat effects, changing instrumentation and observers, and the uneven spatial distribution of the stations. In addition, many stations solely provide precipitation and temperature data at 24-hour intervals. These variables do not adequately reflect many of the changes in climate. However, only a limited number of stations (primarily airports) report pressure, humidity, wind speed and cloud levels. An even smaller number of stations (for example, only three in the state of Illinois in 
USA, and often none in developing countries) release rawinsondes or weather balloons that provide vertical profiles of temperature and pressure at that site.

Weather station coverage in developing countries is highly variable but almost never equal to that of the developed world. It closely follows the pattern of population and significant gaps occur at high altitudes, in forested or desert areas and where access is poor. Although the total number of historic stations in a country may appear adequate, often only a small subset are operating at any given time. It is thought to be a difficult, costly, long-term problem to remedy the gaps by augmenting the permanent national system grid. However, by placement of short-term stations in critical areas, this can be overcome. Careful time series analysis can correlate with existing stations and useful interpolation statistics may be gained from just a few years' data.

\subsection{Reanalysis and satellite data}

Reanalysis data from the US National Center for Environmental Prediction ${ }^{4}$ and the European Centre for Medium-range Weather Forecasts ${ }^{5}$ are another source of data used to characterise past and current climate. Gridded reanalysis data provide many of the atmospheric variables needed to characterise climate over the past century that are not available from station data. In addition to surface-level temperature and precipitation, reanalysis variables include vertically resolved pressure levels, geopotential heights, humidity, cloudiness, winds, vorticity and radiative forcing. Weather models constrained by station and rawinsonde observations at 6-hour intervals are used to calculate these variables. However, these data are limited by the fact that detailed calculations over the US, for example, only began in 1958. In addition, the data are gridded to a relatively coarse spatial resolution of $1^{\circ}$ and only saved as monthly averages that severely limit their application to climate studies. Finally, although the weather models were constrained to fit observed data, these are model calculations and not actual observations.

Data from satellite observing stations mitigate the need for model intervention and interpolation. Many of the problems with reanalysis data are being addressed and should be reduced greatly over the next decade as global satellite coverage becomes denser, instruments are duplicated on multiple satellite platforms, and increasingly accurate and high-resolution (both in terms of time and space), full vertical profiles of clouds, wind, temperature, radiation and other indicators of atmospheric dynamics become available. Satellite data will provide a much tighter constraint on reanalysis than the few profiles currently available from rawinsondes and are likely to improve the accuracy of reanalysis data, particularly at finer spatial scales.

Global coverage by satellites already has supplied several decades of continuous data on temperature, ozone, radiation, sea surface temperature (SST), winds, clouds, land-use change and other key variables that describe

\footnotetext{
${ }^{4}$ http://www.dss.ucar.edu/pub/reanalysis/

${ }^{5} \mathrm{http}: / /$ www.ecmwf.int/research/era/
} 
the earth-ocean-atmosphere system. Satellites provide global coverage that is particularly valuable in regions where reanalysis data are not available and ground-based weather stations are sparse. Although plagued in the past by validation issues and discontinuities in instrumentation, recent collaborative efforts to place duplicate and complementary instruments on a suite of interand multi-national satellites (for example, the $A$ and $B$ trains, otherwise known as the PM and AM Constellations) offer hope for building consistent global databases of observed climate at fine spatial and temporal scales.

\subsection{Global climate models}

The foundations for future climate projections are the three-dimensional coupled GCMs that incorporate the latest understanding of the physical processes at work in the atmosphere, oceans and the Earth's surface. Models are being enhanced constantly as our understanding of climate improves and as computational power increases, enabling additional components of the Earth-ocean-atmosphere system to be dynamically linked and resolution to increase. As output, they produce gridded projections of precipitation, temperature, pressure, cloud cover, humidity and a host of other variables at temporal resolutions ranging from daily to monthly.

Recent advances in AOGCM modelling have produced a suite of models (e.g., PCM, HadCM4 and ECHAM5) that produce realistic simulation of surface heat fluxes, observed global average temperature and precipitation (within $1{ }^{\circ} \mathrm{C}$ for temperature and a slight overestimate of precipitation by $0.1-0.4 \mathrm{~mm} /$ day), and El Niño SST occurrences and the standard deviation of anomalies close to those observed. In particular, HadCM3 plus its successors and PCM are the only models to have completed total forcing runs (including greenhouse gases, aerosols, volcanic eruptions, ozone and solar changes) that successfully reproduce observed variations in global temperature over the last century, although still with regionally varying biases in absolute values of temperature and precipitation.

A key uncertainty in climate model projections is the question of to what extent the model captures spatial variations in change at the regional level required for input to impact assessments and fine-scale bioclimatic scenarios. In terms of regional change, impacts are often dependent on small-scale processes and localised features of climate that may not be well represented when averaged on the coarse resolution of a typical GCM grid, which ranges from $2.5-5^{\circ}$. Climate in areas with rapid changes in elevation or important orographic features is not well characterised at the grid resolution of current global models. Recent high-resolution climate model simulations (e.g., T106 using the ECHAM5 model, $250 \mathrm{~km}^{2}$ using the NCAR/PCM model, and T1279 or $\sim 10 \mathrm{~km}^{2}$ on the Earth System Simulator) address many of these spatial scale issues. However, improvements in model resolution below $\sim 20 \mathrm{~km}^{2}$ currently are limited by our physical understanding of small-scale processes, particularly those of importance in the surface or boundary layer that drive variations in surface impacts on scales of $\sim 100-1000$ metres. 
As model resolution increases, regionally varying biases in absolute values of temperature, humidity, precipitation and other key variables are reduced but not eliminated. And finally, many variables needed for regional scenarios and impact assessments are not simulated directly by AOGCMs (e.g., lake levels, extreme events, biosphere and soil characteristics). For these reasons, downscaling and bias removal techniques will remain an essential step in applying even future high-resolution GCM projections to regional-level climate projections and impact assessments.

\subsection{Integrated assessment models}

Integrated assessment models (IAMs) appear attractive because they are able to dynamically integrate socio-economic and demographic data with land-use change, technology, emissions and climate. The primary strength of IAMs is their ability to capture the full cycle of feedbacks between human activities and the Earth-ocean-atmosphere system, revealing links that may not have been recognised nor fully understood before. Because of their extremely low resolution that is required for efficient linking of multiple human and physical systems, however, IAM-generated climate change scenarios cannot be considered a replacement for those obtained from AOGCMs. Their use is advisable only if the data are made available in a form that is fully comparable with those from the GCM. The latter represents a considerable challenge for any downscaling methodology, since it would have to overcome the shortcomings of the coarse IAM. Since upscaling is easier than downscaling, IAMs may be used better to check that assumptions used within a scenario generation are consistent with the global background.

\section{Gaps and opportunities}

The national circumstances of developing countries vary strongly with respect to those scientific and institutional capacities that deal with climate change in general, as well as climate modelling and adaptation in particular. The following statements should be understood accordingly, realising that the presented list is not exhaustive.

\subsection{Gaps}

- Lack of qualified personnel results from (i) scarce funding for education, (ii) deficiencies in the educational system itself (in particular at the university level) and (iii) insufficient professional prospects for scientists in research and applied science.

- Lack in the continuity of expert and responsible staff and administrations is often due to frequent discontinuities and changes at governmental levels.

- Responsibilities are dispersed over many institutions among which coordination is often lacking. 
- There is a lack of centralised or co-ordinated data collection, often resulting in incompatibility between data-set formats. Unfortunately, too often this makes data unusable for the purpose for which they were originally collected, if indeed the individual organisations are willing to share with others outside their immediate circle.

- There is a distinct lack of meteorological stations and monitoring of climate particularly at high elevations. The recent analysis on the adequacy of the global observing system by the Global Climate Observing System (GCOS, 2003) is to be considered in this context.

- Insufficient dialogue exists between various involved communities such as data collectors, climate modellers, and impacts and adaptation specialists.

- Reanalysis calculations are the primary source for validating RCM performance over the historical period before using the RCM to project future climate change. However, few or no reanalysis data exist for developing countries. Hence, it would be most desirable if the weather models currently used over the US and/or Europe to provide reanalysis data could be adapted for other continents. Even a few years of reanalysis data (e.g., 2005-2010) would provide enormous potential to validate regionspecific RCMs over developing countries.

It is believed in general that progress in addressing climate change will only be achieved in developing countries if there is multi-sectoral and inter-institutional participation in climate change research, in know-how development and maintenance, and in the implementation of adaptive measures. The various stakeholders, including the scientific community, have to foster this broad cooperation.

\subsection{Opportunities}

- Utilise the capacities and findings of existing research institutions and groups that are working on modelling climate change and impacts in developing countries.

- Take advantage of existing co-operation of research groups from developing countries with groups from developed countries, or in the framework of bilateral state-to-state cooperation.

- Take advantage of the opportunities offered by programmes developed by multilateral/regional intergovernmental organisations in the area of, or relevant to, climate change.

\section{Implications for adaptation}

Addressing climate change and its impacts will not receive higher political priority in national agendas in developing countries until it has been recognised as an issue of major relevance for development, particularly sustainable development, that may have important cross-sectoral impacts. Only if this requirement is met will activities, especially adaptation activities, gain higher 
priority in national policies. Thanks to high-resolution climate change scenarios at regional and sub-continental levels, adverse impacts and vulnerabilities can then be identified. This generates the needed basis to define adaptation strategies. Hence, in developing countries, the findings of this work have to be brought to the attention of national governments, policymakers, national development planners, regional organisations, the scientific community, investors and donor countries and institutions.

The effects of climate change in agriculture and forestry can be highly localised. Jones and Thornton (2003) showed that maize yields could vary from increases to almost certain crop failure within ranges of tens of kilometres. This implies that broadscale policies may not be appropriate over national or regional scales but must be tailored to specific locations and systems. Other studies of scale showed that overall estimates of climate impacts on a region vary greatly depending on the degree to which social groups, sectors and regions are resolved (O'Brien et al., 2004).

It is necessary therefore to carefully identify end users for whom findings and recommendations on adaptation are to be developed. The particular needs of the identified end users should be taken into account from the very beginning of such a project, with ongoing dialogue ensuring that the needs of the impact community and decision makers are met, while they in turn inform the climate science and analysis (Cash and Moser, 2000). Other important elements that will sustain adaptation are: (i) the extension of educational services and the dissemination of information on climate change and (ii) the distribution of information for daily decision making within civil society.

Finally, regional- and country-specific impact assessments should encompass the full range of possible scenarios of future climate change, particularly those resulting from scenarios of low up to high greenhouse gas emission. Such information will provide the necessary basis for decision makers to tread a careful and optimal balance between mitigation and adaptation, as well as identifying key areas of vulnerability and hence providing guidance for apportioning funds for adaptive measures at the regional to local level.

\section{Recommendations}

Working Group 1, "Generation of Local Climate Change Scenarios", of this workshop agreed to formulate a set of recommendations which address (i) scientific and technological, (ii) institutional, and (iii) socio-economic and political issues.

\subsection{Scientific and technical issues}

The target audience for these recommendations are national governments and policymakers, in particular national development planners, regional organisations, the scientific community, and investors and donors. 
- Observed data sets should be consistent and prepared in a format compatible with the requirements described above. These should be made available in a user-friendly, easily accessible form at the highest resolution possible.

- GCM model results should be readily available in a user-friendly manner to "downscalers"at the temporal resolution required for the various downscaling approaches. The data sets should allow users to select geographic regions and variables of interest to allow for optimal data transfer and use.

- User-friendly downscaling tools, interpolation techniques and stochastic weather generators should be made available to interested scientists. They should be prepared for a PC environment and ideally should be provided with manuals and training offers.

- A clearinghouse website should be established and maintained by appropriate institutions that offers some of the aforementioned tools together with the accompanying manuals in a user-friendly manner. Preferably the IPCC data centres might be ideal institutions to offer such a new service. This website should also foster virtual co-operation and could offer CVS facilities, which support the development of open source software tools.

\subsection{Institutional}

The target audience for these recommendations are the institutions responsible for national and/or regional science and education.

- National and regional academies are encouraged to make it a priority to provide the resources needed to assist scientists in the dissemination of data and information as stated above.

- Institutions that have proven to be successful in the past in disseminating, coordinating, cooperating and exchanging relevant information and training should be strengthened.

- Scientific institutions, including national academies and similar institutions, are encouraged to promote and find solutions for the financing of exchange programmes involving students from developing countries in climate change scenario generation and impact studies relevant for adaptation.

\subsection{Socio-economic and political}

The target audience for these recommendations are governments and relevant political organisations and bodies.

- Governments need to recognise that their investments can be protected only if the best available tools that the scientific community can bring forward are used to make sound decisions on generating and implementing adaptation and mitigation measures related to climate change and sustainable development.

- Governments must recognise the need to quantitatively assess climate change impacts in order to enable the identification of vulnerabilities and the development of adaptation measures. 
- Governments must recognise the need to generate a range of representative climate change scenarios at the local and regional levels in order to quantitatively assess impacts.

- National and international co-operation should be facilitated to assist the exchange and dissemination of relevant information.

- National institutions responsible for planning and educating must ensure that the results of these efforts are used efficiently.

- Additional resources should be made available at the country level for capacity building on climate change issues.

- Investors and donors as well as host countries of bilateral and multilateral development assistance should aim to include in all projects conducted in a developing country an assessment of the needs for adaptation to climate change based on local criteria.

\section{Conclusions}

The discussions at the workshop have indicated that high-resolution bioclimatic scenarios can already be generated in developing countries, despite challenges occurring both in personnel and at the institutional level. These scenarios are the first step towards defining adaptation strategies and measures to cope with climate change. If additional, targeted efforts are made based on the outlined recommendations, remaining gaps may be closed relatively easily and the main existing hurdles can be overcome to successfully generate regional climate change scenarios for impact assessments.

\section{References}

Ahmad, Q.K., and IPCC WG II Authors (2001) Climate Change 2001: Impacts, adaptation, and vulnerability - Summary for policymakers, IPCC WG II contribution to the TAR, Cambridge University Press, Cambridge.

Arnell, N.W., M.J.L. Livermore, S. Kovats, P.E. Levy, R. Nicholls, M.L. Parry, S.R. Gaffin (2004) 'Climate and socio-economic scenarios for global-scale climate change impacts assessments: characterising the SRES storylines' Global Environmental Change 14: 3-20.

Cash, D.W., S.C. Moser (2000) 'Linking global and local scales: designing dynamic assessment and management processes' Global Environmental Change 10: 109-120.

Fischlin, A., H. Bugmann, D. Gyalistras (1995) 'Sensitivity of a forest ecosystem model to climate parameterisation schemes' Environmental Pollution 87: 267-282.

GCOS (Global Climate Observing System) (2003) 'The second report on the adequacy of the global observing system for climate in support of the UNFCCC', GCOS-82 WMO/TD No. 1143, GCOS: Geneva. 
Gyalistras, D. (1997) Projecting scenarios of climatic change and future weather for ecosystem models: derivation of methods and their application to forests in the Alps, Dissertation ETH No. 12065, Swiss Federal Institute of Technology: Zürich.

Gyalistras, D. (2002) 'An uncertainty analysis of monthly temperature and precipitation scenarios for Switzerland' Internal report of the Climatology and Meteorology Research Group, University of Bern: Bern.

Gyalistras, D. (2003) 'Development and validation of a high-resolution monthly gridded temperature and precipitation data set for Switzerland (19512000)' Climate Research 25(1): 55-83.

Gyalistras, D., A. Fischlin (1999)'Towards a general method to construct regional climatic scenarios for model-based impacts assessments' Petermanns Geographische Mitteilungen 143(4): 251-264.

Gyalistras, D., H. von Storch, A. Fischlin, M. Beniston (1994) 'Linking GCMsimulated climatic changes to ecosystem models: case studies of statistical downscaling in the Alps' Climate Research 4(3): 167-189.

Hayhoe, K., D. Cayan, C. Field, P. Frumhoff, E. Maurer, N. Miller, S. Moser, S. Schneider, K. Nicholas Cahill, E. Cleland, L. Dale, M. Hanemann, L. Kalkstein, J. Lenihan, C. Lunch, R. Neilson, S. Sheridan, J. Verville (2004) Emission pathways, climate change, and impacts on California, Proceedings of the National Academy of Science (PNAS). Internet: http://www.pnas.org/cgi/ report/0404500101v1

Hewitson, B.C., R.G. Crane (1996) 'Climate downscaling techniques and applications' Climate Research 7: 85-95.

Hutchinson, M. F. (1987) 'Methods of generation of weather sequences' in A.H.A. Bunting (ed.) Agricultural environments, $C A B$ International: Wallingford.

Hutchinson, M. F. (1989) 'A new objective method for spatial interpolation of meteorological variables from irregular networks applied to the estimation of monthly mean solar radiation, temperature, rainfall and windrun' Commonwealth Scientific and Industrial Research Organization (CSIRO) Division of Water Resources Technical Memo 89/5, 95-104, CSIRO: Australia.

Jarvis, A., J. Rubiano, A. Nelson, A. Farrow, M. Mulligan (2004) 'Practical use of SRTM data in the tropics - comparisons with traditionally generated cartographic DEMs' Working Document, CIAT: Cali.

Jones, P.G., P.K. Thornton (1993) 'A rainfall generator for agricultural applications in the tropics' Agricultural Forest Meteorology 63: 1-19.

Jones P.G., P.K. Thornton (2000) 'MarkSim: Software to generate daily weather data for Latin America and Africa' Agronomy Journal 93: 445-453.

Jones, P.G., P.K. Thornton (2003) 'The potential impacts of climate change on maize production in Africa and Latin America in 2055' Global Environmental Change 13: 51-59.

Jones, P.G., N. Galwey, S.E. Beebe, J. Tohme (1997) 'The use of geographical information systems in biodiversity exploration and conservation' Biodiversity Conservation 6: 947-958. 
Kling, G.W., K. Hayhoe, L.B. Johnson, J.J. Magnuson, S. Polasky, S.K. Robinson, B.J. Shuter, M.M. Wander, D.J. Wuebbles, D.R. Zak, R.L. Lindroth, S.C. Moser, M.L. Wilson (2003) Confronting climate change in the Great Lakes Region: Impacts on our communities and ecosystems, Union of Concerned Scientists: Cambridge, MA. Internet: http://www.ucsusa.org/greatlakes/ glchallengereport.html

Kunkel, K.E., R.A. Pielke Jr., S.A. Changnon (1999) 'Temporal fluctuations in weather and climate extremes that cause economic and human health impacts: A review' Bulletin of the American Meteorological Society 80: 10771098.

Lenters, J.D. (2001) 'Long-term trends in the seasonal cycle of Great Lakes water levels' Journal of Great Lakes Research 27(3): 342-353.

McCarthy, J.J., O.F. Canziani, N.A. Leary, D.J. Dokken, K. S. White (2001) (eds.) Climate Change2001: Impacts, Adaptation, and Vulnerability, IPCC WG II contribution to the TAR, Cambridge University Press: Cambridge.

Nakicenovic, N, R. Swart (eds.) (2000) Emissions scenarios 2000, Special Report of the IPCC Cambridge University Press: Cambridge.

NASA (National Aeronautics and Space Administration) (2004) 'Shuttle Radar Topography Mission' Internet: http://www-radar.jpl.nasa.gov/srtm

NOAA (National Oceanographic and Atmospheric Administration) (1984) TGPOO6 D. Computer compatible tape, NOAA: Boulder.

O'Brien, K., L. Sygna, J.E. Haugen (2004) 'Vulnerable or resilient? Multi-scale assessments of the impacts of climate change in Norway' Climatic Change 64(1-2): 193-225.

Perruchoud, D., F. Joos, A. Fischlin, I. Hajdas, G. Bonani (1999) 'Evaluating time scales of carbon turnover in temperate forest soils with radiocarbon data' Global Biogeochemical Cycles 13(2): 555-573.

Richardson, C.W., D.A. Wright (1984) 'WGEN: A model for generating daily weather variables' United States Department of Agriculture (USDA) Agricultural Research Service, ARS-8, USDA: US.

Riedo, M., D. Gyalistras, A. Fischlin, J. Fuhrer (1999) 'Using an ecosystem model linked to GCM-derived local weather scenarios to analyse effects of climate change and elevated $\mathrm{CO}_{2}$ on dry matter production and partitioning, and water use in temperate managed grasslands' Global Change Biology 5: 213223.

Sánchez Palmares, O., F. Sánchez Serrano, M.P. Carretero Carrero (1999) 'Modelos y cartografía de estimaciones climáticas termopluviométricas para la España peninsular' Ministerio de Agricultura, Pesca y Alimentación: Madrid.

USGS (United States Geological Survey) (1996) 'Global 30 arc second elevation data' National mapping division, Earth Resources Observation Systems (EROS) Data Center: USA. Internet: http://edcdaac.usgs.gov/gtopo30/ gtopo30.asp

von Storch, H., E. Zorita, U. Cubasch (1993) 'Downscaling of global climate change estimates to regional scales: an application to Iberian rainfall in wintertime' Journal of Climatology 6(6): 1161-1171. 
Watson, R.T., Core Writing Team (2001) Climate Change 2001: Synthesis Report, IPCC: Geneva.

Widmann, M., C.S. Bretherton, J.J. Hack, P.J. Rasch (2003) 'A modified formulation of fractional stratiform condensation rate in the NCAR Community Atmosphere Model CAM2' Journal of Geophysical Research 108(D1): 4035.

Wilby, R.L. (1995) 'Simulation of precipitation by weather pattern and frontal analysis' Journal of Hydrology 173: 91-109.

Wilby, R.L. T.M.L. Wigley (1997) 'Downscaling general circulation model output: a review of methods and limitations' Progress in Physical Geography 21(4): 530-548.

Wilby, R.L., T.M.L. Wigley, D. Conway, P.D. Jones, B.C. Hewitson, J. Main, D.S. Wilks (1998a). 'Statistical downscaling of general circulation model output: a comparison of methods' Water Resources Research 34(11): 2995-3008.

Wilby, R.L., H. Hassan, K. Hanaki (1998b) 'Statistical downscaling of hydrometeorological variables using general circulation model output' Journal of Hydrology 205(1-2): 1-19.

Wilks, D.S., R.L. Wilby (1999)'The weather generation game: a review of stochastic weather models' Progress in Physical Geography 23: 329-357.

Wood, A.W., L.R. Leung, V. Sridhar, D.P. Lettenmaier (2004) 'Hydrologic implications of dynamical and statistical approaches to downscaling climate model outputs' Climatic Change 62: 189-216. 


\title{
Climate Change - Biodiversity and livelihood impacts
}

\author{
Hannah Reid and Saleemul Huq \\ International Institute for Environment and Development \\ 3 Endsleigh Street, London WC1H ODD, United Kingdom. \\ Tel: +44 (0)20 7388 2117, Fax: +44 (0)20 7388 2826, \\ E-mails: hannah.reid@iied.org, saleemul.huq@iied.org
}

"Climate Change will put international action to eradicate poverty and achieve the MDGs at risk. Responding to this risk is an opportunity to move away from the science and towards action to reduce poor people's vulnerability to the climate."

Hilary Benn, UK Secretary of State for International Development, March 2004.

\section{Introduction}

The debate about climate change has now reached a stage where most scientists accept that, whatever happens to future greenhouse gas emissions, we are now locked into a future characterised by significant human-induced changes to our climate. There are two possible responses to these changes: the first is to try to reduce the extent to which our climate is altered. This is known as climate change mitigation. The second is to learn to live with the inevitable changes. This is known as adaptation to climate change.

Biodiversity is inextricably linked to climate; changes in climate affect biodiversity, and changes to natural ecosystems also affect climate (Reid et al., 2004). This chapter considers the linkages between climate change (mitigation and adaptation) and biodiversity, and then relates these linkages to livelihoods, poverty and achieving the Millennium Development Goals (MDGs). The chapter concludes with some suggestions for actions needed at global, national and local levels in order to support local solutions. 


\section{How climate change affects biodiversity}

\subsection{Direct impacts}

Climate change is likely to have a number of impacts on biodiversity - from ecosystem to species level. The most obvious impact is the effect that flooding, sea-level rise and temperature changes will have on ecosystem boundaries, allowing some ecosystems to expand into new areas, while others diminish in size. As floods, sea-level rise and changes in climate alter protected habitats, some of these areas may cease to provide suitable habitats for species they were designed to conserve. Those planning the proposed Greater Addo National Park in South Africa recognise this and have factored climate change into their planning. The proposed park covers a large area with a range of elevations, latitudes, microclimates, ecosystems and almost an entire watershed. Species can therefore migrate to another safe habitat if climate change adversely affects their present one (http://www.upe.ac.za/zoo/addo/addoprop.htm).

As well as shifting ecosystem boundaries, changes in climate will also cause changes in natural habitat - an outcome which will have a knock-on effect on species survival. A growing body of research indicates that, as a result, climate change may cause a sharp increase in extinction rates. Mid-range predictions from one recent study suggest that $24 \%$ of species in five study regions will be heading toward extinction by 2050 due to climate change. The study indicates that for many species, climate change poses a greater threat to their survival than does the destruction of their natural habitat (Thomas et al., 2004).

Global warming is also causing shifts in the reproductive cycles and growing seasons of certain species. For example, higher temperatures have led to an increase in the number of eggs laid by the spruce budworm, already one of the most devastating pests in North America's boreal forests (Gitay et al., 2002).

The impacts of climate change on biodiversity will vary from region to region. The most rapid changes in climate are expected in the polar extremities, and in mountainous regions. These are also the regions where species often have no alternative habitats to which they can migrate in order to survive. Other vulnerable ecosystems and species include small populations or those whose habitat is restricted to small areas. Coral reefs have already shown devastating losses as a result of increased water temperatures (Box 1).

\section{2 impacts of mitigation activities}

It is not just climate change itself that can have an impact on biodiversity. In some cases, the strategies that are adopted to mitigate climate change can affect biodiversity - these effects can be both positive and negative. Investment in renewable energy technology may provide climate change benefits, but outcomes for biodiversity are often poor. For example, some bioenergy plantations replace sites with high biodiversity, introduce alien species and use damaging agrochemicals. Large hydropower schemes can cause loss of terrestrial and aquatic biodiversity, inhibit fish migration and lead to mercury contamination (Montgomery et al., 2000; Fearnside 2001; Fu et al., 2003). They 


\section{Box 1. Coral Reefs and Global Climate Change}

Coral reefs have the highest biodiversity of any marine ecosystem, and they provide important ecosystem services and direct economic benefits to large and growing human populations in coastal zones. Although the natural habitat of coral reefs can be a stressful environment, recent global increases in reef ecosystem degradation and mortality suggest that the rate and nature of recent environmental changes often exceeds the adaptive capacity of coral reefs. This can lead to the replacement of the coral reef community by non-reef systems. Such ecosystem shifts are well advanced in the Caribbean region, where two major reef-building coral species have been devastated by disease, and in the Indo-Pacific region, where repeated episodes of lethal 'bleaching' have occurred.

This crisis is almost certainly the result of interactions between multiple stresses. These include increased nutrient and sediment loading, direct destruction, contamination, over-harvesting, disease and predation. Rising ocean temperatures have been implicated in chronic stress and disease epidemics, as well mass coral bleaching episodes and reduced calcification. Increasing atmospheric $\mathrm{CO}_{2}$ levels can also inhibit calcification. It is difficult to separate the effects of global climatic and local non-climatic influences when considering reef condition or vulnerability.

Predicting the future of coral reefs is difficult because current environmental changes are causing a combination of surface ocean chemistry and temperature conditions that have not occurred in the evolutionary history of modern coral reef systems. Although climate change has the potential to yield benefits for certain coral species in specific regions, such as the expansion of their geographic ranges, most effects are stressful rather than beneficial. Continued climate change will almost certainly cause further degradation of coral reef communities, which will be even more devastating in combination with the continuing non-climatic stresses.

Source: Buddemeier et al., 2004.

can also be net emitters of greenhouse gases if submerged soils and vegetation decay release $\mathrm{CO}_{2}$ and methane. In contrast, fuelwood conservation measures, such as efficient stoves and biogas use, can conserve carbon reservoirs and reduce pressure on forests.

The concept of becoming 'carbon neutral' is gaining widespread popularity with many businesses, which wish to contribute to climate change mitigation activities by offsetting carbon emissions generated through their businessrelated activities. Likewise, many nations have committed to reducing their net greenhouse gas emissions under the Kyoto Protocol to the United Nations Framework Convention on Climate Change (UNFCCC). Projects designed to sequester carbon, and hence mitigate climate change, present the possibility to incorporate biodiversity considerations and have been recognised as win-win opportunities. Afforestation and reforestation activities can restore watershed functions, establish biological corridors and provide considerable biodiversity benefits if a variety of different aged native tree species are planted. Monocultures, however, not only reduce biodiversity, but also increase the chances of pest attacks thus challenging the permanence of carbon stocks. 
The location of afforestation and reforestation projects is also important. Replacing native grasslands, wetlands, shrublands or heathlands may lead to dramatic biodiversity losses, and may also lower the relative increase in carbon sequestered compared to implementing such projects on degraded land (Reid, 2003).

\section{How biodiversity affects climate change}

\subsection{Direct impacts}

Just as climate change affects biodiversity, changes in biodiversity can affect the global climate. Land-use changes that lead to biodiversity losses can cause increased greenhouse gas emissions. Forests are a major store of carbon, and when forests are cut down or burned, $\mathrm{CO}_{2}$ is released into the atmosphere. Continuing deforestation, mainly in tropical regions, is currently thought to be responsible for annual emissions of 1.1 to 1.7 billion tonnes of carbon per year, or approximately one-fifth of human $\mathrm{CO}_{2}$ emissions (Brown et al., 1996).

Peatlands or mires hold roughly one-third of the carbon contained in soil worldwide, and greenhouse gases are released every time peatlands are burned, drained, converted to agriculture or degraded. Peatland forest fires in Indonesia in 1997 released an amount of $\mathrm{CO}_{2}$ equivalent to $40 \%$ of the world's average yearly carbon emissions from fossil fuels (Page et al., 2002). Such peatlands also provide many environmental services, such as improving water quality. Many are important biodiversity reservoirs or stopover points for migratory species.

There are also feedback mechanisms at work between biodiversity and climate change. For example, some species of ocean algae release dimethyl sulfate (DMS) into the atmosphere. Rising ocean temperatures (a consequence of climate change) means that more DMS is released from blooming algal populations. But DMS is also associated with the formation of clouds, which may actually help reduce the amount of heat reaching the Earth's surface, and hence temperatures (Sciare et al., 2000).

\subsection{Biodiversity as a tool for mitigation}

Effective biodiversity conservation and management can lead to higher levels of carbon sequestration and hence contribute to climate change mitigation. For example, forest management activities such as increasing rotation age, low intensity harvesting, reduced impact logging, leaving woody debris, harvesting that emulates natural disturbance regimes, avoiding fragmentation, provision of buffer zones and natural fire regimes can simultaneously provide biodiversity and climate benefits. This is also true for certain agroforestry, revegetation, grassland management and agricultural practices such as recycling and use of organic materials. Integrated watershed management can conserve watershed biodiversity in addition to increasing water retention and availability in times of drought, decreasing the chance of flash floods and maintaining vegetation as a carbon sink. 
Energy production is another key area where biodiversity conservation provides opportunities to help mitigate climate change. Currently, some $60 \%$ of anthropogenic global greenhouse gas emissions originate from the generation and use of energy. Use of renewable energy sources provides an opportunity to reduce emissions from burning fossil fuels (Box 2).

Box 2. Greenhouse Gas Mitigation as a Co-Benefit of the Brazilian Ethanol Programme

The Brazilian ethanol programmewaslaunched in 1975 and remains the world'slargest commercial application of biomass for energy production and use. It demonstrates the technical feasibility of large-scale ethanol production from sugarcane and its use as fuel. Each year more than five million cars run on ethanol, with remaining cars running on gasohol (an ethanol-gasoline mix). Additionally, sugar cane bagasse (a by-product of ethanol and sugar manufacture) is being increasingly used as an industrial fuel, with surplus electricity entering the national grid. The programme has saved foreign exchange due to surplus gasoline exports and reduced oil imports, and created 720,000 jobs directly and 200,000 more indirectly in rural areas. It has curbed city air pollution and has avoided 6-10 million tons of carbon emissions per year since 1980.

Source: Lèbre La Rovere and Romeiro, 2003.

\section{Biodiversity, climate change and livelihoods}

Traditional approaches to poverty (for example, survival on less than US\$1 per day) translate poverty simply as an economic condition. Such approaches have been replaced by those that recognise poverty as more complex, and include factors such as lack of education and skills, poor health, inadequate access to water and sanitation services, inadequate or risky asset base, poor quality or insecure housing, weak safety nets to ensure basic consumption can be maintained when income falls or crops fail, inadequate protection of poorer groups' rights, and lack of power and voice (Satterthwaite, 2003). Vulnerability to shocks is thus a key component of poverty.

Poor people generally depend more on ecosystem services and products for their livelihoods than do wealthy people (Box 5). The means by which a poor family gains an income and meets its basic needs are often met by multiple livelihood activities. For example, exploiting common property resources such as fish, grazing land or forests can provide income, food, medicine, tools, fuel, fodder, construction materials and so on. With regards to food, some species are used on a daily basis, while others are important in times of famine or stress. Poor people are therefore severely affected when the environment is degraded or their access to it restricted. This link between poverty and the environment has been recognised for some time (Bass et al., 2005).

As a result of this dependency, any impact that climate change has on natural systems threatens the livelihoods, food intake and health of poor 
people (Smith and Troni, 2004). Climate change will mean that many semi-arid parts of the developing world will become even hotter and drier, with even less predictable rainfall. Climate induced changes to crop yields, ecosystem boundaries and species' ranges will dramatically affect many poor people's livelihoods. Those most vulnerable to climate change are the poorest groups in the poorest countries of the world. This is because they live in areas more prone to flooding, cyclones, droughts and so on, and because they have little capacity to adapt to such shocks. They are often heavily dependent on climate-sensitive sectors such as fisheries and agriculture, and the countries they live in have limited financial, institutional and human capacity to anticipate and respond to the direct and indirect impacts of climate change (Walter and Simms, 2002; Huq et al., 2003; Sperling, 2003).

Conservation of biodiversity and maintenance of ecosystem integrity may be a key objective for improving the adaptive capacity of such groups to cope with climate change. Functionally diverse systems may be better able to adapt to climate change and climate variability than functionally impoverished systems. A larger gene pool will facilitate the emergence of genotypes which are better adapted to changed climatic conditions. As biodiversity is lost, options for change are diminished and human societies become more vulnerable.

Poor people are particularly vulnerable to extreme weather events (Box 3). Over $96 \%$ of disaster-related deaths in recent years have taken place in developing countries. Extreme weather events are increasing, and during 2001, 170 million people internationally were affected by disasters, $97 \%$ of which were climate-related (Walter, 2002). Women and children are particularly vulnerable. For example, when the 1991 cyclone hit Bangladesh, 90\% of victims were women and children. This was due to a number of factors including their capabilities in survival (e.g. swimming), and socio-cultural beliefs that prevented women with their children from congregating in public cyclone shelters.

\section{Practical ways to provide biodiversity, climate change and livelihood benefits}

Classic top-down approaches to climate change equate to large infrastructure construction projects. Those designed to support adaptation to climate change are often associated with physical protection; for example large sea walls. Those designed to reduce global greenhouse gas emissions and thus mitigate climate change are often associated with large renewable energy schemes, such as hydropower. Such projects often have significant negative impacts on biodiversity and local livelihoods. For example, plans to build scores of dams with massive hydroelectricity generating potential on the Mekong River will affect the livelihoods of the 52 million people currently using river resources, many of whom live below the poverty line. Dam construction will prevent fish migration, and yet Mekong fish provide $40-60 \%$ of the animal protein consumed by the population of the lower basin. The nine proposed mainstream dam projects alone would also displace 60,000 rural people (Abramovitz, 1996). 


\section{Box 3. The Ecological and Social Devastation of Hurricane Mitch}

In October 1998, Hurricane Mitch brought winds of over $180 \mathrm{~km}$ per hour and $127 \mathrm{~cm}$ of rain in only a week to Central America. Over 18,000 people were killed and thousands of homes, bridges, roads, water systems, crops and animals were destroyed. Hurricane Mitch impacted about 6.4 million people, with the poorest groups suffering the greatest losses. Among these groups, the most vulnerable were those living and farming on hillsides and near riverbanks.

Unequal land tenure policies and skewed resource distribution mean that many of Central America's farmers own small plots of land on ecologically fragile, disasterprone lands. With little access to credit, land titles and technical assistance, farmers have few incentives to invest in sustainable farming practices, and ranching, farming, burning and forest removal for timber have all contributed to removing protective vegetative cover. During Hurricane Mitch, heavy rainfall led to massive runoff on these degraded hillsides, which carried away tons of topsoil, rocks and vegetation. Debris-choked rivers also overflowed their banks causing extensive damage to human and natural riverside systems.

Farms using agroecological practices such as soil and water conservation, cover cropping, organic fertilizer, integrated pest management and reduced or zero grazing, were more resilient to erosion and runoff. They withstood Hurricane Mitch's impacts better than those farms using conventional farming methods. Damage from gullies and landslides was equally severe on both farm types, perhaps because many gullies and landslides originated uphill or upstream on poorly managed degraded or deforested slopes. This demonstrates the importance of conserving entire hillsides and watershed ecosystems rather than just individual plots.

Source: World Neighbours, 2000.

While big infrastructure projects can be effective, comparatively little attention has been paid to non-structural alternatives and to 'bottom-up' approaches rooted in existing community-based strategies for managing resources and reducing vulnerability to climatic shocks (IISD, 2003).

Many of the carbon sequestration projects undertaken by companies and nations to mitigate their greenhouse gas emissions do not incorporate biodiversity issues. Even fewer incorporate livelihood and poverty issues as well. The Clean Development Mechanism (CDM) established under the Kyoto Protocol aims to provide developed countries that have accepted targets for reducing greenhouse gas emissions with flexibility for achieving these targets, by allowing them to take credits from emissions reduction projects undertaken in developing nations. Projects are supposed to provide global benefits from carbon sequestration, but also sustainable development benefits to host developing countries (Huq and Reid, 2005). Many projects pay little attention to these sustainable development benefits. However, one project generating electricity from biogas and bio-diesel in Brazil is attempting to provide livelihood, carbon and biodiversity benefits (Box 4). 


\section{Box 4. Electricity Generation from Biogas and Bio-diesel in Brazil}

Garbage is a huge problem in Rio de Janeiro, and a recent emissions inventory shows that the Jardim Gramacho Landfill at Duque de Caxias is the main source of greenhouse gas emissions (in the form of methane) emitted by the city. A new project at the Jardim Gramacho Landfill is converting this polluting open dumpsite into a sanitary landfill, and illustrating the potential for generating electricity from renewable energy sources. This project is one of several under the SouthSouthNorth Project, which seeks to help public and private stakeholders develop the necessary confidence for dealing effectively with the CDM.

Biogas, produced from the decomposition of organic solid waste in landfills, and bio-diesel, produced from used vegetable (cooking) oils, drive a power generator providing partial energy self-sufficiency for landfill site operation. Remaining fuel needs will come from renewable sources. Technological refinements are still required, but the power generation process will convert methane into $\mathrm{CO}_{2}$, thus reducing the greenhouse gas effect by a factor of 21 . It is projected that the project will reduce emissions by an equivalent of 35,000 tons of $\mathrm{CO}_{2}$ over a ten-year period. Income from the sale of this carbon will support the project operation.

Electricity generated by the plant is used to clean the water produced at the landfill site, such that only clean water is returned to Guanabara Bay nearby. This has led to the rehabilitation of local mangrove swamps and improvements in associated livelihood opportunities. Employment generation has also occurred through the selective collection of used vegetable oils. However, those who depend on picking through garbage to earn their living have expressed concerns that their livelihood will be threatened. Efforts to provide these people with alternative employment opportunities at recycling plants elsewhere have met with limited success, as people feel they would earn less (they can earn as much as twice the minimum wage picking through waste) and their quality of work would deteriorate (they currently see themselves as freelancers or small entrepreneurs, which would change with employment at a recycling plant). The provision of local social benefits for some lowincome groups therefore remains a challenge.

Source: Orford, 2004.

Some initiatives succeed in combining biodiversity, livelihood and climate change related benefits. Activities to build the resilience of communities to climate stresses have been built on in Central America, where following Hurricane Mitch, the charity World Neighbours has been working to increase agroecological activities. This is helping vulnerable communities adapt to their changing environments as the incidence and severity of climate changed related disasters increases (Box 3). Similarly, since 1992, PASOLAC (Programa para la Agricultura Sostenible en las Laderas de América Central) has been helping communities in Nicaragua, Honduras and El Salvador to increase the agricultural productivity of their hillsides through improved soil and water management. The programme is characterised by participatory demand-driven approaches. Such hillsides support tropical forests, key freshwater reservoirs, and several important and diverse ecosystems. They also represent the economic base for the majority of the population in Central America (producing grains, coffee 
etc.) but are prone to soil and landscape degradation, problems exacerbated by climate change-induced droughts and floods (IISD, 2003).

'Bottom-up' processes have also met with success in Bangladesh, through the Reducing Vulnerability to Climate Change (RVCC) Project (Box 5), and in Vietnam, where the Vietnam National Chapter of the Red Cross has worked with local communities to rehabilitate mangroves (Box 6).

\section{Box 5. Reducing Vulnerability to Climate Change in Bangladesh}

Bangladesh has always been vulnerable to climatic variability, but global warming will exacerbate its environmental problems. Most of the land is barely above sea level, and rising sea levels could cause Bangladesh to lose $15-17 \%$ of its landmass within the next 50 years. Drought in the dry season could become more severe, and rain in the wet season more intense. Floods and cyclones are likely to be more frequent and more severe. Higher temperatures along with increased salinity and more waterlogged areas will affect agriculture and fisheries, as well as the availability of drinking water. Coastal biodiversity is threatened, particularly in the ecologically important Sundarbans. Farming systems have already been seriously disrupted, and the poverty of local people means that coping mechanisms for adapting to new situations are limited.

The Reducing Vulnerability to Climate Change (RVCC) Project aims to increase the capacity of Bangladeshi communities in the southwest to adapt to the adverse impacts of climate change via the promotion of sustainable development and local level capacity building. The project operates at the household level, working with 4,300 vulnerable households to explore new livelihood opportunities. Local partner organisations work with local government and community leaders to raise awareness of climate change impacts and help develop community adaptation strategies. The project is supporting capacity building of six local organisations in collection and dissemination of climate change information, advocacy on salinity and potable water, climate change awareness campaigns and development of a secondary school climate change module. Project partners regularly interact with national climate change stakeholders on policy and advocacy issues to increase awareness of local climate change implications and local people's needs.

Source: CARE Bangladesh, 2005.

\section{Meeting the Millennium Development Goals}

Climate change is dealt with in MDG seven on ensuring environmental sustainability. One target set for reaching this goal to 'integrate the principles of sustainable development into country policies and programmes and reverse the loss of environmental resources'. Indicators for monitoring whether this target is met are as follows:

- Proportion of land area covered by forest

- Ratio of area protected to maintain biological diversity to surface area

- Energy use (kg oil equivalent) per US\$1 GDP (Purchasing Power Parity)

- Carbon dioxide emissions per capita and consumption of ozone-depleting chlorofluorocarbons (Ozone Depleting Potential tons)

- Proportion of population using solid fuels 


\section{Box 6. Mangrove Rehabilitation in Vietnam}

In Vietnam, tropical cyclones have caused considerable damage to the livelihoods of those living near the coast. In future decades climate change may increase the frequency and severity of tropical storms. However, the relative uncertainty surrounding anticipated climate change impacts makes it difficult for decisionmakers to justify increased costs for coastal protection. Under such circumstances, it is important to adopt precautionary adaptation approaches that minimise future risk and reduce existing vulnerability.

Mangroveecosystem rehabilitation along much ofVietnam's coastline represents such an approach. Mangrove wetlands provide enhanced physical protection from storms and are a reservoir for carbon sequestration. They also provide a resource base for local livelihoods and income generation. Since 1994, the Vietnam National Chapter of the Red Cross has worked with local communities to plant and protect mangrove forests in northern Vietnam. Nearly 12,000 hectares of mangroves have been planted, and the benefits have been staggering. Although planting and protecting the mangroves cost approximately US\$1.1 million, it saved US\$7.3 million per year in dyke maintenance. During the devastating typhoon Wukong in 2000, project areas remained unharmed while neighbouring provinces suffered huge losses in lives, property and livelihoods. The Vietnam Red Cross estimates that some 7,750 families have benefited from mangrove rehabilitation. Family members can now earn additional income from selling crabs, shrimp and molluscs while increasing the protein in their diets.

Source: International Federation of Red Cross and Red Crescent Societies, 2001.

The focus on forests and protected areas assumes that these are the key to natural resource conservation. This overlooks the value of other landscapes, and marine/water-based environments, which often contain considerable biodiversity and have more potential to contribute to poverty reduction (Roe, 2003). Likewise, the focus on energy use and $\mathrm{CO}_{2}$ emissions focuses on mitigating climate change and ignores the fact that climate change is already a reality, and that adaptation needs to be considered. This need for adaptation does not replace the need to mitigate climate change; both adaptation and mitigation are important parts of the solution (Sperling, 2003). The proportion of population using solid fuels is also a poor measure of air quality as it fails to distinguish between the dangers of indoor and external air pollution.

Definitions also vary and remain contested. For example the UN's Food and Agriculture Organisation excludes agroforestry from its definition of a forest, and many privately- or community-owned protected areas have not been gazetted by national governments or international organisations, so are not recognised. Many people still use the discredited 'dollar a day' indicator as a measure of poverty, and many technical questions about how to measure the amount of carbon that forests sequester and release remain unanswered.

The forest indicator would be better if it captured some measure of goods and services coming from forests, such as carbon sequestration, soil protection, biodiversity enhancement and contributions to local livelihoods (Roe, 2003). 
Likewise, the indicators relating to energy use and $\mathrm{CO}_{2}$ emissions would be improved if they captured some measure of broader environmental and social benefits emerging from activities undertaken. If such considerations are taken into account, investment could shift towards projects with multiple livelihood, biodiversity and climate change benefits (or at least projects which do no harm in these additional contexts), as opposed to initiatives (such as large dams), which might meet one Millennium Development Indicator, but which have significant negative impacts on ecosystem integrity, biodiversity, climate change mitigation or adaptation, and local livelihoods. Achieving the MDGs is already proving to be a challenge industrialised countries seem unable to meet, but ensuring that any progress made towards meeting these targets will benefit the poor depends on the process undertaken.

\section{The way ahead: linking climate change, biodiversity conservation and poverty reduction}

The role of local processes in addressing climate change, biodiversity conservation and poverty reduction is often overlooked or undermined. The biodiversity conservation agenda has, for example, been driven by international priorities such as preservation of rare and charismatic mammals. This approach has often superseded local values attached to biodiversity such as livelihood support or risk reduction in the face of climate shocks. Likewise, much attention and funding currently focuses on top-down strategic planning requirements (often stemming from the environmental conventions spawned at the UN Earth Summit in Rio in 1992) such as National Communications, National Adaptation Programmes of Action, National Biodiversity Strategies and Action Plans, National Conservation Strategies, National Environmental Action Plans and Poverty Reduction Strategy Papers. Such initiatives typically challenge poor countries by placing considerable strain on already overloaded institutions with limited capacity (Dalal-Clayton, 2003).

Supporting local solutions requires action at several levels. Globally, actions to reduce poverty and inequity will ultimately reduce vulnerability to climate change and may also reduce unsustainable natural resource use. Such actions include curbing the loss of income from trade barriers and subsidies paid to farmers in high-income nations; improved market access for processed raw materials; external investment and, untied aid (to support accountable local processes); debt relief; and a commitment in high-income nations to change consumption patterns and thus reduce greenhouse gas emissions.

Synergies between the UNFCCC and Convention on Biological Diversity (CBD) need to be explored, alongside links with national development plans such as Poverty Reduction Strategy Papers (CBD Ad Hoc Technical Expert Group on Biodiversity and Climate Change, 2003). This is not easy as the processes have separate constituencies, administration arrangements, negotiators and guiding scientific bodies (Reid et al., 2004). Some feel that encouraging countries to establish a single body to deal with their obligations under all international 
environmental agreements would be useful. For example, disaster management plans drawn up to deal with climate-induced disasters could incorporate impacts on local ecosystems in addition to vulnerable human settlements. This would recognise the role played by ecosystems in local livelihoods and as havens of biodiversity.

Possible tools for integrating biodiversity, livelihood and climate change concerns include the ecosystem approach, which could incorporate climate concerns. Environmental and social impact assessments, and Environmental Assessments can be adapted to support broad uptake of environmental, social and development priorities. Measuring the value of environmental services to capture the true value of environmental goods and services is needed. Participatory processes and an holistic approach incorporating all aspects of sustainable development should be promoted (Reid, 2003).

Nationally, policies that benefit biodiversity, climate change adaptation and mitigation, and poverty reduction need promotion. In particular, development activities should integrate responses to climate risks and thereby minimise the impacts of climate change (Smith and Troni, 2004). Development agencies, national governments and other stakeholders should internalise climate change into their work. However, many adaptation activities are located within the Ministries of Environment, which are traditionally relatively weak and have little influence over line Ministries (such as those responsible for agriculture or water management).

Goodgovernanceisveryimportant, butinevitablyrequirescontextualisation within the complexities of local and national political systems (Bass et al., 2005). Stronger decentralised government can play an important role, but a well-functioning national government with vision and accountability is also critical. Locally, actions that encourage fair and accountable local government, effective land tenure reform and common property resource management in ways that protect rights of poor groups are important.

One key priority in the search for solutions is to build on the considerable body of knowledge already possessed by the poor. Adaptation activities in particular should take account of this knowledge because poor people have had to cope with climate variability for many years. Capacity building activities should support local solutions and bottom-up processes accountable to lowincome groups. Rather than categorising poor people as beneficiaries of aid, support should be provided for them to prioritise their own efforts to reduce climate-related vulnerability through ecosystem management and restoration activities that sustain and diversify local livelihoods. 


\section{References}

Abramovitz, J.N. (1996) Imperiled Waters, Impoverished Future: The Decline of Freshwater Ecosystems World Watch Paper 128. Worldwatch Institute: Washington, D.C.

Bass, S., H. Reid, D. Satterthwaite, P. Steele (2005) Reducing Poverty and Sustaining the Environment: The Politics of Local Engagement. Earthscan: London.

Brown, S., J. Sathaye, M. Cannell, P. E. Kauppi (1996) 'Management of forests for mitigation of greenhouse gas emissions' In R. T. Watson, M. C. Zinyowera, R. H. Moss, D. J. Dokken (eds.) Climate Change 1995 - Impacts, Adaptations and Mitigation of Climate Change: Scientific-Technical Analysis IPCC WG II contribution to the Second Assessment Report, Cambridge University Press: Cambridge.

Buddemeier, R.W., J.A. Kleypas, R.B. Aronson (2004) Coral Reefs and Global Climate Change. Potential Contributions of Climate Change to Stresses on Coral Reef Ecosystems, Pew Centre on Global Climate Change: Washington, D.C.

CARE Bangladesh (2005) RVCC Project Leaflet, Internet: http://www.carebd. org/project_dtls.php?pid=11

CBD Ad Hoc Technical Expert Group on Biodiversity and Climate Change (2003) Interlinkages Between Biological Diversity and Climate Change: Advice on the Integration of Biodiversity Considerations into the Implementation of the United Nations Framework Convention on Climate Change (UNFCCC) and Its Kyoto Protocol, CBD Technical Series no. 10, Draft Report for Experts and Government Review, CBD Secretariat: Montreal.

Dalal-Clayton, B. (2003) 'The MDGs and sustainable development: the need for a strategic approach' in D. Satterthwaite (ed.) The Millennium Development Goals and Local Processes: Hitting the Target or Missing the Point IIED: London.

Fearnside, P.M. (2001)'Environmental impacts of Brazil's Tucurui Dam: unlearned lessons for hydroelectric development in Amazonia' Environmental Management 27(3): 377-396.

Fu, C.Z., J.H. Wu, J.K. Chen, Q.H. Qu, G.C. Lei (2003) 'Freshwater fish biodiversity in the Yangtze River basin of China: patterns, threats and conservation' Biodiversity and Conservation 12(8): 1649-1685.

Gitay, H., A. Suárez, D.J. Dokken, R.T. Watson (2002) Climate Change and Biodiversity, IPCC Technical Paper V, IPCC: Geneva.

Huq, S., A. Rahman, M. Konate, Y. Sokona, H. Reid (2003) Mainstreaming Adaptation to Climate Change in Least Developed Countries (LDCS) IIED, London.

Huq, S., H. Reid (2005) 'Benefit sharing under the clean development mechanism' in D. Freestone, C. Streck (eds.) Making Kyoto Work: Legal Aspects of Implementing the Kyoto Protocol Mechanism Oxford University Press: Oxford. Pp 229-247.

IISD (2003) Livelihoods and Climate Change: Combining Disaster Risk Reduction, Natural Resource Management and Climate Change Adaptation in a new Approach to the Reduction of Vulnerability and Poverty IISD: Winnipeg. 
International Federation of Red Cross and Red Crescent Societies (IFRC) (2001) Coastal Environmental Protection: A Case Study of the Vietnam Red Cross IFRC: Geneva.

Lèbre La Rovere, E., A.R. Romeiro (2003) The Development and Climate Project phase I: Country Study Brasil Centro Clima, COPPE, Federal University of Rio de Janeiro: Rio de Janeiro.

Montgomery S., M. Lucotte, I. Rheault (2000)'Temporal and spatial influences of flooding on dissolved mercury in boreal reservoirs' The Science of the Total Environment 260(1-3): 147-157.

Orford, M. (2004) Climate Change and the Kyoto Protocol's Clean Development Mechanism ITDG Publishing: London.

Page, S.E., F. Siegert, J.O. Rieley, H.D. Boehm, A. Jaya, S. Limin (2002)`The amount of carbon released from peat and forest fires in Indonesia during 1997' Nature 420: 61-65.

Reid, H. (2003) 'A framework for biodiversity and climate' Tiempo 50: 7-10.

Reid, H., B. Pisupati, H. Baulch (2004) 'How Biodiversity and Climate Change Interact' Science and Development Net, Biodiversity Dossier Policy Brief. Internet: http://www.scidev.net/dossiers/index.cfm?fuseaction=policybri efs\&dossier $=11$

Roe, D. (2003) 'The Millennium Development Goals and natural resources management: reconciling sustainable livelihoods and resource conservation or fuelling a divide?' in D. Satterthwaite (ed.) The Millennium Development Goals and Local Processes: Hitting the Target or Missing the Point IIED: London.

Satterthwaite, D. (ed.) (2003) The Millennium Development Goals and Local Processes: Hitting the Target or Missing the Point IIED: London.

Sciare, J., N. Mihalopoulos, F.J. Dentener (2000) 'Inter-annual variability of atmospheric dimethylsulfide in the southern Indian Ocean' Journal of Geophysical Research 105: 26,369-26,377.

Smith, D., J. Troni (2004) Climate Change and Poverty: Making Development Resilient to Climate Change DFID: London.

Sperling, F. (ed.) (2003) Poverty and Climate Change: Reducing the Vulnerability of the Poor Through Adaptation World Bank: Washington D.C.

Thomas, C.D., A. Cameron, R.E. Green, M. Bakkenes, L.J. Beaumont, Y.C. Collingham, B.F. Erasmus, M.F. de Siqueira, A. Grainger, L. Hannah, L. Hughes, B. Huntley, A.S. van Jaarsveld, G.F. Midgley, L. Miles, M.A. Ortega-Huerta, A.T. Peterson, O.L. Phillips, S.E. Williams (2004) 'Extinction risk from climate change' Nature 427: 145-148.

Walter, J. (ed.) (2002) World Disasters Report: Focus on Reducing Risk. IFRC: Geneva.

Walter, J., A. Simms (2002) The End of Development? Global Warming, Disasters and the Great Reversal of Human Progress New Economics Foundation: London.

World Neighbours (2000) Reasons for Resiliency: Toward a Sustainable Recovery after Hurricane Mitch, World Neighbours: Tegucigalpa. 


\title{
Using the sustainable livelihoods approach to reduce vulnerability to climate change
}

\author{
Anne Hammill' ${ }^{1}$ Liza Leclerc' ${ }^{2}$, \\ Outi Myatt-Hirvonen ${ }^{3}$ and Zenia Salinas ${ }^{4}$
}

1. International Institute for Sustainable Development

International Environment House 29 chemin de Balexert 1219 Châtelaine,

Geneva, Switzerland. Tel: +41 (22) 917 8637, Fax: +41 (22) 917 8054, E-mail: ahammill@iisd.ca

2. Climate Change Adaptation Task Manager, United Nations Environment Programme.

P.O. Box 47074, Nairobi 00100, Kenya. Tel: +254 20 623113, Fax: +254 20 624324,

E-mail: liza.leclerc@unep.org

3.Department of ForestEcology, University of Helsinki, P.O. Box 27, FIN-00014University of Helsinki, Finland. Tel: +358-9-191 58152, Fax: +358-9-191 58100, E-mail: outi.myatt-hirvonen@helsinki.fi 4. Global Change Group, Tropical Agricultural and Higher Education Center, CATIE 7170,

Costa Rica.Tel: (506) 5582343, E-mail: zsalinas@catie.ac.cr

\section{Introduction}

Reports from the Intergovernmental Panel on Climate Change (IPCC) have confirmed that we are now locked into inevitable changes in climate. Changes on climate such as mean temperature, sea-level rise and increased frequency and intensity of extreme weather events as well as changes in precipitation patterns have been projected. Although there is a lack of certainty in predicting and quantifying climate change impacts on socio-economic systems, it is well known that climate change impacts threaten a major dimension of human well-being, namely security. However, impacts depend on the exposure and sensitivity of the threatened system. For instance, human systems in which economies rely heavily on natural resources, have inadequate infrastructure as well as weak social and human capital are vulnerable to climate- related hazards. Through an increase in climatic variability, ecosystems will be degraded - this 
will ultimately affect food security. These risks threaten approximately $70 \%$ of rural people living in extreme poverty around the world (OECD, 2001). For the rural poor, human security is synonymous with food security. Extreme droughts, for example, have often led not only to loss of life, but also to an exacerbation of poverty conditions through the degradation of the natural resource base, leading to a downward spiral of poverty. Hence, this group of people is the most vulnerable to the impacts of climate change.

Developing adaptation strategies represents a challenge for those seeking to balance livelihood support while ensuring sound investment in poverty reduction. The risks climate change poses on the livelihoods of the poorest also represent risks to current investments in poverty reduction measures. As an example, the impacts of efforts to improve land-use management practices that have been developed and promoted through the developing world in the name of poverty alleviation - such as soil and water best management practices - may be significantly reduced as a result of climate change. Many international development agencies are considering urgently the need to include climate change adaptation strategies in their poverty reduction agendas (see for example World Bank et al., 2003). In order to have no-regrets benefits therefore, adaptation measures must be based on the reduction of vulnerability of the poor to existing hazards.

Poverty and vulnerability are closely related concepts. Poverty may be seen as a cause of vulnerability, in addition to other factors such as economic marginalisation (O'Brien et al., 2004). Vulnerability is also seen as an important causal dimension of poverty related to human security (Chambers, 1983; OECD, 2001; Devereux, 2002). In addition, they are similar in the sense that they are both dynamic and their reduction relies on our understanding of livelihood activities. However, they differ in that poverty is a characteristic from which people can move away, whereas vulnerability is a characteristic of a system; not all members of vulnerable groups are necessarily poor. Furthermore, the incorporation of vulnerability into poverty assessments has raised awareness in recent decades (Ellis, 2000; IUCN et al., 2003). The way in which livelihoods are built not only determines people's ability to move in or out of poverty, but also their ability to build insurance strategies to face existing risks. Thus, understanding deliberate risk management strategies of the poor can often shed light on important issues for designing adaptation measures, such as how people will respond to future impacts of climate change and how the impacts will be distributed (IUCN et al., 2003). Many hard-won lessons from poverty assessments and poverty reduction projects can be applied to vulnerability and adaptation assessments.

Poverty concepts and strategies have evolved to concepts that include many dimensions of deprivation. Drawing from concerns related to the identification of the poorest regions of the world, discussions on poverty first focused on setting simplistic indicators. For instance, the well-being concept acquired an explicit material core (income and consumption), thus poverty was measured in absolute terms, i.e., using the acceptable minimum income that individuals 
need to satisfy basic nutritional requirements. As a result of neglecting the complexity of factors that cause poverty, the assessment associated with this approach under-reported persistent deprivation (Hulme and Shepherd, 2003). Meanwhile, researchers drew attention to the need to consider a more complex nature of poverty. Thus, dimensions such as education, health, empowerment, freedom of choice, rights, voice, dignity, autonomy, equity, governance, vulnerability, and security progressively broadened conventional concepts of poverty and included the most important areas in which people are deprived and perceived as incapacitated (Chambers, 1989; OECD, 2001).

Currently, therefore, the vast number of enriched alternative poverty concepts enable a reliable identification of those groups that are at most risk. Under this approach, instead of groups or individuals, the livelihood concept is promoted (Devereux, 2002) and the focus is on understanding the lives of the poor. Well-being may even be defined by the poor themselves, so relative terms are used and process and opportunities are taken into account to assess the degree of poverty (Angelsen and Wunder, 2003). In practice, some poverty indicators provided by conventional poverty concepts are still applied to estimate roughly the state of poverty at national or regional levels. Nevertheless, holistic approaches are promoted by international agencies for implementing current poverty reduction agendas at the local level.

Poverty assessments as well as assessments of vulnerability and adaptation are to be carried out in the same diverse, complex, dynamic, context-bound, heterogeneous and generally non-responsive rural poor context. Fortunately, holistic approaches to poverty have already identified that achieving sustainable livelihoods requires building security and reducing vulnerability. The sustainable livelihood concept, which aims for poverty reduction, depends on the ability of a system to recover from shocks. Therefore, building sustainable livelihoods requires a strong understanding of the causes of poverty and the particular context of the livelihoods in question. The Sustainable Livelihood Approach (SLA), provides a framework that allows reliable understanding and identification of conditions to enable poverty reduction through the achievement of sustainability of rural livelihoods, as well as creating a link between macro- and micro-level conditions. Elements resulting from the SLA assessment of poverty are useful for designing relevant poverty measures as they reveal the strengths and weaknesses possessed by the poor in their use of capabilities, assets and activities to construct their livelihoods. Using SLA for developing adaptation strategies and measures can assure a people-centred and bottom-up approach to adaptation, which addresses future climate change by reducing existing vulnerabilities.

This chapter examines how hard-won lessons about poverty assessment and poverty reduction strategies based on natural resources management can be applied in order to assure the design of locally relevant adaptation strategies that effectively lead to reducing adverse consequences of climate change. The relevance and utility of the SLA for understanding and reducing vulnerability and increasing resilience to climate change is demonstrated through examples. 
In addition, natural resources management success stories of Central America, Africa and Asia are used to illustrate how these activities may build the resilience of the rural poor.

\section{Vulnerability and resilience to climate change}

\subsection{Vulnerability}

In the climate change community, the concepts of vulnerability and resilience continue to develop and be challenged by the various schools of thought. Perhaps the most important development in terms of moving towards concepts that can be practically applied by policymakers and development planners is the shift from impacts analysis to vulnerability analysis (Burton et al., 2002). Revealing its meteorological roots, the former view focuses on predictions of climate events and shifts in climate parameters such as tornadoes, precipitation, temperature, and the latter seeks to understand the root causes for losses incurred due to these factors, recognising also that communities are subject to multiple and cumulative stresses.

Certainly, one of the major challenges has been to make the issues of vulnerability and adaptation to climate change relevant to decision makers who must make choices regarding the allocation of scarce resources and time. Scientific uncertainty about future impacts of climate change has impeded planning for climate change. Decision makers are presented with predictions of imprecise and uncertain magnitude, timing and location, yet are expected to make decisions about allocations of scarce resources (Barnett, 2001).

There are several definitions of vulnerability in the literature. In general terms, vulnerability refers to the potential for loss of various kinds (Cutter, 1996). The Intergovernmental Panel on Climate Change (IPCC) defines vulnerability as a function of exposure to stressors, sensitivity of a system to a stressor and the adaptive capacity of a system to recover from an event (IPCC, 2001) (see also Romero, this volume).

The hazards literature suggests that vulnerability stems from location, such as coastal infrastructure, and from socio-economic disadvantages such as access to resources and poverty (Cutter, 1996). Though termed differently, the understanding of vulnerability in the hazards community, as described here, is similar to that in climate change. Essentially, it is the combined result of an outside stimulus and the properties of a system that leads to losses.

There is some discussion in the climate change and hazards literature about resilience as an attribute of a system or as an umbrella concept for a range of system attributes deemed desirable (Klein et al., 2003). A more resilient system is considered to be more able to withstand, react and adjust to a stress.

\subsubsection{Who is vulnerable to climate impacts, and why?}

Understanding vulnerability and the realities of multiple and cumulative stressors is particularly relevant to achieving development benefits and securing 
existing development investments, which are the fundamental objectives of and motivation for an adaptation strategy.

Given its holistic approach to understanding the dynamics of development, the SLA can be usefully applied to understanding vulnerability to climate change in a more complete way. Applying this approach can help identify the factors that determine a system's resilience, the interactions between those factors, and thus target specific areas for priority action through an adaptation strategy.

\subsection{Resilience}

The study of resilience in the nexus of the adaptation and development fields is complicated by the scope of the systems being studied, such as a community of people, and the socio-economic and physical environment in which they live, which are immeasurably complex.

Resilience is generally accepted as a positive attribute of a system. Ecological research has identified a number of characteristics that define system resilience, though there is no consensus among experts. These six principles include: homeostasis; the omnivory principle; high flux principle; flatness principle; buffering principle; and redundancy (Barnett, 2001).

These units of study can be usefully described through the SLA, which takes a comprehensive approach to poverty by considering more broadly the asset base of the poor to include financial, human, physical and social assets (Miltin, 2003) and natural capital.

From the disasters literature, Barnett (2001: 985) further notes that, "strategies enable systems to absorb and recover from sudden changes, and to learn from and adapt to changed conditions". As well as designing slackness, redundancy and speed of supply into social systems (Handmer and Dovers, 1996), the decentralisation of decision-making (Blaike et al., 1994) also enhances resilience.

\subsubsection{System resilience and vulnerability to climate change}

In the context of climate change, resilience can be described as the capacity of a community, or a system, to withstand and recover from changes in climate, such as increased frequency and intensity of extreme weather events. This resilience will be based on a number of factors such as access to early warning systems and information and technical expertise (physical and human assets), the stability of infrastructure (physical assets) and access to savings and contingency plans (financial and social assets), to name a few.

There exists a lack of certainty in predicting and quantifying future climate change impacts and future vulnerability, as well as the social and economic contexts that will affect these. Identifying current system weaknesses in order to address these gaps will build system resilience against climate change and other changes and shocks, producing "win-win" interventions which are palatable and realistic for decision makers. 
These "no regrets" strategies can mean implementing strategies that will be beneficial to development, regardless of the magnitude or direction of the future changes in climate. In other words, regardless of the exact course that climate change takes, the standard of living of a community will have been enhanced today and in the future. This means building buffers against change or planning for change. Communities will then see the ancillary benefit of also becoming more resilient to multiple stressors such as population growth, epidemics and market fluctuations.

For the purposes of this discussion, the determinants of resilience will be disaggregated and applied to the five asset types used in the sustainable livelihoods framework, to suggest targeted adaptation interventions that reduce vulnerability to climate change by enhancing the sustainable livelihoods of the poor.

\section{Reducing vulnerability and increasing resilience through sustainable livelihoods}

Given that the poor are most vulnerable to disruptive shocks and trends such as climate-related disasters and climate change, building their resilience requires an understanding of how their livelihoods are comprised and conducted. By understanding peoples' livelihoods, we can begin to understand how they will be affected by climate change impacts, how they might respond with the resources they have, and how these conditions can be reflected and built upon for successful adaptation strategies.

\subsection{The sustainable livelihoods approach to development and poverty reduction}

\subsubsection{Sustainable livelihoods approach}

The concept of sustainable livelihoods has its origins in the work of World Commission on Environment and Development (WCED), which highlighted the importance of "sustainable livelihoods security" in achieving sustainable rural development (Chambers and Conway, 1991; Shankland 2000). A widely accepted definition of livelihoods states that "a livelihood comprises the capabilities, assets (stores, resources, claims and access) and activities required for a means of living" (Chambers and Conway, 1991: 6) and continues by stating that a livelihood is sustainable "if it can cope with and recover from stress and shocks, maintain or enhance its capabilities and assets, and provide sustainable livelihood opportunities for the next generation; and...contributes net benefits to other livelihoods at the local and global levels and in the short and long term" (Chambers and Conway, 1991: 6).

The sustainable livelihoods approach (SLA) is a result of the operationalisation of the sustainable livelihoods concept, and has been developed especially by UK's Department for International Development (DFID), as well as other international agencies and organisations such as Food and Agriculture 
Organization of the United Nations (FAO), the UN World Food Programme (WFP), CARE International, Oxfam and UN Development Programme (UNDP). It needs to be emphasised that the SLA, or just the livelihoods approach, is not one single approach but various organisations and agencies are applying the key concepts of the SLA in different ways, some placing more emphasis on certain aspects rather than on others. Nevertheless, these approaches share the aim of a more holistic approach to poverty reduction, borne out of criticism of earlier approaches and experiences of rural development and poverty reduction. It should also be noted that originally the focus of the approach was on sustainable rural livelihoods but now also encompasses also urban poverty and urban livelihoods, thus recognising the importance of rural-urban interactions (Carney et al., 1999; Ellis 2000; Hussein 2002). As an example, Figure 1 presents DFID's sustainable livelihoods framework. The framework contains the main factors that affect people's livelihoods and typical relationships between these.

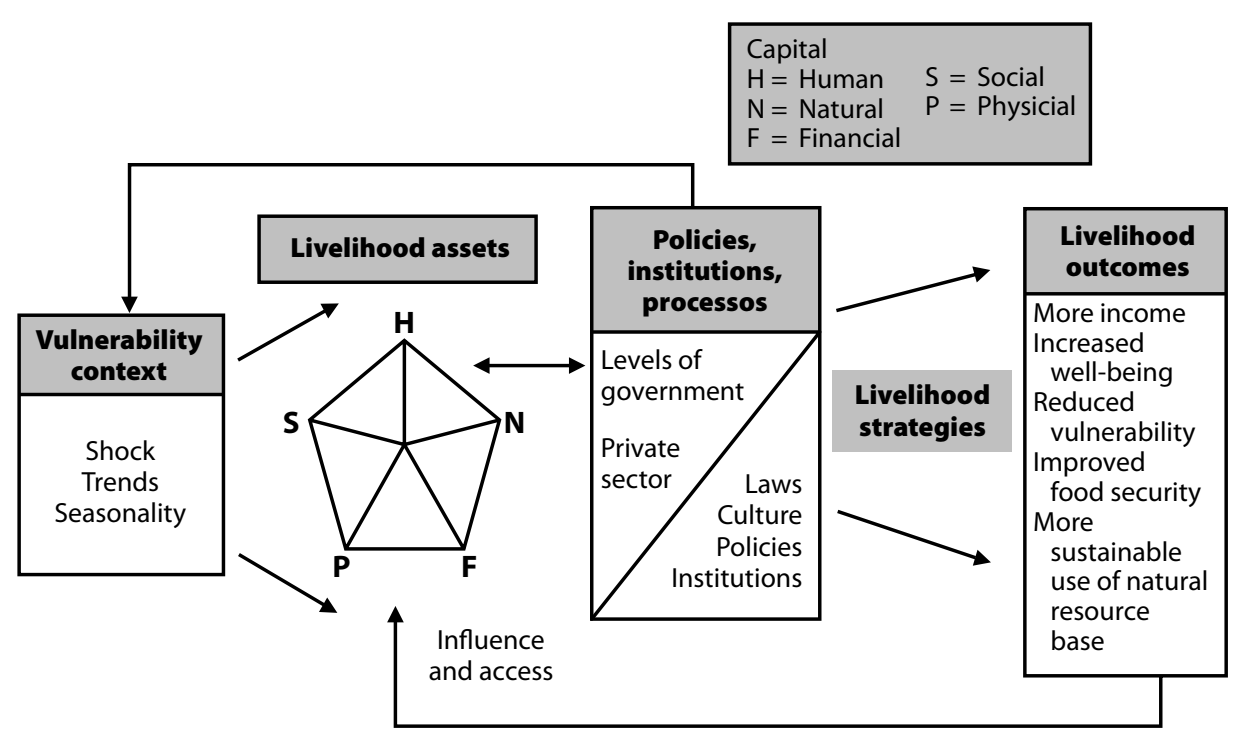

Figure 1. Sustainable livelihoods framework (DFID, 1999)

The vulnerability context refers to the external environment in which people exist. There are external factors over which people have no or only a limited control of and that affect, often negatively, their livelihoods. Shocks represent the most extreme and sudden or unexpected changes in people's livelihoods, for example through disasters, civil conflicts, economic shocks or outbreaks of disease or pests. Shocks might destroy assets directly or force people to abandon their homes and land. Trends, such as economic and population trends, influence people's livelihoods, but are usually more predictable and long-term. Seasonality refers to seasonal fluctuations in prices and employment opportunities, as well as to the availability of food and resources such as water and varying health conditions due to seasonal weather and other factors. 
The livelihoods framework portrays the following five livelihood assets (capitals):

Human capital includes the skills and knowledge, educational and health levels of people, thus determining the quantity and quality of the available labour. Human capital plays a key role in making use of the other capitals. However, accumulation of human capital can also be an end in itself (a livelihood objective), since poverty is often reflected in lack of education and poor health (DFID 1999).

Natural capital refers to things such as land, water, forests, wildlife and quality of the environment. Thus, it comprises assets that can directly be used for production, such as land and trees, and intangible assets, such as environmental quality, that also affect livelihoods.

Financial capital consists of income and savings, both in cash and in kind, and access to credit.

Social capital comprises membership in groups and networks, relations of trust, reciprocity, common rules, norms and sanctions, and connectedness in institutions. In more practical terms, it refers to the social resources that enable people's access to other resources.

Physical capital refers both to infrastructure such as houses and buildings, means of transportation, water and sanitation systems, energy, and means of communication, as well as to means of production, such as tools and equipment.

The "policies, institutions and processes" (PIP) component of the framework is often referred to as transforming structures and processes. Access to the various types of assets is determined and influenced by these transforming structures and processes. Structures are organisations, both at public and private sector, and at all levels, from international and multi-national organisations to local level organisations. These organisations trade, deliver services, and set and implement policies and legislation, thus having direct or indirect impacts on people's livelihoods and livelihood choices. The transforming processes refer to the way structures (organisations and individuals within them) operate and interact, and include policies, legislation, culture, institutions (such as markets) and power relations (DFID, 1999).

Livelihood strategies refer to the combination of activities and choices that people make in order to achieve their livelihood goals (DFID, 1999). They are not only reflected in people's productive activities but also, for example, in their investment decisions and reproductive choices. People's livelihoods and livelihood strategies are dynamic, changing over time and responding to constraints and opportunities. People make changes in their livelihoods both 
by choice and by necessity. Coping strategies are livelihood strategies pursued as response to sudden, unplanned crises or shocks. Adaptive strategies, on the other hand, are strategies that people develop as a response to long-term adverse events, cycles or trends (Ellis, 2000).

As already stated, people's livelihoods are dynamic and change over time, as do the conditions in which they exist. The different components of the livelihoods framework interact with and influence each other, positively and negatively, causing changes both in people's livelihoods and in the external conditions. The arrows and feedback loops of the framework display these interactions and influences.

DFID's sustainable livelihoods framework displays livelihood outcomes as results of livelihood strategies. People pursue certain livelihood strategies to meet their livelihood objectives; however, the actual livelihood outcomes may differ from the original objectives, depending on how successful the respective livelihood strategies turn out to be. Also, in the case of a development intervention, the desired outcome of a donor or an intervening agency may differ from the desired outcome of the people who are the target of the intervention. DFID has identified five desired livelihood outcomes, as shown in Figure 1. They are: more income; increased well-being; reduced vulnerability; improved food security; and more sustainable use of the natural resource base.

Oxfam's list of desired livelihood outcomes includes these and adds two more: improved social equity, and non-use values of nature secured. Ellis (2000), on the other hand, divides the livelihood outcomes into two main categories, depending on their impact on either livelihood security or on environmental sustainability.

The concept of livelihood security is instrumental in regard to people's livelihood goals and livelihood outcomes. People aim at livelihoods which have high resilience and low sensitivity to shocks and stresses, i.e., livelihoods that are more secure and less vulnerable (Rakodi, 1999). According to Ellis (2000), livelihood security consists of a certain income level and income stability, reduction in adverse seasonal effects, and reduction in the overall risk profile of the income portfolio, which in turn makes households less vulnerable to adverse trends or shocks. Sustainable livelihood security requires also the consideration of long-term impacts of current livelihoods, as well as the impacts on other livelihoods local and global level (Chambers and Conway, 1991).

The lists of desired livelihood outcomes and the components of sustainable livelihood security clearly reflect the currently used and generally accepted multi-dimensional concept of poverty which defines it as deprivation of wellbeing; the well-being consisting of material deprivation, inadequate levels of income and consumption, lack of access to health and education, vulnerability and exposure to risk, and voicelessness and powerlessness (World Bank, 2001). As DFID (1999) points out, its ultimate goal is poverty elimination, and sustainable livelihoods is the approach used to achieve this goal. 


\subsubsection{Using the SLA to achieve development and poverty reduction}

As mentioned earlier, the SLA is not one single approach but rather a set of interrelated concepts, aiming at a holistic view on issues related people's livelihoods. These approaches have facilitated understanding the many dimensions of poverty and the underlying causes, as well as the constraints and opportunities people face in trying to rise out of poverty.

An often raised question in regard to the SLA is whether it is an end or a means to an end. Different organisations have diverse interpretations of the purpose of the approach (Ashley and Carney, 1999; Ashley, 2000; Krantz, 2001, Hussein, 2002). Among other things, it has been used as:

- a tool: the framework is used as a checklist of issues and a way of structuring analysis for new or existing development activities;

- a procedure for identifying, planning and assessing new projects or programmes;

- an operational objective where the mission is to improve the sustainability of livelihoods;

- a set of principles: some apply to any situation, others call for specific Sustainable Livelihoods projects or Sustainable Livelihoods programmes;

- an approach to development: using the Sustainable Livelihoods framework and Sustainable Livelihoods principles to guide programme development towards goals that are defined in terms of improved livelihoods;

- a way of thinking about poverty: used in identifying issues that should be addressed in order to reduce poverty;

- guidelines for reshaping existing projects or programmes to enhance the "fit" with livelihoods; and

- a focus of impact assessment.

Despite of the various applications of the SLA, there are some underlying principles that guide these different approaches. Thus, according to DFID (1999) and Carney et al., (1999), any poverty-focused development activity carried out using the SLA should be based on the so called Sustainable Livelihoods principles and should thus be:

- people-centered: focusing on people's own priorities and needs and understanding the diversity of groups of people and the diversity of their livelihood strategies;

- responsive and participatory: enabling the people themselves to identify and address their livelihood priorities;

- multi-level: working both at micro- and macro-levels;

- conducted in partnership: working both with the public and the private sectors;

- sustainable: finding a balance between economic, institutional, social and environmental sustainability; and

- dynamic: recognising the dynamic nature of people's livelihood strategies. 
Using the SLA with its diverse components and focus on multiple levels may seem like an overwhelmingly exhausting task. However, the idea of the framework is not to tackle all issues at once, neither does it aim at a similarly comprehensive approach as, for example, the Integrated Rural Development programmes. The SLA rather attempts to identify the strengths of the people and to build on them in order to achieve positive outcomes. The approach aims to identify key issues related to poverty, both at micro- and macro-levels, and to find strategically important intervention areas for poverty reduction (Krantz, 2001).

The example described in Box 1 demonstrates the diversity of possibilities offered by the SLA in terms of identifying opportunities and constraints that people face and thus identifying entry points for action and areas of intervention.

\section{Box 1. A Diversity of Possibilities}

Reducing people's vulnerability to external forces is a commonly stated goal for any poverty reduction activity. One way to help people to become more resilient, and thus to reduce their vulnerability, is building on their livelihood assets, increasing their access to assets.

However, macro-level organisations may also contribute towards reducing people's vulnerability. Well-functioning markets may reduce the seasonal impacts and adequate policies may be implemented to reduce the impacts of economic or population trends.

Source: DFID, 1999.

\subsection{Using sustainable livelihoods to reduce vulnerability/increase resilience to climate impacts}

Reducing peoples' vulnerability to shocks such as climate-related disasters requires a thorough understanding of the livelihood-climate change interactions. By understanding why people are vulnerable, how they cope, and how this may change as a result of climate change, we can then identify entrypoints for adaptation strategies. This knowledge can be developed through a four-step participatory process: (1) identify how livelihoods are conducted; (2) identify the main climate-induced vulnerabilities that affect livelihoods; (3) identify existing coping strategies; and (4) identify the needs and priorities of stakeholders in the face of climate-induced vulnerabilities.

\subsubsection{Identifying how livelihoods are conducted}

\subsubsection{Livelihood assessment}

The first step in understanding livelihoods-climate change interactions is understanding local livelihoods themselves. A livelihood assessment (or analysis) refers to the process of identifying the assets and strategies of the 
people, the context in which they exist, the institutions and organisations with which they interact, and the sustainability of the livelihood outcomes which they achieve (Shankland, 2000).

It is important to emphasise that the sustainable livelihoods framework is not a ready set methodologies, but rather provides an organising structure for analysis. Various organisations have incorporated the SLA into their development work; some have developed their own modifications of the sustainable livelihoods framework and even some specific methods to facilitate livelihoods analysis. However, in the majority of the cases, existing tools and methodologies and their combinations, which are considered appropriate in a specific context, are used (Hussein, 2002).

Table 1 presents some key questions for a livelihoods analysis and possible methods for data collection. The figure is a modification of the work of Brock ${ }^{1}$ (1999) and also draws on the works of Scoones (1998), DFID (1999) and Ellis (2000).

The five main components of this figure correspond to the five main components of the DFID Sustainable Livelihoods Framework (Figure 1), whereas the frameworks of Brock (1999) and Scoones (1998), to which Figure 2 is based on, do not explicitly portray the vulnerability context. Instead, in the frameworks of Brock and Scoones, the "Vulnerability context" and "Policies, Institutions and Processes" have been partly combined and partly re-divided between two components, namely "Contexts, conditions and trends" and "Institutions and organisations". Ellis (2003), on the other hand, suggests the division into "Vulnerability context" and "Policy and institutional context".

These components, whichever the division and titles, do have overlapping elements and are influenced by each other. One of the challenges of SLA lies in understanding and analyzing the interactions between the various components of the framework and micro- and macro-level influences. Indeed, analysing the PIP has been found to be particularly challenging (Hussein, 2002; Shankland, 2000).

Some issues call for special concern when carrying out livelihoods analysis. Practical evidence suggests that the following issues often receive less attention if not explicitly considered in the analysis (Hussein, 2002; Ellis, 2000):

- Disaggregate analysis:

o The poor and the vulnerable are not a homogenous group; the resources people have and need vary by livelihood context, sex, age and position in life cycle, household status, etc.; and

o Unit of analysis: households, excluded or marginalised groups, women, children, elderly, etc.; and

o Gender issues.

${ }^{1}$ Brock 1999, p. 5, Figure 2: "Range of methods to implement a sustainable livelihoods framework". 
Table 1. Key questions for livelihoods analysis and possible methods of data collection

\begin{tabular}{lllll}
\hline $\begin{array}{l}\text { VULNERABILITY } \\
\text { CONTEXT }\end{array}$ & $\begin{array}{l}\text { LIVELIHOOD } \\
\text { ASSETS }\end{array}$ & $\begin{array}{l}\text { TRANSFORMING } \\
\text { STRUCTURES } \\
\text { AND PROCESSES }\end{array}$ & $\begin{array}{l}\text { LIVELIHOOD } \\
\text { STRATEGIES }\end{array}$ & $\begin{array}{l}\text { LIVELIHOOD } \\
\text { OUTCOMES }\end{array}$ \\
& & &
\end{tabular}

- Power structures: some have suggested adding "political capital" as the sixth livelihood asset (cf. Shankland, 2000):
o Rights issues; and
o Empowerment.

- Cultural issues: some have even suggested adding "cultural capital" to the livelihood assets (cf. Bebbington 1999).

- Time perspective:
- People's livelihoods are dynamic and change over time; and
o Short-, medium- and long-term impacts of policies, trends and other factors.


Carrying out livelihoods analysis calls for expertise from various fields as well as inter-disciplinary analysis. It is also clear that besides diverse skills, a comprehensive analysis requires resources, both temporal and financial. Thus, the adequate scope and scale of the analysis need to be considered in regard to the specific task at hand.

\subsubsection{Identifying the main climate-induced vulnerabilities that affect livelihoods}

The main climate-induced vulnerabilities can be assessed by using the Five Asset Type suggested in SLA.

\subsubsection{Identifying existing coping strategies}

Assess the coping and adaptation strategies that vulnerablecommunitiesalready undertake - crop shifting, asset liquidation, and migration - by answering the following questions: How are these strategies implemented? What resources and skills are needed to implement them? Are they sustainable? How will they be affected by climate change impacts and other external forces?

\subsubsection{Identifying the needs and priorities of stakeholders in the face of climate-induced vulnerabilities}

Determine, through participatory processes, the immediate and long-term steps that need to be taken to minimise the vulnerability of peoples'livelihoods - and existing coping strategies - to climate impacts. What are the local strengths and capabilities that can be built upon for adaptation? What are the weaknesses that need to be addressed? What resources are needed to address these weaknesses and how will they be secured? What changes are needed in the legal, policy and institutional frameworks to facilitate this process?

Based on an assessment of the root causes of vulnerability and factors which contribute to that vulnerability (third row of Table 1), one can suggest a package of interventions which together address the overall resilience of a community to changes, taking into account the need to simultaneously address the preservation of resilience of natural, physical, human, financial and social assets.

An example to illustrate a comprehensive approach to an adaptation strategy follows. Table 3 illustrates how, based on the climate change vulnerability and SLA assessment above (Table 2), one can examine the factors that decrease the resilience of each livelihood asset type and identify measures to remediate these. Implementing each of these as a comprehensive package comprises an adaptation strategy which increases current livelihood security. A number of strategies are possible which will need to be assessed based on national circumstances and priorities. 
Table 2. Disaggregation and assessment of vulnerability to climate change into five livelihood asset types

\begin{tabular}{|c|c|c|c|c|c|}
\hline \multirow{2}{*}{$\begin{array}{l}\text { Climate } \\
\text { Change } \\
\text { Exposure and } \\
\text { Resilience } \\
\text { Factors }\end{array}$} & \multicolumn{5}{|c|}{ Livelihood Assets } \\
\hline & Natural $(\mathbf{N}) \Rightarrow$ & Physical (P) $\Rightarrow$ & Human $(\mathrm{H}) \Rightarrow$ & Financial (F) $\Rightarrow$ & Social (S) $\Rightarrow$ \\
\hline $\begin{array}{l}\text { 1. Climate } \\
\text { Change Event } \\
\text { and Direct } \\
\text { Impact on } \\
\text { Livelihood } \\
\text { Assets } \\
\text { (What?) }\end{array}$ & $\begin{array}{l}\text { Change in } \\
\text { distribution of } \\
\text { precipitation, } \\
\text { increased total } \\
\text { rainfall during wet } \\
\text { season, decreased } \\
\text { total rainfall } \\
\text { in dry season } \\
\text { resulting in loss } \\
\text { or arable lands } \\
\text { and crop failure } \\
\text { due to floods and } \\
\text { droughts }\end{array}$ & $\begin{array}{l}\text { Capital losses } \\
\text { of investments } \\
\text { in agricultural } \\
\text { infrastructure, crop } \\
\text { failure and loss } \\
\text { of livestock from } \\
\text { droughts, homes } \\
\text { devastated by } \\
\text { floods }\end{array}$ & $\begin{array}{l}\text { Rural-urban } \\
\text { migration } \\
\text { leading to } \\
\text { high urban } \\
\text { unemployment } \\
\text { Deterioration } \\
\text { in health due to } \\
\text { malnutrition and } \\
\text { undernutrition in } \\
\text { rural areas }\end{array}$ & $\begin{array}{l}\text { Increased } \\
\text { government } \\
\text { spending to } \\
\text { address urban } \\
\text { insecurity } \\
\text { Decrease in savings } \\
\text { due to emergency } \\
\text { spending } \\
\text { Increased foreign } \\
\text { debt from } \\
\text { borrowing to } \\
\text { recover from losses }\end{array}$ & $\begin{array}{l}\text { Increases in crime in } \\
\text { urban centres due } \\
\text { to increased youth } \\
\text { unemployment } \\
\text { Rapid population } \\
\text { growth in illegal } \\
\text { settlements } \\
\text { Overtaxed and } \\
\text { deteriorating } \\
\text { medical system }\end{array}$ \\
\hline $\begin{array}{l}\text { 2. Reasons for } \\
\text { Losses } \\
\text { (How ?) }\end{array}$ & $\begin{array}{l}\text { Changes in } \\
\text { precipitation } \\
\text { patters and } \\
\text { unpredictability } \\
\text { Poor soil structure } \\
\text { from low inputs of } \\
\text { organic materials, } \\
\text { diversion of dung } \\
\text { for fuel } \\
\text { Overgrazing of } \\
\text { livestock leaving } \\
\text { little vegetation } \\
\text { Easily eroded soil } \\
\text { Inefficient } \\
\text { irrigation systems } \\
\text { and low storage } \\
\text { capacity for } \\
\text { excess rains }\end{array}$ & $\begin{array}{l}\text { Heavy } \\
\text { deforestation for } \\
\text { pastoralism and } \\
\text { fuelwood due to } \\
\text { low access to other } \\
\text { energy sources } \\
\text { Homes built on } \\
\text { floodplains } \\
\text { Poor building } \\
\text { construction }\end{array}$ & $\begin{array}{l}\text { Energy needs } \\
\text { increasing for } \\
\text { cooking and } \\
\text { health needs, } \\
\text { changes in } \\
\text { eating habits } \\
\text { Difficult access } \\
\text { to education } \\
\text { and increase } \\
\text { labour needed to } \\
\text { maintain farms } \\
\text { diverting youth } \\
\text { away from school } \\
\text { Low food supply } \\
\text { and poor water } \\
\text { quality, changes } \\
\text { in eating habits }\end{array}$ & $\begin{array}{l}\text { Financial resources } \\
\text { diverted from } \\
\text { education } \\
\text { programmes to } \\
\text { purchasing food } \\
\text { Decrease in } \\
\text { financial income } \\
\text { due to low crop } \\
\text { yields for sale on } \\
\text { local market } \\
\text { Low savings } \\
\text { from subsistence } \\
\text { farming }\end{array}$ & $\begin{array}{l}\text { Decreased human } \\
\text { security due overly } \\
\text { dense population in } \\
\text { illegal settlements } \\
\text { Malaria new to } \\
\text { the region, health } \\
\text { declining } \\
\text { Disconnection } \\
\text { in sharing of } \\
\text { traditional } \\
\text { knowledge as youth } \\
\text { move away from } \\
\text { home } \\
\text { Lack of alternate } \\
\text { (from farming) } \\
\text { employment } \\
\text { options for } \\
\text { dislocated } \\
\text { communities } \\
\text { Loss of social } \\
\text { cohesion }\end{array}$ \\
\hline $\begin{array}{l}\text { 3. Resilience } \\
\text { Principles } \\
\text { Applied to } \\
\text { Understand } \\
\text { Vulnerability } \\
\text { (Why?) }\end{array}$ & $\begin{array}{l}\text { Buffering: Poor } \\
\text { Soil Structure } \\
\text { from low } \\
\text { agricultural input } \\
\text { of organic matter, } \\
\text { increasing erosion } \\
\text { Buffering: } \\
\text { Inefficient use of } \\
\text { water reduces } \\
\text { water available for } \\
\text { domestic use and } \\
\text { stored water for } \\
\text { times of drought } \\
\text { Buffering: } \\
\text { Natural ability } \\
\text { to buffer against } \\
\text { unpredictable } \\
\text { rainfall lost with } \\
\text { deforestation }\end{array}$ & $\begin{array}{l}\text { Omnivory and } \\
\text { redundancy: Few } \\
\text { energy options } \\
\text { place pressure on } \\
\text { forests } \\
\text { Buffering: homes } \\
\text { vulnerable to } \\
\text { climate }\end{array}$ & $\begin{array}{l}\text { Omnivory } \\
\text { principle: } \\
\text { overdependence } \\
\text { on wood and } \\
\text { dung for energy } \\
\text { High Flux: Speed } \\
\text { at which climate } \\
\text { information gets } \\
\text { to communities } \\
\text { is low. } \\
\text { Flatness: } \\
\text { Inflexible medical } \\
\text { health structure, } \\
\text { decisions made } \\
\text { far away means } \\
\text { response to } \\
\text { malaria is slow }\end{array}$ & $\begin{array}{l}\text { Buffering: Low } \\
\text { savings to draw on } \\
\text { in times of need } \\
\text { Redundancy: } \\
\text { Overdependence } \\
\text { on one crop for } \\
\text { cash flows }\end{array}$ & $\begin{array}{l}\text { Omnivory: } \\
\text { Little economic } \\
\text { diversification } \\
\text { for alternate job } \\
\text { creation } \\
\text { Homeostasis: } \\
\text { Breakdown in social } \\
\text { communication, } \\
\text { networks and } \\
\text { learning }\end{array}$ \\
\hline
\end{tabular}


Table 3. Disaggregation and Assessment of the Factors Affecting Resilience into Five Natural Asset Type of SLA

\begin{tabular}{lll}
\hline SLA Asset Type & Resilience Factor & Adaptation Measures \\
\hline Natural Resilience & $\begin{array}{l}\text { Water efficiency, poor soil } \\
\text { structure, deforestation }\end{array}$ & $\begin{array}{l}\text { Increase water efficiency of irrigation systems, } \\
\text { improve soil structure and avoid deforestation }\end{array}$ \\
\hline Physical Resilience & $\begin{array}{l}\text { Access to alternative } \\
\text { energy sources, poor } \\
\text { land management and } \\
\text { infrastructure, no storage } \\
\text { facilities for water or excess } \\
\text { crops }\end{array}$ & $\begin{array}{l}\text { Develop alternate energy source to reduce } \\
\text { pressure on forests and redirecting dung to } \\
\text { land, invest in simple storage facilities for } \\
\text { domestic water (i.e. rain barrels) and silos } \\
\text { for grain. Alternatively, can form regional } \\
\text { cooperative for exchange of crops and share } \\
\text { risk }\end{array}$ \\
\hline Human Resilience & $\begin{array}{l}\text { Communication of climate } \\
\text { data, slow and inflexible } \\
\text { medical system }\end{array}$ & $\begin{array}{l}\text { Decentralisation of medical services, training } \\
\text { and public awareness regarding malaria, create } \\
\text { dedicated weather prediction office, increased } \\
\text { participation in global observing systems }\end{array}$ \\
\hline Financial Resilience & $\begin{array}{l}\text { Overdependence on one } \\
\text { cash crop for income, low } \\
\text { cash savings }\end{array}$ & $\begin{array}{l}\text { Diversify to non-agricultural income sources, } \\
\text { plant non-timber producing (i.e., fruit) trees for } \\
\text { market and for nutrition (human resilience) }\end{array}$ \\
\hline Social Resilience & $\begin{array}{l}\text { High unemployment, high } \\
\text { urban migration }\end{array}$ & $\begin{array}{l}\text { Select alternative income-generating activities } \\
\text { which employ youth and underemployed, } \\
\text { create incentives for rural migration }\end{array}$ \\
\hline
\end{tabular}

While this chapter has up to here illustrated how to identify and develop adaptation strategies that are based on the livelihoods of the poor and most vulnerable communities, the following section offers examples of where SLtype interventions have already increased community resilience to climate impacts.

\section{Adaptation in action}

As stated above, the ability of vulnerable communities to cope with climate variability is largely determined by the way in which they conduct and secure their livelihoods. As a result, climate change adaptation strategies that target these communities must be based on the assets and capabilities that shape these livelihoods. Given the reliance of many of the world's poor on environmental services for their livelihoods, ecosystem management and restoration (EM\&R) activities should be a central component to such strategies. Protecting and enhancing the natural services that support livelihoods can maintain local safety nets and expand the range of options for withstanding and recovering from disruptive shocks and trends.

Securing local livelihoods through environmental/natural resource management is not a new concept or goal. Decades of conservation and development activities have been designed and implemented to support communities in strengthening their livelihoods without undermining the natural resource base upon which they depend. Whether these activities are labelled community-based natural resource management (CBNRM), integrated conservation and development projects (ICDP), or community- 
based rangeland/pasture/fisheries/forest management or restoration, they have produced a wide range of lessons on the challenges, complexities and enabling conditions that shape livelihood security in the face of different social and environmental risks. These hard-won lessons must not be overlooked but rather built in devising climate change adaptation strategies.

One way of building upon these lessons is to examine the so-called 'success stories', whereby programmes and/or projects have successfully restored or enhanced ecosystem services, diversified local livelihoods, and therefore increased community resilience to shocks and trends such as climate variability. This section highlights three such success stories from different parts of the world: Central America (Nicaragua, Honduras and El Salvador), Northern Africa (Sudan), and South Asia (Bangladesh). In all three cases, the longer term implications of climate change were not taken into consideration during programme/project design and implementation. Yet their contribution towards reducing vulnerability to climate impacts has translated into communities that are better prepared and more capable of dealing with the longer-term implications of climate change. In this sense, it can be said that 'adaptation is already happening'- a message that resonates with communities, project managers, donors and governments alike, who are all seeking a better understanding of the processes, investments and activities associated with climate change adaptation.

\subsection{Experience from Central America: PASOLAC ${ }^{2}$}

\subsubsection{Livelihood and climate context}

Covering between $60-80 \%$ of the continental territories of Nicaragua, Honduras and El Salvador, hillsides represent the economic base for the majority of the rural population in Central America. With the bulk of basic grains, important expert products (such as coffee) and various other agricultural goods come from hillside production, their importance to local and regional livelihoods is clear. But these livelihoods are becoming increasingly vulnerable due to severe soil and landscape degradation. Deforestation has led to an overall deterioration in watersheds, leading to a reduction in the absorbing capacity of exposed soils, decreases in water infiltration rates, and lowered groundwater levels. Water shortages during drier seasons and floods during extreme rainfall are becoming more frequent. Droughts and floods have led to decreased agricultural productivity, yield losses, malnutrition and even starvation particularly among children.

The risk of droughts and floods will most likely increase as a result of climate change. With researchers predicting more frequent and prolonged droughts, more irregular rainfall patterns and more frequent and intense extreme

\footnotetext{
${ }^{2}$ Adapted from IUCN, IISD, SEI-B and Intercooperation's Information Paper entitled, 'Increasing the resilience of tropical hillside communities through forest landscape restoration' (Information Paper 2, December 2003).
} 
rainfall events and hurricanes, more hillside livelihoods will be undermined and even destroyed. Heavy dependence on local production and a general lack of resources and skills for coping with climate impacts only reinforce the vulnerability of these livelihoods. Climate change adaptation strategies must understand and address these different aspects of vulnerability if livelihoods are going to be secured.

\subsubsection{PASOLAC: description and results}

Since 1992, PASOLAC (Programa para la Agricultura Sostenible en las Laderas de América (entral) has been helping local communities in Nicaragua, Honduras and El Salvador to increase the agricultural productivity of their hillsides. As a regional network of more than 50 institutions - including NGOs, farmer institutions, research centres and governments - PASOLAC promotes sustainable agriculture in hill areas by offering technical, methodological and financial support, particularly in sustainable soil and water management (SSWM) practices.

The programme uses a participatory and demand-driven approach to building capacities and promoting co-operation among member organisations to encourage the long-term adoption of SSWM. More specifically, the programme has piloted three innovative methodological approaches for achieving its objectives:

"Invertir la Mirada" ("taking a new look"), an arrangement ensuring that farmers have a say in the content and quality of technical assistance so that it is locally appropriate and responding to real needs in the community.

"Pago por Servicios Ambientales" ("payment for environmental services"), offering cash or in-kind compensation to farmers for maintaining and managing natural resources and services (especially water).

"Mercados para Agricultores de Laderas" ("markets for hillside farmers"), aiming to introduce rural production into the market.

To date, PASOLAC has achieved the following:

- Establishment of a network of organisations working on sustainable agriculture and forestry (including agroforestry) on hillsides;

- Validation and implementation of approximately 50 soil and water management techniques by farmers in all three countries;

- Creation of a competitive fund that partially finances project activities that seek to implement SSWM at the farm and local community level; and

- Design and application of tools for participatory monitoring, validation and evaluation, as well as for knowledge transfer. 


\subsubsection{Relevance to climate change adaptation}

Although the impacts of climate change were not part of the original programme design, PASOLAC's activities have addressed problems associated with extreme climatic events, which are expected to increase as global temperatures rise. In fact, several project activities and results have provided evidence that the programme is helping to reduce the vulnerability of local communities to droughts and heavy rainfall. Soil and water conservation, agricultural diversification, and improvement of soil fertility through organic fertilizers have proven to be effective against droughts. Similarly, soil and water conservation practices appear to have increased the resistance of agroecosystems to heavy rainfall. Some concrete indicators demonstrating the increased resilience of local livelihoods to climate hazards include:

Reduced water shortages: A study measuring the water content in soil during 1993-7 demonstrated that water retention in the top $20 \mathrm{~cm}$ of the soil improved on average by three per cent, which is equivalent to 60,000 litres of water per hectare, or to six $\mathrm{mm}$ of rainfall.

Increased drought resistance: In 2001, farmers of Léon (Chinandega, Nicaragua) lost their maize to drought. The only fields that produced a harvest belonged to a farmer who applied stubble and weed management techniques promoted by PASOLAC.

Restored water supplies: One case has been documented, and at least five others have been reported, where water has started to flow again year-round after the construction of dams in streambeds that used to dry up during the dry season.

Increased resistance to heavy rainfall: A study conducted after hurricane Mitch in 1998 on 902 pairs of plots (one with SSWM and the other with traditional management) in 360 communities in Guatemala, Honduras, and Nicaragua examined the impact of SSWM techniques on the incremental resistance of hillside agroecosystems to heavy rainfall, bringing the following results:

- The fertile soil layer was $1.1-2.6 \mathrm{~cm}$ thicker in the plots treated with SSWM. This is equivalent to a conservation of 109-258 tons of soil per hectare.

- Water in the soil was found $0.3-1.8 \mathrm{~cm}$ deeper in the parcels with traditional management. This difference is equivalent to $1,490-8,970$ litres per hectare.

- The loss of topsoil (the most fertile part of the soil) due to erosion was $34 \%$ higher in the traditional plots.

- Rills and landslides were more frequent in plots not using SSWM.

These, and other, indicators have demonstrated that more resilient ecosystems have translated into more secure livelihoods in the face of climate impacts. The results of PASOLAC's activities have created a basis upon which to design and implement adaptation strategies in areas with similar social and ecological conditions and climate change scenarios. 


\subsection{Experience from Africa: Sudan}

\subsubsection{Livelihood and climate context}

Classified as semi-arid and dominated by sandy soils and poor fertility, most of the Bara Province in western Sudan consists of desert scrub vegetation on undulating sand dunes. Average rainfall in the areas is quite low, at roughly 250 $\mathrm{mm}$ per year, and the region experiences significant seasonal and inter-annual rainfall variability. The cumulative impact of recurring droughts, cultivation of marginal lands, fuelwood gathering and overstocking of livestock have drastically depleted the vegetation. As a result, soil erosion, desertification and atmospheric dust have emerged as significant environmental challenges. The local resource base has been degraded, undermining livelihoods and leaving communities more vulnerable to the adverse effects of future droughts. With a population highly dependent on the productive capacity of rainfed agriculture and grazing lands, land degradation often leads to food insecurity; in countries like Sudan where food insecurity can lead to massive dislocation and loss of life, food security is synonymous with human security.

\subsubsection{Project description}

Recognising that communities were highly vulnerable to the effects of drought and struggling with the effects of degraded soil, failing livestock, dwindling crop production and chronic food insecurity, in 1992 a group of 17 villages within the Gireigikh Rural Council in central Bara Province took part in a pilot project entitled 'Community-Based Rangeland Rehabilitation (CBRR) for Carbon Sequestration'. The project was funded by UNDP's Global Environmental Facility (GEF) and sought to:

- Implement a simple model of CBNRM to prevent overexploitation of marginal lands and rehabilitate rangelands for the purpose of carbon sequestration, biodiversity preservation, and the reduction of atmospheric dust; and

- Help ensure the success and sustainability of this approach by diversifying local production systems and improving socio-economic conditions.

In designing its activities, the CBRR project emphasised strong community participation structured around local, traditional, social institutions, and the implementation of a range of activities that did not explicitly contribute to carbon sequestration, but secured the necessary support of residents by meeting some of their near-term needs. Over 100 mutually-supportive activities were designed as part of the project, which can be broadly categorised as follows: ${ }^{3}$

- Awareness and institution building to mobilise and organise community groups for project planning and implementation;

${ }^{3}$ Dougherty, B., A. Abusuwar and K.A. Razik. 2001. Sudan: Community-based rangeland rehabilitation for carbon sequestration and biodiversity. Report of the Terminal Evaluation, SUD/93/G31. UNDP GEF. 
- Training in a wide range of activities to build local capacity for project implementation and ensure project sustainability;

- Rangeland rehabilitation - including land management, livestock improvement, agroforestry and sand dune fixation - to prevent overexploitation and restore productivity of rangelands; and

- Community development activities to address immediate needs of communities by diversifying local production systems and income-generating opportunities, thereby reducing pressure on rangeland resources.

\subsubsection{Results}

The results of the CBRR management exceeded original expectations. For example, over 700 hectares of rangeland were improved, exceeding the 100 hectare goal. The rehabilitation of additional lands could be attributed to positive leakage, whereby additional communities undertook project activities after witnessing their early benefits. The project's short-term achievements included:

- Establishment of local institutions to coordinate community natural resource management and community development activities: Development on land-use master plans to guide future resource use and implementation of sustainable rotational grazing systems; and establishment of community mobilisation teams to conduct outreach and training

- Rangeland rehabilitation: Revegetation and stabilisation of five $\mathrm{km}$ of sand dunes to halt desert encroachment; construction of $195 \mathrm{~km}$ of windbreaks to protect 30 farms from soil erosion; and restocking of livestock by replacing goat herds with more resilient and less damaging sheep.

- Social organisation for livelihood diversification: Creation of water management sub-committees to better manage wells; establishment of 17 women's gardens to produce vegetables for household consumption, with surplus sold at local markets; establishment of five pastoral women's groups to support supplemental income generating activities including lamb fattening, handicrafts, milk marketing and cheese production.

- Preparation of a drought contingency plan.

\subsubsection{Relevance and link to climate change adaptation}

While originally conceived as a carbon sequestration project, the more immediate and long-term importance of the project was its effectiveness in increasing the capacity of people in the Gireigikh Rural Council to withstand drought. With improved land management and a more secure environmental and socio-economic asset base, communities were able to cope with climate stresses, establishing a solid foundation upon which to base climate change adaptation strategies. 


\subsection{Experience from Asia: Vietnam}

\subsubsection{Livelihood and climate context}

In Vietnam, tropical cyclones have caused considerable loss of livelihood resources, particularly in coastal communities. Although managing coastal resources has great social and economic importance, the country has a limited ability to protect coastal areas against weather hazards. In future decades, climate change may increase the frequency and severity of tropical storms, exacerbating conditions for the poor who already struggle to survive in a rapidly growing economy. Mangrove wetlands provide enhanced physical protection from storms and are a reservoir for carbon sequestration; they also provide a resource base for local livelihoods and income generation.

\subsubsection{Description of project}

Since 1994, the Vietnam National Chapter of the Red Cross has worked with local communities to plant and protect mangrove forests in northern Vietnam.

\subsubsection{Results and outputs}

Nearly 12,000 hectares of mangroves have been planted. The benefits have been staggering. Although planting and protecting themangrovescostapproximately US\$1.1 million, it saved US\$7.3 million per year in dike maintenance. During the devastating typhoon Wukong in 2000, project areas remained unharmed while neighbouring provinces suffered huge losses in lives, property and livelihoods. The Vietnam Red Cross estimates that some 7,750 families have benefited from mangrove rehabilitation. Family members can now earn additional income from selling crabs, shrimp and molluscs while increasing the protein in their diets. This increased physical protection against storm surges and enhanced livelihood security has reduced current vulnerability to climatic stresses and therefore built local capacity to adapt to the impacts of climate change. ${ }^{4}$

\subsection{Lessons learnt}

The three examples of community level 'adaptation' projects generate knowledge that is beneficial for the development of longer-term adaptation strategies. These lessons demonstrate that awareness of certain factors is crucial, including:

- Local livelihoods and vulnerabilities: knowing the assets that comprise peoples' livelihoods and the factors (including climate-related risks) that shape vulnerability to ensure the design of appropriate and locally-relevant project activities.

\footnotetext{
4. International Federation of Red Cross and Red Crescent Soeities, 2001. World Disasters Report: Focus on Reducing Risk. Geneva: IFRC.
} 
- The main climate risks in the region, both today and in the future: Information on current climate hazards is increasingly reaching the communities most affected but there is a gap in understanding and awareness on the projected climate change impacts. This calls for more research, awareness raising and better access to necessary information

- Community-driven implementation: emphasising the active participation of community members in the initiation, design, implementation and monitoring of project activities to secure community support and promote a strong sense of ownership.

- Community organisations: establishing or building upon social institutions - e.g., community self-help groups, women's groups and community water sub-committees - to carry out activities in a structured, participatory and efficient manner.

- Strong participation of women: recognising their role as household and community resource managers, promoting their active involvement in project activities to ensure the success and sustainability of achievements.

- Local training and capacity building: enhancing the local human resource base and the effectiveness of project activities by teaching community members a range of technical, financial and managerial skills.

- Blending of traditional and modern approaches: using local traditional knowledge to develop appropriate project activities.

- Reconciling short-term needs with long-term goals: investing in the long-term success of the project with activities that meet the immediate development needs of the community and build local capacity to sustain the EM\&R efforts.

- Supportive policy environment: working within broader policy frameworks that support de-centralised natural resource management and community development processes.

\section{Conclusions}

Although adaptation is not a new concept, unprecedented changes in climate call for more rapid and effective adaptation actions for those most vulnerable to climate-related impacts. Rural poor have learned to thrive in a variety of adverse conditions despite having scarce resources, and their living strategies aim at livelihoods that have high resilience and low sensitivity to shocks, stresses, and adverse trends. However, climate change impacts threaten the rural poor's adaptive capacity and ability to recover from shocks. Given the reliance of many of the world's poor on environmental services for their livelihoods, they are the most severely affected by deteriorating environmental conditions and factors limiting resource access. While absorbing sudden and extreme external shocks, rural poor systems may deplete their natural, physical, financial and human capitals. Designing climate change adaptation strategies thus become urgent for securing rural poor livelihoods. 
As poverty reduction is at the centre of climate change adaptation, poverty assessment can shed light on the design of locally relevant adaptation measures. Designing climate change adaptation requires a reliable comprehension of the vulnerability context, and rural poor local realities. The ability of vulnerable communities to cope with climate variability is largely determined by the way in which they conduct and secure their livelihoods. Therefore, identifying entry-points for adaptation strategies requires answering three key questions: (1) why are people vulnerable? (2) how do they cope? and (3) how might this change as a result of climate change? This knowledge can be developed through a four-step participatory process: identifying how livelihoods are conducted; identifying the main climate-induced vulnerabilities that affect livelihoods; identifying existing coping strategies; and identifying the needs and priorities of stakeholders in the face of climate-induced vulnerabilities. As the SLA is centred on the assets and capabilities that shape livelihoods while also considering the vulnerability context of the poor, it is recommended for answering the key questions in a reliable way.

Adaptation and poverty reduction should not be treated separately; they should be brought together under their common goal to secure livelihoods. Natural resources management may be a central strategy for rural poor adaptation as these resources are particularly important for the poorest livelihoods. Success stories of natural resource management originally intended to contribute to reducing poverty illustrate how to build resilience in rural poor settlements. This chapter has thus indicated that restoring or enhancing ecosystem services as well as diversifying local livelihoods achieves community resilience to shocks and trends such as climate variability. In such success cases, adaptation is already taking place by securing livelihoods through environmental/natural resource management, maintaining poor people's local safety nets as well as expanding their range of options for withstanding and recovering from disruptive shocks and trends. These lessons can be built into the elaboration of climate change adaptation strategies.

Finally, climate change adaptation rooted in reducing the vulnerability of the rural poor and building their resilience will represent win-win strategies not just for coping successfully with sudden external shocks, but also for improving the ability to build insurance strategies, and to change behaviour patterns in order to intensify short-term responses to crises. As making people's lives secure is closely related to poverty reduction, SLA is a useful framework for understand vulnerability and providing guidance on the design and assessment of relevant adaptation measures.

\section{References}

Angelsen, A., S. Wunder (2003) 'Exploring the Forest-Poverty link: key concepts, issues and research implications' CIFOR Occasional Paper No. 40., CIFOR: Bogor.

Ashley C., D. Carney (1999) Sustainable Livelihoods: Lessons from Early Experience

DFID: London. 
Ashley C. (2000) 'Applying Livelihoods Approaches to Natural Resource Management Initiatives: Experiences in Namibia and Kenya' Overseas Development Institute Working Paper 134, ODI: London.

Barnett, J. (2001) 'Adapting to Climate Change in Pacific Island Countries: The Problem of Uncertainty' World Development 29(6): 977-993.

Bebbington A. (1999) 'Capitals and Capabilities: A Framework for Analysing Peasant Viability, Rural Livelihoods and Poverty' World Development 27(12): 2021-2044.

Blaike, P., T. Cannon, I. Davis, B. Wisner (1994) At risk: natural hazards, people's vulnerability, and disasters Routledge: London.

Brock K. (1999) 'Implementing a Sustainable Livelihoods Framework for PolicyDirected Research: Reflections from Practice in Mali' IDS Working Paper No. 90, IDS: Brighton.

Burton, I., S. Huq, B. Lim, O. Pilifosova, E.L. Schipper (2002) 'From Impacts Assessment to Adaptation Priorities: The Shaping of Adaptation Policy' Climate Policy 2(2-3): 145-159.

Carney D., M. Drinkwater, T. Rusinov, K. Neefjes, S. Wanmali, N. Singh (1999) 'Livelihoods Approaches Compared. A brief comparison of the livelihoods approaches of the UK Department for International Development (DFID), CARE, Oxfam and the United Nations Development Programme (UNDP)' DFID's Sustainable Livelihoods Learning Platform, DFID: London.

Chambers R., G.R. Conway (1991) 'Sustainable Rural Livelihoods: Practical Concepts for the 21st century' IDS Discussion Paper 296. IDS: Brighton.

Chambers, R. (1983) Rural Development: Putting the Last First Longman: London.

Chambers, R. (1989) 'Editorial Introduction:Vulnerability, Coping and Policy'IDS Bulletin 20(2): 1-7.

Cutter, S. (1996) 'Vulnerability to Environmental Hazards' Progress in Human Geography 20(4): 529-535.

Devereux, S. (2002) 'Can Social Safety Nets Reduce Chronic Poverty?' Development Policy Review 20(5):657-675

DFID (Department for International Development) (1999). 'Sustainable Livelihoods Guidance Sheets' DFID: London.

Easterling III, W.E., B.H. Hurd, J.B. Smith (2004) 'Coping with Global Climate Change. The role of Adaptation in the United States' Pew Centre on Global Climate Change: Arlington.

Ellis, F. (2003) 'Human Vulnerability and Food Insecurity: Policy Implications' Theme Paper No. 3 Commissioned by Forum for Food Security in Southern Africa, ODI: London. Internet: http://www.odi.org.uk/food-security-forum/ docs/vulnerability_theme3.pdf

Ellis, F. (2000) Rural Livelihoods and Diversity in Developing Countries Oxford University Press: Oxford.

Hammill, A. (2004) 'Focusing on Current Realities. It's time for the impacts of climate change to take centre stage' IISD Commentary, IISD: Winnipeg.

Handmer, J., S. Dovers (1996) 'A Typology of Resilience: Rethinking Institutions for Sustainable Development' Industrial and Environmental Crisis Quarterly 9(4): 482-511. 
Hulme, D., A. Shepherd (2003) 'Conceptualizing Chronic Poverty' World Development 31(3): 403-423.

Hussein K. (2002) Livelihoods Approaches Compared: A Multi-Agency Review of Current Practice DFID and ODI: London.

IPCC (Intergovernmental Panel on Climate Change). 2001. Impacts, adaptation, and vulnerability to climate change: 2001, Third Assessment Report of the IPCC, University Press, Cambridge, UK.

IISD (International Institute for Sustainable Development) (2003) Livelihoods and Climate Change: Combining Disaster Risk Reduction, Natural Resource Management and Climate Change Adaptation in a new Approach to the Reduction of Vulnerability and Poverty IISD: Winnipeg.

Klein J.T., R.J. Nicholls, F. Thomalla (2003) 'Resilience to natural hazards: How useful is this concept?' Global Environmental Change Part B: Environmental Hazards 5(1-2): 35-45.

Krantz L. (2001) 'The Sustainable Livelihoods Approach to Poverty Reduction: An Introduction' SIDA (Swedish International Development Cooperation Agency) Division for Policy and Socio-Economic Analysis, SIDA: Stockholm.

Miltin, D. (2003) 'Addressing urban poverty through strengthening assets' Habitat International 27: 393-406.

O'Brien, K., S. Eriksen, A. Schjolden, L. Nygaard (2004) 'What's in a word?' CICERO Working Paper 2004:04, CICERO: Oslo.

OECD (Organization for Economic Co-operation and Development) (2001) The DAC Guidelines on Poverty Reduction OECD: Paris. Internet: http://www. oecd.org/dataoecd/47/14/2672735.pdf

Rakodi C. (1999) 'A Capital Assets Framework for Analysing Household Livelihood Strategies: Implications for Policy' Development Policy Review 17: 315-342.

Scoones I. (1998) 'Sustainable Rural Livelihoods: a Framework for Analysis' IDS Working Paper 72, IDS: Brighton.

Shankland A. (2000) 'Analysing Policy for Sustainable Livelihoods' IDS Research Report 49, IDS: Brighton.

Sperling, F. (ed.) (2003) Poverty and Climate Change: Reducing the Vulnerability of the Poor Through Adaptation World Bank: Washington D.C.

UNDP (UN Development Programme) (2003) User's Guide To The Adaptation Policy Framework, UNDP/GEF: New York. Internet: http://www.undp.org/ cc/pdf/APF/TP\%20final/Users_guidebook.qxp_09Sept04.pdf

Vogel, C., K. O'Brien (2004) 'Vulnerability and Global Environmental Change: Rhetoric and Reality' AVISO No. 13. Internet: http://www.gechs.org/aviso/ avisoenglish/thirteen_lg.shtml

World Bank (2001) World Development Report 2000/2001: Attacking Poverty Oxford University Press: Oxford. 


\section{Forests, adaptation and mitigation under the UNFCCC \\ A short note}

\section{Claudio Forner}

Center for International Forestry Research (CIFOR)

Jl. CIFOR, Situ Gede, Sindang Barang, Bogor Barat 16680, Indonesia.

Tel: +62 (251) 622622, Fax: +62 (251) 622100, E-mail: c.forner@cgiar.org

\section{Introduction}

The UN Framework Convention on Climate Change (UNFCCC) entered into force in 1994 with the objective of "stabilising greenhouse gas concentrations in the atmosphere at a level that would prevent dangerous anthropogenic interference with the climate system". Its objective also states that such a level "should be achieved within a time-frame sufficient to allow ecosystems to adapt naturally to climate change, to ensure that food production is not threatened and to enable economic development to proceed in a sustainable manner". These two sentences encompass the two main avenues for action under the UNFCCC: Mitigation, for any activity that either reduces emissions or enhances sinks of greenhouse gases, and Adaptation, for any action aimed at minimising the impacts of climate change. However, no explicit links between these two exist under the UNFCCC; in fact, policy development for each has occurred separately. One of the reasons behind this separation is that mitigation actions have been perceived as different in nature from those of adaptation. The first concentrates on technology options and policy frameworks to reduce emissions from transport, energy and land use, while the second focuses on actions needed to reduce or change the impacts of climate change. On the other hand, the principle of common but differentiated responsibilities, which governs the principles of the UNFCCC, implies that developed countries are responsible for most of the increase in greenhouse gases in the atmosphere (thus these countries should engage in mitigation), while developing countries will be facing most of the impacts from climate change (thus requiring adaptation). 
Commitments relating to both mitigation and adaptation are included in Article 4 of the UNFCCC. With regards to mitigation, these include the reporting of inventories (Article 4.1 (a)), the formulation of programmes to reduce emissions and enhance sinks (Article 4.1 (b)) and the development and transfer of technology (Article 4.1(c)). In addition, developed countries have taken the responsibility of adopting national policies to reduce emissions and enhance sinks in order to return to the emission levels of 1990 (Article 4.1 ( $a$ and b)).

Commitments relating to adaptation include the sustainable management and the conservation and enhancement of sinks and reservoirs (Article 4.1 (d)), cooperation in preparing for adaptation (Article 4.1 (e)) and the consideration of climate change when developing national policies (Article 4.1 (f)). Finally, developed countries have been requested to assist those countries that are particularly vulnerable to climate change (Article 4.4). The UNFCCC specifies the types of countries for which actions of finance, insurance and transfer of technology are needed in order to cope with the adverse effects of climate change (Article 4.8), including small islands, countries with low coastal and semi-arid areas and with fragile ecosystems, countries in areas prone to natural disasters, and others.

With the Kyoto Protocol, developed nations and economies in transition agreed to reduce greenhouse gas emissions to a level below 5\% of 1990 levels. Although some provisions on adaptation are found in its text, the Protocol is a mechanism particularly related to mitigation. With the Clean Development Mechanism (CDM), the Protocol has opened a window for developing countries to participate in mitigation activities; projects implemented in developing countries that reduce emissions or enhance sinks will generate offsets for developed countries to comply with their commitments.

\section{Forests and the UNFCCC}

Forests and forestry play a substantial role in the activities under the UNFCCC. On the mitigation side, deforestation contributes to the increasing levels of $\mathrm{CO}_{2}$ in the atmosphere while afforestation and reforestation contribute to sequestration of this gas. With regards to adaptation, forests could provide alternative livelihood opportunities as part of adaptation strategies.

The UNFCCC has acknowledged the role of forests in the carbon cycle and includes several references to 'sinks' and their role in mitigation (see Figure 1). Furthermore, forestry-related activities form part of the Kyoto Protocol, as developed countries will account emissions and removals of greenhouse gases resulting from afforestation, reforestation, deforestation and forest management. Afforestation and reforestation are also eligible activities under the CDM and, therefore, developing countries will benefit from forestry projects implemented to remove carbon from the atmosphere. 


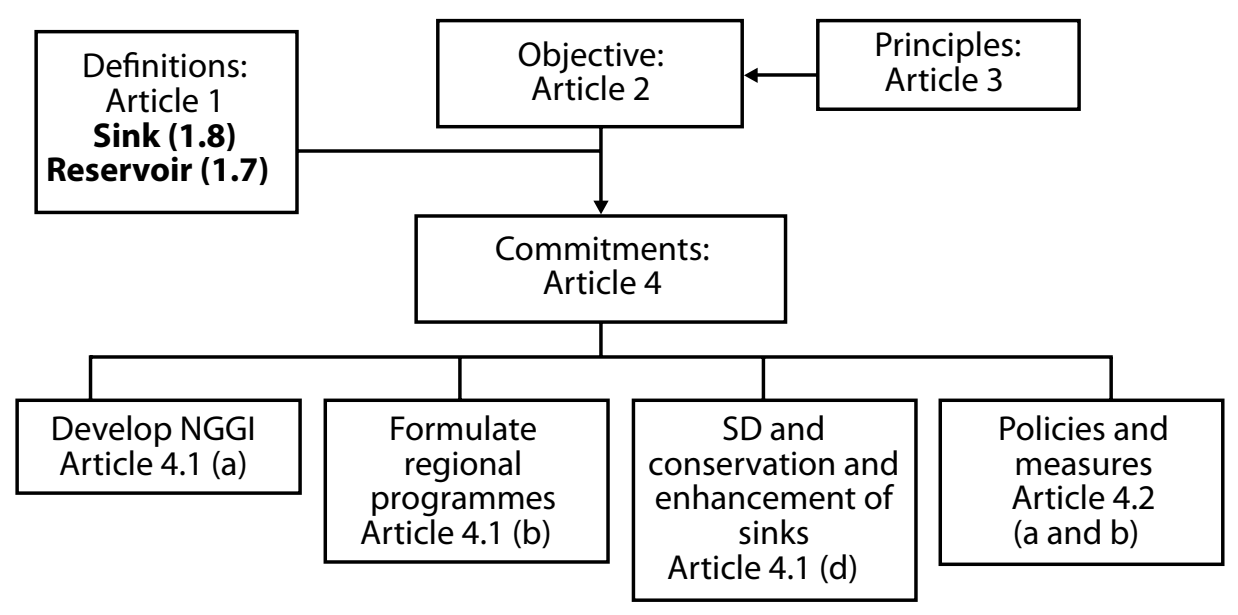

Figure 1. Forests in the UNFCCC

\section{Latest activities on adaptation and mitigation}

As stated above, policy development on adaptation and mitigation at the international level has been done separately and no strong or explicit links have been established by any decision of the Conference of the Parties to the UNFCCC. Activities on mitigation have been focused on the development of guidelines for reporting greenhouse gas inventories, the review of the information within these inventories and the implementation and reporting on policies and measures to reduce emissions and enhance sinks. These activities have been fuelled considerably by the Kyoto Protocol, the instrument toward which most of the efforts within climate change talks have been directed in the last years. In relation to forests, the development of rules for the Kyoto Protocol has been limited to the development of rules for afforestation, reforestation, deforestation and forest management, as defined by the relevant decision'.

On the adaptation side, activities have been more generic. Developing countries in particular have been engaged in the elaboration of national communications, where the component of assessing vulnerability has been emphasised. The least developed countries have received additional support for the process of drafting National Adaptation Programmes of Action (or NAPAs). Other activities relating to adaptation include guidance to the financial mechanism on which types of adaptation activities to fund, and activities related to capacity building. Relating to this last, the UNFCCC secretariat has been engaged in the compilation of methods and tools for assessing the impacts of, and vulnerability to, climate change ${ }^{2}$.

\footnotetext{
${ }^{1}$ See draft decision -/CMP.1, attached to decision 11/CP.7.

${ }^{2}$ see http://unfccc.int/program/mis/meth/index.html
} 
The most important political recent development on adaptation occurred at the tenth session of the Conference of the Parties in Buenos Aires (Argentina) at the end of 2004. This session launched the "Buenos Aires programme of work on Adaptation and response measures" (dec. 1/CP.10) to advance in the implementation of decision 5/CP.7. The decision requests the subsidiary body for scientific and technological advice to develop a five year programme which addresses the technical, scientific and socioeconomic aspects of adaptation. The SBSTA is expected to work on the compilation and dissemination of methodologies, tools and data to assess vulnerability, on proposals to assist countries in assessing vulnerability and on options to mainstream adaptation into sustainable development.

Latest developments on mitigation and forests include the completion of the guidelines for reporting greenhouse gas emissions by sources and removals by sinks resulting from land use, land-use change and forestry (LULUCF) ${ }^{3}$, based on the report by the IPCC entitled 'Good Practice Guidance for LULUCF'. These guidelines divide reporting into six land categories, one of them being forest land. Emissions from deforestation should also be identified in the reporting. Another important milestone is the adoption of the modalities and procedures for afforestation and reforestation projects under the CDM, which introduced the use of temporary credits and special requirements for the assessment of environmental and social impacts. Simplified modalities and procedures for small scale projects were also adopted by the tenth session of the COP and are expected to incentive the participation of low income communities in sequestration projects. On the practical side, theWorking Group on Afforestation and Reforestation of the Executive Board of the CDM has advanced in evaluating methodologies for AR-CDM project activities. This group has also elaborated a proposal for simplified methodologies for small-scale $A / R$ projects that will be discussed by COP 11 in Montreal. It is reasonable to expect that during 2006 a set of approved methodologies will be available for project developers and that the first projects will be registered leading to the issuance of temporary credits as an option to finance afforestation and reforestation.

In addition to the above, the process of national communications is ongoing. Most developing countries have submitted their initial one, and some are finalising their second communication. Literature on adaptation and vulnerability on forests and forestry is limited, as an emphasis has been on agriculture and water resources. Despite this lack of information, most Parties have included the assessment of the impacts of climate change on forests, and some relevant alternatives for adaptation. The analyses have been limited to the development of a climate scenario applied to the current situation of forests in order to develop future scenarios (e.g., using Holdridge life zones). Most countries have followed the Intergovernmental Panel on Climate Change guidelines or the UN Environment Programme handbook for this purpose.

\footnotetext{
${ }^{3}$ See decision $13 /$ CP.9
} 
Little analysis has been undertaken on the feedbacks of climate change, on the analysis of disturbances such as pests and fires, and very little is found on the vulnerability at the social, economic and environmental levels. It is not clear to what extent vulnerability and adaptation issues have been taken into account in national forest plans.

\section{Box 1. Four examples of forests in national communications}

Costa Rica: Developed three climatic scenarios (optimist, pessimist and moderate) in order to forecast a future map of forests. Results show a diminishing topical lifezone. No conclusions were drawn for the forestry sector.

Bolivia: The study took as a starting point the fragmentation of ecosystems as the main problem occurring in Bolivia. Climatic scenarios were applied to existing forest maps, which show that both tropical and sub-tropical wet forests will be the most affected by climate change.

Congo: The analysis was limited to the effects of salinisation on the ecosystems lying on coastal zones. Some analysis on fires was included.

Malaysia: This country presents a more forestry-directed analysis of the effects of climate change in the production of oil from palm plantations, timber and rubber. Both the increment in precipitation and temperatures are expected to decrease the overall productivity of agroforestry systems.

With respect to financing, after the Global Environmental Facility (GEF), as the UNFCCC's main funding body, presented its strategy on adaptation, the GEF was also requested to begin the strategy's operationalisation. Funding for adaptation activities can be obtained where sufficient information is available to enable activities to be carried out with significant adaptation benefits, such as in the areas of land management and fragile ecosystems, and will be available for those Parties that have identified their priorities in their national communications.

It is likely that linking adaptation with mitigation will be directly pursued by each country within the activities of implementation of the UNFCCC; although some Parties have expressed the importance of this linkage, climate change talks have not reached a stage in which this could be taken up. In the meantime, a window for work on adaptation and mitigation was open in the twentieth session of the UNFCCC's Subsidiary Body for Scientific and Technological Advice (SBSTA), where two new agenda items were created: (i) scientific, technical and socio-economic aspects of the impacts of, and vulnerability and adaptation to, climate change, and (ii) scientific, technical and socio-economic aspects mitigation. Topics to be addressed within these two agenda items will include sustainable development, opportunities and solutions for adaptation, and vulnerability and risk. 


\section{Some issues for consideration}

The climate change process has produced an important amount of decisions to guide activities of adaptation and mitigation in both developing and developed countries. This process is at a stage in which Parties need to engage in the implementation of these decisions at the national and sub-national levels. Opportunities for linking adaptation and mitigation may be identified during the planning phase of this stage.

For example, scientists have called attention to the possible feedbacks of climate change on the carbon dynamics of ecosystems, as well as to the limits to the growing stocks. On the one hand, it is likely that increasing temperatures and diminishing rainfall may cause an increase of emissions by soils; on the other, it is expected that the capacity of forests to sequester carbon will be reduced and eventually stop once the systems reach saturation. Links between adaptation and mitigation are clear because the impacts of climate change will limit mitigation activities in the future, and may even exacerbate climate change as a consequence of the increased emissions.

On the other hand, the implementation of forestry projects has potential to contribute to adaptation, for instance the recovery of degraded forests or establishment of new ones could provide barriers for extreme climatic events or prevent soil erosion, while at the same time prevent a specific amount of carbon to be released into the atmosphere. At the same time, the possibility of establishing forests for the production of wood provides an economic alternative for local communities and reduces the pressure on natural forests. The protection of forests could be funded under the activities of adaptation, while the establishment of new forests via the CDM is another opportunity for both carbon sequestration and adaptation.

The extent to which forests could be effective as adaptation and mitigation measures depends on many factors such as the capacity of locals to design and implement forestry projects. For this reason, capacity building is required both for mitigation and adaptation that is specifically directed at the design and implementation of forestry projects; particular emphasis should be on how to design projects so that the social, economic and environmental dimensions are considered within.

In addition, impacts of climate change over forests are not well understood, nor are the full range of alternatives that forests offer in terms of adaptation strategies, and research is required to increase understanding of these issues. Likewise, research organisations could engage in the question of how forestry projects could contribute to adaptation.

From an institutional perspective, national policies and programmes, included those relating to forests, need to take into account both mitigation and adaptation activities. Work in these areas should build upon existing frameworks (for example, the UNDP/GEF Adaptation Policy Framework) and thus reinforce knowledge needed to design and implement these frameworks. 


\title{
Opportunities for linking adaptation and mitigation in agroforestry systems
}

\author{
Louis V. Verchot ${ }^{1 *}$, Jens Mackensen ${ }^{2}$, Serigne Kandji', \\ Meine van Noordwijk ${ }^{3}$, Tom Tomich ${ }^{1}$, Chin Ong ${ }^{1}$, \\ Alain Albrecht ${ }^{4}$, Cynthia Bantilan ${ }^{5}$, K.V. Anupama ${ }^{5}$ \\ and Cheryl Palm ${ }^{6}$
}

\author{
1. World Agroforestry Centre (ICRAF) \\ United Nations Avenue, P.O. Box 30677, Nairobi, Kenya. E-mail: I.verchot@cgiar.org \\ 2. German Development Bank (KfW), Berlin, Germany. \\ 3. ICRAF-Southeast Asia Regional Office, JI. CIFOR, Sindang Barang, Bogor, Indonesia. \\ Tel: +62 251 625415/17, Fax: +62 251 625416, Email: m.van-noordwijk@cgiar.org \\ 4. Institut de Recherche pour le Développement (IRD) and ICRAF, \\ United Nations Avenue, P.O. Box 30677, Nairobi, Kenya \\ 5. International Crops Research Institute for the Semi-Arid Tropics (ICRISAT) \\ Patancheru 502 324, Andhra Pradesh, India \\ 6. Senior Research Scientist, Tropical Agriculture Program, Columbia Earth Institute, \\ 405 Low Library, MC 4335, 535 West 116th Street, New York, NY 10027 USA. \\ E-mail: cpalm@iri.columbia.edu \\ *Corresponding author
}

\section{Introduction}

There is increasing acceptance that even very ambitious climate change mitigation measures, which would go beyond the current international climate agreements, would not be sufficiently effective to halt the increase of atmospheric greenhouse gas concentrations in the medium term and that therefore adaptation measures are as needed as mitigation measures.

The impact of climate change will be affecting developing countries more severely than developed countries not the least because of their generally low adaptive capacities (IPCC, 2003). In these countries, the agricultural sector will be among the most vulnerable putting rural populations at large risks. At the same time, we recognise that climate change is yet an additional threat to urgent rural development demands including food security improvement, poverty reduction and provision of an adequate standard of living for growing populations. Much effort will be needed to integrate what is known about 
climate change response measures into national development planning (Abeygunawardena et al., 2003).

Within the UN Framework Convention on Climate Change (UNFCCC) negotiation process, the development of mitigation and adaptation activities has been dealt with largely as separate matters (see Forner, this volume). Carbon sequestration through land use, land-use change and forestry (LULUCF) as a measure for mitigating climate change has been a very contentious issue during recent international climate negotiations. However, agreements have been made on the modalities and procedures for LULUCF climate projects, which offer, inter alia, opportunities for agroforestry activities under the Clean Development Mechanism (CDM). Adaptation, on the other side, was only recently given more recognition as an important and self-standing topic as expressed, for instance, in the 'Delhi Ministerial Declaration on Climate Change and Sustainable Development' of UNFCCC COP-8 in 2002.

The discussion on the potential synergies between adaptation and mitigation measures is therefore just only starting and the debate is all too often for political reasons reduced to a discussion of the costs of global adaptation versus global mitigation. A practical understanding of the link between adaptation and mitigation measures particular in LULUCF does not yet exist.

However, research in the agricultural sector has focused for some decades now on the need to cope with adverse and irregular climatic conditions including rainfall variability or shifting weather patterns, in particular in the world's arid and semi-arid areas. Equally, years of agricultural research have focused on improving the productivity of agricultural systems leading to the understanding that increasing, for instance, soil carbon stocks is essential for an enhanced productivity.

\section{Expected climate change impacts on resilience and productivity of agro-ecosystems}

Climate change will add additional stress to an already overtaxed system. The risk of losing the gains of the Green Revolution, which has largely eliminated the famines of the 1950s and 1960s, is real. Populations of developing countries, particularly in South Asia and sub-Saharan Africa, continue to grow at high rates, while the extent of harvested areas has stagnated or is decreasing in many grain producing areas of the world (Mann, 1997). To feed everyone adequately, world food production will have to double within the next 30 years (Cleaver and Schreiber, 1994). But, the shortfall in domestic cereal production in the developing world is expected to widen from around than 100 million tons in 1997 to around 190 million tons in the year 2020 (Rosegrant et al., 2001). In many regions of the world, there will be a limited ability for new varieties and increased fertilizer use to further increase yields (Huang et al., 2002). On top of this, degradation of soil and water resources has reached alarming proportions (Vasil, 1998; Smaling et al., 1997) and will undermine future efforts to boost agricultural productivity. 
Several modelling studies that combine spatial analysis with an analysis of the physiological effects of changes in carbon dioxide $\left(\mathrm{CO}_{2}\right)$, rainfall and temperature have been done in South Asia to assess the impact of climate change on crop production (Aggarwal and Sinha, 1993; Rao and Sinha, 1994; Kropff et al., 1996; Berge et al., 1997; Saseendran et al., 2000; Aggarwal and Mall, 2002). These studies have shown a decrease in the growing season and yield of most crops as temperature increases. Such reductions were only partially offset by a positive response to increased $\mathrm{CO}_{2}$ concentrations.

An analysis of maize production in the tropics by Jones and Thornton (2003) suggests that maize production in the tropics will decline by $10 \%$ on average. However, this figures masks large variations. For example, the Sahel and southern Africa regions are likely to suffer disproportionately, while the East Africa highlands are likely to enjoy increased productivity.

Climate change will have also a direct effect on water storage, putting increased stress on water availability for irrigation. Furthermore diseases and insect populations are strongly dependent upon temperature and humidity, and changes could alter their distributions and virulence.

\section{Agroforestry and climate change mitigation}

A wide range of studies (IPCC, 2000; Albrecht and Kandji, 2003; Palm et al., 2005) have substantiated the fact that agroforestry systems, even if not primarily designed for carbon sequestration, present a unique opportunity to increase carbon stocks in the terrestrial biosphere (Table 1). The quantitative importance of agroforestry as carbon sink derives from wide applicability in existing agricultural systems. Worldwide it is estimated that $630 \times 10^{6}$ hectares are suitable for agroforestry (see also Figure 1).

Table 1. Potential carbon storage for agroforestry systems in different ecoregions of the world (Winjum et al., 1992; Dixon et al., 1993; Schroeder, 1993; Krankina and Dixon, 1994; Albrecht and Kandji, 2003)

\begin{tabular}{llll}
\hline & Eco-region & System & Mg C ha $^{-1}$ \\
\hline Africa & humid tropical high & agrosilvicutural & $29-53$ \\
\hline South America & humid tropical low & agrosilvicutural & $39-102^{\text {a }}$ \\
& dry lowlands & & $39-195$ \\
\hline Southeast Asia & humid tropical & agrosilvicutural & $12-228$ \\
& dry lowlands & & $68-81$ \\
\hline Australia & humid tropical low & silvopastoral & $28-51$ \\
\hline North America & humid tropical high & silvopastoral & $133-154$ \\
& humid tropical low & silvopastoral & $104-198$ \\
& dry lowlands & silvopastoral & $90-175$ \\
\hline Northern Asia & humid tropical low & silvopastoral & $15-18$ \\
\hline
\end{tabular}

${ }^{\text {a }}$ Carbon storage values were standardised to 50-year rotation. 


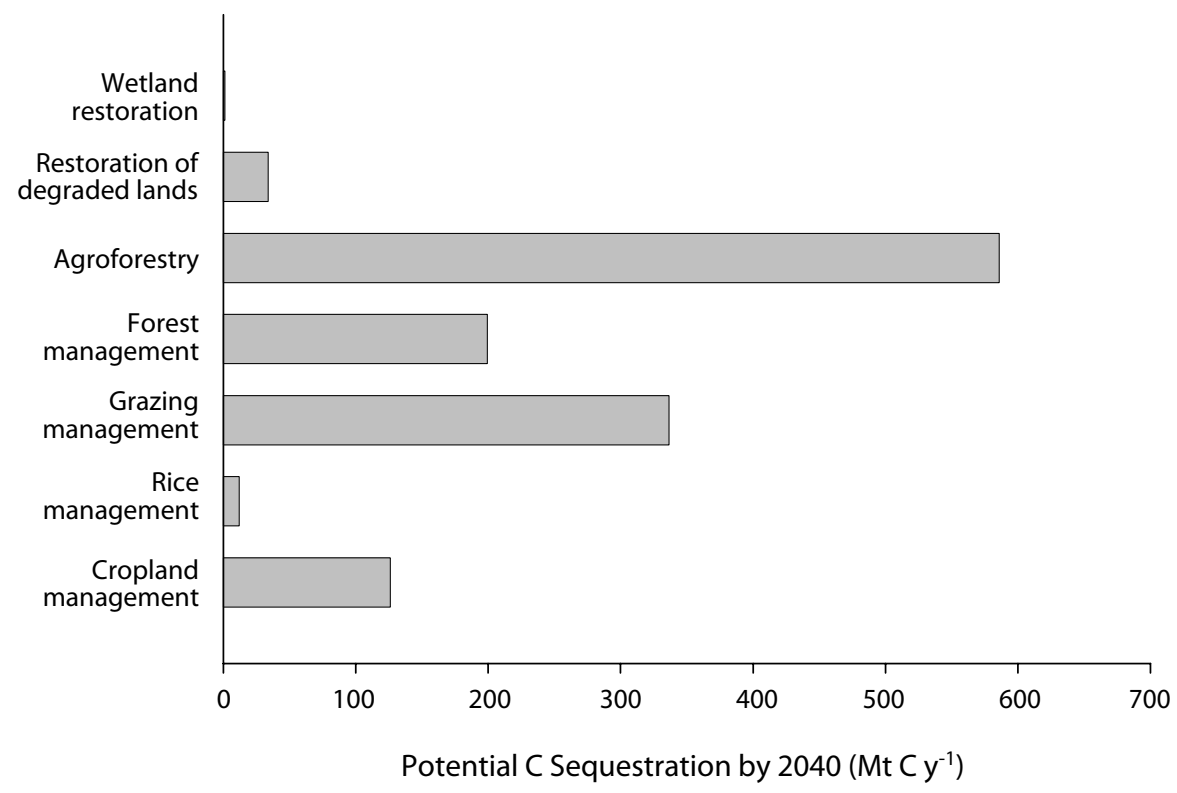

Figure 1. Carbon sequestration potential of different land use and management options (adapted from IPCC, 2000)

Agroforestry practices in the humid tropics are part of a continuum of landscapes ranging from primary forests and managed forests to row crops or grasslands. Figure 2 compares carbon storage in some land-use systems along this continuum. Using the time-averaged method (rotational agroforestry systems are characterised by a succession of harvest and regrowth periods), it has been shown that the conversion of primary tropical forests to agriculture or grassland results in the loss of about $370 \mathrm{Mg}$ of carbon per hectare. Managed or logged forests have about half the carbon stocks of primary forests. Agroforestry systems contain 50 to $75 \mathrm{Mg}$ of carbon per hectare compared to row crops that contain less than $10 \mathrm{Mg}$ of carbon per hectare. The difference in carbon content between both systems indicates the mentioned potential for agroforestry systems to store additional carbon, however, possible tradeoffs between carbon storage and profitability in agroforestry systems have to be taken into account (Gockowski et al., 2001). As shown in Figure 3, land-use systems that maximise both carbon and profit (win-win options) are not realistic. Therefore, climate change mitigation through agroforestry should be based on the promotion of no-regret or win-win options, which would allow medium to high profit while storing an acceptable, rather than a maximum level of carbon in the system.

Distinct from simultaneous crop-tree systems are improved fallow systems that improve nutrient depleted soils and otherwise degraded land. Improved fallow is undoubtedly one of the most promising agroforestry technologies in the sub-humid tropics and has, in recent years, shown great potential for adoption in southern and eastern Africa. Even in drier areas such as the Sudan- 


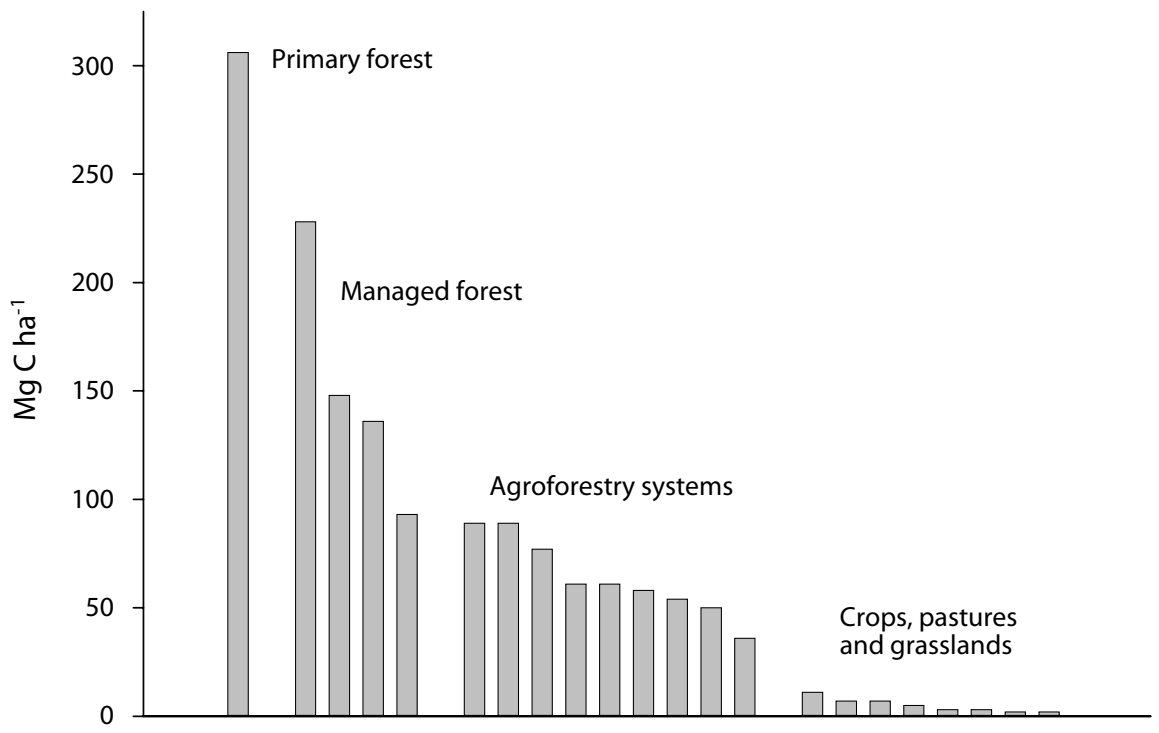

Figure 2. Summary of carbon stocks in different ecosystems of the humid tropics. Data are from the benchmark sites of the Alternatives to Slash and Burn Programme of the Consultative Group for International Agricultural Research (CGIAR)

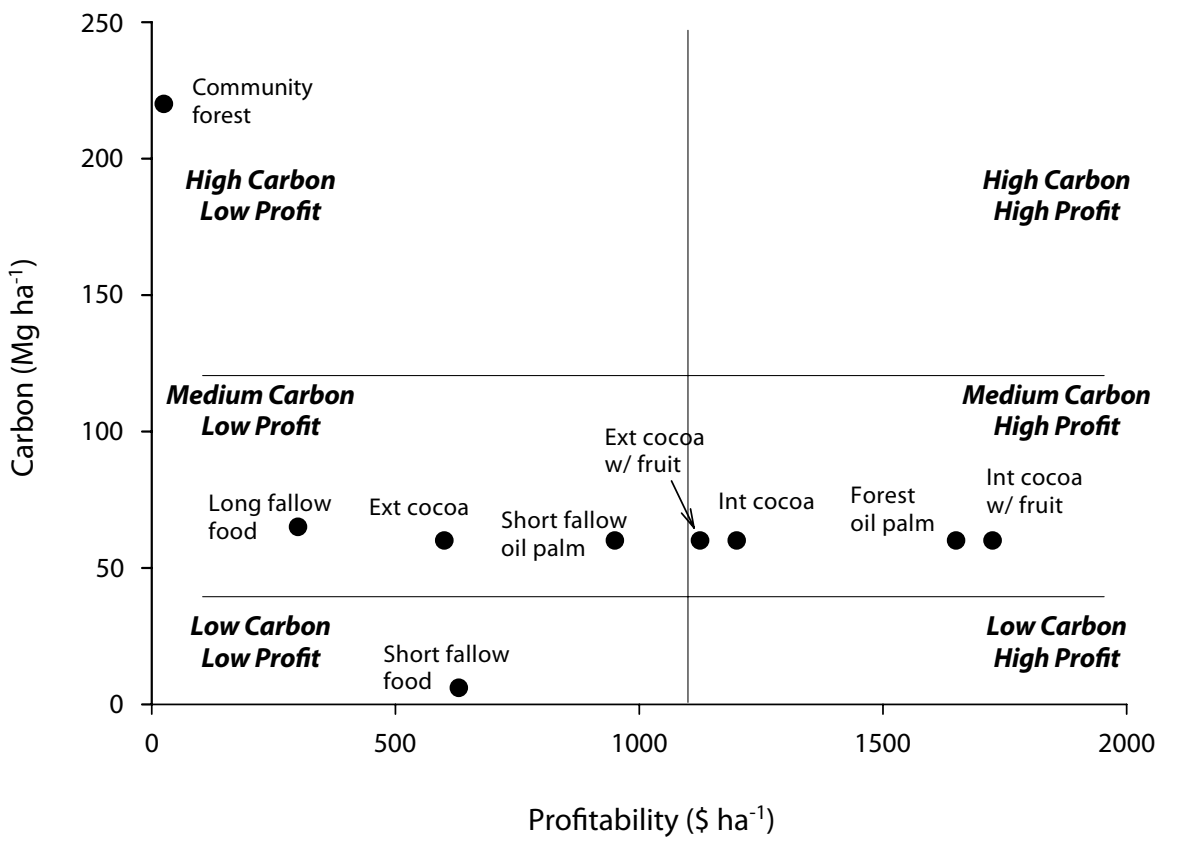

Figure 3. Tradeoffs between carbon stocks and social profitability of land use systems in Cameroon (adapted from Gokowski et al., 2001) 
Sahel zone of West Africa, recent field experiments have shown that the technology could significantly contribute to curbing land degradation and improving farm productivity. Unlike the more perennial systems in the humid tropics, improved fallows are mostly short-rotation and as such sequester much less carbon aboveground. Nevertheless, if the time-averaged aboveground carbon is considered, they store substantial quantities of carbon compared to degraded land, croplands or pastures (Table 2).

Table 2. Carbon stocks $\left(\mathrm{Mg} \mathrm{ha}^{-1}\right)$ in improved fallow systems (adapted from Albrecht and Kandji, 2003, and assuming that biomass is 47\% C) ${ }^{\mathrm{b}}$

\begin{tabular}{lcccc}
\hline Fallow species & Aboveground & Belowground & C in fine root & Total C \\
\hline 12-month-old fallows & & & & \\
\hline Crotolaria grahamiana & 4.0 & 1.3 & - & 5.3 \\
\hline Calliandra calothyrsus & 9.9 & 3.3 & - & 13.2 \\
\hline Cajanus cajan & 4.0 & 1.8 & - & 5.8 \\
\hline Senna spectabilis & 3.3 & 2.3 & - & 5.5 \\
\hline Sesbania sesban & 6.7 & 3.4 & - & 10.1 \\
\hline Tephrosia vogelii & 5.1 & 1.9 & - & 7.0 \\
\hline 18-month-old fallows & & & & \\
\hline Crotalaria grahamiana & 11.6 & 5.1 & 3.0 & 19.7 \\
\hline Crotolaria paulina & 9.3 & 6.4 & 1.7 & 17.4 \\
\hline Tephrosia candida & 14.6 & 15.6 & 1.7 & 31.9 \\
\hline 22-month-old fallows & & & & \\
\hline Calliandra calothyrsus & 12.7 & 7.3 & 1.3 & 21.3 \\
\hline Sesbania sesban & 17.3 & 5.1 & 1.1 & 23.5 \\
\hline Grevillia robusta & 15.3 & 8.3 & 1.3 & 25.0 \\
\hline Eucalyptus saligna & 20.4 & 9.0 & 1.1 & 30.5 \\
\hline Soll was notincludin
\end{tabular}

${ }^{\mathrm{b}}$ Soil $\mathrm{C}$ was not included in the calculation of $\mathrm{C}$ stocks.

Several studies on soil carbon dynamics have indicated increased soil organic matter after a few seasons of tree planting on degraded soils. The examples used in Table 3 mainly come from on-farm trials conducted in the sub-humid tropics of Togo and Kenya. A wide range of tree species have been tested with various degrees of success. Soil organic carbon accretions through improved fallow were estimated between $0.73-12.46 \mathrm{Mg}$ per hectare depending on sampling depth.

If carbon fluxes in agroforestry systems are well documented, we have a much poorer understanding of the effects of these improved practices on non- $\mathrm{CO}_{2}$ greenhouse gases. In the case of nitrous oxide $\left(\mathrm{N}_{2} \mathrm{O}\right)$ emissions, much depends on the presence or absence of legumes in agroforestry system. For example in Sumatra, a jungle rubber system was shown to have lower $\mathrm{N}_{2} \mathrm{O}$ emissions compared to a primary forest, but also lower methane $\left(\mathrm{CH}_{4}\right)$ uptake (Tsuruta et al., 2000). However, the relationship might be different in agroforestry systems that include nitrogen-fixing species. For example, multi-story coffee with a leguminous tree shade canopy in Sumatra had $\mathrm{N}_{2} \mathrm{O}$ emissions five times 
Table 3. Soil organic carbon $(\mathrm{SOC})$ increase in a few tropical soils following improved fallows with different tree species in the sub-humid tropics

\begin{tabular}{|c|c|c|c|c|c|}
\hline Country & $\begin{array}{l}\text { Fallow } \\
\text { duration } \\
\text { (years) }\end{array}$ & Soil type & Fallow species & $\begin{array}{l}\text { Sampling } \\
\text { depth }\end{array}$ & $\begin{array}{l}\text { SOC } \\
\text { increase } \\
\left(\mathrm{Mg} \mathrm{ha}^{-1}\right)\end{array}$ \\
\hline Togo & 5 & $\begin{array}{l}\text { Ferric Acrisol } \\
\text { (sandy) }\end{array}$ & $\begin{array}{l}\text { Acacia } \\
\text { auriculiformis, } \\
\text { Albizzia lebbek, } \\
\text { Azadirachta indica, } \\
\text { Cassia siamea }\end{array}$ & $0-10 \mathrm{~cm}$ & $\begin{array}{l}3.41 \\
-12.46\end{array}$ \\
\hline Kenya & 1.5 & $\begin{array}{l}\text { Arenosol } \\
\text { (sandy) }\end{array}$ & $\begin{array}{l}\text { Crotalaria } \\
\text { grahamiana, } \\
\text { C. paulina }\end{array}$ & $0-20 \mathrm{~cm}$ & $1.69-2.15$ \\
\hline Kenya & 1.5 & $\begin{array}{l}\text { Ferralsol } \\
\text { (clayey) }\end{array}$ & $\begin{array}{l}\text { C. grahamiana, } C \text {. } \\
\text { paulina, Tephrosia } \\
\text { vogelii }\end{array}$ & $0-20 \mathrm{~cm}$ & $2.58-3.74$ \\
\hline Kenya & 1 & $\begin{array}{l}\text { Ferralsol } \\
\text { (clayey) }\end{array}$ & $\begin{array}{l}\text { Cajanus cajan, } \\
\text { Leucaena } \\
\text { leucocephala, } \\
\text { Sesbania sesban }\end{array}$ & $0-30 \mathrm{~cm}$ & $0.73-8.34$ \\
\hline
\end{tabular}

higher than open-grown coffee and about half the $\mathrm{CH}_{4}$ uptake (Verchot et al., unpublished data). In Peru, agroforestry systems (multi-strata coffee and a peach palm plantation) with leguminous cover crops had lower $\mathrm{N}_{2} \mathrm{O}$ emissions than both intensive and low-input agriculture, and similar emissions to a nearby secondary forest (Palm et al., 2002). Soil uptake of $\mathrm{CH}_{4}$ was similar to other landuse systems, with the exception of the intensive agriculture site, which became a net source to the atmosphere.

It is apparent from the case studies above that the agroforestry systems, which promote the use of legumes as fertilizer or shade trees, may increase $\mathrm{N}_{2} \mathrm{O}$ emissions compared to unfertilized systems. Similarly, tree-based systems that encourage the introduction and development of livestock farming may contribute to increasing $\mathrm{CH}_{4}$ emissions. While efforts should be made to minimise the emission of these trace gases, what ultimately matters in terms of climate change mitigation is how these emissions compare to the amount of carbon sequestered in these agroforestry systems. For example, in an improved fallow system in Zimbabwe, $\mathrm{N}_{2} \mathrm{O}$ emissions were found to be almost 10 times those of unfertilized maize (Chikowo et al., 2003), but these levels were still extremely low in comparison to the amount of carbon stored. Therefore, despite the likelihood of accrued trace gas emissions in some cases, most agroforestry systems are likely to be net greenhouse gas sinks because of the important amount of carbon they can store in the living plant biomass, in the soil and in durable wood products. 
It is also worth to note that the financial cost of carbon sequestration through agroforestry appear to be much lower (approximately $\$ 1-69 / \mathrm{Mg}$ of carbon, median $\$ 13 / \mathrm{Mg}$ of carbon) than through other $\mathrm{CO}_{2}$ mitigating options. Economic analyses showed that these costs could be easily offset by the monetary benefits from agricultural and tree products.

Beyond the apparent mitigation effects of agroforestry systems as outlined above, agroforestry offers a potential as biomass energy provider. Producing firewood from arable or grazed land presents interesting opportunities in $\mathrm{CO}_{2}$ mitigation through the substitution of fossil energy consumption by using wood as energy sources and the protection of existing forests and other natural landscapes. Adequate understanding of these secondary effects of agroforestry with regards to $\mathrm{CO}_{2}$ mitigation will require more research.

\section{Enhancing adaptive capacity through agroforestry}

The effects of different agroforestry techniques in enhancing the resilience of agricultural systems against adverse impacts of rainfall variability, shifting weather patterns, reduced water availability, soil erosion as well as pests, diseases and weeds is been well tested. Much of this knowledge is relevant for mainstreaming adaptation measures to climate change into the agricultural sector. As adaptation is yet developing as science, the role of agroforestry in reducing the vulnerability of agricultural systems (and the rural communities that depend on them for their livelihood) to climate change or climate variability should be more strongly emphasised.

Rainfall variability is a major cause of vulnerability in many areas of the tropics, especially in the semi-arid regions. However, its effects are often exacerbated by local environmental degradation. In reality, vulnerability in many of these fragile ecosystems is often the result of a degenerative process due a combination of factors (deforestation, continuous cropping and overgrazing), which, when associated with extreme climate, represents a major setback for agricultural and economic development. Therefore, curbing land degradation can play an important role in mitigating the negative impacts of climate change/variability, and that is where agroforestry can be a relevant practice.

A successful and well-managed integration of trees on farms and in agricultural landscapes inevitably results in diversified and sustainable crop production, in addition to providing a wide range of environmental benefits. Systems such as hedgerow intercropping and boundary plantings are effective in protecting soils from erosion and restoring some fertility in degraded lands. In western Kenya, the World Agroforestry Centre, in collaboration with the Institut de Recherche pour le Développement (IRD) and Kenyan national agricultural research services, has tested the potential of improved fallow for controlling soil erosion, using fast growing shrubs such as Crotalaria grahamiana and Tephrosia spp. These species showed great promise in reducing soil losses (Figure 4). Soil protection through improved fallow is a process that starts right from the fallow period when tree cover reduces soil battering by raindrops, but continues way 


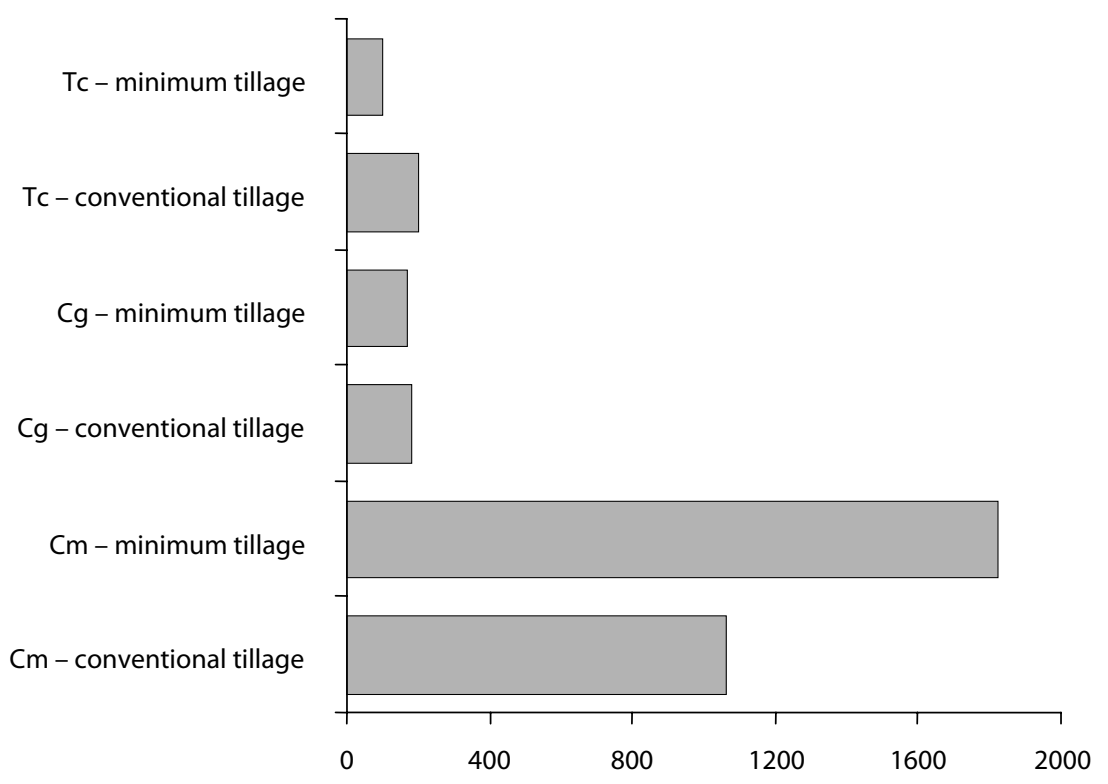

Figure 4. Effect of improved fallow on soil erosion in the long rains (MarchJuly) of 2003, Luero, western Kenya (data from Boye, unpublished)

The total rainfall for the season was $871 \mathrm{~mm}$

Legend: $\mathrm{Cm}=$ continuous maize; $\mathrm{Cg}=$ Crotalaria grahamiana; $\mathrm{Tc}=$ Tephrosia candida

NB: Soil loss is resultant of both runoff and turbidity (the solid load of the runoff water). The substantial decrease in soil loss due to improved fallow (nine times less than continuous cropping) is explained by the fact that : (1) runoff was higher and therefore infiltration lower in the continuous crop situation and (2) turbidity was higher in the continuous crop situation than in the improved fallows.

after fallow clearance thanks to the improvement of soil structure (increased soil organic matter, formation of water-stable aggregates, better soil cohesion and aeration, and improved water infiltration).

Improved infiltration of water, while reducing runoff and transportation of sediments, also has a direct effect on water storage in the soil. Studies on water dynamics in a maize field in western Kenya showed that, after a rainfall event, soil moisture accumulates much faster under improved fallow than under maize crop and natural fallow. In addition, the improvement of the soil structure and the soil organic matter allows the water to be stored much longer in the improved systems than in the continuous maize during a dry period (Figure 5). The implication is tremendous from an agronomic point of view. If rainfall is scarce, then crops that follow an improved fallow are likely to have a better water supply than those which follow another crop. We now understand that climate change in many areas, especially in semi-arid regions, will translate into 


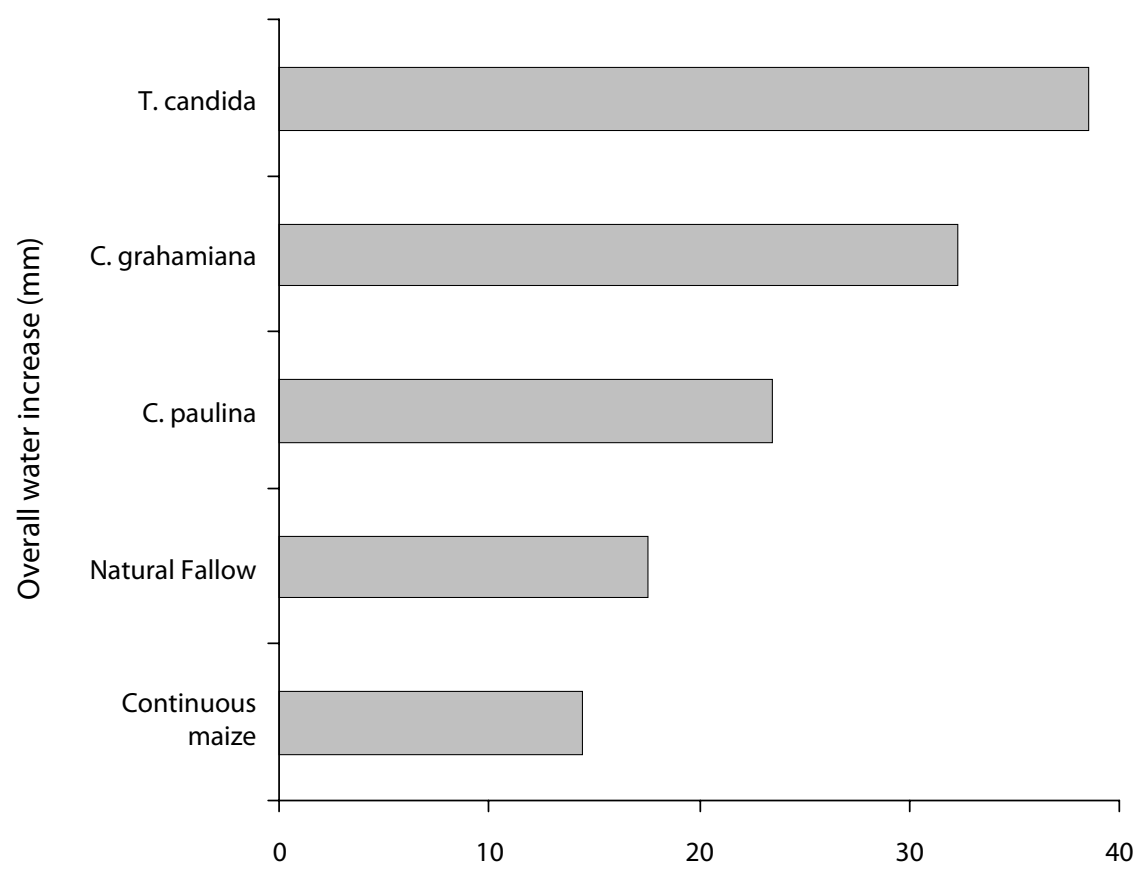

Figure 5. Change in soil water stocks (0-60 cm depth) in a western Kenyan soil under continuous maize, natural fallow and improved fallow systems (data from Orindi, 2002)

a reduced total rainfall or an increased occurrence of dry spells during rainy seasons. Therefore, optimising the use of increasingly scarce rainwater through agroforestry practices such as improved fallow could be one effective way of improving the adaptive capacity of systems to climate change.

Under many farmer practices in Africa, crops fail completely or yield very little in drought years. Yet, recent results from improved trials suggest that it would be possible to produce an acceptable amount of food in low rainfall years if practices such as improved fallows were pursued. Such a scenario was observed in an experiment in Malawi (Table 4). As expected, maize production was higher after improved fallow than in a continuous cropping system in good rainfall years (962-1017 $\mathrm{mm}$ ). A similar trend was observed in low rainfall years $(<600 \mathrm{~mm}$ ). More interestingly, maize yield after Sesbania sesban in a low rainfall year was even higher than maize yield in the continuous cropping in a good rainfall year. If we use rainfall use efficiency (RUE) as the amount of maize (in $\mathrm{kg}$ ) produced with each millimetre of rainwater, then apparently, the maize crop after improved fallow made better use of rainfall than the continuous crop, especially in low rainfall years (Table 4).

The fact that improved fallows have the ability to maintain yields under adequate water supply is nothing new and indeed has been widely linked to an improvement in the physical, chemical and biological properties of soils. In low rainfall years, however, water availability is paramount and seems to 
be the dividing factor between absolute crop failure and reasonable food production. Buffering agricultural crops against water deficiencies is, therefore, an important function that agroforestry would have to play in the adaptation battle, but there are also other mechanisms such as improved micro-climate and reduced evapotranspiration through which agroforestry practices may improve the adaptive capacity of agroecosystems in the occurrence of extreme climate. For example, a study on a Faidherbia albida - millet parkland system in Niger demonstrated that shade-induced reduction of soil temperatures, particularly at the time of crop establishment, contributes to the better growth of millet under trees (Vandenbeldt and Williams, 1992). Also, Jonsson et al. (1999) measured temperatures, photosynthetically active radiation (PAR) and millet biomass under and away from tree canopies in a parkland system. The results showed that despite the heavy shading by Shea butter tree (Vitellaria paradoxa), known in the Sahel as karité and Parkia biglobosa (or néré), millet biomass was similar under these trees and the open plots away from tree canopy (Table 5). The absence of yield penalty under trees is explained by the fact that millet seedlings under tree canopies experienced only 1-9 hours per week of supra-

Table 4. Grain yield ( $\mathrm{kg} \mathrm{ha}^{-1}$ ) and rainfall use efficiency (RUE) of maize in continuous maize and improved fallow (Sesbania sesban) systems in Makoka, Zambia

\begin{tabular}{lccccccccccc}
\hline & $\begin{array}{c}\text { Season 1 } \\
(\mathbf{1 0 0 1} \mathbf{m m})\end{array}$ & $\begin{array}{c}\text { Season 2 } \\
(\mathbf{1 0 1 7} \mathbf{m m})\end{array}$ & $\begin{array}{c}\text { Season 3 } \\
(\mathbf{5 5 1} \mathbf{m m})\end{array}$ & $\begin{array}{c}\text { Season 4 } \\
(\mathbf{9 6 2} \mathbf{m m})\end{array}$ & $\begin{array}{c}\text { Season 5 } \\
(\mathbf{5 2 2} \mathbf{m m})\end{array}$ \\
\hline & Maize & IF & Maize & IF & Maize & IF & Maize & IF & Maize & IF \\
\hline Grain yield & 990 & 1100 & 1300 & 2400 & 600 & 1850 & 1100 & 2300 & 500 & 1180 \\
\hline RUE & 0.99 & 1.10 & 1.28 & 2.36 & 1.09 & 3.36 & 1.14 & 2.39 & 0.96 & 2.26 \\
\hline
\end{tabular}

Table 5. Mean temperature $(T)$, thermal time $(\theta)$, duration when temperature exceeds $40^{\circ} \mathrm{C}(\mathrm{H} 40)$, photosynthetically active radiation (PAR) and millet biomass, harvested under and away from the tree canopies (standard errors in parentheses; source Jonsson et al., 1999)

\begin{tabular}{lccccc}
\hline Treatment & $\begin{array}{c}\mathbf{T} \\
\left({ }^{\circ} \mathbf{C}\right)\end{array}$ & $\begin{array}{c}\boldsymbol{\theta} \\
\left({ }^{\circ} \mathbf{C ~ d}\right)\end{array}$ & $\begin{array}{c}\mathbf{H 4 0} \\
(\mathbf{h} / \text { week) }\end{array}$ & $\begin{array}{c}\text { PAR } \\
\left(\boldsymbol{\mu} \mathbf{E ~ m}^{-2} \mathbf{~ s}^{-1}\right)\end{array}$ & $\begin{array}{c}\text { Millet biomass } \\
(\mathbf{g} \text { dry weight/ } \\
\text { plant) }\end{array}$ \\
\hline karité (large) & - & - & - & $429(57)$ & $46.2(16.5)$ \\
\hline karité (small) & $29.1(0.3)$ & 19 & 1 & $541(64)$ & $43.3(17.5)$ \\
\hline néré (large) & $28.3(0.5)$ & 18 & 9 & $451(57)$ & $56.2(14.6)$ \\
\hline néré (small) & $27.0(0.3)$ & 17 & 5 & $660(45)$ & $36.8(14.3)$ \\
\hline Control & $29.98(0.4)$ & 2 & 27 & $2158(40)$ & $39.8(15.2)$ \\
\hline
\end{tabular}

'Control plots away from tree canopies. 
optimal temperatures $\left(>40^{\circ} \mathrm{C}\right.$ ) compared with 27 hours per week in the open. In other words, the shorter exposure to extreme temperatures compensated for the millet biomass loss, which would otherwise have occurred as result of shading. This underscores the important role trees could play in mitigating the negative effects of extreme temperatures on crops, especially in semi-arid areas.

Pests, diseases and weeds already stand as major obstacles to crop production in many tropical agro-ecosystems and there are strong reasons to believe that their prevalence and their deleterious effects on crops may increase with a warmer climate. It is strongly believed, yet not sufficiently tested, that enhancing plant biodiversity and mixing tree and herbaceous species in agricultural landscapes can produce positive interactions that could contribute to controlling pest and disease outbreak.

Weeds are one of the most serious limiting factors to tropical agriculture and their control has proved to be beyond the capacities of many smallholder farmers (Akobundu, 1991; Akobundu, 1993; Gallagher et al., 1999). Following climate change scenarios weed pressure can be expected to become more serious in most parts of Africa. The most obvious mechanism of weed control through trees in agricultural systems is through competition for light (shading effect), water and nutrients (Impala, 2003). But there are other specific processes such as allelopathy, which have also been described in some of fallow trees (Gallagher et al., 1999). In addition, some agroforestry trees are known to act as trap crops triggering the germination of the weed seeds without being suitable hosts. For example, Sesbania sesban, Markhamia lutea and Leucaena diversifolia have shown good potential in controlling Striga hermonthica, a parasitic weed that plague many cereal production systems in Africa (Oswald et al., 1996; Rao and Gacheru, 1998).

\section{Income generation through tree products}

Beside the biophysical resilience, which allows the various components of the agroforestry systems to withstand the shocks related to climate variability, the presence of trees in agricultural croplands can provide farmers with alternative or additional sources of income thus strengthening the socio-economic resilience of rural populations.

Tree products (timber, fodder, resins and fruits) are normally of higher value compared to maize or hard grains such as millet and sorghum and can buffer against income risks in case of crop failure. Therefore, one of the major strengths of agroforestry systems is that they can significantly contribute to the objective of climate change mitigation (through carbon sequestration) while providing enough biophysical and economic flexibility and resilience to adapt to the negative effects of climate change or climate variability. The Sahelian Eco-Farm (SEF) provides an eloquent example of how an agroforestrybased integrated natural resource management regime can help improve the livelihood of the rural poor in vulnerable regions such as the Sahel (Pasternak, 
unpublished). The SEF is an integrated land-use system that incorporates highvalue multipurpose trees/shrubs with soil and water conservation structures, which are in turn reinforced. The value produced is in the form of food, firewood, forage, cash, plant nutrients, biomass for mulch (which contributes to increased infiltration of rainfall, and addition of organic matter to the soil), and protection from wind erosion. The first on-station test of the SEF took place at the ICRISAT Sahelian Center in Niger during 2002. The estimated income from a one hectare farm was US\$600, some 12 times the value of a typical millet crop (Table 6). The estimated costs of establishing the SEF are not high; the plant material costs about US\$60 per hectare, and the one-time application of fertilizer is about US\$10. The labour requirements for land preparation and tree planting are met by farmers and their families.

Table 6. Value of Sahelian Eco-Farm (SEF) products from SEF - ICRISAT Sadore station during 2002 (source Pasternak, unpublished)

\begin{tabular}{|c|c|c|c|c|c|c|}
\hline Species & $\begin{array}{c}\text { Quantity- } \\
\text { area }\end{array}$ & $\begin{array}{l}\text { Yield/ } \\
\text { units }\end{array}$ & $\begin{array}{l}\text { Unit Value } \\
\text { (US\$) }\end{array}$ & $\begin{array}{l}\text { Forage } \\
\text { Value }\end{array}$ & $\begin{array}{l}\text { Fire- } \\
\text { wood } \\
\text { Value }\end{array}$ & $\begin{array}{c}\text { Revenue } \\
\text { (US\$) }\end{array}$ \\
\hline Acacia colei & $\begin{array}{c}320 \text { trees/ } \\
\text { ha }\end{array}$ & $\begin{array}{c}2 \text { kg seeds/ } \\
\text { tree }\end{array}$ & $0.14 / \mathrm{kg}$ & None & $?$ & 90 \\
\hline $\begin{array}{l}\text { Zizyphus } \\
\text { mauritiana }\end{array}$ & 63 trees/ha & $\begin{array}{l}30 \mathrm{~kg} \text { fresh } \\
\text { fruit/tree }\end{array}$ & $0.14 / \mathrm{kg}$ & High & High & 225 \\
\hline $\begin{array}{l}\text { Andropogon } \\
\text { gayanus }\end{array}$ & $\begin{array}{c}567 \\
\text { meters/ha }\end{array}$ & $\begin{array}{c}1 \text { bundle/ } \\
10 \mathrm{~m}\end{array}$ & $0.8 /$ bundle & Limited & None & 45 \\
\hline Millet & $1 / 3 \mathrm{ha}$ & $500 \mathrm{~kg}$ & 0.1 & Medium & Low & 50 \\
\hline Cowpea & $1 / 3$ ha & $420 \mathrm{~kg}$ & 0.2 & High & None & 84 \\
\hline Roselle & $1 / 3$ ha & $133 \mathrm{~kg}$ & 0.8 & High & Medium & 106 \\
\hline Total & 1 ha & & & $?$ & $?$ & 600 \\
\hline
\end{tabular}

The SEF appears to provide countless Sahelian farming households with a real opportunity to break the endemic regional cycle of poverty and environmental degradation. The strength of the Sahel Eco-Farm lies in the fact that it promotes crop diversification and system resilience by combining various species of trees or shrubs (Acacia colei, Zizyphus mauritiana also known as 'pomme du Sahel'), grass (Andropogon gayanus) and annual crops such as roselle (Hibiscus sabdariffa), a relatively high value crop with food crops (millet and cowpea).

The parkland or scattered-tree system is another important agroforestry system worth mentioning. In the drylands of Africa, where climate variability is commonplace and adverse impacts of climate change are expected, farmers 
have evolved to appreciate the role of trees in buffering against production risk (Ong and Leakey, 1999). For example, one of the most valued (and probably most intriguing) trees in the Sahel is Faidherbia albida. Thanks to its reversed phenology (the tree sheds its leaves during the rainy season), F. albida contributes significantly to maintaining crop yield through biological nitrogen fixation and favourable micro-climate while minimising tree-crop competition. Furthermore, its protein-rich leaves, twigs and pods constitute a precious source of animal feed for livestock during the long dry seasons in the Sahel. This phenomenon of reversed phenology is not observed with other parkland trees such as shea butter tree (Vitellaria paradoxa) and néré (Parkia biglobosa), whose negative shading effect may reduce millet yield under the tree by $50-80 \%$ in some cases (Kater et al., 1992). Farmers are well aware of this yield penalty, but do not mind it. In fact, they put a great value on these trees because the economic yields from marketable tree products compensate for the loss of crop yield.

Parklands are also gaining popularity in the semiarid zone of Kenya. However, unlike in the Sahel, where trees are often naturally established, here farmers plant the fast-growing indigenous species Melia volkensii (Meliaceae) in a more intensive arrangement. This tree is reputed to be highly compatible with crops and can provide high value timber in five to ten years (Stewart and Blomley, 1994). A study by Ong et al. (1999) in the Kitui district of Kenya showed that in a 11-year rotation, the accumulated income from tree products exceeds the accumulated value of crop yield lost through competition by US\$10 or $42 \%$ during average years and US\$22 or $180 \%$ with the assumption of $50 \%$ crop failure due to drought. In such a hostile environment, where crops normally fail every other year, good and secure financial returns from $M$. volkensii even in drought years can provide significant relief for farmers. This will be all the more necessary as climate extremes are likely to increase in frequency and in magnitude in the near future.

\section{Conclusions}

Impacts of climate change will be felt on several levels in the agricultural sector: at the level of the individual crop species, at the farming system level (entire farm), and at the level of the natural resource base upon which rural communities depend. Preliminary vulnerability estimates may be too pessimistic for many agricultural systems with high adaptive capacity, but there clearly are limits to adaptation within agriculture. Impacts will be felt most by rural poor in developing countries, who are the most vulnerable because of their low adaptive capacity. The adaptive capacity of farmers in developing countries is severely restricted by heavy reliance on natural factors and lack of complementary inputs and institutional support systems.

The concepts of resilience and sustainable productivity are well established in agriculture and can be linked directly to the discussions about adaptation to and mitigation of climate change. Thus, policy makers can draw upon a substantial body of knowledge on how to enhance the adaptive capacity and 
mitigation potential of agricultural systems. The adaptation and mitigation synergies of agroforestry management systems are worth further and more focused research.

Within international fora, there is much talk about 'mainstreaming' adaptation into planning processes. We have shown above, through the specific case of agroforestry, that some mitigation measures simultaneously provide opportunities to increase the resilience of agricultural systems. It is suggested that such synergies ought to be promoted more intensively also through the mechanisms of the UNFCCC such as the CDM.

However, if agroforestry is to be used in carbon sequestration schemes such as the CDM, better information is required in several areas. For example, we need better data on aboveground and belowground carbon stocks, and the non- $\mathrm{CO}_{2}$ emissions of different agroforestry systems. Whereas agroforestry systems are primarily production systems, there will be periodic harvesting and marketing of wood products. The debate on durable wood products is ongoing, but provisions will be needed to allow farmers to market wood products from their agroforestry systems and accounting methods will be needed to account for the lifetime of the carbon sequestered in agroforestry products. As small-scale farmers are enrolled in carbon offset projects, we will need to develop a better understanding of the implications for carbon sequestration by agroforestry and what it means to livelihoods. Finally, the CDM has very stringent rules for participation that may be beyond the reach of small-scale farmers to understand or to provide evidence of compliance. There is a need for institutional support by national, regional and international centres of excellence to facilitate an effective participation of small-scale farmers in the CDM.

In an effort to develop adaptation strategies for the agricultural sector, scientists and policymakers must consider the complex interactions of constraints created by changing climates in light of other stress factors. Government and international support in terms of research, education, and extension will be required to help farmers in developing countries cope with the additional stresses created by climate change and increased climate variability. Agroforestry can very likely contribute to increasing the resilience of tropical farming systems. However, our understanding of the potential of agroforestry to contribute to adaptation to climate change is rudimentary at best. Better information is required on the role of agroforestry in buffering against floods and droughts from both the biophysical (hydraulic lift, soil fertility) and financial (diversification, income risk) points of view.

Agroforestry offers the potential to develop synergies between efforts to mitigate climate change and efforts to help vulnerable populations adapt to the negative consequences of climate change. The research agenda in this area is fairly well defined. Yet, much is already known and putting these ideas into practice on the ground with small-scale farmers will allow us to learn important lessons through practical experience. 


\section{References}

African Development Bank, Asian Development Bank, UK Department for International Development, European Commission Directorate-General for Development, German Federal Ministry for Economic Cooperation and Development, The Netherlands' Ministry of Foreign Affairs Development Cooperation, Organization for Economic Cooperation and Development, UNDP, UNEP, The World Bank (2003) Poverty and Climate Change-Reducing the Vulnerability of the Poor through Adaptation, World Bank: Washington, D.C.

Aggarwal, P.K., R.K. Mall (2002) 'Climate change and rice yields in diverse agroenvironments of India. II. Effect of uncertainties in scenarios and crop models on impact assessment' Climate Change 52: 331-343.

Aggarwal, P.K., S.K. Sinha (1993) 'Effect of probable increase in carbon dioxide and temperature on productivity of wheat in India' Journal of Agricultural Meteorology 48: 811-814.

Akobundu O. (1991) 'Weeds in human affairs in sub-Saharan Africa: implications for sustainable food production' Weed Technology 5: 680-690

Akobundu O. (1993) 'Integrated weed management techniques to reduce soil degradation' IITA Research 6: 11-16

Albrecht, A. S.T. Kandji (2003) 'Carbon sequestration in tropical agroforestry systems' Agriculture, Ecosystems and Environment. 99: 15-27

Bidinger, P.D., T.S. Walker, B. Sarkar, A. Ram Murthy, P. Babu (1991) 'Consequences of Mid-1980s drought: Longitudinal Evidence from Mahbubnagar' Economics Group Progress Report, Resource Management Program ICRISAT: Patancheru.

Chikowo, R., P. Mapfumo, P. Nyamugafata, K.E. Giller (2003) 'Mineral N dynamics, leaching and nitrous oxide losses under maize following two-year improved fallows on a sandy loam soil in Zimbabwe' Plant and Soil 259: 315-330

Chirwa, P.W. (2003) Tree and Crop Productivity in Gliricidia/Maize/Pigeonpea Cropping Systems in Southern Malawi, Ph.D thesis, University of Nottingham: Nottingham.

Cleaver, K.M., G.A. Schreiber (1994) Reversing the spiral: The population, agriculture and environment nexus in sub-Saharan Africa, World Bank: Washington, D.C.

Crill, P.M, M. Keller, A. Weitz, B. Grauel, E. Veldkamp (2000) 'Intensive field measurements of nitrous oxide emissions from a tropical agricultural soil', Global Biogeochemical Cycles 14: 85-95.

Dunfield, P.F., E. Topp, C. Archambault, R. Knowles (1995) 'Effect of nitrogen fertilizers and moisture content on $\mathrm{CH}_{4}$ and $\mathrm{N}_{2} \mathrm{O}$ fluxes in a humisol: measurements in the field and intact soil cores' Biogeochemistry 29: 199222.

Food and Agriculture Organization (FAO) (1999) The State of Food Insecurity in the World, FAO: Rome.

Gallagher R.S., E.C.M. Fernandes, E.L. McCallie (1999) 'Weed management through short-term improved fallows in tropical agroecosystems' Agroforestry Systems 47: 197-221. 
Gockowski, J., G.B. Nkamleu J. Wendt (2001) 'Implications of Resource-use Intensification for the Environment and Sustainable Technology Systems in the Central African Rainforest' in D.R. Lee, C.B. Barrett (eds.) Tradeoffs or Synergies? Agricultural Intensification, Economic Development and the Environment, $\mathrm{CAB}$ International: Wallingford.

Hansen, S., J.E. Maechlum, L.R. Bakken (1993) ' $\mathrm{N}_{2} \mathrm{O}$ and $\mathrm{CH}_{4}$ fluxes in soils influenced by fertilization and tractor traffic' Soil Biology and Biochemistry, 25: 62-1630.

Huang, J., C. Pray, S. Rozelle (2002) 'Enhancing the crops to feed the poor'Nature 418: 678-684.

Hutsch, B.W. (1996) 'Methane oxidation in soils of two long-term fertilization experiments in Germany' Soil Biology and Biochemistry 28: 773-782.

Hutsch, B.W., C.P. Webster, D.S. Powlson (1994) 'Methane oxidation in soils as affected by land use, soil $\mathrm{pH}$ and $\mathrm{N}$ fertilization' Soil Biology and Biochemistry 26: $1613-1622$.

Hutsch, B.W., C.P. Webster, D.S. Powlson (1993) 'Long-term effects of nitrogen fertilization on methane oxidation in soil of the Broadbalk wheat experiment', Soil Biology and Biochemistry 25: 1307-1315.

Impala (2001) 'First annual report of IMPALA Project' October 2000 - December 2001, ICRAF: Nairobi.

Jain, M.C., K. Kumar, R. Wassmann, S. Mitra, S.D. Singh, J.P. Singh, R. Singh, A.K. Yadav, S. Gupta (2000) 'Methane emissions from irrigated rice fields in Northern India (New Delhi)' Nutrients Cycling in Agroecosystems 58: 75-83.

Jodha, N.S. (1975) 'Famine and famine policies: Some empirical evidence' Economic and Political Weekly 10: 1609-1623.

Jones, P.G., P.K. Thornton (2003) 'The potential impacts of climate change on maize production in Africa and Latin America in 2055' Global Environmental Change 13: 51-59.

Jonsson, K., C.K. Ong, J.C.W. Odongo (1999) 'Influence of scattered néré and karité trees on microclimate, soil fertility and millet yield in Burkina Faso, Experimental Agriculture 35: 39-53

Kater L.J.M., S. Kante, A. Budelman (1992) 'Karité (Vitellaria paradoxa) and néré (Parkia biglobosa) associated with crops in South Mali' Agroforestry Systems 18: 89-105.

Keller, M., M.E. Mitre, R.F. Stallard (1990) 'Consumption of atmospheric methane in tropical soils of central Panama: Effects of agricultural development' Global Biogeochemical Cycles 4: 21-28.

Kropff, M.J., P.S. Teng, P.K. Aggarwal, B. Bouman, J. Bouma, H.H. van Laar (1996) Applications of Systems Approaches at the Field Level. Volume 2. Kluwer Academic Publishers: Dordrecht.

Lal, M., T. Nozawa, S. Emori, H. Harasawa, K. Takahashi, M. Kimoto, A. Abe-Ouchi, T. Nakajima, T. Takemura, A. Numaguti (2001) 'Future climate change: Implications for Indian summer monsoon and its variability' Current Science 81: 1196-1207.

Mann, C. (1997) 'Reseeding the Green Revolution’ Science 277:1038-1043. 
Mosier, A.R., J.A. Delgado (1997) 'Methane and nitrous oxide fluxes in grasslands in western Puerto Rico' Chemosphere 35: 2059-2082.

Nagarajan, S., L.M. Joshi (1978) 'Epidemiology of brown and yellow rusts of wheat over northern India. II. Associated meteorological conditions' Plant Disease Reporter 62: 186-188.

Ong, C.K., R.R.B. Leakey (1999), 'Why tree crop interactions in agroforestry appear at odds with tree-grass interactions in tropical savannahs' Agroforestry Systems 45: 109-129.

Ong, C.K., J. Wilson, J.D. Deans, J. Mulatya, T. Raussen, N. Wajja-Musukwe (2002) 'Tree-crop interactions: manipulation of water use and root function' Agricultural Water Management 53: 171-186.

Oswald A., H. Frost, J.K. Ransom, J. Kroschel, K. Shepherd, J. Sauerborn (1996) 'Studies on the potential for improved fallow using trees and shrubs to reduce striga infestations in Kenya' Proceedings of Sixth Parasitic Weed Symposium, 16-18 April 1995, Cordoba, Spain, Dirección General de Investigación Agraria, Servicio de Publicaciones y Divulgación: Cordoba.

Palm, C.A. S.A. Vosti, P.A. Sanchez, P.J. Ericksen (eds.) (2005) Slash and Burn: The Search for Alternatives, A Collaborative Publication by the Alternatives to Slash and Burn Consortium, the World Agroforestry Centre, The Earth Institute at Columbia University and The Center for Natural Resources Policy Analysis at the University of California, Davis, Columbia University Press: New York.

Palm, C.A., J.C. Alegre, L. Arevalo, P.K. Mutuo, A.R. Mosier, R. Coe (2002) 'Nitrous oxide and methane fluxes in six different land use systems' Global Biogeochemical Cycles 16: 1073.

Rao, G.D., S.K. Sinha (1994) 'Impact of climatic change on simulated wheat production in India'in C. Rosenzweig, A. Iglesias (eds.) Implications of Climate Change for International Agriculture: Crop Modelling Study, EPA: USA.

Rao, K.P.C., M.C.S. Bantilan, Y. Mohan Rao, V.K. Chopde (2003) `What does villagelevel evidence suggest for research and development priorities?'Policy Brief 4. Strategic assessment and development pathways for agriculture in the semi-arid tropics, ICRISAT: Patancheru.

Rao M.R., E. Gacheru (1998) 'Prospects of agrofrestry for Striga management' Agroforestry Forum 9(2): 22-27.

Rosegrant, M.W., M.S. Paisner, S. Meijer, J. Witcover (2001) Global Food Projections To 2020: Emerging Trends and Alternative Futures, International Food Policy Research Institute: Washington, D.C.

Saseendran, S.A., K.K. Singh, L.S. Rathore, S.V. Singh, S.K. Sinha (2000) 'Effects of climate change on rice production in the tropical humid climate of Kerala, India' Climatic Change 44: 495-514.

Smaling, E.M.A., S.N. Nandwa, B.H. Janssen (1997) 'Soil fertility in Africa is at stake' Soil Science Society of America, Special Issue No. 51.

Steudler, P.A., R.D. Bowden, J.M. Mellilo, J.D. Aber (1989) 'Influence of nitrogen fertilization on methane uptake in temperate forest soils' Nature 341: 314316. 
Stewart, M., T. Blomley (1994) 'Use of Melia volkensii in a semi-arid agroforestry systems in Kenya' Commonwealth Forestry Review 73: 128-131.

Ten Berge, H.F.M., P.K. Aggarwal, M.J. Kropff (eds.) (1997) 'Applications of Rice Modelling' Field Crops Research, Special Issue 51(1-2).

Tsuruta, H., S. Ishizuka, S. Ueda, D. Murdiyarso (2000) 'Seasonal and spatial variations of $\mathrm{CO}_{2^{\prime}} \mathrm{CH}_{4}$, and $\mathrm{N}_{2} \mathrm{O}$ fluxes from the surface soils in different forms of land-use/cover in Jambi, Sumatra' in D. Murdiyarso and H. Tsuruta (eds.) The Impacts of Land-use/cover Change on Greenhouse Gas Emissions in Tropical Asia, Global Change Impacts Centre for Southeast Asia and National Institute of Agro-Environmental Sciences: Bogor and Tsukuba.

Vandenbeldt, R.J., J.H. Williams (1992) 'The effect of soil temperature on the growth of millet in relation to the effect of Faidherbia albida trees' Agricultural and Forest Meteorology 60: 93-100.

Vasil, I.K. (1998) 'Biotechnology and food security for the 21 st century: A realworld perspective', Nature Biotechnology 16: 399-400.

Wassmann, R., R.S. Lantin, H.U. Neue (2000) 'Methane Emissions from Major Rice Ecosystems in Asia' Nutrient Cycling in Agroecosystems 58: 1-398.

Weitz, A.M., E. Linder, S. Frolking, P.M. Crill, M. Keller (2001) ' $\mathrm{N}_{2} \mathrm{O}$ emissions from humid tropical agricultural soils: effects of soil moisture, texture and nitrogen availability' Soil Biology and Biochemistry 33: 1077-1093. 


\title{
Linkages between mitigation and adaptation in land-use change and forestry activities
}

\section{Daniel Murdiyarso', Carmenza Robledo², Sandra Brown 3 , Oscar Coto 4 , John Drexhage 5 , Claudio Forner', Markku Kanninen', Leslie Lipper ${ }^{6}$, Nicole North ${ }^{7}$ and Marco Rondón ${ }^{8}$}

\author{
1. Center for International Forestry Research (CIFOR) \\ J. CIFOR, Situ Gede, Sindang Barang, Bogor Barat 16680, Indonesia. \\ Tel: +62 (251) 622622, Fax: +62 (251) 622100, E-mails: d.murdiyarso@cgiar.org, \\ c.forner@cgiar.org,m.kanninen@cgiar.org
}

2. Intercooperation. Bern, Switzerland; and Technology and Society Laboratory, Swiss Federal Laboratories for material Testing and Research, EMPA. Dübendorf, Switzerland.

Tel: +41 182343 21, Fax: +41182340 07, E-mail: carmenza.robledo@empa.ch

3. Winrock International, Ecosystem Services Unit, 1621 N Kent St., Suite 1200, Arlington,

VA 22207, USA. Tel: 703-525-9430, ext 678, Fax: 703-525-1744, E-mail: sbrown@winrock.org

4. Global Change Group, Tropical Agricultural and Higher Education Center,

CATIE 7170, Costa Rica.

5. International Institute for Sustainable Development (IISD)

6. Economist, Agricultural and Development Economic Analysis Division,

Food and Agriculture Organization of the U.N., Viale delle Terme di Caracalla,

00100 Rome Italy. Tel: 390657055342 , Fax: 39065705 5522, E-mail: leslie.lipper@fao.org.

7. INFRAS. Zürich, Switzerland.

8. TSBF Institute of CIAT. Centro Internacional de Agricultrura Tropical. A.A. 6713 Cali, Colombia. Tel: 57-2-4450000, Fax: 57-2-4450073, E-mail: m.rondon@cgiar.org

\section{Introduction}

The UN Framework Convention on Climate Change (UNFCCC) presents two ways to address causes and consequences of human-induced changes in the climatic system: mitigation and adaptation (see Forner, this volume). The starting point for this chapter is the recognition that these two possibilities are complementary to one another, while also being key to the overall goal of sustainable development. 
Linking mitigation and adaptation through activities in the land use, landuse change and forestry (LULUCF) sector can be an efficient way to meet the main objective of the UNFCCC, which is to stabilise atmospheric greenhouse gas concentrations at a level that would prevent dangerous anthropogenic interference with the climate system. This requires knowledge in understanding the potential impacts of climate change on forest ecosystems as well as understanding the potential of forest management activities to mitigate climate change. Unfortunately, the linkages between climate change, forest ecosystems and the performance of the forest sector are currently not well understood. This is especially true for tropical forests (Robledo, 2004).

A relationship between access to natural resources and adaptive capacity is widely recognised (Reid et al., 2005). Social groups with least access to resources usually have a low capacity to adapt to the changing climate and therefore are the most vulnerable groups. This generally includes poor people in rural areas with limited infrastructure who are dependent on natural resources. For such people, adaptation to climate change must imply a reduction of vulnerability and an increase in the resilience of the natural resources concerned (African Development Bank, 2003).

This chapter explores the opportunities for linking mitigation activities with efforts to increase adaptive capacity. Because the issue involves two separate objectives, each with multiple stakeholders and scales of analysis, win-win situations are emphasised. Criteria and indicators for monitoring adaptation to climate change are discussed in the light of emerging standards for mitigation project development and monitoring.

\section{Mitigation activities and adaptation measures in LULUCF}

\subsection{Mitigation activities}

Mitigation of climate change is defined as a human intervention to reduce the sources or enhance the sinks of greenhouse gases (Metz et al., 2001). With regards to LULUCF activities, enhancing sinks may be achieved by enhancing carbon sequestration and reducing sources can be achieved by conserving carbon stocks under threat of degradation. Conservation activities are aimed at preventing lands with high carbon stocks from being converted to lands with lower carbon stocks. Sequestration activities are aimed at increasing carbon stocks through shifting activities from land with low carbon stocks to land with potentially higher capacity for storing carbon.

Land use refers to the total of arrangements, activities, and inputs undertaken in a certain land-cover type. It is also defined as human actions that have the social and economic purposes for which land is managed (Watson et al., 2000). The following land-use categories, as described in the IPCC Good Practice Guidance for LULUCF (Penman et al., 2003), are considered in this chapter: 
Forest land: This category includes all land with woody vegetation consistent with thresholds used to define forest land in national greenhouse gas inventories, sub-divided into managed and unmanaged, and also by ecosystem type as specified in the IPCC Guidance. It also includes systems with vegetation that currently fall below, but are expected to exceed, the threshold of the forest land category.

Cropland: This category includes arable and tillage land, and agro-forestry systems where vegetation falls below the thresholds used for the forestland category, consistent with the selection of national definitions.

Grassland: This category includes rangelands and pasture land that are not considered cropland. It also includes systems with vegetation that fall below the threshold used in the forest land category and are not expected to exceed, without human intervention, the threshold used in the forest land category. The category also includes all grassland from wild lands to recreational areas as well as agricultural and silvopastoral systems, subdivided into managed and unmanaged, consistent with national definitions.

Wetlands: This category includes land that is covered or saturated by water for all or part of the year (e.g., peatland) and that does not fall into the forest land, cropland, grassland or settlements categories. The category can be subdivided into managed and unmanaged according to national definitions. It includes reservoirs as a managed sub-division and natural rivers and lakes as unmanaged sub-divisions.

Settlements: This category includes all developed land, including transportation infrastructure and human settlements of any size, unless they are already included under other categories. This should be consistent with the selection of national definitions.

Other land: This category includes bare soil, rock, ice, and all unmanaged land areas that do not fall into any of the other five categories. It allows the total of identified land areas to match the national area, where data are available.

Mitigation strategies through LULUCF activities have been defined in a number of decisions of the Conference of Parties (COP) to the UNFCCC. Based on decision 17/CP.7 (modalities and procedures for the Clean Development Mechanism [CDM], as defined in Article 12 of the Kyoto Protocol) and the work of the IPCC (Watson et al., 2000) several activities are considered eligible under the Kyoto Protocol mechanisms. The activities may involve the management of land and vegetation through activities, such as: 
Afforestation: A direct human-induced conversion of land that has not been forested for a period of at least 50 years to forested land through planting, seeding and/or the human-induced promotion of natural seed sources.

Cropland management: A system of practice on land on which agricultural crops are grown and on land that is set aside or temporarily not being used for crop production.

Avoiding deforestation: Deforestation is the direct human-induced conversion of forested land to non-forested land. Therefore avoiding deforestation should be considered equivalent to maintenance of existing carbon stocks or pools in the ecosystems that mitigate climate change.

Forest management: A system of practice for stewardship and use of forest land aimed at fulfilling relevant economic, social and ecological (including biological diversity) functions of the forest in a sustainable manner.

Grazing land management: A system of practice on land used for livestock production aimed at manipulating the amount and type of vegetation and livestock produced.

Reforestation: A direct human-induced conversion of non-forested land to forested land through planting, seeding and/or the human-induced promotion of natural seed sources, on land that was forested but that has been converted to non-forested land. For the first commitment period, reforestation activities will be limited to reforestation occurring on those lands that did not contain forest as of 31 December 1989.

Revegetation: A direct human-induced activity to increase carbon stocks on sites through the establishment of vegetation that covers a minimum area of 0.05 hectares and does not meet the definitions of afforestation and reforestation set out above.

According to the decision 19/CP.9 (modalities and procedures for afforestation and reforestation project activities under the CDM in the first commitment period of the Kyoto Protocol) only afforestation and reforestation activities are eligible under the CDM, the only Kyoto mechanism that involves the implementation of projects in both developed and developing countries. Under the given definition of reforestation or afforestation, the following forestry activities can be included:

- New plantations, including native and exotic species and bio-energy plantations;

- Forest land restoration, defined as a management strategy applied in degraded forest land that aims at restoring the capacity of a forest to 
produce goods and services (ITTO, 2002);

- Agroforestry activities; and

- Silvopastoral activities.

The implementation of these activities can have a range of positive or negative collateral impacts that are of interest from the perspective of adaptation to climate change as well as to the overall goal of sustainable development (see Table 1).

Table 1. Some examples of CDM-eligible activities and their impacts on sustainable livelihoods

\begin{tabular}{|c|c|c|c|}
\hline \multirow{2}{*}{$\begin{array}{l}\text { Activities to } \\
\text { mitigate GHG } \\
\text { emissions }\end{array}$} & \multicolumn{2}{|c|}{ Potential positive impacts } & \multirow{2}{*}{$\begin{array}{l}\text { Potential negative } \\
\text { impacts }\end{array}$} \\
\hline & Ecosystems & Socio-economic & \\
\hline $\begin{array}{l}\text { Afforestation with } \\
\text { native species on } \\
\text { steep degraded } \\
\text { croplands }\end{array}$ & $\begin{array}{ll}\text { - } & \text { Reintroduce } \\
\text { native species } \\
\text { - } & \text { Reduce soil } \\
\text { erosion } \\
\text { - } \text { Increase } \\
\text { biodiversity } \\
\text { - } \text { Improve degraded } \\
\text { forest and pasture } \\
\text { - Extend fallow } \\
\text { - } \text { Eeriod } \\
\text { Enhance roles of } \\
\text { corridors }\end{array}$ & 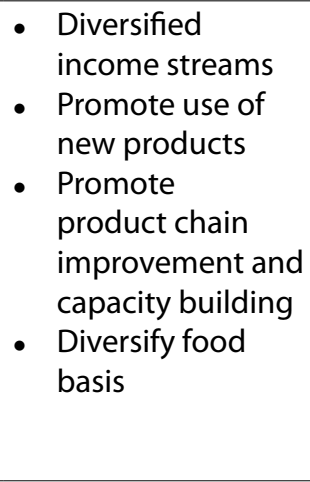 & $\begin{array}{ll}\text { - } & \text { Reduced } \\
\text { agricultural crop } \\
\text { return } \\
\text { - } \text { Intensify land-use } \\
\text { - } \text { Exacerbate } \\
\text { resource demand } \\
\text { (e.g., water) } \\
\text { - } \\
\text { Negative impacts } \\
\text { on biodiversity } \\
\text { due to use of } \\
\text { monocultures }\end{array}$ \\
\hline $\begin{array}{l}\text { Reforestation at } \\
\text { various scales and } \\
\text { practices }\end{array}$ & $\begin{array}{l}\text { Establish mixed } \\
\text { species and age- } \\
\text { classes } \\
\text { - Form habitat for } \\
\text { forest-dependent } \\
\text { species }\end{array}$ & $\begin{array}{ll}\text { - } & \text { Diversified } \\
\text { income streams } \\
\text { - } & \text { Promote use of } \\
\text { new products } \\
\text { - Promote } \\
\text { product chain } \\
\text { improvement and } \\
\text { capacity building } \\
\text { - Diversify food } \\
\text { basis }\end{array}$ & $\begin{array}{l}\text { - Establish large- } \\
\text { scale exotic } \\
\text { species plantation } \\
\text { - Promote mono- } \\
\text { species and single } \\
\text { age-class } \\
\text { - Perform clear } \\
\text { felling } \\
\text { - Exacerbate } \\
\text { resource demand } \\
\text { (e.g., water) } \\
\text { - Negative impacts } \\
\text { on biodiversity } \\
\text { due to use of } \\
\text { monocultures }\end{array}$ \\
\hline
\end{tabular}

\subsection{Adaptation measures}

The implementation of adaptation measures is the third stage in the adaptation process as defined in decision 11/CP.1 (initial guidance on policies, programme priorities and eligibility criteria to the operating entity or entities of the financial mechanism) (see Romero, this volume). Forner and Robledo (2005) describe 
adaptation as a dynamic process in time. Such process, as the development process, must be focused on continuous improvement, which means that vulnerability to climate change should be diminished over time. Continuous improvement occurs when a prior experience gives information that enables the improvement. With this in mind, the adaptation process must be implemented based on three essential components: (1) a vulnerability assessment, (2) capacity building and (3) implementation of adaptation measures (see Figure 1).

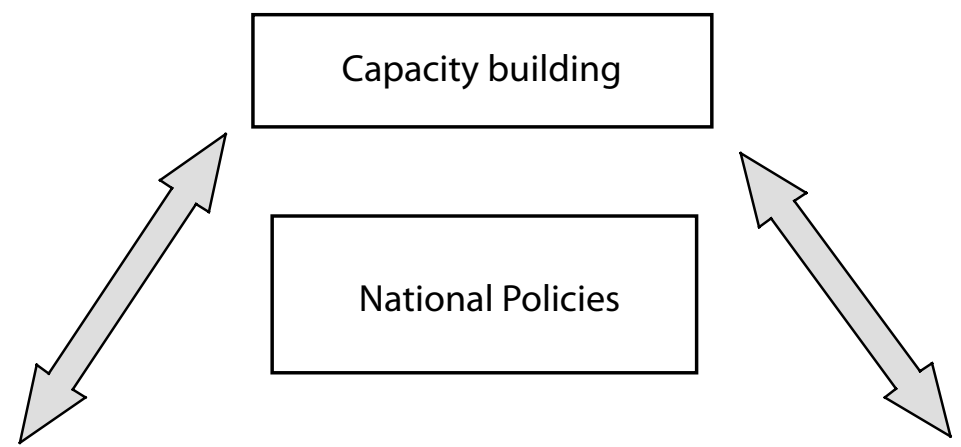

Vulnerability assessment

Implementation of adaptation measures

Figure 1. The adaptation process (Source: Forner and Robledo, 2005)

Potential adaptation measures with respect of LULUCF can cover a wide range of possibilities,from improving governance and capacities within the sector to relocating land-tenure or changes in management of natural resources (Forner and Robledo, 2005). As these measures are to be implemented in the forest or agriculture sectors this will imply some important impacts on global development goals, such as those set out in the Millennium Declaration (see Table 2). Many of these measures have also an impact on global carbon balance, reducing emissions or enhancing sinks.

All three funds of the UNFCCC - the Adaptation Fund, the Least Developed Countries' (LDC) Fund and the Special Climate Change Fund - include several components on promoting adaptation. Even if activities in LULUCF are not specifically mentioned these funds can cover measures in these sectors

\subsection{Application at the field level}

Implementation of a number of carbon sequestration projects has already begun. These experiences can provide insight into where and how such projects can be designed to enhance adaptive capacity to climate change, and contribute to the promotion of sustainable livelihoods. In particular, we look at the experience of projects that involve small- and low-income producers, as these represent those most vulnerable to climate change. Furthermore, it is likely that such activities will have the largest potential to enhance sustainable development. 
Table 2. Potential adaptation measures and their impact on the global development agenda

\begin{tabular}{|c|c|c|}
\hline Activity & Adaptation measures & Development agenda \\
\hline $\begin{array}{l}\text { Natural } \\
\text { resource } \\
\text { governance }\end{array}$ & $\begin{array}{l}\text { - Implementation of } \\
\text { adaptation plan of actions }\end{array}$ & $\begin{array}{l}\text { - Improvement of local governance } \\
\text { - Institutional development }\end{array}$ \\
\hline $\begin{array}{l}\text { Biodiversity } \\
\text { conservation }\end{array}$ & $\begin{array}{l}\text { - } \text { Creation and legitimating } \\
\text { nature reserves } \\
\text { - Stabilizing wetlands and } \\
\text { peatlands water table } \\
\text { - } \quad \text { Forest landscape restoration }\end{array}$ & $\begin{array}{l}\text { - Conservation of endangered } \\
\text { species and sensitive ecosystems } \\
\text { - Carbon and water budget } \\
\text { maintenance } \\
\text { - Diversification of income }\end{array}$ \\
\hline $\begin{array}{l}\text { Combating } \\
\text { desertification }\end{array}$ & $\begin{array}{l}\text { - Sand dunes re-vegetation } \\
\text { - Vegetative and engineering } \\
\text { approaches for erosion } \\
\text { control }\end{array}$ & $\begin{array}{l}\text { Increasing the resilience of arid } \\
\text { and semi-arid ecosystems } \\
\text { - Drought early warning systems }\end{array}$ \\
\hline $\begin{array}{l}\text { Watershed } \\
\text { protection }\end{array}$ & $\begin{array}{l}\text { - Adaptation of recharging } \\
\text { areas and flood control } \\
\text { systems } \\
\text { Valuation and payment for } \\
\text { ecosystem services }\end{array}$ & $\begin{array}{l}\text { - Conservation of natural } \\
\text { vegetation and construction of } \\
\text { drainage systems } \\
\text { - Promotion of water resource } \\
\text { accounting } \\
\text { - Diversification of income }\end{array}$ \\
\hline $\begin{array}{l}\text { Sustainable } \\
\text { agriculture }\end{array}$ & $\begin{array}{l}\text { - Use of resistant species and } \\
\text { agro-forestry systems }\end{array}$ & $\begin{array}{l}\text { - Ensuring food for local } \\
\text { communities }\end{array}$ \\
\hline
\end{tabular}

\subsubsection{Cost and payments}

Estimates of projected supply costs and demand prices in the market for Emission Reductions (ERs) indicate that several types of land-use changes and energy-efficiency enhancements are appropriate for small- and low-income land users, and that these services could be supplied at a competitive rate, given the current likely market prices, particularly under the CDM (Smith and Scherr, 2000; Lipper and Cavatassi, 2002). However, results from pilot projects in developing countries demonstrate that payments for ERs certified under the CDM (CERs) do not always cover the transaction costs for Kyoto mechanisms, including project design, validation, registration, monitoring, verification, and certification.

For such projects, especially for those involving poor communities, investment constraints are perhaps the most common barrier to the adoption of new land uses and technologies. Poor farmers may not adopt land uses that offer higher productivity over the long-term due to lack of capital to invest in the short term when resources are required up front. Additionally, CER payments are not up front. Even those funds willing to make advance payments, such as the BioCarbon Fund or the Community Development Carbon Fund, will not pay more than $25 \%$ of the potential CERs in advance. One possibility to overcome this problem is to add some kind of adaptation payments for those CDM projects that reduce vulnerability. However, currently no such payment mechanism is recognised at the international level. 
Even where there is significant potential for carbon offset payments to contribute to poverty alleviation and increase the adaptive capacity of lowincome communities to climate change, considerable effort will be required to move from the objectives to the reality. In some cases, this may be made through the structure of carbon offset payments, to address the investment and insurance needs of poor producers and provide adequate incentives for participation. In other cases it will require actions to reduce transactions costs. Some examples are: facilitating the improvement of capacity of social groups to co-ordinate land use and energy-efficiency increasing activities through the establishment of new institutions or by working with ones already in operation. This would contribute to enhancing the benefits from carbon payments to poor producers.

Besides the average return or profitability of an activity, the impact on livelihoods and adaptation to climate change should be considered in mitigation activities. A risk to food security, for example, is a critical issue when assessing the opportunity costs of adopting carbon-sequestering land-use changes and the contribution of these activities to sustainable livelihoods.

\subsubsection{Risks}

Risk enters into mitigation activities on at least two levels:

At the farm level: risk of reduced production of primary goods and services, such as food, as a result of a reforestation activity; and

At the carbon market level: risk that the offset credit is reversed due to human or natural disturbance such that the carbon is re-emitted to the atmosphere.

The first level of risk is land-use changes that reduce the production of food for self-consumption, which is a key component of the food security of many poor producers. Turning to the second level of risk identified above, significant price reductions for non-permanence may result in very restricted opportunities for suppliers of carbon sequestration through land-use change. Decisions regarding permanence ${ }^{1}$ could result in a reduction of payment levels for sequestration services provided by the poor if these services are perceived to be at high risk of reversing. Due to the fact that prices for temporary CER (tCERs) and long term CER (ICERs) are likely to be lower than for CERs, lower participation rates among sequestration providers in general can be expected. At this point, the potential effects of these prices difference with regard to the increase of vulnerability to climate change are not clear.

\footnotetext{
${ }^{1}$ Permanence has been defined as the longevity of a carbon pool and the stability of its stocks, given the management and disturbance environment in which it occurs (Watson et al., 2000).
} 
However, land-use changes associated with carbon sequestration can also be associated with a reduction in risk. Some examples are activities that allow households to adopt a system of production which is more stable (e.g., agroforestry) or activities that help to reduce impacts of climate hazards (e.g., restoration of forest as a mean to reduce floods risk). Some mitigation projects already exist that have considered this twofold possibility, especially under the CDM (see Box 1).

\section{Box 1. The Colombian experience}

The San Nicolas Project in Colombia is a pilot experience aimed testing a long-term financing method for sustainable forest management that includes payments for climate mitigation through the CDM. The project is located in the Andean region with altitudes of 800-3000 metres.

Based on a participatory scheme, project partners and the local community designed a forest management plan for the next decades. The management plan includes CDM eligible activities, such as agroforestry and small bio-energy plantations on land that was non-forest in 1990. Additionally, the forest management plan defines activities for forest conservation and enrichment. Although these activities are not eligible for the $\mathrm{CDM}$, they reduce greenhouse gas emissions, particularly $\mathrm{CO}_{2}$. Altogether the project will reduce 1.8 million tonnes of carbon over 40 years. Besides many positive socio-economic impacts, the project will have important environmental effects like the creation of biological corridors and the conservation and management of watersheds (EMPA, 2003).

The vulnerability analysis for the project region demonstrates that the significant fragility of the Andean mountain forests as well as intense human pressure, fragmentation, biotic losses and degradation, means that this ecosystem is one of the most vulnerable to climate change in Colombia.

Adaptation could only be proposed as an immediate measure, with wideranging programs for conservation of the residual forests, ecological restoration and the creation of conservation corridors, together with the general ecological improvement of the surrounding agricultural systems. The forest management plan in San Nicolas, which is being currently implemented, corresponds entirely with this adaptation option.

Source: Tropical Forests, 2004.

Based on the experience coming from individual projects in different fields, the Climate, Community \& Biodiversity Alliance (CCBA) has been developing standards for LULUCF mitigation activities that include adaptation to climate change. These standards are designed to identify land-use projects that will likely deliver measurable climate, biodiversity and community benefits. The standards are primarily designed for carbon markets but can also apply to sustainable development, adaptation to climate change and biodiversity efforts more broadly².

\footnotetext{
${ }^{2}$ For more information, see http://www.climate-standards.org/standards/.
} 
Experiences with adaptation measures in the field are very new. Some bilateral agencies, such as the German Technical Cooperation Agency (GTZ) or the Swiss Agency for Development and Cooperation (SDC), have undergone a portfolio assessment aimed at finding impacts of co-operation projects for reducing vulnerabilities at the local level. Generally speaking, results of these assessments indicate that the promotion of sustainable development is very much in line with adaptation priorities in developing countries, and that there is a need for methods and tools to plan adaptation measures in the field of natural resource management (Klein et al., 2003).

\section{A framework for linking mitigationand adaptation}

\subsection{Parameters and principles}

Three key parameters of adaptation and mitigation activities are identified here to determine the degree to which there are potential synergies or tradeoffs between mitigation and adaptation objectives:

1) who will be participating in the activities;

2) where the activities will take place; and

3) which activities will be implemented.

Who. The key issue here is the degree to which social groups targeted for adaptation and mitigation activities coincide. To a large extent, the identity of the population to be involved in adaptation is determined by the process of climate change in terms of defining which groups are likely to be the most vulnerable to the changes. Aside from location, addressed in the following section, vulnerability to climate change among a population is determined by factors such as food security status, skills and capacity, level of economic development and primary economic activities present. Food insecure people dependent on subsistence agricultural activities in areas with little alternative economic opportunities have less flexibility in responding to climate change than others. Turning to mitigation, the socio-economic characteristics of the population will determine capacity and willingness to participate in mitigation strategies employed to attain the respective policy objectives.

It is then appropriate to ask to what degree social groups involved in adaptation and mitigation likely to overlap? One of the most vulnerable groups of population to climate change is poor, food insecure farmers who are dependent on agricultural activities for their subsistence. This same group could potentially provide sequestration through land-use changes, but their incentives to participate will be driven by factors such as land tenure, access to technology and investment, among other things. Among social groups vulnerable to climate change, the design of sequestration programs to address constraints arising from vulnerability is likely to be necessary to obtain synergies between mitigation and adaptation. 
Where. Location is a key determinant of the need for adaptation and the effectiveness of mitigation, and thus critical in determining the degree of overlaps between the two strategies. The impacts of climate change are spatially defined; some areas are more likely than others to experience change, either because the climate is expected to change more radically in such areas, and/or because their agro-ecological endowments are more vulnerable to changes in climate. Low-lying island states are highly vulnerable to changes in sea level, while parts of Africa are expected to experience more extreme fluctuations in temperatures and rainfall patterns. Mitigation potential is also highly spatially defined. Tropical humid zones have greater capacity to sequester aboveground carbon than arid zones. Characteristics of soils, topography, land cover and climate patterns drive the potential productivity of sequestration, as well as alternative land-uses, which ultimately will determine the feasibility and incentives to participate in sequestration programs. Mitigation through fuel switching and energy efficiency improvements are somewhat less spatially dependent than sequestration, although both the baseline situation and the potential mitigation scenario will be defined by the presence or absence of energy resources (fossil fuels, bio-energy, wind and hydro-electric) which is a characteristic of the location in question.

Which activities. There is a wide range of activities that may fall under an adaptation or mitigation strategy. Adaptation strategies seek to increase the resilience of ecosystems or social systems in the face of climate change, while mitigation strategies seek to reduce greenhouse gas emissions or increase their sequestration. To what extent could mitigation strategies lead to increased resilience of social and ecosystems? Increasing resilience can be accomplished by either ex ante by reducing the variability in the system or expost by increasing the capacity to respond to variation. Soil carbon sequestration through the adoption of no till agricultural systems is an example of a potential mitigation strategy that can lead to reduced ecological variation. Increasing soil carbon can generate increased capacity of the soil to retain moisture and thus provides greater resistance to variations in rainfall patterns and lower crop yield variability. Turning to social systems, market variability is a significant source of risk to vulnerable populations and interventions that increase supply stability and can be an effective way to increase market stability.

Mitigation strategies that involve the development of sustainable energy sources can reduce the risk exposure of countries and populations to variations in energy supply and prices and thus generate increased resilience to climate change variability. In terms of increasing capacity to respond to variation, an important strategy is diversification. Mitigation can provide an important means of income diversification for populations vulnerable to climate change - both in terms of potential income from mitigation services (e.g., carbon markets) and also in terms of increasing agricultural product diversification (e.g., agroforestry, non-timber forest products, energy crops). In the energy sector, mitigation activities can provide an important means of diversifying energy sources and can generate adaptation benefits through increased adaptive capacity. 
Unfortunately, projects that actually demonstrate the positive links between community ecosystem management and bio-energy service provision are rare. Although project developers have seized opportunities to link the emerging carbon market with the community based natural resource management (CBNRM) model (Smith and Scherr, 2003), this community development model has not yet been extended to include energy services via bio-energy applications. Kammen et al. (2002) argue that despite the many advantages of coupling bio-energy to community ecosystem and forest management, the institutional, technical, and decision-making complexities have precluded these integrated approaches.

Applying these parameters in an analysis of the potential for synergies and tradeoffs between adaptation and mitigation strategies, we derive the matrix presented in Table 3 below. In each box of the matrix we describe conditions that are necessary (but not sufficient) for the strategy to fall into one of four categories.

Table 3. Conditions under which synergies and tradeoffs between adaptation and mitigation can be obtained

\begin{tabular}{|c|c|c|c|}
\hline \multirow{4}{*}{ 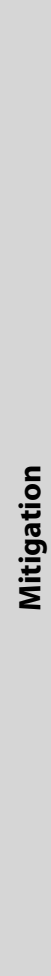 } & & \multicolumn{2}{|c|}{ Adaptation } \\
\hline & & High & Low \\
\hline & & $\begin{array}{l}\text { Population and location vulnerable } \\
\text { to climate change and suitable for } \\
\text { mitigation coincide. } \\
\text { Mitigation activities increase } \\
\text { resilience of production systems. } \\
\text { Mitigation activities increase the } \\
\text { resilience of social systems through } \\
\text { the provision of insurance, income } \\
\text { diversification, market stabilisation. }\end{array}$ & $\begin{array}{l}\text { Population and location with greatest } \\
\text { mitigation potential are not vulnerable } \\
\text { to climate change. } \\
\text { In cases where population and location } \\
\text { of climate change vulnerability and } \\
\text { mitigation coincide, the mitigation } \\
\text { strategy adopted is highly risky or } \\
\text { highly capital intensive and is unlikely } \\
\text { to produce significant adaptation } \\
\text { benefits. }\end{array}$ \\
\hline & دو & $\begin{array}{l}\text { Population and location are } \\
\text { vulnerable to climate change but } \\
\text { not very efficient mitigators (e.g., } \\
\text { either sequestration or emissions } \\
\text { reductions). } \\
\text { Adaptation strategy requires } \\
\text { activities that increase greenhouse } \\
\text { gas emissions (energy development, } \\
\text { livestock production, land } \\
\text { conversion). }\end{array}$ & $\begin{array}{l}\text { Populations and locations vulnerable } \\
\text { to climate change and suitable for } \\
\text { mitigation may or may not be the } \\
\text { same. } \\
\text { Environmentally degrading } \\
\text { agricultural production and energy } \\
\text { systems are adopted leading to } \\
\text { increased ecological and social } \\
\text { vulnerability as well as emissions. }\end{array}$ \\
\hline
\end{tabular}

According to these parameters of who, where and which activities, we propose four principles for linking adaptation measures and mitigation activities:

1) Prioritise mitigation activities that help to reduce pressure on the natural resources; 
2) Include vulnerability to climate change as one of the risks to be analysed in mitigation activities;

3) Prioritise mitigation activities that enhance local adaptive capacity; and

4) Increase sustainability of livelihoods, with particular consideration for the poor.

Availability of data and information is of central importance for the application of these principles at the field level. This explains the need to develop accurate local climate scenarios that can ensure an appropriate decision-making processes that mainstreams adaptation and mitigation into sustainable development. One of the major barriers to linking mitigation with adaptation activities is that mitigation activities are often planned and implemented without taking into account future climate scenarios and their potential impacts. Forner and Robledo (2005) propose a simple method to include these risks in forestry projects during the planning phase. The method begins with the recognition of future risks as impacts of changes in climatic patterns in a project area. These risks can augment as a result of droughts or landslides caused by changes in rainfall patterns. Changes in land use, such as those defined as mitigation activities, can help to reduce this vulnerability (e.g., promoting some plantation systems).

In addition to the consideration of land-use change as a possible means of reducing vulnerability, the decision to move to a new land-use should also consider the future demand and availability of specific resources, such as water. For example, it would not be advisable to promote any of the mitigation activities described above that are highly water-intensive if future climate scenarios foresee water scarcity.

\subsection{Some implications at the national and local levels}

The parameters and principles explained above will be reflected at many possible levels, including international decision-making, national strategic planning or local implementation. However, even if we recognise the outstanding necessity for establishing the linkages at the global level we have concentrated on the demand for co-ordinating mitigation and adaptation at the national and local levels, so that win-win options can be identified and major risks can be avoided. Such co-ordination must be based on a holistic understanding of the sustainable management of the landscape.

Additionally, we note that this understanding of the complementary character between mitigation and adaptation has to go beyond the current state of the UNFCCC negotiations; especially beyond those decisions regarding LULUCF activities under the Kyoto Protocol ${ }^{3}$.

\footnotetext{
${ }^{3}$ The following are the key decisions of the Conference of the Parties that rule the use of LULUCF in the Kyoto Protocol until 2012: decision 11/CP.7, decision 17/CP.7, decision 19/CP.9, decision 13/CP.10 and decision 14/CP.10
} 
In this section, we explain the need for co-ordinating mitigation and adaptation at the national level and present a possible procedure aimed at identifying synergies or incremental risks between mitigation and adaptation projects at the local level.

\subsubsection{Co-ordinating mitigation and adaptation at the national level}

Why is it important to co-ordinate the adaptation and mitigation strategies within a country? Let us start this discussion with an example: to reduce greenhouse gas emissions, a given country has decided to switch from coalbased energy to renewable energy, especially hydro-power and bio-energy. The current situation in the country $X$ demonstrates good availability of water resources. However, projections were done without taking into account the potential impacts of climate change.

For this specific country a medium scenario demonstrates a shortfall in average precipitation as well as an increase in storms. As a result of the decrease in precipitation, water availability will be reduced and the risk of forest fires will increase. A successful implementation of the mitigation strategy (emissions reduction through using renewable energy) will need some complementary adaptation measures like an improved management of the watersheds as well as the recalculation of some infrastructure due to the increase in storms or a forest fire management plan.

Although the scenario and outcome for the example above is obvious, the fact that different institutions are responsible for decision making at the national level can create an important challenge for co-ordination. Following our example, in country $X$ the Ministry of Energy is responsible for decisions regarding electricity generation and distribution as well as for the mitigation strategy. Meanwhile the Ministry of Environment is responsible for adaptation to climate change as well as for the national communications program (where the analysis of climate change impacts and vulnerability is undertaken). Additionally, the Ministry of Forestry is responsible for the management of all forest ecosystems, including watersheds. If the activities and programmes of these three ministries are not well co-ordinated, there is a significant risk that the mitigation strategy will fail, as well as a risk that forests fires will increase (which will raise greenhouse gas emissions).

There are many other examples that demonstrate the need to co-ordinate the mitigation and adaptation strategies (Forner and Robledo, 2005). The national development goals will be the starting point of such co-ordination. After that, an inter-sectoral co-ordination is also needed that is aimed at:

- Reducing the risk that mitigation programmes can fail or reduce their performance due to negative impacts of climate change;

- Avoiding additional stresses on natural resources that are highly vulnerable to climate change (e.g., promoting water consumption for agriculture in an area vulnerable to drought); and

- Promoting the potential for mitigation in the most promising areas. 
There are some key elements that are required to facilitate the above:

- Spreading knowledge regarding impacts of and vulnerability to climate change to many sectors, especially energy, agriculture, trade, technology transfer and forestry;

- Exchanging information among sectors regarding their mitigation potential; and

- Defining institutional responsibility for co-ordination between mitigation and adaptation.

\subsubsection{Identifying synergies or incremental risks in mitigation and} adaptation projects

At the level of specific projects, synergies between mitigation and adaptation should be used and risks should be avoided. We recommend a simple procedure that could help to establish those synergies or risks.

\subsubsection{Analysis of synergies}

An analysis of synergies between mitigation and adaptation comprises of the following steps:

- Define the current land uses according to IPCC definitions;

- Define the forestry activities with the highest potential for mitigation for this land use considering also socio-economic and environmental issues;

- Based on existing information (e.g., national communications, specific studies), identify the most likely impacts of and vulnerabilities to climate change in the project area;

- Define potential activities/measures that could reduce vulnerability to climate change, including socio-economic and environmental issues; and

- Adjust mitigation activities.

Table 4. Some examples for the steps for an analysis of synergies

\begin{tabular}{lllll}
\hline $\begin{array}{l}\text { Current } \\
\text { land use }\end{array}$ & $\begin{array}{l}\text { Mitigation } \\
\text { potential }\end{array}$ & $\begin{array}{l}\text { Impacts of and } \\
\text { vulnerability to } \\
\text { climate change }\end{array}$ & $\begin{array}{l}\text { Potential } \\
\text { adaptation } \\
\text { measures }\end{array}$ & $\begin{array}{l}\text { Adjusted } \\
\text { management } \\
\text { alternative }\end{array}$ \\
\hline $\begin{array}{l}\text { Natural } \\
\text { forest }\end{array}$ & $\begin{array}{l}\text { Reduce } \mathrm{CO}_{2} \\
\text { emission }\end{array}$ & $\begin{array}{l}\text { Changes in raining } \\
\text { patterns } \\
\text { Lost of agricultural } \\
\text { land }\end{array}$ & $\begin{array}{l}\text { Increase food } \\
\text { security } \\
\text { Protect } \\
\text { watersheds }\end{array}$ & $\begin{array}{l}\text { Forest } \\
\text { management } \\
\text { (including } \\
\text { watershed } \\
\text { management) }\end{array}$ \\
\hline Grazing land & $\begin{array}{l}\text { Carbon } \\
\text { sequestration } \\
\text { through } \\
\text { plantations }\end{array}$ & $\begin{array}{l}\text { Erosion due to } \\
\text { changes in rain } \\
\text { patterns (extended } \\
\text { drought periods and } \\
\text { increase in storms) }\end{array}$ & $\begin{array}{l}\text { Build up } \\
\text { adequate } \\
\text { infrastructure }\end{array}$ & $\begin{array}{l}\text { Agroforestry } \\
\text { (including living } \\
\text { barriers) }\end{array}$ \\
& & $\begin{array}{l}\text { Soil } \\
\text { protection }\end{array}$ & \\
& agricultural land and \\
infrastructure & Increase food & \\
& & & security & \\
\hline
\end{tabular}


For successful implementation of these projects, it is necessary to consider some incentives that make the 'adjusted management alternative' attractive to the communities that are managing the land. It implies careful consideration of social and institutional aspects (e.g., relationship between social groups, land tenure, user rights) and economic incentives (e.g., payments for ecosystem services, access to markets for new products) as well as some elements regarding technology and transfer of know-how.

\subsubsection{Analysis of incremental risks}

In this case it is necessary to determine if a mitigation project can fail due to the vulnerability to climate change of the planned forestry system. Similar to the procedure explained before, we recommend comparing the available information on mitigation potential and vulnerability to climate change in order to identify the potential for incremental risks.

Table 5. Comparison of mitigation potential and impacts

\begin{tabular}{|c|c|c|c|}
\hline $\begin{array}{l}\text { Land use } \\
\text { proposed as } \\
\text { mitigation } \\
\end{array}$ & $\begin{array}{l}\text { Potential for } \\
\text { mitigation }\end{array}$ & $\begin{array}{l}\text { Potential impact of } \\
\text { climate change in the } \\
\text { project area* }\end{array}$ & Incremental risk \\
\hline $\begin{array}{l}\text { Fast growing } \\
\text { plantation }\end{array}$ & $\begin{array}{l}\text { Carbon } \\
\text { substitution } \\
\text { (e.g., bio- } \\
\text { energy) }\end{array}$ & $\begin{array}{l}\text { Reduction of water } \\
\text { availability }\end{array}$ & $\begin{array}{l}\text { Risk of desertification } \\
\text { Risk of failure of the } \\
\text { mitigation project due } \\
\text { to low rates of growth as } \\
\text { result of water shortness }\end{array}$ \\
\hline $\begin{array}{l}\text { Reforestation } \\
\text { with native } \\
\text { species }\end{array}$ & $\begin{array}{l}\text { Carbon } \\
\text { sequestration }\end{array}$ & $\begin{array}{l}\text { Significant increase in } \\
\text { temperature causing } \\
\text { shifting of some native } \\
\text { species in the next } 30 \\
\text { years }\end{array}$ & $\begin{array}{l}\text { Risk of failure of the } \\
\text { mitigation project before } \\
\text { the end of the crediting } \\
\text { period (non-permanence) }\end{array}$ \\
\hline
\end{tabular}

Notes: * as defined in the national communication

Incremental risks can be also the consequence of an adaptation programme defined at the national level. Local knowledge, specially regarding autonomous adaptation can be very useful for defining a project that reduces risks and creates an win-win situation.

\section{Monitoring adaptation}

Costs and benefits of adaptation measures cannot be as easily determined, compared and aggregated as those of mitigation. Expressed in $\mathrm{CO}_{2}$ equivalent, the emission reductions achieved by mitigation can be compared with those from other mitigation options and if the implementation costs are known, the cost-effectiveness of these options can be quite reliably determined and compared.

Some argue that, in principle, the benefits of adaptation are the costs one avoids by taking adaptation measures (assuming that for example, climate 
change would have adverse consequences). Thus, if one quantifies the potential impacts of climate change on a system assuming no adaptation, as well as its residual impacts assuming adaptation, the benefits of adaptation are given by the difference between the two. From the value thus obtained one can subtract the costs of implementing the adaptation options to arrive at the net benefits of adaptation (Callaway et al., 1998; Fankhauser, 1998). However, as argued by Klein et al. (2003), the practice of assessing and comparing adaptation benefits is fraught with difficulties related to the uncertainty about and differences between the impacts avoided.

Estimating the state and change of carbon stocks alone for adaptation in LULUCF, as is done for mitigation measures, is not sufficient. Other environmental and socio-economic benefits have to be assessed in order to define what can be attributed to a true adaptation effect and what has to be attributed to general development.

The purpose of monitoring is to keep track of progress in the implementation of any adaptation and/or mitigation measures and their various components in relation to targets. Indicators to be monitored and frequencies of monitoring could evolve over time with the adaptation matures. In case of adaptation on a national level, monitoring could even lead to the point where adaptation strategies are being mainstreamed into a country's overall policy mix.

Figure 2 indicates a broad framework for adaptation and clearly highlights the monitoring and evaluation function as an important component of any adaptation process. The design of any adaptation to a long-term hazard should, as a result, include specific plans for careful ex post evaluation of performance and performance indicators. Klein et al. (1999) include this aspect as part of an iterative process, where the feedback mechanisms can improve existing adaptation management practices. Well-constructed monitoring and evaluation mechanisms can even go beyond that. Properly informed and conducted, these can contribute to an evolutionary learning-by-doing function that will provide

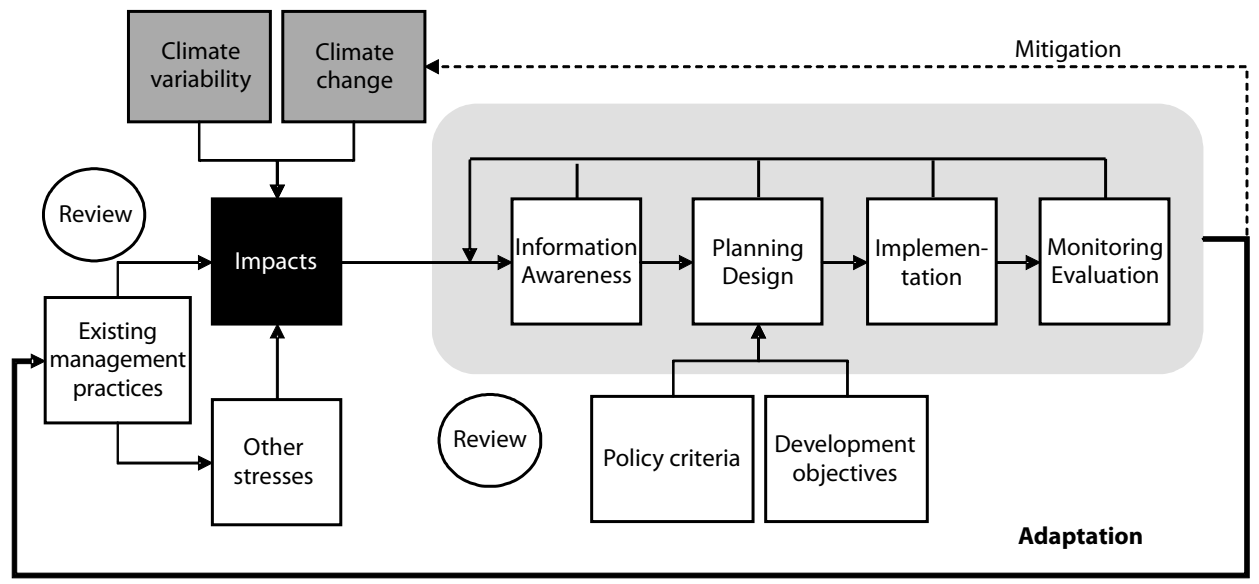

Figure 2. Conceptual framework on response to climate variability and change (from Klein et al., 1999) 
insights into exactly how the adaptation process can evolve most efficiently. In short, evaluation results should be used when formulating new adaptation strategies (Perez and Yohe, 2004).

\subsection{The adaptation policy framework as method for monitoring adaptation}

With support from the Swiss, Canadian and Dutch governments, the National Communications Support Unit of the UN Development Programme (UNDP) has developed an Adaptation Policy Framework (APF) that provides guidance to developing countries as they shape strategies to confront the threat of climate change. The APF offers a flexible approach through which countries can clarify the key issues related to adaptation and develop responsive adaptation strategies, policies and measures. Ultimately, the APF aims to help developing countries as they integrate adaptation concerns into the broader goals of national development.

The APF comprises of five basic components: defining project scope, assessing current vulnerability, assessing future vulnerability, developing an adaptation strategy and continuing the adaptation process. These components are balanced by two cross-cutting components: engaging stakeholders and enhancing adaptive capacity.

Implementing the APF components does not require an abundance of high-quality data, or extensive expertise in computer-based models. Rather, it relies on a thoughtful assessment and a robust stakeholder process, both focused on adaptation to climate change. The last component of the APF focuses on continuing the adaptation process. This involves implementing, monitoring, evaluating, improving and sustaining the initiatives begun by the adaptation project.

The APF is supported by a series of nine Technical Papers (TPs). Each TP explores a specific aspect of the APF and provides detailed guidance on one or more of the APF components. Technical Paper 9 discusses a framework for monitoring implemented adaptation strategies mainly at the national level and evaluating the results of those strategies (Perez and Yohe, 2004).

A project sponsored by the UNDP/GEF is currently applying the APF in the context of capacity building for adaptation to climate change in Central America, Mexico and Cuba on a pilot basis. The project is intended to be the first regional application of the APF in the context of developing country based programmes in areas such as water resources, agriculture, human health and land use and forests.

\subsection{Promising indicators for measuring and monitoring adaptation}

Monitoring adaptation is dependent on a well-developed set of indicators and extends well beyond keeping track of the climate risk only. Socio-economic drivers of exposure and sensitivity that frame the adaptation baseline must also be monitored. 
Indicators provide the basis for before-and-after analyses and describe the effects (positive and negative) of programme and project interventions - anticipated and unanticipated, intended and unintended. Performance indicators are quantitative or qualitative measures that can be used to describe existing situations and measure changes or trends over time. Indicators should include both outputs and outcomes (impacts), with explicit statements of why the indicator demonstrates that the goal of the project has been met, and what the functional relationship is between a change in the indicator and a change in the outcome of a project.

Indicators can be described as part of a causal chain. The inter-relationships between natural and social processes have been demonstrated by many studies and summarised in the following way: human activities exert pressures on the environment, including climate, and change the state of the environment while society responds to these changes through environmental, economic, and sectoral policies (the social responses). Perez and Yohe (2004) propose a Pressure-State-Response (PSR) framework, adopted by many international organisations for defining environmental indicators, that can be used to monitor the implementation of adaptation strategies to address climate variability and change in many contexts. For example:

- Indicators can describe pressures on the climate caused by human activities (e.g., greenhouse gas emissions);

- Indicators can describe the state of the environment in terms of environmental quality and aspects of quantity and/or the quality of natural resources; and

- Response indicators can, in the context of the PSR framework, refer only to societal (not ecosystem) responses.

Indicators, however, can be described in at least four other dimensions:

- Indicators of implementation of the adaptation strategies in the various focal areas can enumerate the delivery of technical services, operating funds, and capital inputs with related disbursements and the resulting outputs generated (facilities created, activities and participatory processes organised);

- Indicators of institutional change can demonstrate capacity development, attitudinal and awareness shifts, and policy reorientations;

- Indicators of impact in global and local terms can demonstrate the environmental accomplishments of the adaptation strategies (e.g., disaster damages trend); and

- Indicators of socio-economic conditions can be interrelated with the environmental results and impacts, including measures of the consequences of adaptation strategies interventions.

Table 6 shows the possibility of combining the PSR framework and the three pillars of sustainable development, which have social, environmental and economic dimensions. 
Table 6. Proposed multi-dimension indicators for some adaptation measures in vulnerable systems of LULUCF sector

\begin{tabular}{|c|c|c|}
\hline Dimension & Adaptation measures & Indicator \\
\hline \multirow[t]{4}{*}{$\begin{array}{l}\text { Institutional } \\
\text { change and } \\
\text { community } \\
\text { involvement }\end{array}$} & $\begin{array}{l}\text { Local and national consultation } \\
\text { for the development of } \\
\text { adaptation plan of actions }\end{array}$ & $\begin{array}{l}\text { Adoption of adaptation strategies } \\
\text { Public awareness and } \\
\text { stakeholders' capacity }\end{array}$ \\
\hline & $\begin{array}{l}\text { Land-use planning and decision } \\
\text { making }\end{array}$ & Property rights secured \\
\hline & Creation and legitimisation of & Improved access to information \\
\hline & nature reserves & $\begin{array}{l}\text { Number of nature reserve } \\
\text { legitimised }\end{array}$ \\
\hline \multirow[t]{3}{*}{ Environment } & Stabilisation of wetlands and & Increased ecosystem resilience \\
\hline & Stabilisation of desert expansion & $\begin{array}{l}\text { Reduced erosion, regulated water } \\
\text { yield and enhanced carbon stocks }\end{array}$ \\
\hline & $\begin{array}{l}\text { Watershed protection through } \\
\text { flood, land slide and erosion } \\
\text { control }\end{array}$ & \\
\hline \multirow[t]{2}{*}{$\begin{array}{l}\text { Poverty } \\
\text { alleviation }\end{array}$} & $\begin{array}{l}\text { Improvement of production } \\
\text { systems }\end{array}$ & Improved productivity \\
\hline & $\begin{array}{l}\text { Valuation and payment for } \\
\text { ecosystem services }\end{array}$ & $\begin{array}{l}\text { Improved access to financial } \\
\text { support and market }\end{array}$ \\
\hline
\end{tabular}

Whatever indicators are selected and measured, it is important that a well-designed monitoring protocol be developed and used to attain a predetermined acceptable level of precision (where precision is used to indicate the range within which the true value lies). Generally, monitoring of the total project area or all participants cannot be accomplished and the monitoring must rely on a statistically-based approach where a sample of the population of interest is monitored. In designing such a system it is important that a statistically sound method be used to determine how many samples must be monitored. It is important to remember why one is monitoring the project - in order to determine, with a high degree of confidence, whether the activity has made a difference when compared to a baseline or pre-activity period. Thus resources must be made available to allow for a sound monitoring programme where the sampling design is based on statistical analysis. For instance, if the statistical design suggests that 50 samples (could be plots on the land or communities or people) need to be $95 \%$ confident that the true value of the change in the indicator is within $\pm 15 \%$ of the mean value (pre-determined level of precision), then sampling fewer units will unlikely provide the required results and may appear to show no significant difference between baseline and performance. Thus it is important that adequate resources be allocated to measuring and monitoring the performance of adaptation and mitigation project activities, but often this is not the case and monitoring is often given 'short shrift'. 


\section{Adaptation and mitigation in other UN conventions}

The UNFCCC acknowledges the importance of the linkages to other multilateral policy processes and the need to ensure coherence among their mandates. Its Article 7.2(I) calls for the COP to seek and utilise the services and co-operation from relevant international organisations, including NGOs, and its Article 8.2(e) requests the UNFCCC secretariat to ensure the necessary co-ordination with the secretariats of other bodies. Co-operation among international conventions has received greater attention by the UNFCCC in the past few years, as Parties have recognised the need for ensuring that decisions under different bodies are not conflicting and for promoting synergies aimed at reducing the costs of implementation of different decisions and obtaining increased collateral benefits from the actions undertaken to comply with them.

For some years now, Parties to the UNFCCC have been engaged in the task of identifying the best way to pursue this collaboration while at the same time ensuring the environmental integrity of each process and compliance with their mandates. The discussions among them have been compiled in two decisions of the UNFCCC COP ${ }^{4}$ and several conclusions of its Subsidiary Body for Scientific and Technological Advice (SBSTA). These conclusions have highlighted that most of the opportunities for collaboration and synergy exist at the national level, when Parties engage in activities for the implementation of several mandates. Although explicit references have not been made, some Parties believe that forests could be one of these areas, given their role in the issues of desertification, climate change and biodiversity.

The main channel for co-operation at the convention level is the establishment of the Joint Liaison Group (JLG), which consists of the executive secretaries, relevant coordinators and chairs of the different bodies to the UNFCCC, the Convention on Biological Diversity (CBD) and the UN Convention to Combat Desertification (UNCCD) - the three 'Rio Conventions'. The mandate of the group is to improve the exchange of information, to explore opportunities for synergy and to increase co-ordination between these conventions and their secretariats. The JLG meets on a regular basis and works upon the mandate of the COPs of the different conventions. In its fifth session, which took place on January $2004^{5}$, the JLG stressed that the objectives of the three conventions are interlinked and that realising synergies is important to achieve these objectives and to use resources efficiently. It also called attention to the fact that the

\footnotetext{
${ }^{4}$ The UNFCCC COP has adopted two decisions on co-operation between conventions. The first is decision 13/CP.8, which supports the mandate of the Joint Liaison Group and requests the Subsidiary Body for Scientific and Technological Advice (SBSTA) of the UNFCCC to continue to co-operate with the Subsidiary Body for Scientific, Technical and Technological Advice (SBSTTA) of the Convention on Biological Diversity (CBD) and the Committee on Science and Technology (CST) of the UN Convention to Combat Desertification (UNCCD). A second decision in relation to the report on the linkages between biological diversity and climate change was adopted by the UNFCCC in December 2004.

${ }^{5}$ The report of this meeting is available at: http://unfccc.int/resource/docs/2004/sbsta/inf09.pdf.
} 
Global Environment Facility (GEF) could enhance synergies by promoting project implementation in a co-ordinated and co-operative manner. The group also supported what has been discussed at SBSTA, by stating that synergies are most important at the national level, where implementation takes place.

Rather than focusing on a specific issue (such as forests), the UNFCCC has made progress in identifying areas where potential collaboration between conventions could be pursued-education and outreach, research and systematic observation, capacity building, reporting and impacts and adaptation to climate change. A significant amount of activities under the UNCCD, the CBD and the UNFCCC are covered by these areas and, thus, opportunities for joining efforts could be focused in these.

As stated above, the UNFCCC has stressed the fact that co-operation and synergy between the different conventions is more effective at the national level, where Parties jointly implement activities relating to each convention. It is up to Parties to develop the best way to join these activities according to their national realities and institutional structures. In relation to forests, the room for joint efforts and co-operation between conventions is indeed large given the connection between activities such as forest management and conservation, reporting and others that are needed to implement each international process.

However, at the international level, the CBD has taken some steps in enhancing co-operation between the conventions specifically directed at ensuring that activities for the implementation of one convention do not go against the principles and activities of the others. The implementation of the UNFCCC, in particular decisions on LULUCF ${ }^{6}$, have triggered concerns on the possible impacts on biodiversity and landscape from activities intended to sequester carbon. This matter has been considered by the Subsidiary Body for Scientific, Technical and Technological Advice (SBSTTA) of the CBD, which requested the IPCC to elaborate a report on the links between climate change and biodiversity. The report (Gitay et al., 2002) provides a thorough description of the impacts of climate change on biodiversity in general and also provides an analysis of the possible impacts of the implementation of LULUCF activities.

In April 2004, the secretariats of UNCCD and CBD in co-operation with the UNFCCC secretariat, organised a workshop to promote synergies in their implementation. It was recognised that these conventions share a common concern for many environmental and sustainable development issues. The emerging significance of the inter-linkages and trade-offs concerning core issue areas covered by the conventions point to the strong potential for synergies. It has been largely recognised that LULUCF is such an area. But this raises questions about how these activities should be synergise, and where or on which level to begin. It also requires us to ask what sort of mechanisms could effectively promote these proposed synergies.

\footnotetext{
${ }^{6}$ See decisions 11/CP.7 for LULUCF under the Kyoto Protocol and 19/CP.9 for afforestation and reforestation under the CDM.
} 
The workshop recognised a number of relevant work including the Expanded Programme of Work on Forest Biological Diversity (CBD decision $\mathrm{VI} / 22$ ), the Joint Work Program between the CBD and the UNCCD on biological diversity of dry and sub-humid lands, the Proposals for Action of the Intergovernmental Panel and Forum on Forests (IPF/IFF Proposals for Action) and three UNFF 4 documents, 'Enhanced Cooperation and Policy and Program Coordination', 'Traditional Forest-Related Knowledge' and 'Scientific ForestRelated Knowledge'.

\subsection{LULUCF activities serve as an entry point}

Synergising the UNFCCC, CBD, and UNCCD requires linking their provisions on sustainable forestry, adaptation measures, monitoring and environmental impact assessment. LULUCF activities, as noted in the language of UNFCCC, can serve as an entry point where links and synergies can take place. The steps towards this would eventually lead to joint efforts among these conventions to analyse the impacts of climate change on biological diversity and integrate biodiversity considerations into the implementation of LULUCF activities under the CDM for mitigating climate change or under adaptation measures as well as to combat desertification and land degradation. It is extremely important that the reporting systems under the conventions facilitate such effort prior to the first commitment period of the Kyoto Protocol (2008-2012). Subsidiary bodies of the conventions should be able to provide technical advice to the COPs, especially the COP that serves as the meeting of the Parties (MOP) of the Protocols. The instruments and tools to address and resolve the conflicts under the conventions have to be developed and applied in the implementation of LULUCF-CDM projects.

There are a number of provisions under the Rio Conventions that can be applied to enhance adaptation measures while engaging in mitigation activities. In light of the alarming rate of deforestation such an effort is becoming very urgent. However, there is no single provision that is legally binding. On the other hand, some provisions under the UNFCCC and its Kyoto Protocol bundled with activities with multiple objectives could attract new markets.

As shown in Table 7, there are strong interfaces between the Rio Conventions regarding sustainable forestry, monitoring, reporting and information exchange, environmental impact assessment, and financial mechanisms. Because the $\mathrm{CBD}$ is not legally binding, biodiversity conservation hardly receives attention as far as the mobilization of public funding is concerned. On the other hand, private engagement on bio-prospecting leading to financial benefits and property rights ownership often neglect local communities who are frequently the conservation agents at their own costs (Balmford and Whitten, 2003). The situation becomes more complicated when LULUCF or carbon offset projects are involved where afforestation and reforestation are eligible under the $\mathrm{CDM}$ and thus legally binding under the Kyoto Protocol. Synergising the two conventions is apparently unavoidable and increasingly becomes an important national agenda to be implemented at local level. Innovative actions with 
Table 7. Interfaces between the articles of UNFCCC, CBD and UNCCD

\begin{tabular}{lccc}
\hline Issues & UNFCCC/ Kyoto Protocol & CBD & UNCCD \\
\hline Sustainable forestry & $4.1 \mathrm{~d} /$ & 10 & - \\
\hline Adaptation measures & $3.3,3.4,3.7$ & - & 18 \\
& $\begin{array}{c}4.1 \mathrm{~b}, 4.4 / \\
12.8\end{array}$ & 7 & 26 \\
\hline $\begin{array}{l}\text { Monitoring, reporting, } \\
\text { information exchange }\end{array}$ & $\begin{array}{c}4.1 \mathrm{a} / \\
6,12\end{array}$ & 14 & - \\
\hline $\begin{array}{l}\text { Environmental impact } \\
\text { assessment }\end{array}$ & $4.1 \mathrm{f}$ & 20,21 & 20,21 \\
\hline Financial mechanism & $\begin{array}{c}4.3,4.11 / \\
11\end{array}$ & & \\
\hline
\end{tabular}

proper guidance from the subsidiary bodies through the secretariats would encourage national governments to facilitate and implement projects with multiple objectives. Leverage from biodiversity values will increase relevance from the perspective of local livelihoods and enhance the public image of investors.

Simplified procedures should be encouraged and devised because they will not only encourage participants, but also attract potential investors. It is important to note that synergies should be demand-driven rather than generalised undertakings, as this would allow for a greater alignment of national development agendas with global priorities. More voluntary markets are expected to emerge and compete with the existing CDM market mandated by the Kyoto Protocol.

When carbon benefits and biodiversity values are targeted, trade-offs between global and local objectives should be demonstrated. This may be ensured during the development of project design at which point approval will be given by the Designated National Authority (DNA) after going through various review processes, including by stakeholders. Lessons from the UNFCCC's activities implemented jointly (AIJ) and recent pilot projects in anticipation of the entry into force of the Kyoto Protocol (CBD Ad Hoc Technical Expert Group on Biodiversity and Climate Change, 2003) may be carefully analysed.

\section{The way forward}

\subsection{Attracting new markets and payment for ecosystem services}

It is widely recognised that financial resources will always be limited, and will not be sufficient to meet the increasing demand for mitigating the effects of loss of biodiversity and climate changes. Besides the stringent rules that are imposed on LULUCF-CDM activities, the carbon market may become oversupplied. It means that investing in forest carbon projects is less attractive or perhaps even risky. Financial mechanisms to protect and utilise biodiversity values are currently being explored by various intermediaries and certifiers who will later play key roles in the implementation phase. Figure 3 represents pathways 


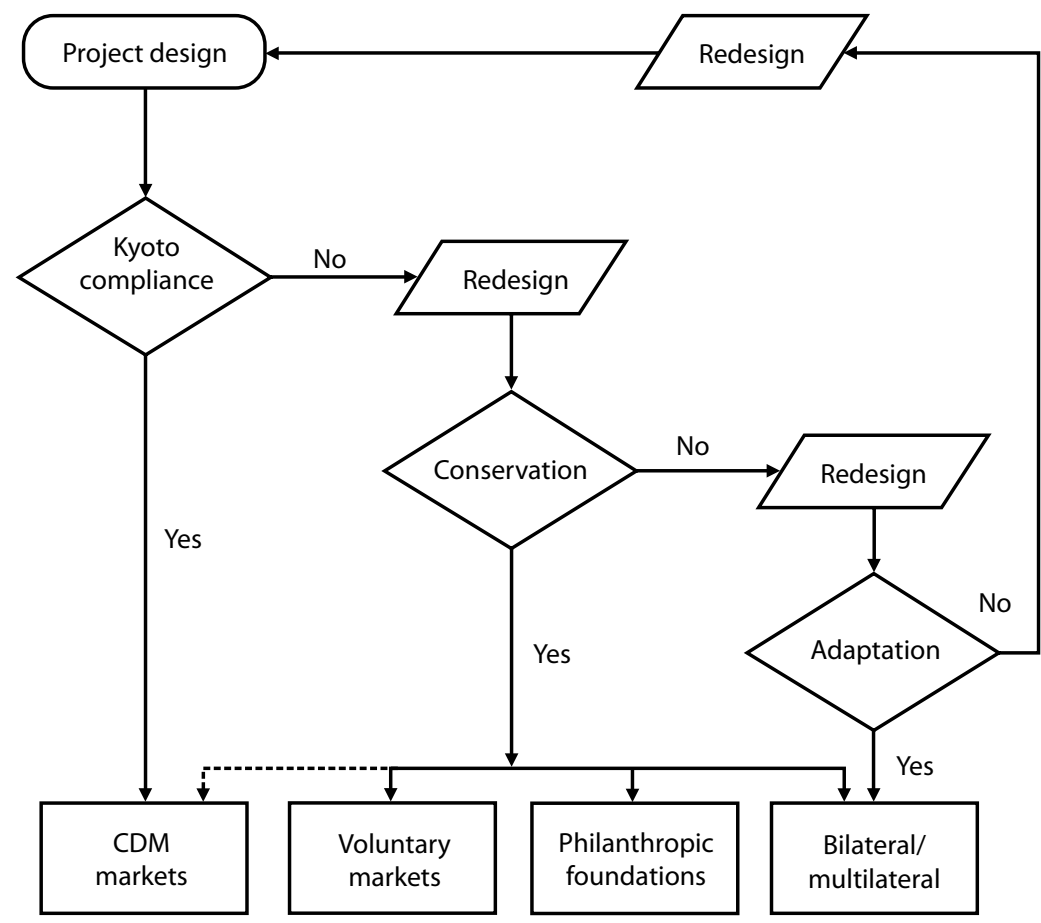

Figure 3. Possible pathways for mitigation and adaptation measures in LULUCF sector to attract potential markets (Source: Murdiyarso, 2004)

that allow project developers to design and redesign the proposed activities with regards to meeting the requirements of the potential markets. Voluntary and incremental mechanisms for conservation and adaptation activities are currently excluded from CDM market (Murdiyarso, 2004).

Straightforward carbon sequestration projects that comply with Kyoto rules may be less favourable from the perspective of the sellers since they will bear high transaction costs with the embedded market uncertainties and longterm engagements (Milne, 2001). Likewise, isolated biodiversity conservation projects will not receive much attention from the perspectives of the buyers, especially when private sector engagement is expected. Small-scale carbon projects that address local livelihoods and are implemented at community level are likely to survive. This may result in the design of adaptation measures where win-win situations between adaptation and mitigation may be achieved. Replicating projects would build confidence, narrow the gaps, and lead to more lessons allowing better design for future projects.

The project would be cost-effective when the objectives of the conventions are synergised. Leverage from Official Development Assistance (ODA) may be optimised without breaking the agreement, such as that approved at UNFCCC COP-7 in November 2001. Simultaneously, the private sector will be increasingly in supporting the implementation of environmental and sustainable development agreements. 
The conservation of natural resources including forests is too often carried out at the expense of the poor rural communities by the imposing of restrictions on resource use without adequate compensation for lost opportunities. As a result, private and individual investments that sustain nature and livelihoods have been neglected. Meanwhile, a traditional model of publicly financed conservation is declining due to growing government budget crises and shifted priorities. At the same time, public funding through Multilateral Environmental Agreements (MEAs) such as the Rio Conventions is limited and highly competitive among Parties, depending on capacity of the duty-bearers or governments. Moreover, the funding is not easily accessible to stakeholders, especially the rural poor.

Consistent with conservation activities, there is an increasing interest to manage forests in light of services they provide, including carbon sequestration, biodiversity conservation, and watershed protection. Promotion of marketbased activities and policy instruments to capture the value of these services is underway on state and international levels. Modalities and procedures for carbon credits have been well defined and may be used as an entry point for the payment for environmental services. However, rules for implementing other ecosystem services should be explored, defined and tested.

Public policy making should be improved to integrate biodiversity, climate change and desertification and drought issues, which should be supported in a holistic and co-ordinated manner through forest landscape management that includes:

- Prevention and mitigation of threats to forest ecosystems;

- Forest landscape restoration;

- Sustainable forest management; and

- The creation of enabling environments.

Payment for environmental services may be explored to reduce poverty, improve livelihoods and finance conservation activities by capturing forest ecosystem services through:

- Carbon benefits for sustainable livelihoods;

- Access and share the benefits of forest genetic resources;

- Appropriate technologies to restore water yields and degraded lands; and

- Forest-related knowledge to adapt with future change of society and physical environment

\subsection{Levels of action}

As we have discussed, there are many opportunities and challenges in using linkages between climate change adaptation and mitigation. These can be found at the local as well as national and even international levels. As a preliminary guidance we present a summary of key issues that should be considered at these levels during the planning, implementation and monitoring of programmes and projects dealing with land-use change and forestry. 
Efficient communication between the conventions, national focal points and other relevant stakeholders, particularly the UN Forum on Forests (UNFF) and the GEF, through suitable operational institutional arrangements, could ensure harmonised planning and implementation of the conventions, i.e., effective consultation and mutual co-operation between National Biodiversity Strategy and Action Plan (NBSAPs) under the CBD and National Adaptation Programmes of Action (NAPAs) under the UNFCCC. Analysis and reporting of national-level impacts of national forest programme implementation will enrich the preparation of technical work for COPs.

National capacity in negotiating at international level and in facilitating stakeholders' interactions at local level should be strengthened. The national forest programmes may be used as a platform to exercise these activities in both directions. Initiatives under other UN auspices, such as the Food and Agriculture Organization (FAO), UNFF, and Collaborative Partnership on Forests (CPF) may also be utilised (Table 8).

\subsection{Applied research and capacity building needs}

It is anticipated that from the lessons learned, information gaps will emerge. A research agenda will need to accommodate these emerging issues. This is particularly important when the benefits of biodiversity values are optimised to achieve climate change mitigation and adaptation in the long run. Among other issues, research needs include the development of guidelines to participate in projects, tools for analysing impacts and vulnerability, and methodologies for monitoring synergised projects.

There are three research questions that guide the efforts to understand the vulnerability of ecosystems, mitigation and adaptation to climate change:

1) What is our fundamental understanding of vulnerability to climate change?

Forest ecosystems across the world may adapt to the changing climate in different ways. By identifying key areas (e.g., biodiversity hotspots) one could develop and test the vulnerability of ecosystems and adaptability of the natural and human systems.

2) How can knowledge be disseminated to influence public policy making?

Since adaptation measures are not on the 'radar screen' of many national decision-making bodies, there are opportunities to influence policymakers in facilitating initiatives from various stakeholders with different needs and interests.

3) What are the management options to mitigate and adapt to the changing climate?

Scientific findings would help provide strategic frameworks and eventually practical management options to adapt and mitigate the changing climate in the interest of the sustainable use of natural resources and livelihoods. Access to markets would be a critical issue where conservation activities by the community would earn payments for their living. 
Table 8. Key issues and actions needed during the planning, implementation and monitoring of programs and projects at various levels

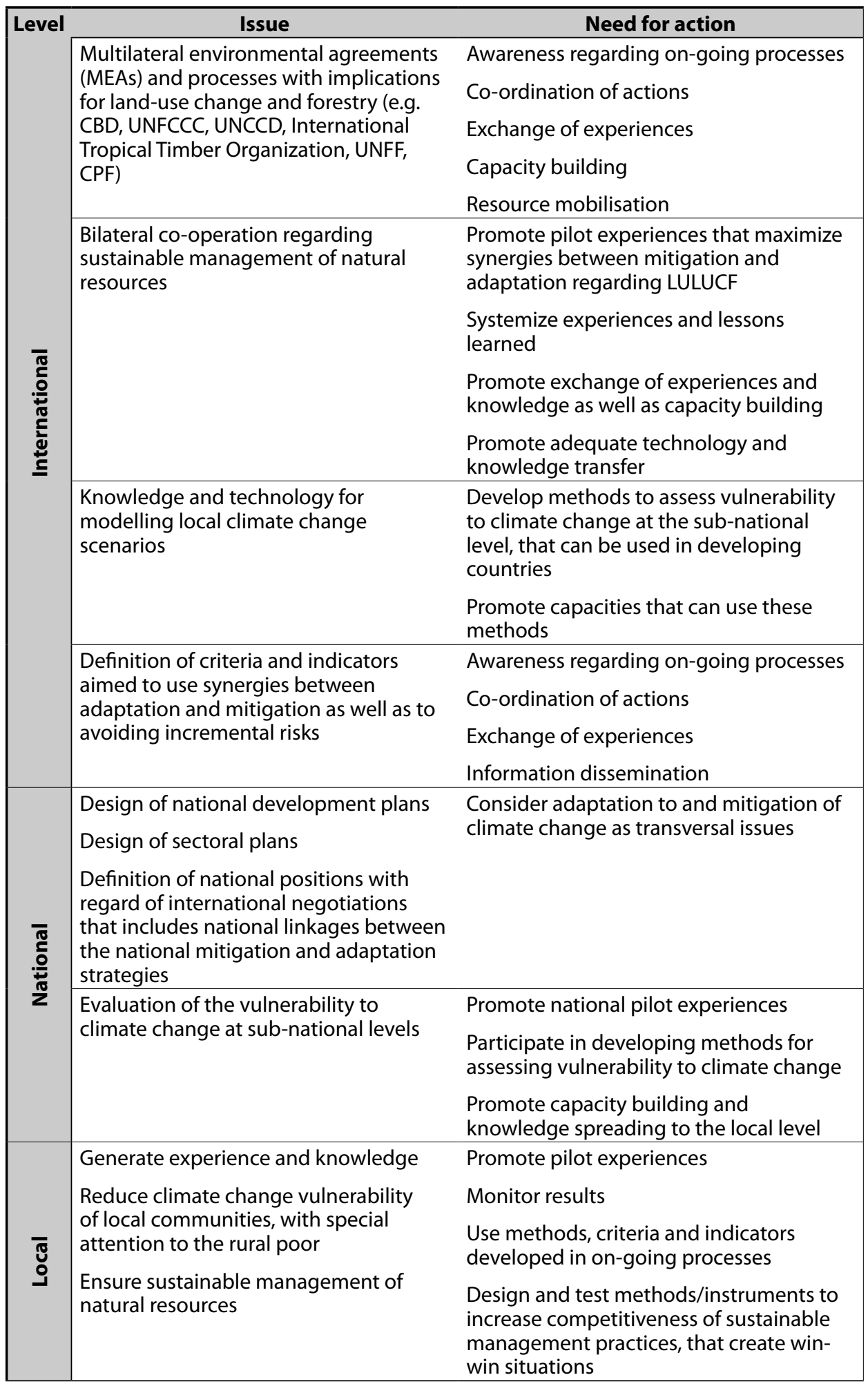


There is no doubt that the process of identifying the best adaptation/ mitigation interventions is a complex task. National bodies need to gain insight into the many tradeoffs involved. However, there is currently no suitable mechanism in place to help institutions obtain the required knowledge and interaction. Unless a critical mass of individuals and institutions at the national level are involved in the process, many countries will lag behind emerging opportunities to link mitigation and adaptation, and they will necessarily bear higher costs of adaptation by not making necessary and timely interventions. This is identified as a critical bottleneck that needs to be addressed to make effective use of possibilities like the CDM to promote sustainable development, particularly in developing countries where vulnerability to climate change is frequently the highest.

One of the challenges in capacity building activities is that most of the institutions at national level dealing with international agreements do not always communicate. Communication gaps are also found across institutions. There is an opportunity that national forestry programmes to be used as national platforms, through which public or private enterprises could be engaged in real projects. National-level action plans, namely UNFCCC NAPAs, National Action Plans (NAPs) under the UNCCD, and NBSAPs under the CBD may be integrated. The capacity of governments to monitor, report, and communicate the implemented projects is relatively low. Strengthening this capacity will undoubtedly narrow the knowledge gaps and improve the synergised implementation of these conventions, particularly in forestry sector.

Capacity building in countries where tropical forests reside should focused on:

- Project identification and information gathering;

- Project formulation and development;

- Market assessment and benefit/cost analysis; and

- Risk analysis and management.

With such capacities, countries could efficiently engage in project in costeffective manner to achieve sustainable development objectives.

\section{References}

African Development Bank, Asian Development Bank, UK Department for International Development, European Commission Directorate-General for Development, German Federal Ministry for Economic Cooperation and Development, The Netherlands' Ministry of Foreign Affairs Development Cooperation, Organization for Economic Cooperation and Development, UNDP, UNEP, The World Bank (2003) Poverty and Climate Change - Reducing the Vulnerability of the Poor through Adaptation, World Bank: Washington, D.C. 
Alarcón, J. and many others (2001) Primera Comunicación Nacional ante la Convención Marco de Naciones Unidas sobre Cambio Climático (Colombia's first national communication to the UNFCCC) IDEAM: Santafé de Bogotá.

Applegate, G., D. Raymond (2001) Code of Practice for Industrial Tree Plantation Development in the Tropics CIFOR; Bogor.

Balmford, A., T. Whitten (2003) 'Who should pay for tropical conservation, and how could the costs be met?' Oryx 37(2): 238-350.

Cacho O., G. Marshall, M. Milne (2002) 'Smallholder Agroforestry Projects: Potential for Carbon Sequestration and Poverty Alleviation' FAO ES Technical Series Working Paper, FAO: Rome. Internet: http://www.fao.org/ es/esa/estudies.html.

Callaway, J.M., L.O. Naess, L. Ringuis (1998) 'Adaptation Costs: A Framework and Methods' in Mitigation and Adaptation Cost Assessment, Concepts, Methods and Appropriate Use UNEP Collaborating Centre on Energy and Environment, Risoe National Laboratory: Risoe.

CBD Ad Hoc Technical Expert Group on Biodiversity and Climate Change (2003) Interlinkages Between Biological Diversity and Climate Change: Advice on the Integration of Biodiversity Considerations into the Implementation of the United Nations Framework Convention on Climate Change (UNFCCC) and Its Kyoto Protocol, CBD Technical Series no. 10, Draft Report for Experts and Government Review, CBD Secretariat: Montreal.

Fankhauser, S. (1998) 'The Costs of Adapting to Climate Change' Global Environment Facility: Washington, D.C.

Forner, C., C. Robledo (2005, forthcoming) An Introduction to Adaptation of Forest Ecosystems and the Forest Sector to Climate Chang. Prepared for SDC (Swiss Agency for Development and Cooperation) and FAO: Rome.

Gitay, H., A. Suárez, D.J. Dokken, R.T. Watson (2002) Climate Change and Biodiversity, IPCC Technical Paper V, IPCC: Geneva.

ITTO (International Tropical Timber Organization) (2002) ITTO Guidelines for the restoration, management and rehabilitation of degraded and secondary tropical forests. ITTO Policy Development Series No 13. ITTO: Yokohama.

Klein, R.J.T., R.J. Nicholls, N. Minura, N. (1999) 'Coastal adaptation to climate change: can the IPCC Technical Guidelines be applied?' Mitigation and Adaptation Strategies for Global Change 4: 51-64.

Klein, R.J.T., E.L. Schipper, S. Dessai (2003)'Integrating mitigation and adaptation into climate and development policy: three research questions' Tyndall Centre for Climate Change Research Working Paper 40, Tyndall: Norwich.

Lipper, L, R. Cavatassi (2004) 'Land-use Change, Poverty and Carbon Sequestration' Environmental Management 33(3): S374-S387.

Metz, B., O. Davidson, R. Swart, J. Pan (2001) (eds.) Climate Change 2001: Mitigation, IPCC WG III contribution to the TAR, Cambridge University Press: Cambridge.

Milne, M. (2001) 'Transaction costs of forest carbon projects' Working Paper CC05 ACIAR Project ASEM 1999/093, CIFOR: Bogor. 
Murdiyarso, D. (2004)'Implications of the Kyoto Protocol: Indonesia's Perspective' International Review for Environmental Strategies 5(1): 145-154.

Noor, Y.R., J. Heyde, I.N. Suryadiputra (2005) 'Community-based approach to peatland adaptation and management in Central Kalimantan, Jambi and South Sumatra, Indonesia' in D. Murdiyarso (ed.) Carbon Sequestration and Sustainable Livelihoods. CIFOR: Bogor.

Penman, J., M. Gytarsky, T. Hiraishi, T. Krug, D. Kruger, R. Pipatti, L. Buendia, K. Miwa, T. Ngara, K. Tanabe, F. Wagner (eds.) (2003) IPCC Good Practice Guidance for Land Use, Land-Use Change and Forestry, Institute for Global Environmental Strategies (IGES): Kanagawa.

Perez, R., G. Yohe (2004) 'Continuing the Adaptation Process' Technical Paper 9 of the Adaptation Policy Framework, UNDP/GEF: New York.

Poulsen, J., G. Applegate (2001) C\&I for Sustainable Development of Industrial Tropical Tree Plantations, CIFOR: Bogor.

Reid, W.V., H.A. Mooney, A. Cropper, D. Capistrano, S.R. Carpenter, K. Chopra, P. Dasgupta, T. Dietz, A.K. Duraiappah, R. Hassan, R. Kasperson, R. Leemans, R.M. May, T.A.J. McMichael, P. Pingali, C. Samper, R. Scholes, R.T. Watson, A.H. Zakri, Z. Shidong, N.J. Ash, E. Bennett, P. Kumar, M.J. Lee, C. RaudseppHearne, H. Simons, J. Thonell, M.B. Zurek (2005) Millennium Ecosystem Assessment Synthesis Report, Pre-publication Final Draft Approved by MA Board on March 23, 2005, Internet: http://www.millenniumassessment. org/en/products.synthesis.aspx

Ritchie, B., C. McDougall, M. Haggith, N. Burford de Olivera (2000) Criteria and Indicator of Sustainability in Community Managed Forest Landscapes: An Introductory Guide CIFOR: Bogor.

Robledo, C. (2003) 'Modelo Alternativo para el Manejo Sostenible de los Bosques de San Nicolás' Final Technical Report for Project OIMT PD 54/99, EMPA (Swiss Federal Laboratories for Materials Testing and Research): Dübendorf.

Robledo, C. (2004) 'Developments in UNFCCC/IPCC Discussions Regarding Forests and Implications for Tropical Forests and Tropical Timber Producers' Report for the ITTO, Document ITTC(XXXVI)/14, ITTO: Yokohama

Sedjo, R., B. Sohngen, P. Jagger (1998) 'Carbon sinks in the Post-Kyoto World' Weathervane Digital Forum on Global Climate Policy. Internet: http://www. weathervane.rff.org/features/feature050.html.

Smith, J. (2002) 'Afforestation and reforestation in the clean development mechanism of the Kyoto Protocol: implications for forests and forest people' International Journal of Global Environmental Issues 2(3-4): 322-343.

Smith, J., S. Scherr (2002) 'Forest carbon and local livelihoods: Assessment of opportunity and policy recommendations' CIFOR Occasional Paper No. 37, CIFOR: Bogor.

Tomich T.P., M. van Noordwijk, S. Budidarsono, A. Gillison, T. Kusumanto, D. Murdiyarso, F. Stolle, A.M. Fagi (1998) 'Alternatives to Slash-and-Burn in Indonesia' Summary Report and Synthesis Phase II. ASB Indonesia Report No. 8, ICRAF (World Agroforestry Center): Bogor. 
Tropical Forests (2004) 'Alternative financing model for sustainable forest management in San Nicolás - Second Phase: Non-Kyoto rehabilitation areas (Colombia)' Project description on Tropical Forests website, Internet: http://www.tropicalforests.ch/project.php?id=73

UN (1992) United Nations Framework Convention on Climate Change, in 'Report of the Intergovernmental Negotiating Committee for a Framework Convention on Climate Change on the work of the second part of its fifth session, held at New York from 30 April to 9 May 1992. Addendum', Document No. A/AC.237/18 (Part II) /Add.1, Annex I, UN: New York. Internet: http://www.unfccc.int

Watson, R.T., I.R. Noble, B. Bolin, N. H. Ravindranath, D.J. Verardo, D.J. Dokken (eds.) (2000) IPCC Special report on Land-use, Land-use Change and Forestry Cambridge University Press: Cambridge. 


\title{
Biodiversity in a changing climate: A framework for assessing vulnerability and evaluating practical responses
}

\author{
Jennifer Biringer', Manuel R. Guariguata², \\ Bruno Locatelli ${ }^{3}$, Jean-Laurent Pfund ${ }^{4}$, \\ Erika Spanger-Siegfried ${ }^{5}$, Avelino G. Suarez ${ }^{6}$, \\ Sam Yeaman ${ }^{7}$ and Andy Jarvis ${ }^{8}$
}

1. World Wildlife Fund, Jennifer.biringer@wwfus.org

2. Environmental Affairs Officer, Conservation Ecology, Secretariat of the Convention on Biological Diversity, 413 rue Saint-Jacques, Suite 800, Montreal, Quebec, Canada H2Y1N9,

Tel: +514-288-2220, Fax: +514-288-6588, E-mail: manuel.guariguata@biodiv.org

3. CIRAD-CATIE, 7170 Turrialba, Costa Rica,

Tel: +506.558.22.16, Fax: +506.556.84.70, E-mail: bruno.locatelli@cirad.fr

4. Intercooperation, Maulbeerstr. 10, 3001 Bern, Switzerland.

Tel: ++41-31-385-10-10, Fax: ++41-31-385-10-09, E-mail: jlpfund@intercooperation.ch

5 . Union of Concerned Scientists, www.ucsusa.org

6. Institute of Ecology and Systematic, Cuban Environmental Agency,

Carr. Varona km 3 1/2, Capdevila, P.O. Box 802910800 Havana, Cuba.

Tel: (53 7) 87919 17, Fax: (53 7) 86680 54, E-mail: ecologia.ies@ama.cu

7. Zoology Department, UBC, 5270 University Blvd.Vancouver, BC V5T 2P8.

E-mail: yeaman@zoology.ubc.ca

8. (1) International Centre for Tropical Agriculture (CIAT), AA6713, Recta Cali-Palmira km13,

Cali, Colombia. Tel. +57 2445 0000, E-mail: a.jarvis@cgiar.org

(2) International Plant Genetic Resources Institute (IPGRI), AA6713, Recta Cali-Palmira km13,

Cali, Colombia.

\section{Introduction}

Habitat conversion and degradation, overexploitation, displacement by invasive alien species and global climate change are the main processes currently impacting biodiversity. In particular, it is expected that within the next 100 years, terrestrial ecosystems will suffer the most from land use change, followed by climate change and nitrogen deposition (Sala et al., 2000). Although 
past changes in the global climate during the last 1.8 million years produced dramatic contractions of the habitat range of most species, as well as marked reorganisation of biological communities, these shifts occurred in response to rates of climate change that were much lower than those experienced today, and which occurred in landscapes not as fragmented and/or degraded as present and with little human influence.

The effects of global environmental change are already being felt on the Earth's biodiversity at unprecedented rates. Over the last few decades, increases in global temperature linked to anthropogenic greenhouse gas emissions have changed both the timing of reproduction of animals and plants and their habitat distributions, the length of the growing season, and the frequency of pest and disease outbreaks (IPCC, 2002; CBD Ad Hoc Technical Expert Group on Biodiversity and Climate Change, 2003; Root et al., 2003; Parmesan and Yohe 2003). Modern climate change has been directly responsible for the extinction of at least one vertebrate species (Pounds et al., 1999). Even if all anthropogenic additions of greenhouse gases to the atmosphere were to be halted today, the associated impacts of global climate change would be expected to continue for decades to come, making adaptation options and policies to climate change necessary. However, climate change is not likely to affect all species similarly. Certain species or communities will be more prone to extinction than others due to the direct or underlying effects of such change. Particular ecosystem types that are expected to be more vulnerable to global warming are mangroves, coral reefs, high mountain ecosystems, and ecosystems overlying permafrost. The risk of extinction will increase especially for those species that are often characterised with one or more of the following features: limited climatic ranges; restricted habitat requirements; long generation times; and small breeding populations.

There is strong evidence that biodiversity significantly influences the provision of ecosystem services. Examples of ecosystem services affected by biodiversity are pollination, seed dispersal, climate regulation, carbon sequestration, agricultural pest and disease control, and human health regulation. Also, by affecting processes such as primary production, nutrient and water cycling, and soil formation and retention, biodiversity indirectly supports the production of food, fibre, and drinking water. Therefore, human well-being in the face of changing global climate is directly linked to ecosystem conservation and for human systems to adapt to climate change. For the purposes of this chapter, we use the term biodiversity as the variability among living organisms from all sources, including terrestrial, marine, and other aquatic ecosystems and the ecological complexes of which they are part. The definition includes diversity within and between species and among ecosystems types. The most appropriate measure of biodiversity will depend on the value and/or process being assessed.

In light of the value of biodiversity, it is important to assess the vulnerability of populations, species, and ecosystems to both contemporary climatic change and other anthropogenic stresses, and to evaluate the prospects for reducing 
these impacts. While the physical environmental aspects of climate change are largely beyond human control, other biological and environmental stresses can limit the resilience to these changes, and should be addressed where possible. Enhancing the resilience of biodiversity to climatic changes therefore involves a dynamic assessment of the degree of impact resulting from any significant stresses versus the difficulty of mediating the effects of these stresses. This will inevitably require consideration of the local conditions in each given context, which may often involve methods that are highly case-specific (e.g., impacts of localised industrial pollutants).

Thus, this chapter aims to provide an overview of methods and approaches which may be generally applicable across a wide variety of contexts and at different levels of biological organisation in order to perform vulnerability assessments to enable users define relevant issues and provide adaptation options to minimise biodiversity loss due to climate change. The next section relates on assessing a system's vulnerability to climate change; its first part considers stresses to the system in question and the second part considers the ability of the system to adapt. As a response to this assessment, the chapter finishes with a range of policy/management options.

\section{Assessment Process}

\subsection{Vulnerability assessment}

Climate plays a fundamental role in the physiology and ecology of species. Factors such as the ambient environmental temperature and the availability of moisture (in terrestrial ecosystems) are defining characteristics in the niches of all species on earth. Climatic change therefore poses a considerable threat to species survival and biodiversity, and changing environmental conditions are thought to be a principal cause of previous periods of widespread species extinction (Wilf et al., 2003). To survive climatic changes, species must either adapt to the changing conditions or migrate to areas where the climate resembles their niche and is suitable to their survival. In most cases, responses to climate change will likely involve both of these aspects (Davis and Shaw, 2001). The principal aim of a vulnerability assessment is therefore to predict the probable extent of climatic change and to examine the likelihood that a given species will be able to adapt or migrate, taking into account existing non-climatic stresses affecting its survival. In many cases, non-climatic stresses may exacerbate problems caused by climate change, or limit the ability of a species to respond to the changes in their environment. A simple example is how anthropogenic habitat fragmentation presents barriers which can limit migration and the tracking of changes in climate. As plants are typically much more limited in their migratory ability and are often more directly impacted by changes in climate, the following sections will focus heavily on assessing vulnerability in plant species; however, many of the methods described will also be of general applicability. 
Here we divide the vulnerability assessment into two sections: stresses to the system and adaptive capacity. We have also divided these into sub-sections describing various methodologies, however it should be kept in mind that many of these sections are inter-linked and must not be considered in isolation (e.g., genetic diversity may often depend upon the connectivity between populations). While a variety of other environmental threats can also impact the ability of species and ecosystems to survive climatic change (e.g., pollution, invasive species), here we discuss only the most generally applicable stresses and techniques for assessment, as a full survey of these more specific impacts is beyond the scope of this paper. Nevertheless, any assessment of vulnerability should always consider the full spectrum of impacts including those not covered in detail. Following the Intergovernmental Panel on Climate Change (IPCC), vulnerability is defined as "the degree to which a system is susceptible to, or unable to cope with, adverse effects of climate change, including climate variability and extremes". It must be pointed out also that while climate change is an ongoing process with anticipated lag-time effects, most of the types of analysis discussed here require the definition of a given window in which the changes and biological responses are to be considered.

\subsubsection{Stresses to the system and assessment tools}

\subsubsection{Modelling climate change}

Knowing the potential magnitude of change that a specific location is expected to experience is a fundamental variable in assessing impact and adaptation of biodiversity in the face of climatic change. Global Circulation Models (GCMs) provide scenarios for future climatic change, the details of which are discussed in previous chapters. GCM models produce climate change scenarios at a coarse scale (typically with grid cells exceeding $2 \times 2$ degrees), which is inappropriate for examining potential changes in biodiversity. The fundamental problem occurs because biodiversity varies spatially at a much finer scale than the results of GCMs, so the first step in examining climate change effects on biodiversity requires downscaling of GCM data. Temperature changes can easily be downscaled using a digital elevation model (DEM), through application of lapse rate models which adjust the ambient temperature based on the elevation. However, changes in rainfall are a little more complicated to deal with. Jones et al., (2003) used co-variable interpolation to combine large-scale climatic changes (derived from GCMs) with more regional-scale spatial variation in climate (using the present distribution of temperature, rainfall etc.). This method assumes that regional distribution of climate stay the same (i.e., areas of rain shadow in present day climate will also be rain shadow in future climates), but applies GCM derived absolute changes to these values. The resultant surfaces of predicted climate change have a grid cell size of 10 minutes (approximately $18 \mathrm{~km}$ at the equator), representing a more suitable scale at which to examine the potential changes expected to impact biodiversity in any given site. 
These models can be used to extract information to gain an understanding of the likely degree of climate change in any areas of interest. This information can then be used to experimentally assess species responses or can also be applied to species distribution modelling (described below) to predict changes in range. Techniques are more fully described in Chapter 1 of this volume.

\subsubsection{Assessment of species distribution and conservation coverage}

The combination of analyses of species distribution and coincidence with areas under different levels of protection permits a crude assessment of vulnerability of a species. Species distribution models provide an extra layer of information for vulnerability assessments, providing detailed quantification of the 'adaptation envelope', often climate related. These results can then be coupled with future climate predictions from GCMs to provide scenarios for future movement in species distribution, and potential implications for conservation.

Harvesting and land-use change present significant stresses to the longterm survival of both species and ecosystems. By imposing a limit on these impacts, conservation areas present one means of mitigating such stresses. The degree to which the range of a species or ecosystem type is included in reserves and protected areas is therefore a useful indicator of the level of stress it faces at present. While reserve coverage may have little effect on mitigating the direct impacts of climate change (i.e., physical temperature and moisture availability), it may aid in protecting biodiversity by reducing other indirect threats which limit the ability of populations and ecosystems to adapt to climatic change (e.g., fragmentation or reduced population size).

Numerous approaches to assess the effectiveness of conservation coverage have been developed over time. Generally speaking, they consist of two parts: an analysis of the geographical distribution of the species or ecosystems of interest, and a comparison to the spatial coverage and degree of protection afforded by any existing conservation areas. This general approach also requires considerable understanding of the species or ecosystem biology, since raw numbers describing percentage or absolute area of conservation coverage are of little meaning without an accompanying understanding of the minimum requirements of a population or ecosystem.

Methods used to describe the distribution of the species or ecosystem will depend upon the resources available and the extent of current scientific understanding. Species distribution maps were often originally prepared using field-based observations of the presence/absence of the species. More recently, various methods have been developed to predict the distribution of a species or ecosystem using components that are considered to be predicting factors in its niche or characteristic environmental adaptation. Species distribution models use the conditions at points where a species has been found to build a statistical model of the species adaptation envelope. The model is then applied across the larger region to locate areas where the conditions are potentially suitable for the species in question. Many of these range estimation methods assume that climatic variables are the principal drivers of geographic 
distribution (Walker and Cocks, 1991; Franklin, 1995; Guisan and Zimmerman, 2000), although other factors also have been used, including soils (Anderson et al.,, 2002), topography (Draper et al., 2003), specific habitat conditions (Reutter et al., 2003), landform type, or solar radiation (Maggini et al., 2002; Ray et al., 2002; Powell et al., 2003; Lipow et al., 2004). Guisan and Zimmerman (2000) discuss some of the applications of species distribution modelling and the various algorithms that have been applied to the problem. Perhaps the most widely recognised method uses generalised linear models (GLMs), specifically logistic regression, to predict species distribution (Cumming, 2000; Pearce and Ferrier, 2000; Guisan et al., 2002; Osborne and Suárez-Seoane, 2002; Draper et al., 2003), though many other methods exist, including principal components analysis (Jones et al., 1997; Jarvis et al., 2003) and neural networks (Anderson et al., 2002). No single method is better than the other, and very much depends on the type of data available and the precise aims of the study.

Studies can also use remotely-sensed information (e.g., vegetation cover) to further refine model-based predictions, as has been used for mapping the distribution of great bustards (Osborne et al., 2001). Since different types of ecosystems can often be delineated by satellite image analysis alone, it is sometimes possible to map ecosystem types using remotely-sensed images, as was done by Armenteras et al. (2003).

It is important to note that the predictive models discussed above are based on an evaluation of the niche conditions in areas that are known to be inhabited by the given species. As such, these predictions could be biased by under-collection of samples (which would tend to underestimate niche breadth and species distribution) or by collection of samples in areas that are non-typical of their niche (which would tend to overestimate the breadth and niche distribution). It should also be noted that since these models calculate the maximum probable extent of a species distribution, they will tend to overestimate the distribution in areas where other unaccounted factors could exclude a species (e.g., human impacts, particular edaphic conditions, or interspecific competition).

To evaluate coverage, these species distributions can then be compared with maps of conservation areas, which are typically obtained by digitizing existing paper maps for use in geographical information systems (GIS). Studies typically rank conservation areas based on the degree of protection that they provide, and how effectively this coverage will protect the species or ecosystem involved from harvesting and land-use change. A global GIS map of conservation coverage is also available from the World Database on Protected Areas (World Commission on Protected Areas, 2004). Nevertheless, the categories describing the type of conservation area should always be compared with local policy and assessments to ensure accuracy. Quantitative comparisons can generate statistics such as the percentage of a species range under conservation, absolute area of a species range under conservation, and number of populations conserved. 
Evaluating only the current extent of reserve coverage for a species fails to account for possible changes in the geographic distribution of species and ecosystems if they migrate as a response to climate change. Jarvis et al. (2001) coupled climate change scenarios from GCMs with species distribution modelling to evaluate the potential changes in species range. This method uses the downscaled future climate scenarios of Jones et al. (2003) to apply the species climatic envelope to surfaces of future climate. The method was applied on 17 species of wild peanut in South America, and predicted that 12 of these species had no overlapping species distribution between the climatic envelope in the present climate and a 2055 predicted climate. This method assumes no degree of adaptation for the species in question, though it is expected that each species has a certain degree of adaptability.

\subsubsection{Assessment of harvesting activities}

The harvest of plants and animals is a major non-climatic stress to biodiversity. The assessment of this stress is necessary for evaluating the vulnerability of biodiversity to climate change, as unsustainable harvesting of resources may reduce the adaptability of populations or ecosystems. The assessment of harvesting activities aims to determine which resources are harvested, where, when, at which rate, and also to evaluate the sustainability of the current harvesting regime.

In an overall adaptation programme, the assessment of harvesting activities is also a way to evaluate social vulnerability to climate change because of the relevance of harvesting in many livelihoods strategies. For reducing the non-climatic stress on biodiversity, some current harvesting regimes may be modified as an adaptation measure. This modification require knowing who are the harvesters and how, when, where, and particularly why they harvest. Taking into account that major threatened ecosystems by climate change (e.g., mountain forests, mangroves, etc.) are natural assets for rural livelihoods, the assessment of harvesting will help conservation and management practices and identify information dedicated to future adaptation needs for both community and biodiversity, e.g., the 'domestication/replanting' of useful species, the management of corridors and of protective forests (coastal, riparian, mountain zones).

How can harvesting practices be assessed?

Stakeholder analysis is a way to study the key actors of natural resource management, their actions, and their interests (Grimble and Chan, 1995). A stakeholder analysis starts with the identification of principal stakeholders in relation to resource management. Then, the stakeholder interests, characteristics and circumstances must be analysed. Interviews of sampled stakeholders must collect data on how they use and manage the resource, what benefits they receive from the resource, and how they take individual or collective decisions on resource use and management. The information related the spatial distribution of practices may be stored in simple maps or more 
elaborated GIS. The stakeholder analysis gives an insight into the harvesting practices and the possibility of modifying current management, as stakeholder interest and motivations are investigated. However, the method is not suitable for situations where stakeholders are not transparent with the interviewer, for instance by concealing some harvesting activities.

Another way to study the harvesting practices may use field estimations, especially in the case where the harvesters can not be identified or interviewed (e.g., illegal or diffuse activities, migratory stakeholders). The objective is to get an estimation of the harvesting rates (e.g., hunted animals or gathered medicinal plants) by evaluating quantities carried by stakeholders met during field trips in the ecosystem or at strategic points, such as at markets or along roads. Some information may be gathered by interviews with the harvesters. This method is generally expensive as it requires an extensive fieldwork.

How can the sustainability of harvesting practices be evaluated?

A first approach for evaluating the sustainability of harvesting practices is based on an estimation of regeneration rates. The comparison of harvesting and regeneration rates help to assess the stress on the resources. Models of renewable resource dynamics may be used to predict the evolution of the resources under distinct harvesting scenarios, such as the logistic curve or more complex population models (Caddy, 1999; Saphores, 2003; Rosser, 2004). Simulation is useful when the temporal and spatial heterogeneity of natural dynamics and harvesting practices has to be taken into account. However, regeneration dynamics and growth rates are very scarcely documented, principally for less-known species, non-timber forest products (NTFPs) and a lot of wildlife species (e.g., marine). This may prevent the comparison between harvesting and regeneration or the calibration and validation of models.

Regarding timber, the classic assessment methods are based on the regular quantification of standing volume by forest surveys and the estimation of timber yield (Biolley, 1920; Prodan, 1968; Assmann, 1970; Loetsch et al., 1973; Clutter et al., 1983). These methods determine the possible harvested volume that maintains a defined sustainable standing volume. When past harvesting practices (fluxes of resources) are known, they may be correlated to current spatial patterns of resource (stocks) estimated by inventories, in order to evaluate the impact and the sustainability of harvesting practices. In forestry, numerous sampling designs have been developed (see Schreuder et al., 1993; Frayer and Furnival 1999). The recent multi-phase forest surveys combine terrestrial plots to aerial photographs and/or satellite data to improve the costefficiency (Köhl, 1995). However, forest surveys remain generally expensive and assessments methods have to be adapted to available means and to existing strategies. Recent statistical works tried to optimise the sampling schemes according to fixed costs (Mandallaz and Ye, 1999).

Recent guidelines and tools (Carter 1996; Doig 2001; CIFOR - CIMAT, Purnomo et al., 2002; FSC approach - WWF 2004; ITTO - Pokorny and Desmond, 2004) propose step-by-step (iterative) implementation and assessment 
processes and are now already linked with social considerations. In the case of the use of non-timber forest products (NTFPs), the characteristics of the resources (e.g., the harvested part of plant) should be known in order to design the inventories.

Unlike timber, NTFPs such as flowers, seeds and leaves of plants are regularly produced and shaded, and there is no accumulation of products through the year. This means that periodic production and temporary available biomass are better indicators for determining sustainable harvesting rates than increment and production (Ohja et al., 2001). Aluma (2000) gives a review of current assessment methodologies and the issue is now analysed at regional scales (see for example the results of the fourth regional workshop of the NTFP exchange programme on Community Assessment and Monitoring of NTFP Sustainability in South and Southeast Asia held in 2004).

\section{Harvesting assessment and management adaptation}

Assessment methods were adapted to new ecosystem management principles, such as the 'close-to-nature silviculture' which intends to enhance biodiversity (Parviainen and Bücking, 1997), the sustainable forest management as defined by criteria and indicators (ITTO, Appanah and Kleine 2000; FSC, principle 8) and the multifunctionality of the forests. Thus, they became more and more integrated and participatory (Davis-Case, 1990), as demonstrated by the multidisciplinary landscape assessments initiated by CIFOR (Sheil et al., 2003). Nevertheless, for determining management practices (areas, timing, etc.), the basic set of variables under consideration usually still includes the composition and quantity of natural resources, and the regeneration and growth rates of major products.

Spatial and vocational mapping using GIS (Jeffers, 1996) help to adapt harvesting regulations to landscape and regional considerations (Oliver, 1992). However, in several developing countries, the harvesting rules have to be adapted to local capacities, especially with regards to professional skills and financial resources for planning or transactions. In remote areas, simple limitations (fixed harvesting periods, minimal timber diameter, etc.) and minimal planning requirements may be more efficient than ideal complex management requirements. Refinement of management practices in response to the results of an impact assessment can be done in four major steps: scenariobuilding; enhanced monitoring, biological survey; and review and revision of management practices (Hannah, 2003).

In the case of assessment of harvesting activities as well as in the case of the facilitation of adaptation to climate change, local level and management skills form the core of the necessary monitoring process. At this local level, climate change may influence the ecosystems by extreme events (hurricanes, floods, droughts) or in a more linear way through changes in moisture content, light and temperature conditions. The assessment of harvesting activities must link local livelihoods and the expected climate impacts on the ecosystem structure and composition. Key elements such as plant aspect, plant yield or key species 
may be traditionally known and observed; local knowledge will thus be central in the assessment phase as well as for the monitoring process. On the scientific level, a specific issue will be to adapt continuously the estimated growth and regeneration models according to the observed effects of changing climatic conditions.

\subsubsection{Assessment of socio-economic baseline}

A socio-economic baseline will help in assessing the current and future stress on biodiversity (e.g., through harvesting) and understanding which adaptation options are socially and economically adequate. Socio-economic assessments have a long methodological history. Approaches shifted from externally analysed perceptions to participatory rural assessments (Chambers, 1997) and they are now becoming increasingly interactive between local stakeholders and external assessors or facilitators from public structure or NGOs (Burdge, 2004). Modern socio-economic analyses distinguish social groups within a community, including the marginal people (Stakeholders analysis, cf. Brugha and Zsuzsa, 2000; Jennings and Lockie, 2004; Gilmour and Fischer, 1991) and they may be adapted to the context of conservation (The Nature Conservancy, 2001; Borrini-Feyerabend, 1997).

The livelihoods approach developed by the UKDepartment for International Development (DFID, 2000) provides a framework for analyzing household situations and activities. It considers five types of capital asset: human, natural, financial, social and physical. The households use and valorise their asset through activities based on natural resources (e.g., agriculture or forestry) or access to financial resources (e.g., through employment). The activities will depend on the vulnerability context (shocks, trends, and seasonality) and on policies, institutions and processes (Ellis, 2000).

Bond and Mukherjee (2002) developed a 'Livelihood Asset Status Tracking' (LAST) which has already been tested in an applied project for adaptation to climate change (SEI, 2003). Key elements are the ability to provide 'adhoc learning exercises' to enforce the good understanding and the followup of the process and to select a 'reasonably' homogenous area in terms of cultural, economic and agroecological practice. The sustainable livelihood approach gives a useful framework to design baseline assessment of the socioeconomic conditions and the LAST-system may initiate a 'lasting' monitoring process. Numerous other specific assessment tools and methods (RietbergenMcCracken and Narayan, 1998) may be combined to study more in depth one or the other 'asset'.

In the UNDP/GEF Adaptation Policy Framework, Malone and La Rovere (2004) propose to describe the socio-economic conditions using quantitative or qualitative indicators under five categories: demographic analysis (population density and spatial distribution, growth, migration, age distribution, etc.), economics analysis (activities, food security, sources of income, markets, infrastructure), natural resource use (land, water, forest, biodiversity, etc.), governance and development policies (development and environmental 
policy, recent or planned state reform, capacity of institutions, policymaking process), and culture (cultural aspects related to the relationships among stakeholders and between stakeholders and institutions, forms of governance, implementation of new technologies, etc.).

With any method, information on current socio-economic conditions may be gathered through fieldwork (stakeholder interviews and activity observations). If the method works with indirect indicators and does not require direct contact of stakeholders, expert opinion may be used to reduce costs. As adaptation to climate changes is intended to be integrated into a long-term planning process, assessment of baseline socio-economic conditions must ideally also be long-term. For estimating future socio-economic scenarios, various methods and sources of information can be used, such as expert opinion, statistical methods of forecasting applied to quantitative data, and models. Simulation models may be developed for representing the functioning of a simplified socio-natural system and for developing future scenarios for the system under different assumptions.

\subsubsection{System adaptive capacity}

Many consider that resilience is key to enhancing adaptive capacity of humanecological systems. Likewise, the adaptive capacity of a socio-ecological system determines its ability of to cope with novel situations without compromising options for the future (Folke et al., 2002). Resilience is defined here as the amount of change a system can undergo and still remain within the same state, be capable of self-organizing, and adapt to changing conditions (Carpenter et al., 2001). The attributes that enhance resilience and that make reorganisation possible include redundancy, diversity, spatial heterogeneity, rapid feedbacks and ecological and social "memory" (see Box 1). As these attributes are found in all natural systems, adaptive capacity to climate change and biodiversity are thus highly interlinked-as more resilient ecosystems may be better able to cope with global climate change and have the adaptive capacity necessary to reorganise themselves following disturbance so to keep providing essential services to people.

\subsubsection{Adaptive genetic diversity and phenotypic plasticity}

A comprehensive assessment of the adaptive function of genetic diversity requires lengthy and expensive investigation. Where possible, this should include common garden experiments planted to reflect the predicted changes in climate. Diversity in neutral molecular markers should not be used as a surrogate for adaptive diversity, however it may be useful as a general indicator of population fitness (as per Reed and Frankham, 2003). Mapping of environmental heterogeneity may prove a useful method for rapid estimation of adaptive diversity, however at present, this still requires further testing. In cases where practical limitations do not permit the establishment of common garden experiments, it is recommended that conservation programmes take a precautionary approach and assume that populations will not be able to 
Box 1. Main Attributes that Enhance Ecosystem Resilience

\section{Redundancy:}

The number of species is less important to an ecosystem than the presence of 'functional groups' (e.g., short-lived and long-lived trees, shrubs, annual and perennial grasses). If a functional group loses a species, other species within that group are likely to take over by increasing in abundance.

\section{Complementarity:}

The number of species plays an important role in the way an ecosystem works, as different species contribute to its structure and function in complementary ways (e.g., co-existing tree species with shallow and deep root systems).

\section{Spatial heterogeneity:}

Tends to favour the co-existence of different species in a given area (to fulfil the above-mentioned roles) and makes reorganisation possible.

\section{Memory:}

(i) Genetic makeup present in current biological communities selected over long time periods (favourable/unfavourable) and that is expressed in a selective manner under different environmental conditions.

(ii) Dormant seeds in the soil that allow a forest to regenerate after large-scale or extreme events such as hurricanes, deforestation.

adapt to changes in climate. In this case, plans should be made to assess the possibility of migration as a coping strategy.

High levels of adaptive genetic diversity can improve the likelihood that a species will be able to survive changes in climatic conditions. Alleles that offer comparatively low survival advantages in a given environment can be of significant advantage when conditions change. As a result, populations with a diversity of adaptive responses are more likely to be able to persist in the face of environmental change. Much like adaptive genetic diversity, phenotypic plasticity gives a species a certain capacity to adapt to changes in the environment. Genes which are phenotypically plastic can be expressed differently depending on the environment, thereby allowing adaptation to a range of conditions within a single individual or genotype. Populations that are genetically homogenous can therefore still cope with changing climates provided the genes responsible for environmental adaptation are phenotypically plastic.

In order to adequately assess how these factors may contribute to survival under changing climatic conditions, it is necessary to test the responses of populations to different climates under common garden conditions (Davis and Shaw, 2001). By planting provenances from various populations in areas where the present-day climate closely resembles that of the predicted future climate, this method can aid in directly assessing the probability of survival 
through adaptation. Where populations occupy diverse environments, it can aid in assessing whether their adaptive responses are plastic or genetically based. Similarly, this method can be used to assess how adaptive diversity is partitioned throughout the range of a species, and whether there are high levels of variation within and/or between populations. This approach has been used to examine adaptation and the effects of climate change on the pine trees Pinus contorta and Pinus sylvestris (Rehfeldt et al., 1999; 2002) and to assess plasticity in Pinus ponderosa (Maherali et al., 2002). While this is the most robust approach to assessing physiological adaptive capacity, it tends to be expensive and time-consuming, and may therefore be an unacceptable option for all but the most highly-valued species.

An alternative to investigating both diversity and adaptive function is to focus directly on measuring levels of genetic diversity and assume that this will be correlated with actual adaptive function. Ideally, this approach should focus on genes with an identified adaptive function, however with the exception of a few model experimental species, very few such genes have been identified and studied extensively. Furthermore, the search for these genes is often prohibitively time-consuming and expensive, and therefore beyond the reach of most conservation programmes. As a result, many conservation biologists have used easily-measured molecular markers as surrogates for examining overall diversity and for inferring levels of adaptive diversity (Geburek, 1997). Molecular markers however are increasingly being seen as poor surrogates for adaptive diversity. As most markers are selectively neutral (or nearly-neutral), they do not respond to the same evolutionary forces that shape adaptive traits, and as such have often found to have patterns of diversity that are uncorrelated to those of adaptive traits (Reed and Frankham, 2001). While adaptive traits are preferable to neutral markers, any studies of diversity completed without an accompanying physiological component may inaccurately assess the actual degree to which adaptive genetic diversity may prepare a species to cope with climatic change. Another limitation of both genetic surveys and common garden experiments is that they require species-by-species and population-by-population assessments, and as such are often not feasible for the characterisation of an entire species distribution.

Since adaptive genetic diversity is the result of heterogeneity in selective pressures (Hedrick et al., 1976; Linhart and Grant 1996), it may be possible to estimate relative levels of diversity by measuring variation in environmental variables. A recent study found significant correlation between regional heterogeneity in drought stress conditions and within-sub-population diversity in adaptive responses for drought tolerance in the Andean conifer Araucaria araucana (Yeaman and Jarvis, submitted). Since this type of surrogate can be calculated from maps of precipitation or temperature, it may be used for estimating relative levels of genetic diversity across the entire range of a species with minimal cost and time. This approach could be of very broad utility, in that measurements of heterogeneity are non-species-specific and could be applicable to predicting diversity in any species inhabiting the study 
area. This method has not yet been extensively tested however, and as such, is of questionable practical utility until it is more rigorously examined.

\subsubsection{Genetic connectivity, migratory ability, and fragmentation}

While both migration and physiological/genetic adaptation are thought to be integral to coping with climate change, migratory capacity tends to be more directly impacted by human activities. As such, enhancing migratory capacity is more often within the reach of conservation activities, as discussed below. Assessment of migratory capacity tends to be fairly species-specific however, and as such, there are few broadly-applicable models or tools. A comprehensive assessment of migratory capacity will generally require the species-specific methods discussed here, together with an assessment of both the predicted spatial change in climatic conditions and the regional patterns of land use/ fragmentation, as described above.

Migration is one of the principal ways in which a species can cope with climatic change. Where changes in environmental conditions are too rapid for species to adapt, migration to new areas with favourable climates provides an alternative survival strategy. Migration from one area to another may be relatively rapid in the case of highly mobile animals but require several generations in the case of plants with limited seed dispersal. The specific factors that affect the possibility of migration differ greatly from one species to the next, but in all cases, successful migration requires both a viable path for displacement, and a suitable area for colonisation. In the first case, the nature of the intervening environment and presence of a suitable transport vector (e.g., wind, water, animal host) can have considerable impacts on success of migration. Mountains, large bodies of water, and unsuitable land use/habitat types (e.g., agriculture, urban development, dense forest) can all effectively act as barriers to migration, depending on the species and its method and rate of displacement. In the second case, any areas where an organism must reside for any length of time must be of a suitable habitat to enable their survival.

Any analysis of the migratory ability of a species therefore depends upon the distance that it will likely have to migrate to encounter suitable climate and habitat, and its ability to travel through the intervening landscape. Because of the great differences in migratory ability from one species to another, assessment generally requires specific research into species biology. Fieldbased experiments however are costly and time-consuming, and for the purposes of conservation research and planning a literature review will often provide sufficient information for an approximate estimate of species migratory capacity and ecological requirements. Various models have been developed to assess migration and dispersal, which can also be used as a surrogate for fieldwork (Dyer, 1995; Malanson and Cairns, 1997; Higgins and Richardson, 1999).

The actual likelihood of a species being able to migrate to cope with climate change can then be assessed by comparing its migratory ability to the assessments of habitat fragmentation and displacement of climatic envelope 
(species distribution). Habitat fragmentation can generally be analysed by measuring distances between appropriate patches using maps or GIS-based data, while modelling of a climatic envelope is described above. This type of assessment has previously been completed with Pinus virgiana in the United States (Iverson et al., 1998) and with Arachis species in South America (Jarvis et al., 2001; 2003). A general review of migration and climate change is covered in Pitelka (1997). Ray et al., (2002) used GIS-based maps to model spatial migratory routes, which is an approach which could similarly be applied to assess capacity to migrate as a way of coping to climate change.

\subsection{Identification of options}

Adaptation options are thought to be the most practical options since mitigation of climate change itself is a long-term endeavour. Human interventions that enhance ecosystem resilience - and hence its adaptive capacity - need to focus first on treating the causes of biodiversity loss (i.e., reduce habitat conversion, over-harvesting, pollution, and alien species invasions on native ecosystems), maintain ecosystem structure and function, and maintain natural disturbance regimes that create heterogeneous conditions, minimise habitat fragmentation, and promote, when feasible, rehabilitation/restoration practices that enhance ecosystem integrity and maximise historical levels of biodiversity. In other words, conserving the composition and structure of present biological communities through reducing non-climatic stresses - rather than simply maximizing species numbers - is more likely to maintain higher levels of ecosystem service provision. Recent studies show that a loss of resilience is thought to lead to switches to so-called "alternative ecosystem states" (Scheffer et al., 2001) suggesting that long-term sustainability should focus on maintaining resilience. Integrated approaches to natural resource management also constitute an essential element of adaptation to climate change. Adaptation options for selected ecosystems are presented in Box 2.

\subsubsection{Protected areas}

A major adaptation option is to conserve biodiversity in protected areas and to counter habitat fragmentation by establishing biological corridors between protected areas, particularly in forests. Adaptation options through protected areas may need to incorporate climate-driven scenarios of biodiversity change as a reserve selection criterion. Managing both for landscape connectivity and the surrounding matrix becomes essential to biodiversity conservation in a changing climate. One example is the proposed Greater Addo National Park in South Africa. The park covers a large area within a range of elevations and ecosystems. By protecting as many different habitats as possible, park planners were able to take into account the potential effects of climate change on species distribution and migration. An existing reserve which is likely to allow for climate-driven species migration is the La Selva-Braulio Carrillo land corridor in Costa Rica which is the last intact gradient of rain forest (from near sea level to $\sim 2900 \mathrm{~m}$ elevation) on the Caribbean slopes of the Central 


\section{Box 2. Adaptation Options in Selected Ecosystem Types: Links to Enhancing Ecosystem Resilience}

Forests - Options may include:

(i) maintaining representative forest ecosystem types across environmental gradients, providing buffer zones for possible spatial shifts in reserve boundaries and practice lowintensity harvesting and site preparation methods;

(ii) avoiding fragmentation and providing ecological connectivity through planted forests;

(iii) as there are strong links with mitigation (Chapter 3), when planting forests: establish indigenous, mixed-species stands, maximise natural genetic diversity (and minimise highly selected material), mimic the structural properties of surrounding natural forests, and avoid the direct replacement of native ecosystems.

Marine and coastal - Options may include:

(i) designing marine protected areas so that they include reef areas that have demonstrated resilience/resistance to raised sea temperatures;

(ii) conserving and restoring coastal ecosystems to protect coastlines from the impacts of climate induced sea-level rise;

(iii) undertaking aquaculture and mariculture as options to potential climate-change induced decline of wild fisheries in a sustainable manner. In the context of integrated marine and coastal area management, these options are important as unsustainable farming of carnivorous fish species can have further detrimental impacts on wild populations (e.g., use of small fish for food) in addition to current over-harvesting, and because large-scale aquaculture projects that lead to clear-cutting of coastal forests may reduce the ecosystem's capacity to mitigate floods and sea-level rise.

Inland waters - River biota is - within reasonable limits - relatively well adapted to rapid and unpredictable changes in environmental conditions. In contrast to many terrestrial ecosystems, much of the functions of inland water ecosystems are determined to a large extent by physical features rather than species composition/diversity per se. Thus, options may include maintaining near-natural flow patterns, channel morphology, water quality and quantity, and overall connectivity.

Traditional agroecosystems - Local, traditional agroecosystems harbour centuries of locally adaptive information that result in diverse landscapes managed for multiple uses. They are more knowledge- than use-intensive and are shown to spread the risk of climatic variability through: high species numbers, high structural diversity in time and space, exploitation of the full range of micro-habitats available, complex biological interactions leading to pest suppression, and use and maintenance of local varieties of crops, wild plants and animals. Resilience in the face of changing climate has been documented for smallholder farmers that depend on local agroecosystems in many locations across the globe. Options may include conservation of crop genetic resources, and their incorporation in breeding programmes to maintain future options arising from the impacts of climate change.

Mountain and arctic ecosystems are under particular stress and threat of degradation due to their high sensitivity and vulnerability to climate change but few adaptation options are available except for building barriers against coastal erosion. Adaptation activities that best address how mountain ecosystem management leads to adaptation benefits may be those that link upland-lowland management strategies.

Source: CBD Ad Hoc Technical Expert Group on Biodiversity and Climate Change, 2003. 
American isthmus - although this one was not explicitly set up with climate change considerations in mind. Is should be noted that the design of these 'dynamic' conservation systems at the landscape/regional scale may have to rely on local/regional models, as discussed in Chapter 1.

\subsubsection{Replanting/colonisation/assisted migration}

Replanting via reforestation and afforestation need to pay attention to species selection and site location in order to promote - and not displace - the return, survival, and expansion of native ecosystems. Afforestation of native grasslands and other indigenous ecosystems would entail significant loss of biodiversity. Plantations of exotic species support only some of the local biodiversity but may contribute to biodiversity conservation if appropriately situated in the landscape. Tree plantations may be designed to allow for the colonisation and establishment of a diverse understory. Specific sites may make better candidates than others for implementing such activities based on past history, level of degradation, and the local or regional importance of the their associated biodiversity. Furthermore, plantations may contribute to providing ecological connectivity in fragmented habitats (CBD Ad Hoc Technical Expert Group on Biodiversity and Climate Change, 2003).

\subsubsection{Ex-situ conservation}

Overall, species whose natural range is likely to be most threatened by climate change should have the highest priority for ex-situ conservation. One limitation of captive breeding is the lack of space available. Zoos and off-site breeding facilities can be expected to accommodate no more than a small fraction of the number of species that might be threatened. In the case of plants, botanical gardens are better suited to accommodate many plant species threatened by climate change. Due to our incomplete known of the biology of many plants, particularly the endemics, these species will not be able to survive and reproduce in habitats created in botanical gardens.

Captivebreedingand translocation, whencombined with habitatrestoration and ex-situ conservation may help to prevent local extinction of key taxa under small to moderate climate change. Captive breeding for reintroduction and translocation is likely to be less successful if climate change is more dramatic, as such change could result in large-scale modifications of environmental conditions, including the loss or significant alteration of existing habitats of some or all of a species' range. However captive breeding is technically difficult, often costly, and unlikely to succeed in the absence of complete knowledge of the species' biology (CBD Ad Hoc Technical Expert Group on Biodiversity and Climate Change, 2003).

It is important to note that efforts designed to minimise genetic changes in order to maintain the original genotypes to the extent possible (mostly connected to breeding programmes), versus efforts which support continued natural selection in response to new or changing environments (evolutionary conservation) are different but complementary parts of ex-situ conservation 
programmes. Both types of conservation efforts have a role to play in strategies for sustainable use and conservation of genetic resources in the face of changing climate.

\subsection{Key challenges for identifying options}

Adaptation helps both to reduce and spread future risk and plans for the movement of species and ecosystems. Yet the effects of specific adaptation strategies on biodiversity in particular ecosystems are less known. Emphasis will be needed on species/ecosystems either with restricted dispersal capability to the projected nearest suitable 'climate space' or with extreme habitat specialisation. Increasing our understanding of ecosystem/species adaptations to current environmental change may provide important information for designing future options.

Similarly, documenting long-term responses in agricultural practices in regions with extreme and/or deteriorating climatic conditions is likely to identify key determinants of adaptation. It is estimated that $10-15 \%$ of the 960 million hectares of land under cultivation in the developing world are managed through traditional agroecosystems (Altieri, 2004). Scientists can help small farmers translate the principles of species and functional diversity, organic matter accumulation, species interactions, and minimisation of resource loss into practical strategies to enhance production.

Management that expands across protected area boundaries to include the matrix may have to be co-ordinated across political sub-divisions as species range shifts will not respect political boundaries. Countries that are drawing up plans to deal with climate-induced disasters could identify not simply vulnerable human settlements but also the local ecosystems on which they depend both for economic and conservation reasons.

\section{The adaptation strategy: Development and implementation}

Identifying which aspects of biodiversity will be most vulnerable to climate change and the management strategies for coping with such change is meant to be an objective, scientific process. At the same time, it is a process that can be approached from a number of directions, depending on the objectives. Effective adaptation strategies will be motivated by clear and focused objectives that respond to the unique needs and context of the vulnerability assessment. The first step in clarifying these objectives is of course to identify the biodiversity priority or priorities to which the strategy aims to respond. The priority could be an individual species or population, a specific area of habitat or habitat type, a landscape, an ecosystem process, etc. The priority of the adaptation strategy will likely be the initial priority of the vulnerability assessment, but it may also be a more focused subset of that assessment, based on the assessment findings.

The manner in which a strategy responds to priority needs - i.e., the form it takes and the manner in which it functions - will depend on the context 
within which the strategy is being developed. For instance, in certain countries, biodiversity may be included as one of the handful of sectors prioritised for vulnerability and adaptation assessment within the countries' national communications to the UN Framework Convention on Climate Change. In these instances, the resulting adaptation strategy may include highly integrated options, which accomplish objectives in several sectors (e.g., water, forests and biodiversity), as well as a set of sector-specific options, focused on key sectoral needs. In other cases an adaptation strategy focused solely on biodiversity might be developed independently (e.g., as part of a migratory corridor longterm management plan). In such cases, the resulting strategy might include a richer array of options focused specifically on biodiversity, but perhaps only a series of recommendations (as opposed to an agreed plan) for integrating with other sectoral management strategies. As still another example, adaptation strategies may be developed which focus on areas other than biodiversity (e.g., coastal zones, rangelands, water), but include adaptation options (e.g., hillside reforestation, mangrove restoration) that are based on ecosystem management and other biodiversity-focused approaches.

In general, efforts to increase the resilience of biological systems to the impacts of climate change will be more successful if the scope is sufficiently broad to incorporate the non-climatic root causes of biodiversity loss. In all instances, implementation of adaptation strategies is an iterative process, and will require long-term dedication to monitoring, and revision of management strategies as the need arises. By entering the strategy development process with a clear understanding of the priority needs, desired outputs and larger policy and planning context, planners can help to ensure that a targeted and effective strategy is produced.

Efforts to increase the resilience of biodiversity to climate change can be carried out at a range of temporal and spatial scales, can be worked with a number of different policy processes, and can draw on a variety of resources. A key preliminary step in developing an adaptation strategy is therefore to clarify the scope, scale and inputs to the process, a step that is closely linked to the initial prioritisation process outlined above.

The range of participants included in the development and implementation of the adaptation strategy will be dependent on both the scope and scale of adaptation efforts. It will be necessary to identify whether the adaptation strategy is at the regional, national, landscape or site level. Transboundary efforts that include multiple geo-political units will also become more important as species assemblages shift with climate change.

From a biodiversity perspective, adaptation efforts will ideally be defined by the size and distribution of land and habitat areas required for conserving key biodiversity that will be affected by climate change - a concept referred to as the 'biological landscape' (Loucks et al., 2003). The vulnerability analysis should assist in the definition of the biological landscape by identifying species, habitats, and processes that will need to be conserved given projected impacts. An expert workshop can be used to gain consensus on the implications of climate 
impacts from a management perspective. A Decision Support System (DSS) is increasingly used to define critical habitats, a computer-based tool that assists decision-makers to evaluate scenarios about land uses; and is often paired with geographic information systems to help define boundary areas (Loucks et al., 2003). Smaller priority areas can be compiled for the national or regional level to ensure harmony with approaches at a broader geographic scale.

The scope of an adaptation strategy will therefore be governed by both the participants and the resources, as well as by the identified problems and their causes, as discussed above. For example, a degraded coastal site vulnerable to inundation from rising sea-level due to lack of erosion control could focus explicitly on regeneration of the ecosystem (e.g., planting of mangroves). A broader scope would include activities that address the source of coastal degradation (e.g., alternative uses of mangrove wood, or increased efficiency of wood-burning stoves). In general, efforts to increase the resilience of biological systems to the impacts of climate change will be more successful if the scope is sufficiently broad to incorporate the non-climatic root causes of biodiversity loss. In all instances, implementation of adaptation strategies is an iterative process, and requires long-term dedication to monitoring, and revision of management strategies as the need arises.

The collection of data for assessing vulnerability and understanding the realm of adaptation options will likely include participation of multiple types of stakeholders. Moreover, weighing that information and determining what course of action is realistic and desirable will require extensive input from an even broader community of stakeholders. Thus, the importance of involving a wide array of stakeholders in the development and implementation of an adaptation strategy cannot be overemphasised. As Loucks et al. (2003) have stated, an effective mechanism for engaging key stakeholders marks the difference between an excellent plan that is never used, and one that has sufficient cross-sector support to be implemented. The long-term nature of climate change requires that segments of a particular community, from local communities to national government authorities are included in the process. Broad participation will help ensure the long-term success of an adaptation strategy, especially as it is revised and reworked as further monitoring and research is undertaken. Likely participants in the development and implementation of an adaptation strategy will include the following:

- Ecosystem managers - those currently 'in charge' of management of the given area. This could include government foresters, as well as local communities, and private land-holders.

- Local communities-peoplewho are affected by the impacts of climatechange and changes in management in order to conserve biodiversity. Communities living in or near the focal area will likely have extensive knowledge of past impacts and will be a wealth of knowledge in observing changes.

- Government staff - besides government-employed land managers, those principally responsible for environment and biodiversity and involved in 
policy and legislation that affects the area in question will have a role to play in the adaptation strategy. Participation of government staff, including local, regional, and national will be necessary at various stages, both for assisting in overcoming legislative or policy barriers to adaptation as well as assistance with funding, and eventually to facilitate the sharing of lessons and awareness-raising at higher levels beyond the specific area in question.

- Scientists - preferably those biologists that conducted the vulnerability analysis, or who have expertise in conservation of species that are likely to be especially impacted by climate change (e.g., biologists with specialty in coral reefs, mangroves, tropical mountain cloud forests, boreal forests, grasslands, or arctic environments).

- Civil society organisations (CSOs) - non-governmental organisations, from national-scale conservation groups down to the small-scale, communitybased organisations, have been shown to be important actors and innovators in the sustainable management of biodiversity (see e.g., Banuri and Najam, 2002). In their proximity to the community level, CSOs can help to facilitate the harmonisation of community needs with the needs of biodiversity. In particular, groups with experience related to the specific priority(ies) of the adaptation strategy (from a river basin facing multiple stresses to a degraded micro-catchment) can provide key insights during the planning process.

The first order of priority is to designate a co-ordinator who will facilitate the development and implementation of the adaptation strategy. Consultation amongst stakeholders will assist to identify the co-ordinator as well as determine the roles of other participants throughout the process. For example, a government agency with capacity and interest in managing for climate change may lead the process, with research and conservation organisations and local communities serving as catalysts and active participants.

\subsection{Developing an adaptation strategy}

A biodiversity adaptation strategy provides a framework for prioritising and organising efforts to address the impacts of climate change on the focal elements of an ecosystem. It will likely be based upon a set of management and policy measures. A comprehensive adaptation strategy will include the following components:

1. Strategy priorities and objectives.

2. Area of focus (scope and geographic scale of adaptation efforts, including priority landscapes or sites).

3. Stakeholders and project participants.

4. Overview of climate impacts on biodiversity in area of focus (baseline and future projections).

5. Identification and formulation of adaptation options.

6. Evaluation and selection of adaptation options. 
7. Action plan of selected adaptation options:

a. Description of planned activities,

b. Timetable,

c. Resources needed,

d. Baseline and targets,

e. Participants and their roles.

8. Monitoring programme.

The first four components are described in the preceding section, and the following section discusses consideration of and planning for adaptation and monitoring activities.

\subsubsection{Identification and formulation of adaptation options}

An advisory group led by a scientific expert or land manager can assist in the identification and elaboration of potential adaptation options, building on the general categories outlined in Section 3.

\subsubsection{Evaluation and selection of adaptation options}

Once the options are laid out, a set of criteria can be used to identify which activities are most desirable and feasible. Box 3 below is a sample checklist for identifying a balanced suite of adaptation activities that should lead to increased resilience within a biological landscape. This type of list can be adapted to suit local circumstances and the specific biodiversity priority to which adaptation options should respond.

Box 3. A Checklist for Identifying Adaptation Activities that Enhance Biological Resilience

(To be rated 1-5, with 5 agreeing most with statement)

o Does the activity address existing, non-climatic stresses to the system that decrease overall resilience?

o Does the activity ensure that the affected species has sufficient habitat, distribution, and connectivity to maintain its function and ecological processes that will ensure successful response to changing climate? OR Does the activity have as its focus either the protection of functional groups, keystone species, climatic refugia, or multiple micro-habitats within a biome to provide adequate representation throughout the future?

o Does the activity involve local communities or private sector interests with a stake in the focal area or resource? Does it improve the resilience of those dependent on the targeted site?

o Is the land manager on-site to oversee the activity if necessary?

o Are the economic costs surmountable?

o Is the activity co-ordinated with existing management strategies for the area; or are potential implementation barriers surmountable?

o Does the strategy include a mix of resilient and vulnerable focal areas to ensure a balanced strategy? 


\subsubsection{Monitoring programme}

Ongoing monitoring of management and policy efforts geared towards ameliorating the effects of climate change are especially important. Not only will progress toward established targets need to be monitored to ensure activities are having their intended result, but long-term analysis of the targets and overall strategy itself is crucial. There is relative uncertainty about the exact impacts climate change will have on many systems, and also with regard to the cascading impacts upon the complex interrelationships between species structure, composition, and functions.

A monitoring and evaluation plan should be established in the initial stages of planning for adaptation. The monitoring plan will need to monitor progress against a baseline which is defined in the vulnerability assessment process. Indicators should be chosen in order to measure whether actions are strategic and effective, that is whether biodiversity is becoming more resilient (and at least not less so) to the impacts of climate change. The outputs of monitoring can also be used as the vehicle for communicating results to stakeholders and external audiences for increasing awareness about climate change.

\subsection{Implementing an adaptation strategy}

An adaptation strategy is a plan for increasing the capacity, over time, of vulnerable groups and systems to cope with climate impacts and adapt to climate change. It is clearly a long-term endeavour, and one that will require strong stakeholder support, an able institutional framework, strategic use of existing policy synergies, careful monitoring, evaluation and adjustment, as well as long-term, if gradual, mainstreaming into more central policy and planning processes. Though by no means a universal recipe for implementation, this section outlines some steps that are likely to be common and useful across implementation processes.

\subsubsection{Build stakeholder awareness and receptivity}

It is widely appreciated that, across the range of policy processes, stakeholders are critical to implementation. This is true from the macro-scale, at which national government ministries can provide the political support necessary to ensure broader buy-in, to the meso-scale, where resource managers can help to ensure effective co-ordination of implementation, to the micro-scale, where local awareness and acceptance can determine the success of ground-level implementation. This holds true for implementation of an adaptation strategy, where the support of central ministries such as finance and development, and the buy-in of local farmer's unions can both determine whether a strategy for improving food security can be successfully implemented. Stakeholder awareness building - from high-level government meetings to communitybased workshops - can be an important tool for laying the ground for strategy implementation. Finally, over the long-term, the awareness and support of the general public will be essential to successful implementation of adaptation policies and measures. 


\subsubsection{Create an institutional framework}

An adaptation strategy will tend to include a collection of policies and measures that, generally speaking, no single institute will be suited to implement and sustain alone. Instead, some form of institutional framework will likely be necessary. This framework would include those institutions directly implicated in strategy implementation, affording a more central role to those institutions that can help to sustain the adaptation process over time. In the case of an adaptation strategy for biodiversity, the framework might include those government ministries responsible for implementing the national development strategy as well as plans to comply with multilateral environmental agreements (MEAs) and to meet the Millennium Development Goals. The framework may be strengthened by inclusion of institutions at smaller operational scales, from the sub-national to the local, and by the articulation of (and buy-in to) clear roles, responsibilities and divisions of labour.

\subsubsection{Ensure policy integration}

Because of the nature of adaptation, adaptation strategies will tend to involve activities with strong overlaps and synergies with existing policies and measures. In a world of limited resources (financial, human, institutional, etc.), there is clearly enormous value to identifying those synergies and designing an adaptation strategy that builds on and around existing, complementary activity. Viewed from a different angle, the failure to take advantage of synergies can introduce significant waste and redundancy. In terms of adaptation, commonly cited synergies are those with the global biodiversity and desertification conventions and national action plans, as well as general national conservation plans.

However, while recognised as an important adaptation planning principle (see e.g., Least Developed Countries' [LDC] Expert Group, 2002), the process of capitalizing upon synergies has notyet been adequately explored or operationalised. In response, new guidance (e.g., the LDC National Adaptation Programme of Action Guidelines and the UNDP/GEF Adaptation Policy Framework) is increasingly advising users to scope key policy integration opportunities related to each adaptation option. For adaptation in general, these opportunities may be found in disaster management policies, poverty alleviation strategies, natural resource management plans, to name a few. For biodiversity, synergies will clearly be found in National Biodiversity Strategy and Action Plans, and in a range of other natural resource and environmental policies. However, synergies with other policy arenas also exist and should be explored.

\subsubsection{Monitor, evaluate and adjust}

As the roadmap for a long-term process, an adaptation strategy must remain effective and well suited to the changing circumstances in which it operates. To do so, strategies will require careful, regular monitoring and evaluation (M\&E), and adjustment based on M\&E observations. Since each adaptation option will need to be followed independently in order to determine its relative success, planners may wish to develop a monitoring and evaluation plan, including outcome indicators, as part of the write-up for each of the candidate adaptation 
options. Periodic monitoring, coupled with evaluation and recommendations, can provide an indication of where an adaptation strategy requires adjustment in order to achieve its goals.

\subsubsection{Mainstream}

From the adaptation and biodiversity perspectives, mainstreaming is a process whereby adaptation and biodiversity goals become part of the 'mainstream' discourse and policy framework, in whatever scale they are operating. Sustainable development provides a useful example of a concept becoming more mainstream over the course of roughly a decade. However, it also captures many of the challenges of mainstreaming, including the ease with which mainstreaming is discussed and lauded in comparison to the infrequency with which it is achieved in a meaningful way. It is no surprise that the prospect of mainstreaming adaptation in general, and adaptation for biodiversity in particular, should pose a challenge, since there is no shortage of competing needs and concerns that warrant mainstreaming on some level. Conversely, there is only a limited capacity of policy processes and society in general (e.g., financially, socially) to respond to any of them. Thus, while mainstreaming is an essential and widely touted goal (see e.g., LDC Expert Group, 2002), it continues to prove elusive.

An adaptation strategy will benefit from a clear plan for mainstreaming that outlines specific entry points and ways of using these to their fullest. Key opportunities for mainstreaming adaptation for biodiversity will most likely be identified during the policy integration process outlined above. Here, planners will have identified near-term opportunities for connecting adaptation policies and recommended activities with existing policies and ongoing activities, in a mutually beneficial way. Exploiting these opportunities represents a valuable near-term step that can be made toward mainstreaming, and can lay the groundwork for more significant mainstreaming progress in the future.

\subsection{Key challenges for implementation}

Key challenges for implementing adaptation strategies include:

- Sustaining stakeholder and institutional support: The linked processes of adaptation strategy development and implementation require well-coordinated engagement of a variety of stakeholders, and sustained support of key institutions.

- Identifying and exploiting synergies: Taking advantage of synergies between proposed and existing adaptation policies and actions can provide significant benefits to both endeavours. Failure to do so can create significant waste and replication of effort. However, synergies are not always easily exploited, and doing so can require the revamping of policy, the reinvention of institutional relationships, and the weakening - or breaking down - of traditional institutional and policy boundaries. Therefore, careful shepherding and strong leadership are required to ensure that political inertia does not preclude innovation in policy implementation. 


\section{- Monitoring and evaluating adaptation strategy impacts on biodiversity:} The process of monitoring change in biological systems can be complex and resource intensive, requiring involved observation and data collection, painstaking analysis, etc. Care should be taken to ensure that an M\&E plan is developed which ensures a robust yet streamlined M\&E process.

- Achieving mainstreaming: As outlined above, the process of mainstreaming will be essential for the long-term prospects of adaptation. At the same time, mainstreaming adaptation must contend with competing societal priorities, as well as a history of policy mainstreaming (certainly with regard to the mainstreaming of environmental issues) which is fairly mixed and inconclusive. Mainstreaming will require, among other conditions, sustained political will and thereby a sustained awareness-building programme focused on stakeholders and the public at large.

\section{References}

Altieri, M.A. (2004) 'Linking ecologists and traditional farmers in the search for sustainable agriculture' Frontiers in Ecology and the Environment 2: 35-42.

Aluma, J. (2002) 'Book Review: Non-Wood Forest Products No. 13. Resource Assessment of Non-Wood Forest Products.' African Journal of Ecology 40: 413417.

Appanah, S., M. Kleine (2000) 'Auditing of Sustainable Forest Management: A practical guide for developing local auditing systems based on ITTO's Criteria and Indicators' GTZ Programme Office for Social and Ecological Standards, Forest Certification Working Paper No. 4, GTZ: Eschborn.

Assmann, E. (1970) The Principles of Forest Yield Study Pergamon Press: New York.

Banuri, T., A. Najam (2002) Civic Entrepreneurship: A Civil Society Perspective on Sustainable Development, Volume 1 - Global Synthesis, Ghandhara Academy Press: Islamabad.

Biolley, H., (1920) 'L'aménagement des forêts par la méthode expérimentale et spécialement la méthode du contrôle' Beiheft zu den Zeitschriften des Schweizerischen Forstvereins 66: 51-134.

Bond, R., N. Mukherjee (2002) 'Livelihood Asset Status Tracking (LAST): a case from Rajasthan' Working Paper No. 3, Impact Assessment for Sustainable Development Unit, IDPM, University of Manchester: Manchester.

Borrini-Feyerabend, G. (1997) Beyond Fences: Seeking Social Sustainability in Conservation, Volume 1, IUCN: Gland.

Brugha, R., V. Zsuzsa (2000) 'Stakeholder analysis: a review' Health Policy and Planning 15(3): 239-246.

Burdge, R.J. (2004) A Community Guide to Social Impact Assessment, $3^{\text {rd }}$ edition, Social Ecology Press: Middleton.

Caddy, J.F. (1999) 'Fisheries management after 2000: will new paradigms apply?' Reviews in Fish Biology and Fisheries 9(1): 1-43.

Carpenter, S. R., B. Walker, J. M. Anderies, N. Abel (2001) 'From metaphor to measurement: resilience of what to what?' Ecosystems 4: 765-781.

Carter, J. (ed.) (1996) 'Recent approaches to participatory forest resource assessment' Rural Development Forestry Study Guide 2, ODI: London. 
CBD Ad Hoc Technical Expert Group on Biodiversity and Climate Change (2003) Interlinkages Between Biological Diversity and Climate Change: Advice on the Integration of Biodiversity Considerations into the Implementation of the United Nations Framework Convention on Climate Change (UNFCCC) and Its Kyoto Protocol, CBD Technical Series no. 10, Draft Report for Experts and Government Review, CBD Secretariat: Montreal.

Chambers, R. (1997) Whose Reality Counts?: Putting the First Last. ITDG Publishing: London.

Clutter, J.L., J.C. Forston, L.V. Pienaar, G.H. Brister, R.L. Bailey (1983) Timber Management: a Quantitative Approach John Wiley \& Sons: New York.

Davis, M.B., R.G. Shaw (2001) ‘Range shifts and adaptive responses to quaternary climate change' Science 292: 673-679.

Davis-Case, D. (1990) 'The community's toolbox: The idea, methods and tools for participatory assessment, monitoring and evaluation in community forestry', Community Forestry Field Manual 2, FAO: Rome.

Department for International Development (DFID) (2000)'Sustainable Livelihoods Guidance Sheets' DFID: London. Internet: http://www.livelihoods.org

Doig, M. (2001) 'Self-Assessment in Farm Forestry Extension: Future directions' Proceedings of the Extension Working Party (S6.06-03) Symposium 2001 Assisting Forest Owner, Farmer and Stakeholder Decision-Making, International Union of Forestry Research Organisations, Lorne, Victoria, Australia, 29 October to 2 November 2001. Internet: http://www.regional. org.au/au/iufro/2001/

Dyer, J.M. (1995) 'Assessment of climatic warming using a model of forest species migration' Ecological Modelling 79: 199-219.

Ellis F. (2000) Rural Livelihoods and Diversity in Developing Countries Oxford University Press: Oxford.

Folke, C., S.Carpenter, T.Elmqvist, L.Gunderson, C. S. Holling, B.Walker, J.Bengtsson, F. Berkes, J. Colding, K. Danell, M. Falkenmark, L. Gordon, R. Kasperson, N. Kautsky, A. Kinzing, S. Levin, K-G. Maler, F. Moberg, L. Ohlsson, P. Olsson, E. Ostrom, W. Reid, J. Rockstrom, H. Savenije, U. Svedin (2002) 'Resilience and sustainable development' Scientific background paper for the World Summit on Sustainable Development, Swedish Ministry of Environment: Stockholm.

Frayer, W.E., G.M. Furnival (1999) 'Forest survey sampling designs: a history' Journal of Forestry 97(12): 4-10.

Gilmour, D.A., R.J. Fischer (1991) Villagers, forests and foresters Sahayogi Press: Kathmandu.

Grimble, R., M.K. Chan (1995) 'Stakeholder analysis for natural resource management in developing countries' Natural Resources Forum 19(2): 113-124.

Hannah, L. (2003) ‘Regional Biodiversity Impact Assessments for Climate Change: A Guide for Protected Area Managers' in L.J.Hansen, J.L. Biringer, J.R. Hoffman (eds.) Buying time: A User's Manual for Building Resistance and Resilience to Climate Change in Natural Systems, WWF: Berlin.

Hedrick, P.W., M.E. Ginevan, E.P. Ewing (1976) 'Genetic polymorphism in heterogeneous environments' Annual Review of Ecology and Systematics 7: 1-32.

Higgins, S.I., D.M. Richardson (1999)'Predicting plant migration rates in a changing world: the role of long-distance dispersal' American Naturalist 153: 464-475. 
Huq, S., A. Rahman, M. Konate, Y. Sokona, H. Reid (2003) Mainstreaming Adaptation to Climate Change in Least Developed Countries (LDCS) IIED, London.

Iverson, L.R., A. Prasad, M.W. Schwartz (1999)'Modelling potential future individual tree-species distributions in the eastern United States under a climate change scenario: a case study with Pinus virginiana' Ecological Modelling 115: 77-93.

Gitay, H., A. Suárez, D.J. Dokken, R.T.Watson (2002) Climate Change and Biodiversity, IPCC Technical Paper V, IPCC: Geneva.

Jarvis, A., P. Jones, G. Mottram, D. Williams, L. Guarino, M. Ferguson (2001) 'Predicting the impacts of climate change on the distribution of plant genetic resources in wild peanuts', contribution to conference Challenges of a Changing Earth: Global Change Open Science Conference, Amsterdam, the Netherlands, 10-13 July 2001.

Jeffers, J.N.R. (1996) 'Measurement and characterisation of biodiversity in forest ecosystems. New methods and models' in P. Bachmann, K. Kuusela, J. Uuttera (eds.) Assessment of Biodiversity for Improved Forest Management, Proceedings No. 6, International Workshop, Koli, Finland, 12-17 June 1995. European Forest Institute: Koli.

Jennings, S.F., S. Lockie (2002) 'Application of stakeholder analysis and social mapping for coastal zone management in Australia', paper presented at the Sixth International Conference Littoral 2002 - The Changing Coast, Porto, Portugal, 22-26 September 2002.

Jones, P.G., P.K. Thornton (2002) 'Spatial modelling of risk in natural resource management' Conservation Ecology 5(2): 27. Internet: http://www.consecol. org/vol5/iss2/art27.

Köhl, M. (1995) Multi-phase Sampling Schemes for Extensive Forest Surveys in Tropical Forests' in R. Päivinen, J. Vanclay, S. Miina (eds.) New Thrusts in Forest Inventory, Proceedings of the Subject Group S4.02-00 Forest Resource Inventory and Monitoring and Subject Group S4.12-00 Remote Sensing Technology, International Union of Forestry Research Organisations XX World Congress, Tampere, Finland, 6-12 August 1995.

Köhl, M., P. Bachmann, P. Brassel, G. Preto (eds.) (1995) The Monte Verita Conference on Forest Survey Designs: Simplicity Versus Efficiency. Swiss Federal Institute for Forest, Snow and Landscape Research: Birmensdorf.

Least Developed Countries' Expert Group (2002) 'Annotated guidelines for the preparation of national adaptation programmes of action' UNFCCC Secretariat: Bonn.

Linhart, Y.B., M.C. Grant (1996) 'Evolutionary significance of local genetic differentiation in plants' Annual Review of Ecology and Systematics 27: 237277.

Lipow, S.R., K. Vance-Borland, J.B. St. Clair, J. Henderson, C. McCain (2004) 'Gap analysis of conserved genetic resources of forest trees' Conservation Biology 18: 412-423.

Loetsch, F.,F. Zöhrer, K.E. Haller (1973) Forest inventory, Volume 2. BLV Verlagsgesellschaft: München.

Loucks, C., J. Springer, S. Palminteri, J. Morrison, H. Strand (2003) From the Vision to the Ground: A guide to implementing eco-region conservation in priority areas. WWF: Washington, D.C. 
Maggini, R., A. Guisan, D. Cherix (2002) 'A stratified approach for modelling the distribution of a threatened ant species in the Swiss National Park' Biodiversity and Conservation 11:2117-2141.

Maherali, H., B.L. Williams, K.N. Paige, E.H. Delucia (2002) 'Hydraulic differentiation of Ponderosa pine populations along a climate gradient is not associated with ecotypic divergence' Functional Ecology 16: 510-521.

Malanson, G.P., D.M. Cairns (1997) 'Effects of dispersal, population delays, and forest fragmentation on tree migration rates' Plant Ecology 131: 67-79.

Malone E.L., E.L. La Rovere (2004) 'Socio-economic conditions and prospects' Technical Paper No. 6, Adaptation Policy Framework, UNDP/GEF: New York. Internet: http://www.undp.org/cc/apf.htm

Mandallaz, D., R.H. Ye (1999) 'Forest inventory with optimal two-phase two-stage sampling schemes based on the anticipated variance' Canadian Journal of Forest Research 29: 1691-1708.

Ojha, H.R., B.P. Subedi, S.P. Dangal (2001) 'Assessment and Sustainable Harvesting of Non-Timber Forest Products: Some Initiatives in Community Forestry in the Hills of Nepal' Mountain Forum on-line library document. Internet: http:// www.mtnforum.org/resources/library/ojhax01a.htm.

Oliver, C.D. (1992) 'A landscape approach: achieving and maintaining biodiversity and economic productivity' Journal of Forestry 90: 20-25.

Osborne, P.E., J.C. Alonso, R.G. Bryant (2001) 'Modelling landscape-scale habitat use using GIS and remote sensing: a case study with great bustards' Journal of Applied Ecology 38: 458-471.

Parmesan, C., G. Yohe (2003) 'A globally coherent fingerprint of climate change impacts across natural systems' Nature 421: 37-42.

Parviainen, J., W. Bücking (1997) Strict forest reserves in Europe: Effort to enhance biodiversity and strengthen the research of natural forest in Europe, Programme and abstracts of conference Naturalness and European Forests, Strasbourg, France, 26-29 October 1997.

Pitelka, L.F. (1997) 'Plant migration and climate change' American Scientist 85: 464473.

Pokorny, B., H. Desmond (2004) 'Networking and information management for enhancing the implementation of criteria and indicators for sustainable forest management' Discussion Paper presented at the International Conference on the Contribution of Criteria and Indicator, Cebu City, Philippines, 2-4 March 2004.

Pounds, J.A., M.L.P. Fogden, J.H. Campbell (1999) 'Biological response to climate change on a tropical mountain' Nature 398: 611-615.

Powell, G.V.N., J. Barborak, S.M. Rodriguez (2000) 'Assessing representativeness of protected natural areas in Costa Rica for conserving biodiversity: a preliminary gap analysis' Biological Conservation 93: 35-41.

Prodan, M. (1968) Forest Biometrics Pergamon Press: Oxford.

Purnomo, H., R. Prabhu, Y. Yasmi, C.J.P. Colfer, J.P.P. Simarmata, T. Zacharias, A. Rizal, M. Haggith, J. Taylor, E. Yulianto, D. Sukadri, G.E. Helianthy, E. Sartika, Y. Indriatmoko, I.I. Isbadi, (2002) 'CIMAT - Criteria and Indicators Modification and Adaptation Tool', Version 2, CIFOR: Bogor.

Ray, N., A. Lehmann, P. Joly (2002) 'Modelling spatial distribution of amphibian populations: a GIS approach based on habitat matrix permeability' Biodiversity and Conservation 11:2143-2165. 
Reed, D.H., R. Frankham (2001) 'How closely correlated are molecular and quantitative measures of genetic variation? A meta-analysis' Evolution 55: 1095-1103.

Rehfeldt, G.E., N.M. Tchebakova, Y.I. Parfenova, W.R. Wykoff, N.A. Kuzmina, L.I. Milyutin (2002) 'Intraspecific responses to climate in Pinus sylvestris' Global Change Biology 8: 912-929.

Rehfeldt, G.E., C.C. Ying, D.L. Spittlehouse, D.A. Hamilton Jr. (1999) 'Genetic responses to climate in Pinus contorta: niche breadth, climate change, and reforestation'Ecological Monographs 69(3): 375-407.

Rietbergen-McCracken J., D. Narayan-Parker (1998) Participation and Social Assessment: Tools and Techniques World Bank: Washington, D.C.

Root, T.L., J.T. Price, K.R. Hall, S.H. Schneider, C. Rosenzweig, J.A. Pounds (2003) 'Fingerprints of global warming on wild animals and plants' Nature 421: 5760.

Rosser B. (2004) 'Complexities of Dynamic Forestry Management Policies' Paper presented at International Conference on Economics of Sustainable Forest Management, Toronto, Canada, 20-22 May 2004.

Sala, O.E., F.S. Chapin, III, J.J. Armesto, E. Berlow, J. Bloomfield, R. Dirzo, E. HuberSanwald, L.F. Huenneke, R.B. Jackson, A. Kinzig, R. Leemans, D.M. Lodge, H.A. Mooney, M. Oesterheld, N. LeRoy Poff, M.T. Sykes, B.H. Walker, M. Walker, D.H. Wall (2000) 'Global biodiversity scenarios for the year 2100' Science 287: 17701774.

Saphores, J.D. (2003) 'Harvesting a renewable resource under uncertainty' Journal of Economic Dynamics and Control 28: 509-529.

Scheffer, M., S. Carpenter, J.A. Foley, C. Folke, B. Walker (2001) 'Catastrophic shifts in ecosystems' Nature 413: 591-596.

Schreuder, H.T., T.G. Gregoire, G.B. Wood (1993) Sampling Methods for Multiresource Forest Inventory John Wiley and Sons: New York.

Sheil, D., R.K. Puri, I. Basuki, M. van Heist, Syaefuddin, Rukmiyati, M.A. Agung Sardjono, I. Samsoedin, K. Sidiyasa, Chrisandini, E. Permana, E. Mangopo Angi, F. Gatzweiler, B. Johnson, A. Wijaya (2003) `Exploring biological diversity, environment and local people's perspectives in forest landscapes: Methods for a multidisciplinary landscape assessment' CIFOR: Bogor.

Stockholm Environment Institute (SEI) (2003) 'Community-Scale Adaptation Assessment: Fieldwork methods for project impact assessment' Paper presented at first AIACC Regional Workshop and Open Meeting for Africa and Indian Ocean Islands, Hartebeespoortdam, Brits, South Africa, 10-13 March, 2003.

The Nature Conservancy (2001) People matters: The Nature Conservancy's use of social science to understand and work within the human context of conservation, The Nature Conservancy: Arlington.

World Commission on Protected Areas (2004) World database on protected areas. Internet: http://sea.unep-wcmc.org/wdbpa/

Wilf, P., K.R. Johnson, B.T. Huber (2003) 'Correlated terrestrial and marine evidence forglobal climate changes before mass extinction at the Cretaceous-Paleogene boundary' Proceedings of the National Academy of Sciences 100: 599-604. 


\section{Conclusions}

\section{Carmenza Robledo', Markku Kanninen ${ }^{2}$ and Lucio Pedroni ${ }^{3}$}

1. Intercooperation. Bern, Switzerland; and Technology and Society Laboratory, Swiss Federal Laboratories for material Testing and Research, EMPA. Dübendorf, Switzerland.

Tel: +41 182343 21, Fax: +41 182340 07, E-mail: carmenza.robledo@empa.ch

2. Center for International Forestry Research

Jl. CIFOR, Situ Gede, Sindang Barang, Bogor Barat 16680, Indonesia,

Tel: +62 (251) 622622; Fax: +62 (251) 622100, E-mail: m.kanninen@cgiar.org

3. Tropical Agricultural Research and Higher Education Center, CATIE, 7170 Turrialba, Costa Rica.

Tel: +506-5582334, Fax: +506-5568470, E-mail: Ipedroni@catie.ac.cr

The negotiations within the UNFCCC have already produced a complete framework for promoting adaptation to changes in the climate system. Such a framework presents a dynamic process of three major steps: assessing vulnerabilities, creating or improving capacities and planning and implementing adaptation measures (see Romero, "Adaptation to climate change: findings from the IPCC TAR").

The implementation of this process faces enormous challenges at different levels. Currently, one of the major tasks is to model local climate change, so that vulnerabilities can be assessed. This is especial significant for developing countries, where negative impacts are likely to be greater. As explained in the first chapters some bioclimatic scenarios can be generated for and in developing countries (see the articles from Jones, P. "Modelling local climate change in developing countries: Problems and possible solutions"; Jones, P. and Thornton, P: "How crop production will be affected by climate change in Africa and its repercussions on the continent;" and Jones, P et all: "Generating Climate Change Scenarios at High Resolution for Impact Studies and Adaptation: Focus on Developing Countries"). Nevertheless, the interpretation of such scenarios in terms of assessing vulnerabilities requires also including institutional, social and economic variables in the analysis as these variables determine the land use and therefore have huge implications on the resilience of both social and natural systems. Consequently, besides elaborating local climate scenarios 
complementing tools are required to include other variables in the assessment of vulnerabilities as e.g. land ownership regimes, interactions between social groups, access to markets or financing instruments for adaptation.

Further, as stated in the contribution made by Raid and Huq ("ClimateChange - Biodiversity and Livelihood Impacts ") understanding local circumstances and their inter-linkages to climate vulnerability needs to be done considering not only national and international frameworks but also local experience and knowledge. This is special important with regard of rural poor, which deeply depends on natural resources. Local circumstances shall be considered in a twofold approach: On one side priorities of high vulnerable natural and social systems have to be considered as a priority. On the other communities that have been exposed to climate hazards since longer, have developed corresponding coping strategies. Experiences and knowledge coming from such no-planed adaptation should systematically be considered so that other communities can make use of them.

The article from Hammill et al. ("Using the Sustainable Livelihood Approach to Design Strategies for Reducing Vulnerability to Climate Change") demonstrates how the livelihood approach can be used as an integrating tool for considering climate change adaptation into the broader objectives of poverty reduction and sustainable development. This article indicates that restoring or enhancing ecosystem services and diversifying local livelihoods can have an important impact on increasing resilience of both natural and social systems. The livelihood approach, which includes the so called five capitals as human, natural, physical, financial and social, allows integration of climate change variables (e.g. changes in rain patterns or in temperature) to a wider process of promoting sustainable development, especially for the poor.

Implementation of adaptation measures can imply some increments in costs up front, especially when changes in land management or building new infrastructure are considered. In many cases this financing concerns could jeopardise the implementation of such measures. For activities related to land use, the payments for carbon credits within the Clean Development Mechanism -CDM- (a flexible mechanism defined in the Kyoto Protocol that allows trade of mitigation credits coming from projects in developing countries) could help to reduce this financial burden. Moreover some CDM projects in forestry activities could also help to reduce vulnerabilities while increasing carbon sequestration. In the specific case of agroforestry systems as CDM projects other positive impacts like increasing food security or diversifying farmer's income through trading of non-timber forest products (NTFP) can be also achieved (see Verchot et al. "Opportunities for Linking Adaptation and Mitigation in Agroforestry Systems").

Further, as stated by Murdyaso et.al. ("Linkages Between Mitigation and Adaptation in Land-Use Change and Forestry Activities") considering adaptation to climate change during the planing and implementation of CDM projects in forestry can also reduce risks. However, monitoring performance of the projects 
with regard of so many variables can become very complex. Scientist and project participants are called to design monitoring schemes able to register progress while being reasonable in cost.

The last chapter of this book is dedicated to the linkage between adaptation to climate change and conservation of biodiversity. In this chapter a method to assess vulnerability of a given ecosystem is presented, including the assessment of harvesting and the assessment of the socio-economic baseline. Such an assessment should become the basis for identifying adaptation options. This method is based on the need to understand ecosystems as a whole and their resilience to changes in climatic stimuli. It goes beyond the simple identification of endangered species and asks for using the ecological approach given by the UN Convention on Biological Diversity (CBD). This is obviously a more complex alternative. However, for the experts present in the workshop it appears to be the only alternative to really establish the linkage between adaptation to climate change and objectives of the CBD.

Considering all the elements given above the great challenge is to design, implement and monitor integrative projects, so that as much as possible positive effects on natural and social systems can be achieved. Moreover adaptation capacity includes both the reaction of the natural system to climatic stimuli and also the impacts of such stimuli on the socio-economic baseline. Improvement of adaptation capacity has thus to involve ecological, economical and social considerations as well as the improvement of institutional frameworks. Consequently adaptation to climate change has to be understood as a constitutive element of promoting sustainable development.

Due political, economic and social constrains that hinder the adaptation process, developing countries need support to increase their adaptation capacity. A combination of improving tools and methods applicable at the local level, ensuring capacity building for project participants and enhancing pilot projects can be seen therefore an appropriate strategy. This strategy should combine advances in science as well as systematisation of local knowledge and experience and promotion of institutional development. The development cooperation brings a good platform to bring such a strategy to action. 
The Center for International Forestry Research (CIFOR) is a leading international forestry research organization established in 1993 in response to global concerns about the social, environmental, and economic consequences of forest loss and degradation. CIFOR is dedicated to developing policies and technologies for sustainable use and management of forests, and for enhancing the well-being of people in developing countries who rely on tropical forests for their livelihoods. CIFOR is one of the 15 Future Harvest centres of the Consultative Group on International Agricultural Research (CGIAR). With headquarters in Bogor, Indonesia, CIFOR has regional offices in Brazil, Burkina Faso, Cameroon and Zimbabwe, and it works in over 30 other countries around the world.

\section{Donors}

The Center for International Forestry Research (CIFOR) receives its major funding from governments, international development organizations, private foundations and regional organizations. In 2004, CIFOR received financial support from Australia, African Wildlife Foundation (AWF), Asian Development Bank (ADB), Belgium, Brazil, Canada, Carrefour, China, CIRAD, Conservation International Foundation (CIF), European Commission, Finland, Food and Agriculture Organization of the United Nations (FAO), Ford Foundation, France, German Agency for Technical Cooperation (GTZ), German Federal Ministry for Economic Cooperation and Development (BMZ), Indonesia, International Development Research Centre (IDRC), International Fund for Agricultural Development (IFAD), Innovative Resource Management (IRM), International Tropical Timber Organization (ITTO), Italy, Japan, Korea, Netherlands, Norway, Organisation Africaine du Bois (OAB), Overseas Development Institute (ODI), Peruvian Institute for Natural Renewable Resources (INRENA), Philippines, Sweden, Swedish University of Agricultural Sciences (SLU), Switzerland, The Overbrook Foundation, The Nature Conservancy (TNC), Tropical Forest Foundation, United States, United Kingdom, United Nations Environment Programme (UNEP), Waseda University, World Bank, World Resources Institute (WRI) and World Wide Fund for Nature (WWF). 
